University of Rhode Island

DigitalCommons@URI

Open Access Dissertations

2014

\title{
A New Maritime Archaeological Landscape Formation Model: Thunder Bay National Marine Sanctuary
}

Alicia Lynn Caporaso

University of Rhode Island, aliciacaporaso@yahoo.com

Follow this and additional works at: https://digitalcommons.uri.edu/oa_diss

\section{Recommended Citation}

Caporaso, Alicia Lynn, "A New Maritime Archaeological Landscape Formation Model: Thunder Bay National Marine Sanctuary" (2014). Open Access Dissertations. Paper 271.

https://digitalcommons.uri.edu/oa_diss/271

This Dissertation is brought to you for free and open access by DigitalCommons@URI. It has been accepted for inclusion in Open Access Dissertations by an authorized administrator of DigitalCommons@URI. For more information, please contact digitalcommons-group@uri.edu. 


\section{A NEW MARITIME ARCHAEOLOGICAL \\ LANDSCAPE FORMATION MODEL: THUNDER \\ BAY NATIONAL MARINE SANCTUARY}

BY

ALICIA LYNN CAPORASO

A DISSERTATION SUBMITTED IN PARTIAL FULFILLMENT OF THE

REQUIREMENTS FOR THE DEGREE OF

DOCTOR OF PHILOSOPHY

IN

OCEANOGRAPHY

UNIVERSITY OF RHODE ISLAND

2011 


\section{DOCTOR OF PHILOSOPHY DISSERTATION}

OF

ALICIA LYNN CAPORASO

\section{APPROVED:}

Dissertation Committee:

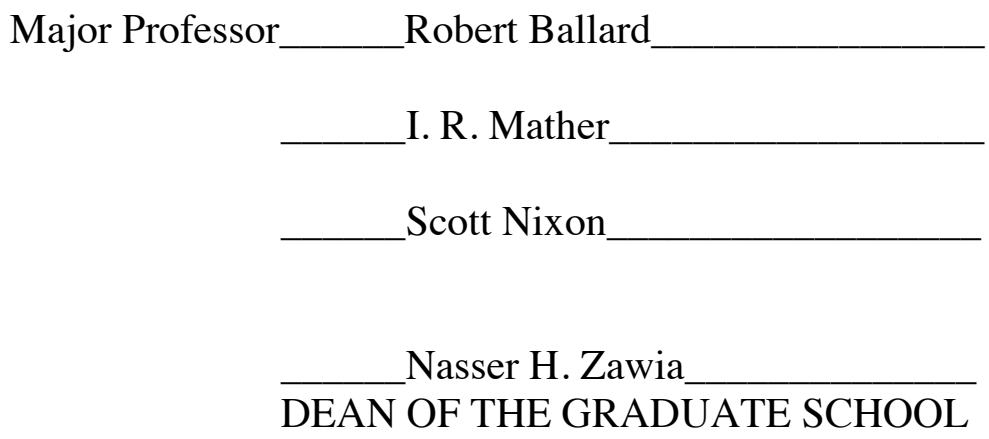

UNIVERSITY OF RHODE ISLAND

2011 


\begin{abstract}
Archaeology should strive to explore and seek to improve our understanding of human behavior. Underwater archaeology, especially shipwreck archaeology, tends to be particularistic focusing on the human activities associated with a ship or shipwreck itself. Human behavior and its resultant material remains exist on a physical and cultural landscape and cannot be separated from it. Studying known archaeological sites within the landscape reveals patterns of human behavior that can only be identified within that context.

This research explores the relationship between the social and natural world and the archaeological landscape at Thunder Bay National Marine Sanctuary and Underwater Preserve. The 448 square miles of sanctuary range in depth from a few feet to nearly 200 feet, and hold at least 100 known and identified shipwrecks and perhaps another 100 unidentified shipwrecks, at various depths ranging from zero to over 100 feet. The lake floor is also littered with ship timbers, wrecked cargo and hardware, fishing gear, and other cultural debris.

The natural environment constrains and informs human behavior and plays a large and important role in the development of maritime culture and the maritime landscape. The processes by which this occurs can also be studied through analysis of the archaeological record.

The focus of this research is an approach to integrating the components of the maritime landscape with the understanding of the archaeological and historic records as well as oceanographic processes in the Great Lakes to develop a new phenomenological model that takes into account not only the shipwrecks but also the
\end{abstract}


totality of the remains of human activity in a region both on land and on the water. Three levels of analysis associated with the model are: that a vessel will wreck or become irrecoverable in a given location; that wreck material will arrive at a given location; and that wreckage material will survive at a given location.

Three general goals are associated with the application of the model: to determine the importance of each behavioral and natural input to each level; to determine the importance of each level in determining the location where archaeological materials may be identified; and to determine if it is possible to derive the agent human activity from the total collection of archaeological material that led to its initial deposition and in many cases modification. This in turn facilitates the determination of higher-order broad anthropological questions to ask of the archaeological record.

The efficacy of the model is illustrated through two combined anthropological, archaeological, and oceanographic analyses. First, the model is used to explain decade-by-decade and overall patterns in human behavior interpreted through the maritime archaeological landscape of the shipwrecks themselves. This incorporates the known historical attributes associated with each wreck site including any natural physical inputs recorded at the time of the accident. Secondly, the model is used to explore the patterns apparent in the mobile wreckage recorded in the vicinity of North Point in the context of primarily local geology. These patterns are then used to make hypotheses about potential human activity and environmental inputs that affect the preservation of the archaeological record of Thunder Bay. 


\section{ACKNOWLEDGMENTS}

This research was made possible by the funding and support of the National Oceanographic and Atmospheric Administration, Thunder Bay National Marine Sanctuary and Underwater Preserve. I would like to thank everyone at Thunder Bay who supported me throughout this endeavor. I would also like to thank the National Park Service (NPS) and Dr. Robert Ballard and the Institute for Exploration who also funded me while a graduate student.

While many people worked directly with me on my research, I want to give particular thanks to Dr. Rod Mather who supervised my project and, along with Dr. Ballard, served as my co-major advisor.

I would like to thank the faculty and staff at the Graduate School of Oceanography (GSO) at the University of Rhode Island (URI) for their academic guidance. Special thanks go to Dr. John King (GSO), Dr. Scott Nixon (GSO), Dr. Vergil Noble (NPS) and Dr. Leo Carroll (URI) who served on my dissertation committee.

Lastly, I want to give especial thanks to my husband Daniel for whom, as long as he has known me, I have been a graduate student. Let us move on to new adventures. 


\section{TABLE OF CONTENTS}

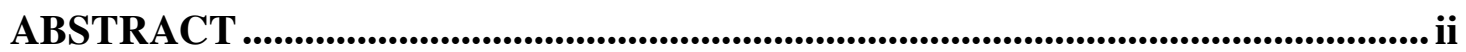

ACKNOWLEDGMENTS _............................................................................................ iv

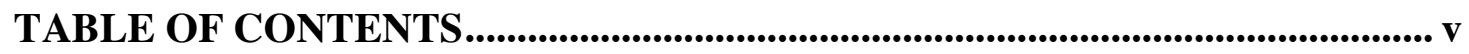

LIST OF TABLES ............................................................................................................................ vii

LIST OF FIGURES .............................................................................................ii

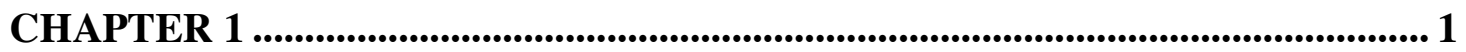

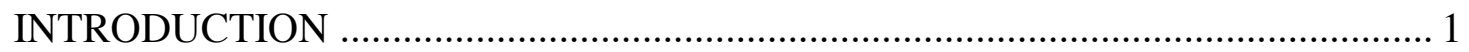

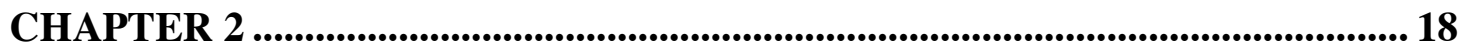

THE TOTAL GEOGRAPHIC LANDSCAPE AND MARITIME ARCHAEOLOGY 18

CHAPTER 3 ....................................................................................................................... 33

ANTHROPOLOGICAL RISK AND THE MARITIME LANDSCAPE ..................... 33

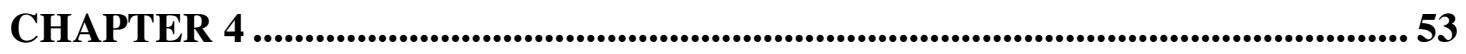

THE PHYSIO-HISTORIC LANDSCAPE OF THUNDER BAY ………………..... 53

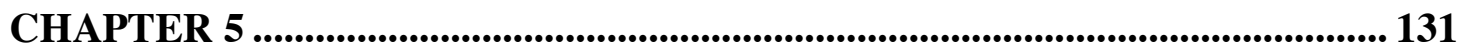

ARCHAEOLOGICAL INVESTIGATIONS AT THUNDER BAY NATIONAL MARINE SANCTUARY AND UNDERWATER PRESERVE ............................. 131

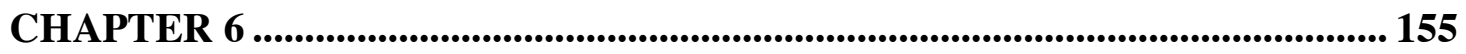

A NEW MARITIME ARCHAEOLOGICAL LANDSCAPE FORMATION MODEL

CHAPTER 7 ............................................................................................................................ 177

THE SHIPWRECKED LANDSCAPE OF THUNDER BAY NATIONAL MARINE

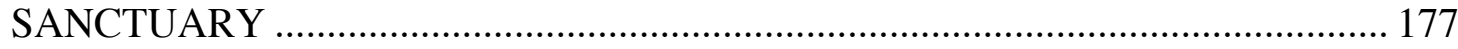

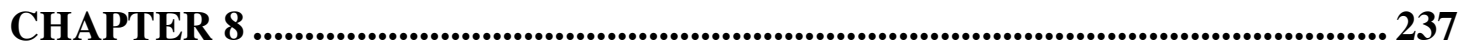


THE MOBILIZED ARCHAEOLOGICAL LANDSCAPE OF THUNDER BAY NATIONAL MARINE SANCTUARY ……………….................................. 237

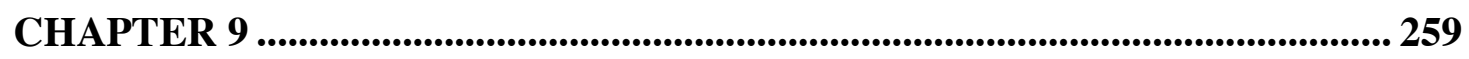

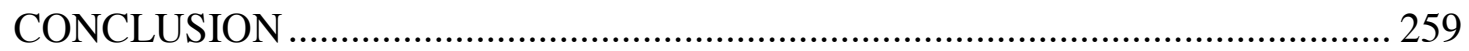

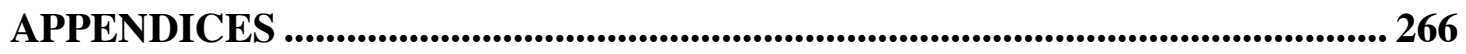

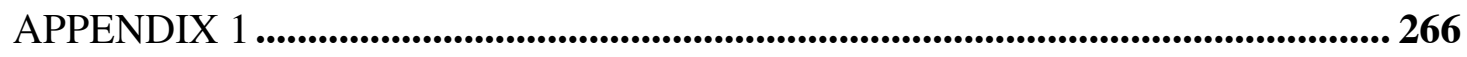

THE ARCHAEOLOGICAL RECORD AT THUNDER BAY NATIONAL MARINE SANCTUARY AND UNDERWATER PRESERVE............................................. 266

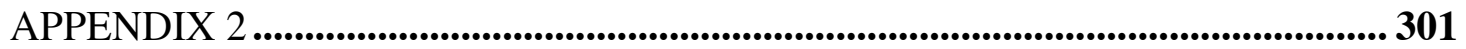

THUNDER BAY NATIONAL MARINE SANCTUARY SHIPWRECK DATABASE 301

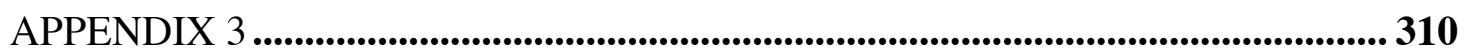

VALUED SIDE-SCAN SONAR TARGETS ……………................................... 310

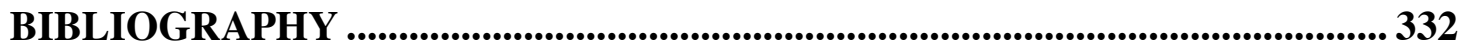




\section{LIST OF TABLES}

TABLE

PAGE

4.1 Final Laurentide Ice Sheet Retreat (after Farrand 1987) .................................. 117 4.2 Compilation of Great Lakes Shipping Disasters for the $19^{\text {th }}$ Century (Gjerset

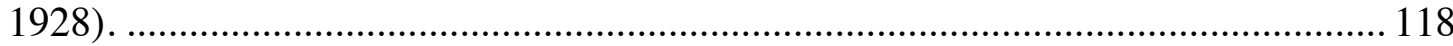




\section{LIST OF FIGURES}

FIGURE

PAGE

1.1 Thunder Bay National Marine Sanctuary and Underwater Preserve (Coleman 2003) 15

1.2 Standard Deviation of Shipwreck Locations in the Vicinity of Thunder Bay ....... 16

1.3 North Point Peninsula ...................................................................................... 17

2.1 Bay and Coastal Maritime Transport Zones in the Vicinity of Thunder Bay ........ 29

2.2 Potential Danger Zones within in the Vicinity of Thunder Bay ........................... 30

2.3a The Isaac M. Scott Underway (Courtesy Thunder Bay National Marine

Sanctuary) ....................................................................................................... 31

2.3b Side-scan Sonar Image of the Isaac M. Scott (Courtesy of the Institute for

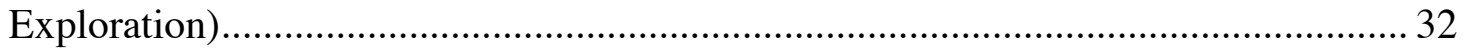

3.1 Age of Vessel and Cargo at Loss, 1870-1899 .................................................. 52

4.1 The Late Wisconsinan Glacier Complex (Energy Mines and Resources Canada n.d.)

4.2 Glacial Lakes in the Great Lakes Basin (US Army Corps of Engineers, Detroit

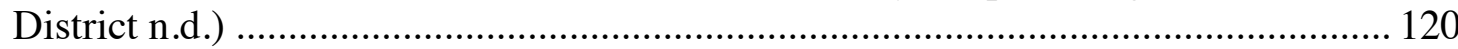

4.3 Lake Huron Basin Sedimentary System ....................................................... 121

4.4 Karst Sinkholes in the Vicinity of Thunder Bay (Biddanda et al. 2006) ............. 122

4.5 Pound Net Fishery (Smith and Snell 1889) ................................................. 122

4.6 Pound Net Fishery Net Stake in Thunder Bay ............................................... 123

4.7 The Wooden Propeller Isabella J. Boyce with a Consort in Tow (Courtesy Thunder

Bay National Marine Sanctuary) ........................................................................ 124

4.8 Commercial Sail versus Steam-Powered Vessels on the Great Lakes (after Barnett

1992: 147-149) ........................................................................................... 125

4.9 Total Tonnage on the Great Lakes (after Barnett 1992: 147-149) ..................... 126

4.10 A Typical Great Lakes Schooner, the John T. Johnson (Courtesy Thunder Bay

National Marine Sanctuary) ............................................................................. 127

4.11 Commercial Sail versus Steam Powered Vessels Normalized by Tonnage (after

Barnett 1992: 147-149) ...................................................................................... 128

4.12 The Whaleback Clifton (Courtesy Thunder Bay National Marine Sanctuary) .. 129

4.13 A Towed Log Raft on Lake Michigan (Curwood 1909).................................. 130

5.1 The Institute for Exploration 2001 Systematic Side-scan Sonar Survey ............. 146

5.22005 East Carolina Survey Targets ............................................................... 147

5.32005 University of Rhode Island Pedestrian Survey and Targets...................... 148

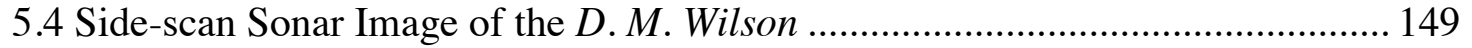

5.5 Side-scan Sonar Image of the $O$. E. Parks ..................................................... 150

5.6a 2005-2007 Side-scan Sonar Survey Coverage .............................................. 151

5.6b 2008 Side-scan Sonar Survey Coverage ..................................................... 152

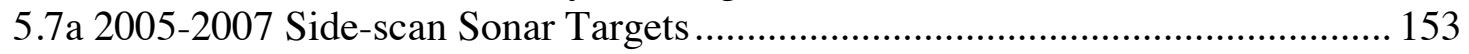

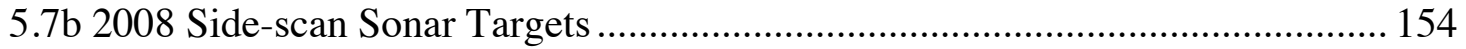

6.1 The First Shipwreck Site Formation Model (Muckelroy 1978) ........................ 173 
6.2 Dynamic Processual Shipwreck Site Formation Model (Ward et al. 1999) ........ 174

6.3 Dynamic Cultural Processes in Shipwreck Site Formation Model (Gibbs 2006) 175

6.4 Dynamic Processual Maritime Archaeological Landscape Formation Model .... 176

7.1 Nearest Neighbor Analysis of Shipwrecks in the Vicinity of Thunder Bay ........218

7.2 The Spatial Mean and Median of Shipwrecks in the Vicinity of Thunder Bay ... 219

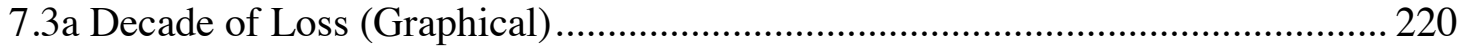

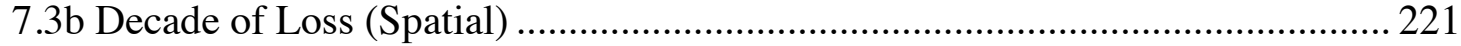

7.4a Month of Loss, Nineteenth Century (Graphical)............................................ 222

7.4b Month of Loss, Twentieth Century (Graphical) ............................................ 223

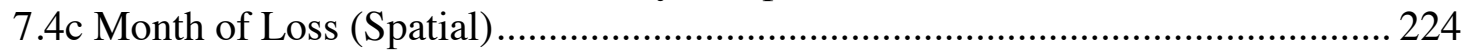

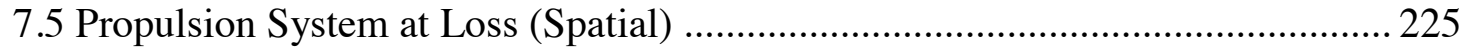

7.6a Type of Loss (Sail), Nineteenth Century (Graphical) ..................................... 226

7.6b Type of Loss (Mechanical), Nineteenth Century (Graphical) .......................... 227

7.6c Type of Loss (Sail), Twentieth Century (Graphical) ....................................... 228

7.6d Type of Loss (Mechanical), Twentieth Century (Graphical) ........................... 229

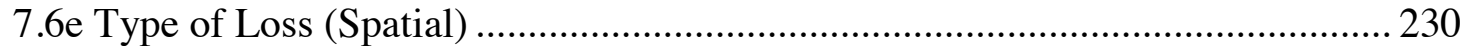

7.7a Cargo at Loss, Nineteenth Century (Graphical) ............................................. 231

7.7b Cargo at Loss, Twentieth Century (Graphical) ............................................... 232

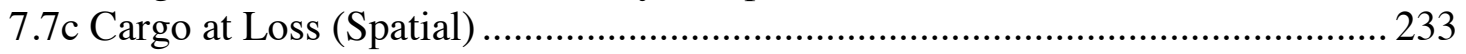

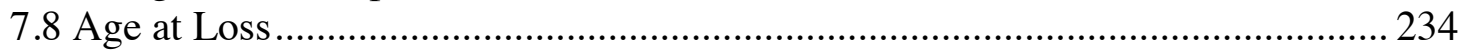

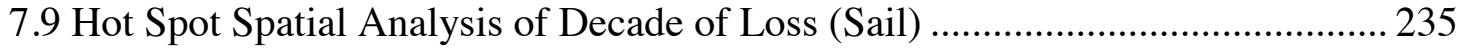

7.10 Cluster Spatial Analysis of Type of Loss ......................................................... 236

8.1 Concentrations of Mobilized Wreckage in the Vicinity of North Point Peninsula

8.2 Distribution of Mobilized Wreckage by Type ............................................... 253

8.3 Distribution of Mobilized Wreckage by Depth................................................ 254

8.4a The Association of Mobilized Wreckage with Netstakes ................................. 255

8.4b Side-scan Sonar Image of Mobilized Wreckage with Netstakes ....................... 256

8.5 Average Current Flow within Lake Huron (Beletsky et al. 1999) ...................... 257

8.6 The wreck of the O.E. Parks (Courtesy Thunder Bay National Marine Sanctuary)

258

A1.1a 2005-2007 Valued Side-scan Sonar Targets: Mobilized Wreckage................ 298

A1.1b 2008 Valued Side-scan Sonar Targets: Mobilized Wreckage......................... 299

A1.2 Netstakes (Each point represents one or more Netstakes). ............................ 300 


\section{CHAPTER 1}

\section{INTRODUCTION}

Archaeology should strive to explore and seek to improve our understanding of human behavior. Underwater archaeology, especially shipwreck archaeology, tends to be particularistic focusing on the specific human activities associated with a distinct ship or shipwreck. This is not surprising, nor is there ultimately anything wrong with this approach. A great deal can be learned from studying shipwreck sites, and for even the most thoroughly investigated sites, new information and insights await discovery. However, there is a limit to what can be learned by studying individual archaeological sites. Human behavior and its resultant material remains exist on a physical and cultural landscape and cannot be separated from it. Studying known archaeological sites within the landscape reveals patterns of human behavior that can only be identified within that context. We can move from the realm of the familiar and known to begin to ask new questions about peoples and society of the archaeological record.

Archaeology is well known for being a holistic science, using tools and techniques from the various other social sciences to develop theories and models to explain past human experience. In the last several years, archaeological research has greatly expanded to take advantage of many other sciences including engineering, materials science, biology, and chemistry. Much as geophysical tools and other remote sensing techniques revolutionized terrestrial archaeological survey in the 20th century, oceanography can reveal new avenues for archaeological prospecting and 
research. It allows for scientists to explicitly and effectively incorporate the ecological and physical environment into the understanding of submerged cultural resources.

Archaeological oceanography at the University of Rhode Island was developed as a subfield of archaeological and oceanographic research in the early 2000s. It is a multi-disciplinary methodological approach combining oceanography, ocean engineering, maritime history, anthropology, and archaeology into one academic research program. Early research activity focused on technology development and survey design for deep-seafloor exploration and investigation. Most current projects consider mapping the seafloor over wide-areas to determine patterns of human use over long time periods and to determine patterns of archaeological deposition incorporating physical, biological, geological, and chemical oceanographic data. This study takes the above research parameters a step further by investigating how the active environment might affect the in situ preservation of submerged cultural materials.

At first, projects were initiated by oceanographers who in turn worked with archaeologists who were interested in and directed research on the sites in question. Over the past several years, the focus has become decidedly more archaeological with the addition of both faculty and students with backgrounds in anthropology, archaeology, history, and art history. It is important to note, however; that though archaeologists and oceanographers might be interested in the same topics of research, there are subtle differences in how they approach archaeological oceanography. 
From an oceanographic perspective, the technology primarily developed for oceanographic research in addition to the oceanographic and geophysical methodologies for exploration and survey applied to archaeological investigation form the basis for conducting archaeological oceanography. Often, research starts with the methodology in hand and a search for its application in archaeology. For the most part, these methodologies best serve large-scale marine landscape research. Previous investigation conducted under the banner of archaeological oceanography includes Coleman's (2003) use of geological and paleo-limnological data to explore the possibility for intact inundated prehistoric habitation sites in the vicinity of Thunder Bay National Marine Sanctuary and Block Island Sound.

From an archaeological perspective, oceanographic techniques and understanding provide a suite of new research tools that can be applied to archaeological investigations, especially concerning site formation processes, excavation, and preservation. Research programs are designed to start with and answer questions of archaeological importance. Incorporating oceanographic methods and perspectives to the study of maritime archaeology allows for the transition from archaeological site to archaeological landscape. The physical and ecological regime in which the archaeological sites are located becomes important, both as a constraint to human behavior and as an entity with which humans negotiate on the landscape. Without considering the environmental regime, and human interactions with and within it, it is impossible to fully understand the maritime landscape and associated human behaviors. 
This research explores the relationship between the social and natural world and the archaeological landscape at Thunder Bay National Marine Sanctuary and Underwater Preserve (Figure 1.1). Thunder Bay is located in northwestern Lake Huron near the city of Alpena, Michigan. In 2000, Thunder Bay became the thirteenth National Marine Sanctuary designated by the National Oceanographic and Atmospheric Administration (NOAA). It is the only fresh water sanctuary and was the first to be created for the preservation of a large body of submerged cultural resources. The 448 square miles of sanctuary range in depth from a few feet to nearly 200 feet, and hold at least 100 known and identified shipwrecks and perhaps another 100 unidentified shipwrecks, at various depths ranging from zero to over 100 feet. The lake floor is also littered with ship timbers, wrecked cargo and hardware, fishing gear, and other cultural debris.

Thunder Bay National Marine Sanctuary is an ideal laboratory for developing the methodology and practicing archaeological oceanography. Even though it is located within a freshwater lake, the bay and environs are subject to many physical limnological processes including waves, currents, and ice formation. All of these processes have affected the distribution of submerged cultural resources. They have also adversely impacted the ability of these resources to be preserved in situ. To develop a model for submerged site distribution and preservation, it is imperative that these physical processes are considered and understood. In addition, preservation of submerged cultural resources is highly affected by biological and chemical processes occurring in the water column and lake floor sediments. For example, a specific concern of the sanctuary is the proliferation of non-native zebra mussels that have 
colonized many of the shipwreck structures and other submerged architecture. The presence or absence of zebra mussels on different sites clearly indicates that the biological and chemical structures of the different areas of the sanctuary can be quite dissimilar.

Most of the known shipwreck sites as well as many presumed ones derive from familiar, well-known ships and accidents. Dating primarily between 1860 and 1930, we know their names, the identities of their crews, the form and construction of the vessels, their cargo, and when, where, why, and how they wrecked. However, the shipwrecks individually inform only part of the story of human activity. For example, a large proportion of shipwrecks in Thunder Bay resulted from the same mode of accident, collisions with other vessels while underway. A description and analysis of three of these events illustrates important patterns of human behavior that have worked to form the archaeological record.

On November 7th, 1860, the two-masted schooner Kyle Spangler, carrying a cargo of 15,000 bushels of corn, collided in the dark with the schooner Racine off Presque Isle, just north of Thunder Bay. This region was dangerous to sail; it was where ships began to make the turn northwestward towards the St. Mary's River, the entrance to Lake Superior. With a gaping hole in its hull, the Spangler did not survive the collision.

On August 9th, 1865, on a warm, calm, and clear day, the package freighter and passenger wooden propeller steamship Pewabic passed near its sister ship, the Meteor, traveling in the opposite direction, in order to pass news and mail between them. Without warning, the Pewabic cut across the bow of the Meteor. The Meteor struck a 
fatal blow to the Pewabic, sending it to the lake floor within minutes of the accident. Though many passengers were rescued, approximately 125 people died. In addition to passengers, the Pewabic carried a valuable load of copper ingots. Over the following decades, several divers lost their lives attempting to salvage this cargo.

On June 22nd, 1909, the small wooden propeller bulk freighter William Peter Thew was struck by the steel steamer William Livingston in thick early morning fog approximately two miles from the Thunder Bay Lighthouse located on Thunder Bay Island. Though the Livingston apparently did not stop to assist the dying ship, another nearby vessel rescued the crew from their lifeboat. The Thew quickly sank to the lake floor to a depth of about 90 feet. The Thew carried no cargo and did not have a functioning anchor on board.

It is easy to get lost in the details of why each of these wrecks, apart from their loss through collision, appear completely different from one another. The Spangler, a sailing ship carrying grain, sank in the dark at a transportation bottleneck; the Pewabic carried light cargo and passengers and sank on a calm clear day in the process of setting out from the harbor; and the Thew, steaming with no cargo, sank in the early morning in thick fog near the North Point coast. However, each shipwreck provides insights into the behavior of maritime peoples as they negotiated sailing on a potentially dangerous landscape. In each of these cases, it was impossible for the sailors to predict what other vessels would do in areas in which the conditions of sailing had recently changed. In the case of the Spangler, the commercial exploitation of the Lake Superior region for Canadian grain production with its wildly variable freight rates had recently begun altering the transportation routes, the number of 
vessels on these routes, and the competition among vessels to secure valuable cargo. For the Pewabic, long distance immigrant transportation in the upper Great Lakes at the end of the Civil War required a new way of exchanging news during long voyages and thus vessels sailing within close proximity to each other. Lastly, for the Thew, the small wooden-hulled steamboat had to share the historic shipping lane, generally conceived of for the use of small nineteenth-century vessels, with large new steel bulk freighters.

The 50 years of disaster through collision represented by these shipwrecks indicates that safety at sea was a pervasive concern for those tied to the lake for their livelihoods. The differences in the circumstances of these shipwrecks allow us to tease out behaviors tied to the landscape. For example, the decisions made by the owners and captain of the Thew, an old, small, wooden bulk carrier, operating in competition with modern twentieth-century steel freighters. The risks taken by the pilot of the Spangler, plotting a course change at a time when there were no prescribed shipping lanes or required ship lights or signals. Or the dismissal by the helmsman of the Pewabic of the potential danger in passing so close to another ship in order to exchange greetings, all of which resulted in the same outcome, collision. The shipwreck and its archaeological site are components of the narrative of human behavior on the archaeological landscape.

The natural environment in turn constrains and informs human behavior and plays a large and important role in the development of maritime culture and the maritime landscape. The processes by which this occurs can also be studied through analysis of the archaeological record. For example, standard deviation from the spatial mean of 
the location of shipwrecks within Thunder Bay National Marine Sanctuary indicate clustering of shipwrecks within certain areas of the sanctuary and provides statistical directionality of shipwreck locations (Figure 1.2). This distribution can be explained by constraints on shipping placed by the natural environment. For example, Thunder Bay was considered the only safe harbor during storms along Lake Huron's northwestern coast. Many of the ships that wrecked at Thunder Bay foundered or stranded while seeking shelter along the southern shore of North Point peninsula. Additionally, pilot books from the late nineteenth and early twentieth centuries promoted the lee passage between Thunder Bay Island and North Point as safe harbor for ships in peril. This passage, however, is characterized by dangerous shoal reefs, which require careful knowledgeable piloting, a difficult chore in calm weather let alone in heavy seas. This protected yet hazardous passage is close to the spatial mean of Thunder Bay shipwrecks. One ship that suffered such a loss was the $B . W$. Blanchard, a wooden hulled propeller steamship which was down-bound to Detroit with a cargo of lumber towing two lumber-laden barges. The Blanchard and its tows grounded on North Point Reef on November 28th, 1904 while attempting to escape a gale. It broke in two and was unrecoverable.

The focus of this research is an attempt to integrate the components of the maritime landscape with the understanding of the archaeological and historic records as well as oceanographic processes in the Great Lakes to develop a new phenomenological model that takes into account not only the shipwrecks but also the totality of the remains of human activity in a region. To create a useful maritime archaeological landscape formation model, archaeological space and time must be 
defined in three levels: maritime behavior before the commencement of the accident; activities, actions, and material effects associated with mitigation of the accident; and formation of the archaeological record post-accident. It is important also to recognize that that there are three levels or stages of preservation and spatial analysis within this system upon which variables can act. These three levels of analysis are: that a vessel will wreck or become irrecoverable in a given location (at the surface); that wreck material will arrive at a given location (on the lake floor or margin); and that wreckage material will survive at a given location (on the lake floor or margin).

Natural formation transforms are defined as environmental inputs that can be characterized or measured in space. For example, they might include the local sediment budget, bottom currents, and prevailing winds. They can be both variable and non-variable and exist at different scales. These transforms can be measured directly in the environment, derived from historic data, or inferred from historic accounts. Depending on the area and scale studied, different transforms will have more influence than others.

Three general goals are associated with the application of the model: to determine the importance of each behavioral and natural input to each level; to determine the importance of each level in determining the location where archaeological materials may be identified; and to determine if it is possible to derive the agent human activity from the total collection of archaeological material that led to its initial deposition and in many cases modification. This process should in turn facilitate the determination of higher-order broad anthropological questions to ask of the archaeological record. 
Two general types of spatial data are used in the creation of this new archaeological model: new data generated through field survey and previously collected data. Both are entered into a Geographic Information Systems (GIS) database and evaluated for applicability to the model. The primary aim of this study is to discover and explore the implications of these data for intensive archaeological, anthropological, and environmental research and for applicability towards archaeological and environmental resource management. Also, it will build the foundation for the creation of potentially robust analytical mathematical models.

The research required to build and test such an archaeological model is limited by the amount of useful data that can feasibly be collected, therefore the focus of the current research will be restricted to a definable area of Thunder Bay: North Point Peninsula (Figure 1.3).

North Point Peninsula is a heavily forested landmass that extends southeast into Lake Huron and forms the eastern shore of Thunder Bay. The surface geology of the tip and heel of North Point is comprised of dune sand, and the remainder of lacustrine sand and gravel. The approximate total area of North Point is 35 square kilometers. The tip of North Point has been privately owned for over a century and has had archaeologically negligible impact from modern human activity. Three significant islands lie just east of North Point, two of which form a shoal corridor through which vessels historically passed and anchored (Thompson 1878: 69). These are Sugar and Thunder Bay Islands, the latter of which hosts a lighthouse. North Point Peninsula is both identifiable on the modern landscape of northwest Lake Huron as well as on the historic maritime landscape of Thunder Bay. 
This dissertation is organized in such a way as to provide the theoretical basis for the model with regard to maritime behavior over time, a description of the physical and cultural landscape with emphasis on maritime behavior, commercial activity, maritime technology, and maritime safety, and a description of archaeological research carried out at Thunder Bay National Marine Sanctuary and its environs and the resulting identified archaeological record. The model is then developed in the context of the evolution of previous submerged archaeological site formation models. Lastly, the archaeological record and the social and natural inputs that affect the formation of the maritime archaeological landscape for both the shipwreck sites themselves and for mobilized wreckage and other debris are analyzed in the context of the new model.

Chapter Two considers the total geographic landscape in the context of maritime archaeology. Included is a discussion of the type of time- and space-dependent inputs that force social change in maritime behavior and perception of the associated landscape. Chapter Three explores the concept of risk as it relates to the classdependent control of participant behavior in the maritime landscape. Chapter Four outlines the geological, prehistoric, and historic chronology of northwest Lake Huron, the latter focused on maritime activities. Chapter Five describes the archaeological investigations that have taken place at Thunder Bay National Marine Sanctuary including the four seasons of geophysical survey conducted as part of this research. Chapter Six delineates the evolution and construction of the new maritime archaeological landscape formation model incorporating maritime landscape theory in the context of patterns initially observed in the archaeological record at Thunder Bay. 
Chapter Seven takes the new model and uses it to explain decade by decade and overall patterns in human behavior interpreted through the maritime archaeological landscape of the shipwrecks themselves. This incorporates the known historical attributes associated with each wreck site including any natural physical inputs recorded at the time of the accident. Lastly, Chapter Eight explores the patterns apparent in the mobile wreckage recorded in the vicinity of North Point in the context of primarily local geology and uses these patterns to make hypotheses about potential human activity and environmental inputs that affect the preservation of the archaeological record of Thunder Bay. The dissertation closes with a discussion of the efficacy of the model.

Methodology

The assemblage of historic shipwrecks and other associated archaeological debris around North Point Peninsula is being approached from a marine landscape perspective. The methodology of this study is comprised of five primary steps:

1. Collection of new data through terrestrial and marine geophysical survey

2. Mining literature and other historical and/or scientific sources for applicable data

3. Applying collected data to the region of study though GIS

4. Determining if the collected data can be used to explain the distribution patterns of the archaeological record 
5. Determining if and why (or if not and why not) the collected data can (or cannot) be incorporated into the proposed new phenomenological archaeological landscape formation model.

A series of side-scan sonar surveys to determine the location of cultural debris and derivable environmental data was developed for Thunder Bay National Marine Sanctuary. Initially a Phase I remote sensing survey (summers 2005-2008) of North Point Reef and surroundings in Thunder Bay was conducted, an area where historical evidence suggests high vessel concentrations within the sanctuary. Determining the locations of shipwrecks lays the groundwork for subsequent site assessment and characterization, as well as the establishment of baseline documentation of vessel integrity, and cultural and environmental changes affecting these valuable resources.

The model takes the form of a set of linking process-based flowcharts in which cultural and environmental data and information can be defined and categorized. The model is developed with the data and information collected, derived, and created for Thunder Bay. A more generalized model is then extracted that can be applied to any defined maritime landscape.

The efficacy of this model is tested through exemplars of spatial analysis with available data whose spatial resolution is appropriate to the total defined area and archaeological site and material distribution. For Thunder Bay, the majority of available qualified data is geological and therefore, spatial analysis, for the purpose of this study, will be restricted to the relationship between local geology and the archaeological resources. To develop a statistically valid analysis of the data that are collected, the GIS software package ArcEditor is being used. Of primarily interest is 
the spatial relationship between cultural artifacts, features, and scattered debris. The anthropological, historical, and limnological data are applied to the GIS database as series of point, linear, and shape files and as coverage attributes, which are saved as discrete and nested database sets.

The overall intent is to assess the relative utility of different spatial analyses and to see if combining techniques gives a more holistic view for better interpretation. Spatial analysis will delineate the degree to which variables are relevant in given situations and provide correlations that can be further examined in the future to hopefully produce robust predictive algorithms. It is assumed that the basic energy structure determinant found by Ward et al. (1999), that low energy hydrodynamic environments will be dominated by biochemical processes and high energy hydrodynamic environments will be dominated by physical limnological processes, will be evident in these expanded analyses. 
Figures

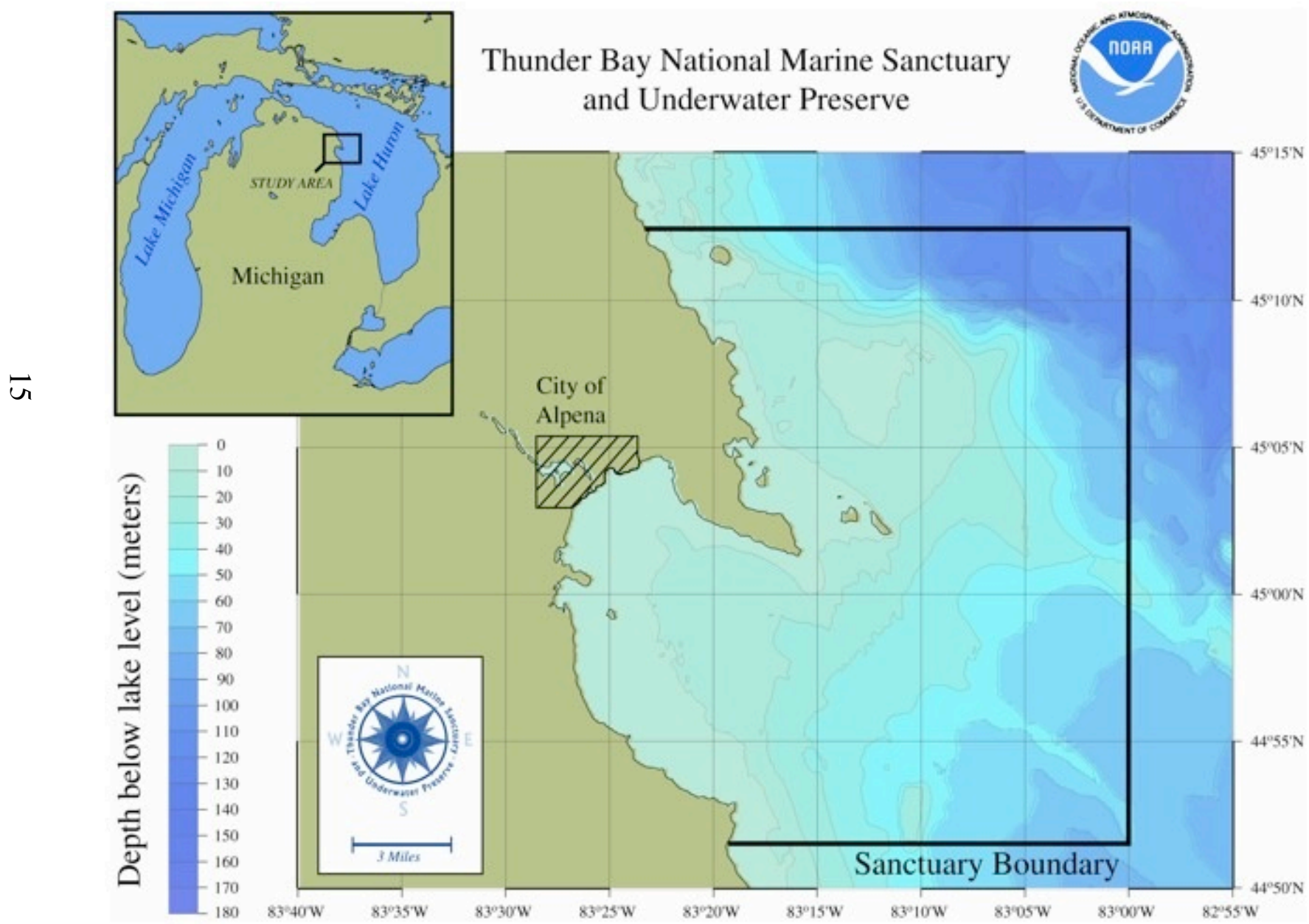

1.1 Thunder Bay National Marine Sanctuary and Underwater Preserve (Coleman 2003) 


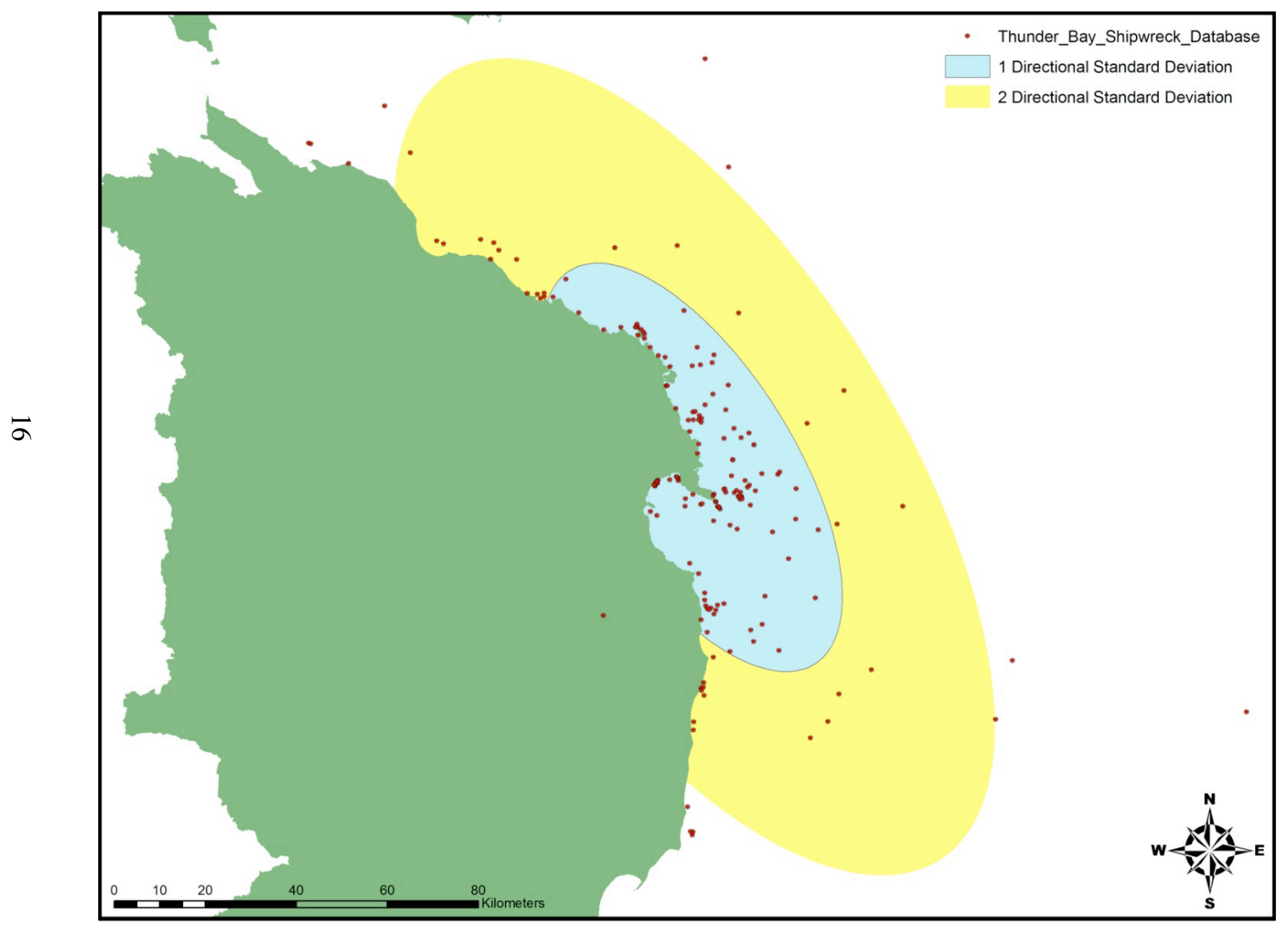

1.2 Standard Deviation of Shipwreck Locations in the Vicinity of Thunder Bay 


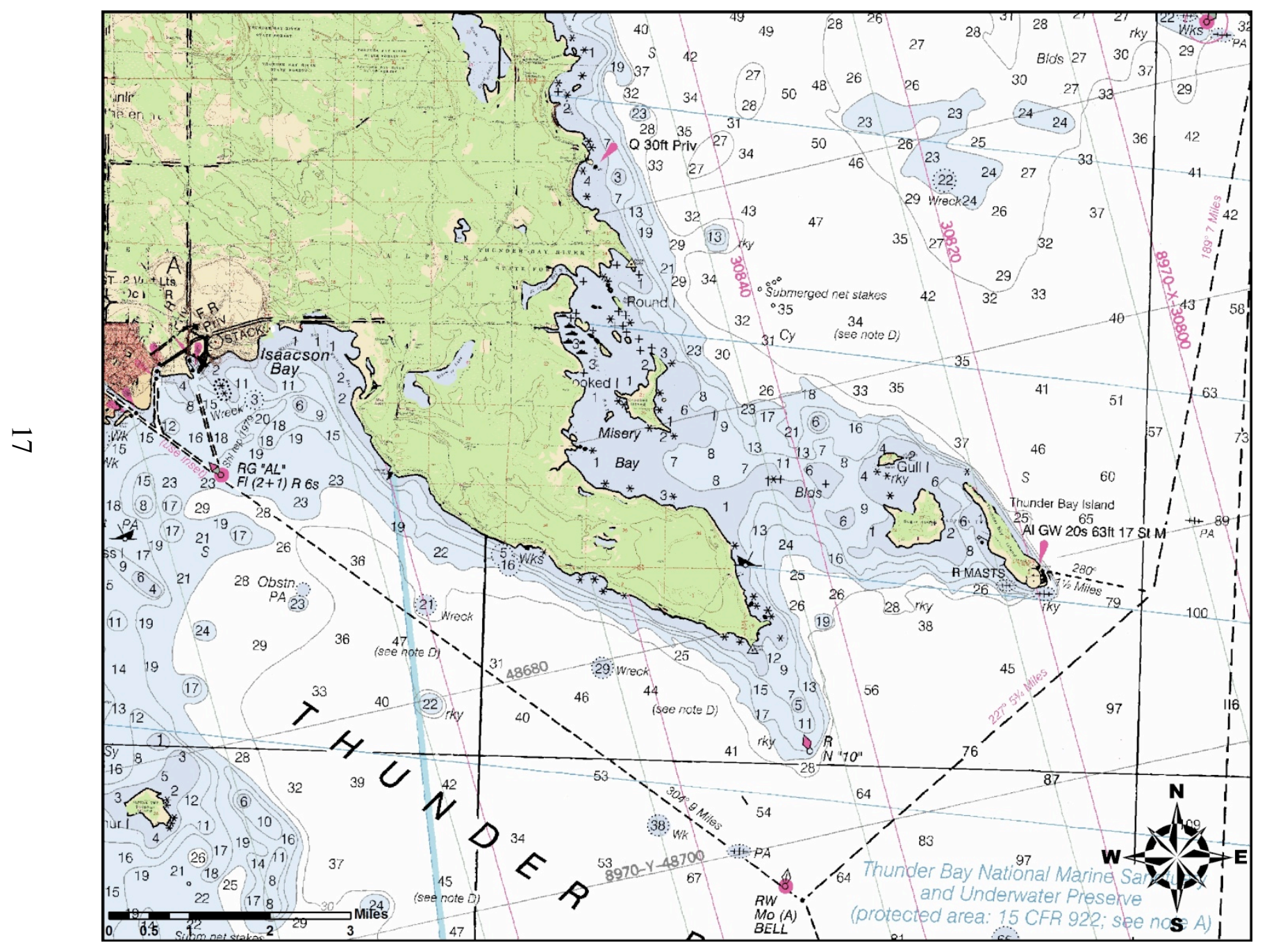

1.3 North Point Peninsula 


\section{CHAPTER 2}

\section{THE TOTAL GEOGRAPHIC LANDSCAPE AND MARITIME ARCHAEOLOGY}

A total geographic landscape perspective incorporates anthropological, archaeological, and environmental data. This allows the landscape to be approached and analyzed as an integrative whole rather than merely a sum of its constituent parts. An important tenant of the total landscape perspective is that the landscape cannot be fully defined materially, but has to be understood as a both physical and cognitive social, spatial, and temporal construct of what is physically present and what those who live within and those who study it perceive. As it will be shown, this does not mean that the total geographic landscape cannot be studied scientifically; rather it informs a more robust empirical understanding of human behavior and its relationship with the natural world.

Traditionally, archaeologists have viewed the landscape in one of two ways: as a physical phenomenon of human construction focusing on the human-land relationship in economic terms, or as a subject, reconstructing snapshots of historical elements (Darvill 1999: 105). Darvill (1999: 108-110) states that these approaches necessarily over-emphasize the built landscape that can be experienced visually. They also assume that the landscape is essentially stable in at least the short term. He recommends considering the landscape as a socially imposed conception of space, time, and social action on what is perceived to be the natural and social world. The partitioning of space and time can be physical or cognitive, defined through attributed 
meaning. Social action is different from general behavior as it must be collectively intentional. In other worlds, society structures landscape.

Lest the above seem to devolve landscape archaeology into a phenomenological exercise, it is important to understand that incorporating the cognitive and social component of the total landscape approach does not preclude scientific rigor. Participant subjectivity can be analyzed objectively if its parameters are explicitly defined. Archaeologists must caution against hyper-interpretive attempts to "know" the people whose lived activity and behavior are being studied (Fleming 2006).

The total geographic landscape incorporates a combination of referents (physical constructs/phenomena capable of being sensed) and signifiers (the sense and recognition/description/interpretation of the referent). When these components endure temporally and spatially, a cultural discourse, or habitus, is transmitted and can evolve over successive generations (Layton and Ucko 1999). The patterning of these referents and signifiers, as with other forms of archaeological phenomena, can become residual, observable, and capable of being empirically studied in the landscape, primarily because they provide evidence of repetitious actions (Darvill 1999). The patterning is visible at many spatial scales (Darvill 1999). This landscape-tied patterning can also be transported to places other than those in which they were created. In other words, the environment or natural landscape is not neutral, but is a formidable agent in the formation and production of culture and can serve as its repository, literally and figuratively (Harris 1999: 434-436).

Ideas of landscape are traditionally used in maritime contexts in primarily four ways: the landscape of maritime economy, inundated formally lived surfaces, the 
setting of generalized coastal life, and the physical and interpretive management of archaeological resources (Firth 1997). All of these can form components of the total geographic landscape. For a true maritime landscape to exist, the society living it must be attuned in some way to a body or bodies of water. It must form a significant preoccupation of the society. The mere presence of the water does not define maritimity (Westerdahl 1998; Firth 1997).

Many Western anthropologists and archaeologists assume that maritime culture and its associated landscapes are born of a "confrontation" between people on land and survival on water (Flatman 2003: 149), the shore and the coastal community forming a liminal zone in which maritime identity or communitas is formed. Flatman (2003: 151) notes that water as an uncontrollable chaotic barrier [where maritime travel is the liminal state in a bounded right-of-passage], is a western construct that does not exist in many other cultures (e.g. Oceania), however the concept can be utilized in this study as it informs the maritime philosophy of the historical societies whose archaeological remains this dissertation considers.

Westerdahl (1998) identifies two fundamentally important socially constructed physical components of the maritime landscape: transport zones and maritime technology. Transport zones are enduring or traditional zones of transport geography. It requires community consent and cognitive recognition for their existence. They exist in physical space yet their parameters of use are structured socially. Two parts to their understanding are long-term perspective where transport zones have associated direction (vector) attributes and their cultural, environmental, and technological restrictions of use such as transport techniques, climatic adaptation, seasonal 
variations, anthropogenic factors such as technology use-skill, etc. For example, a zone may not exist during the period of time in which it is iced over, but exist with the appearance of icebreakers. Shipping accidents often occur when activity operates outside of transport zone boundaries or when the attributes of transport zones are altered, such as during violent storms.

Westerdahl (1998) defines seven fundamental zone-types: trans-isthmian, ferry corridors, zones based on river or other far-reaching water courses, coastal transport, estuary/lagoon, lake, and open water. All but the first two are relevant to the current study (Figure 2.1). Zone identification can vary depending on spatial scale of analysis; they can split and reform in response to outside forces; they can be temporary or periodic, and the loci of transfer between zones can be dangerous, often the location of several wrecking events, the consequences of non-uniform change on the landscape. Additionally, understanding the relationship between these loci and the archaeological site formation factors imposed by the landscape is a key aspect of predicting unknown sites. The boundary between coastal transport and open water on the Thunder Bay maritime landscape can be identified as the historic shipping lane defined in contemporary coast pilots used by Great Lakes mariners.

A second category of maritime transportation zones can be patterned onto the above physical transportation zones: the duality of danger versus safe zones (Duncan 2004). Both danger and safe zones have physical and cognitive definitions, and identification varies according to the same parameters as the physical transport zones; however, what sets them apart from the fundamental zone types is the fact that their physical and cognitive identifications can often be in opposition to one another. For 
example, the shoal, difficult to navigate passage between Sugar and Thunder Bay Islands and North Point was considered a safe respite for vessels attempting to enter Thunder Bay (Figure 2.2) (Thompson 1878: 69). Pecoraro (2007) has shown that this passage actively functioned as a ship trap that served to concentrate maritime accidents into a condensed area. Additionally, mitigation of risk in physical danger zones, such as erecting a lighthouse, may actually elicit a false sense of security by changing the assignation of a perceived danger zone to safe, increasing high-risk behavior, and may ultimately lead to more accidents. In the long-term, danger zone identification swapping may become cyclical (Duncan 2004: 21).

The significance of maritime technology is that it is assumed to be adapted to the transport zones in which it is being operated. It is also dependent on peripheral social factors such as risk recognition and behavior. The combination of the two components allows for a landscape approach to maritime behavior incorporating both the social and natural components of the total geographic landscape.

A useful paradigm for treating the total geographic landscape in the formation of a new conceptual regional site formation process-based model is to treat the maritime landscape as a "nonlinear dynamical system whose evolution is governed by abrupt transitions" (McGlade 1999). This does not preclude the presence and efficacy of non-abrupt transitions, but necessitates that they are not the primary mode of or condition rates of social and physical change. McGlade (1999) refers to this as a human ecodynamic approach, concerned with the dynamics of human-modified landscapes from a long-term perspective. This therefore is useful for the consideration of maritime landscapes and associated transport zones. The human-environment 
relationship involves the co-evolution of socio-historical and environmental process and their intersection in time and space producing the socio-natural system as an analytical framework (McGlade 1999: 462). This then can be incorporated into the tripartite framework being used to construct the site formation model.

Socio-cultural evolution is spurred by "positive" feedback, which produces temporary and/or permanent destabilizing social effects that push society through unstable transitions (McGlade 1999: 464). The socio-natural system can be conceptualized as a framework of stored system energy. System efficiency is realized when energy enters the system as pulses (Odum 2007). Shipping accidents and accident mitigation can be considered systemic energetic pulses. Other maritime examples of this process are the invention of new shipping technology or the discovery of a new natural resource. Within an ecodynamic system, a small change in one variable can have catastrophic effects on the system as a whole (e.g. a shipping accident or wreck). The social response therefore can be considered as a form of selfreorganization rather than mere adaptation to the effects of positive feedback (McGlade 1999: 464). Often however, affective change is partial, with parts of society able to withstand change more than others.

An excellent example that illustrates these social processes in the maritime landscape is the dramatic loss of ships and life during the "White Hurricane" of November 1913. By the twentieth century, the Great Lakes had known many destructive and deadly storms, however, no experience had prepared the maritime community for the White Hurricane, which began November 6th, 1913, and lasted nearly a week. Using all available equipment at the time, such as storm warning flags 
and Marconi wireless radio, weather stations warned owners, captains, and their crews of the possible impending danger. The gale warning flag raised however, indicating the most severe weather warning on the lakes, did not prepare the sailors for the strength of the storm into which they steamed, as they had seen this flag before and had successfully mitigated these storms' effects.

Being the end of the navigation season on the Great Lakes, many ships embarked in the face of danger, looking towards profits, and betting on the new maritime technologies used in their construction. Several modern straight-decked bulk freighters steamed northwards in Lake Huron towards the ore fields on the shores of Lake Superior carrying cargoes of coal. Though the bad weather had been reported, many of these ships had weathered storms before, coming out little worse for wear. Quickly however, it became clear that the storm was too dangerous to continue en route. At least 20 ships attempted to ride out the storm in the safety of Thunder Bay. Those who could not make it to the relative safety of the Bay and those newer vessels believed to be able to withstand the gale, followed established protocol and turned south to steam back towards Detroit, several being able to report their predicament via their Marconi systems. It was considered the safest course of action for ships in the open water transport zone. This action doomed many of the freighters (Brown 2004). Why did so many of these straight-decked freighters perish in the storm? Why were they believed to be able to withstand powerful gales? Most of these ships were but a few years old. They were also some of the largest bulk freighters on the Great Lakes (Figure 2.3a). The power of their engines however had not kept pace with the growing size and weight of the ships. It appears that the wrecked ships did not have 
enough power to maintain headway into the heavy seas, caught in the troughs, and foundered. Many actually flipped and eventually "turned turtle" and sank (Figure 2.3b). The state of many of the identified crew from these ships that washed ashore indicates that these events happened too quickly for any mitigation to take place. The cook of the Price washed ashore with his galley apron still tied around his waist (Brown 2004).

In interviews with Great Lakes sailors after this event, several reported to the press that they knew that if these vessels became damaged they would sink. It, however, was not profitable for ship owners to invest in mitigating this issue. Most expressed surprise that such new ships would wreck (Brown 2004). Of the 70 freighters caught in the storm, 12 sank and 31 were stranded onshore. Of the 17 ships underway on the evening of November 9th, only two arrived at their destinations, both seriously damaged. In all, 248 sailors were killed.

This example illustrates how participants in the maritime landscape actively negotiate real and perceived constructs on the landscape. The doomed ships owners, captains, and crew acted within the socially created structure of maritime activity. Most of the ships and their crew turned southward when faced with a late season Great Lakes storm. They acted as was expected and as what was perceived as normal within the identified maritime transport zone open water. They trusted their maritime technology to perform as expected though the performance proved that the technology was misunderstood. Within the constraints imposed by the natural environment, established protocol and beliefs in maritime technology proved inadequate. These 
physical and social processes acted to form what is today the archaeological record associated with the White Hurricane.

The large loss of capital, infrastructure, and life, compared with what would be considered "normal" loss during a storm was a systemic pulse in the ecodynamic system, the recognition of which was strong enough to create positive feedback that forced systemic changes on the maritime landscape. The recognition of the event as abnormal was only possible when considering the nature of storm-related shipwreck activity in the long-term. The maritime community accepted that vessels have a higher chance of wrecking in storms than on a clear day, however the losses during the White Hurricane was characterized as egregious at the societal level. The immediate response was an attempt to analyze the root causes of the systemic impulse to mitigate future similar events and to normalize the effects of the event should it happen again.

The aftermath of the events of the White Hurricane resulted in a significant behavioral response and reorganization. Most of the blame for the tragedy was placed on the Weather Bureau by the socially powerful, wealthy shipping conglomerates. Severe weather identifications and signals were revised to reflect newly identified possibilities in Great Lakes weather patterns, such as the identification of and signals for hurricane force winds. Though many sailors and engineers stated in the press that there was now proof of inadequacies in ship design and safety protocols, the political force of ship owners was enough to mask deserved blame for their lack of investment in safety. The outcome of the loss however was enough for ship designers to learn from technological shortcomings revealed during the storm. 
Increased diversity of the temporal and spatial scales of phenomena within the total geographic landscape increases lag in social evolution, the results of which can cause disruptive socio-cultural and natural dynamics (McGlade 1999: 465; Gould 1983). Because in the short term, these system responses are non-linear, it is necessary to define patterns in long-term behavior. In the long term, discontinuous transitions that result in patterns of social activity and environmental events in nonequilibrium are normal (McGlade 1999: 465). This is akin to the intermediate disturbance hypothesis in biology (Connell 1978).

Hence, understanding patterns of behavior in the long term is the only really effective way to understand the behavioral components of maritime disasters and associated shipwreck distribution, and a landscape of maritime disasters is a very useful place to compile relevant data. Having a model within which to collate, interpret and communicate the data - and give due attention to oceanographic factors that influence the data - makes it able to be compared to similar research conducted in other areas, so that landscapes and individual archaeological sites can be connected to greater landscape processes.

Maritime landscapes, when combined with historical information and statistics, are maps of human behavior in the long term, in particular as it relates to risk-taking strategies. Approaching maritime archaeology from a landscape perspective reveals patterns of human behavior that can be empirically studied to reveal the constantly evolving process of negotiation within society and with the natural world. The narratives of individual shipwreck events are real human tragedies, but they can be used to develop an abstract archaeological landscape formation model, which in turn is 
very useful for identifying patterns of human behavior on the maritime landscape.

The study of this landscape is inherently interdisciplinary, and this is why adding an oceanographic perspective to the anthropological and archaeological analysis becomes critical - it provides the ability to analyze all factors that influence the maritime landscape. 
Figures

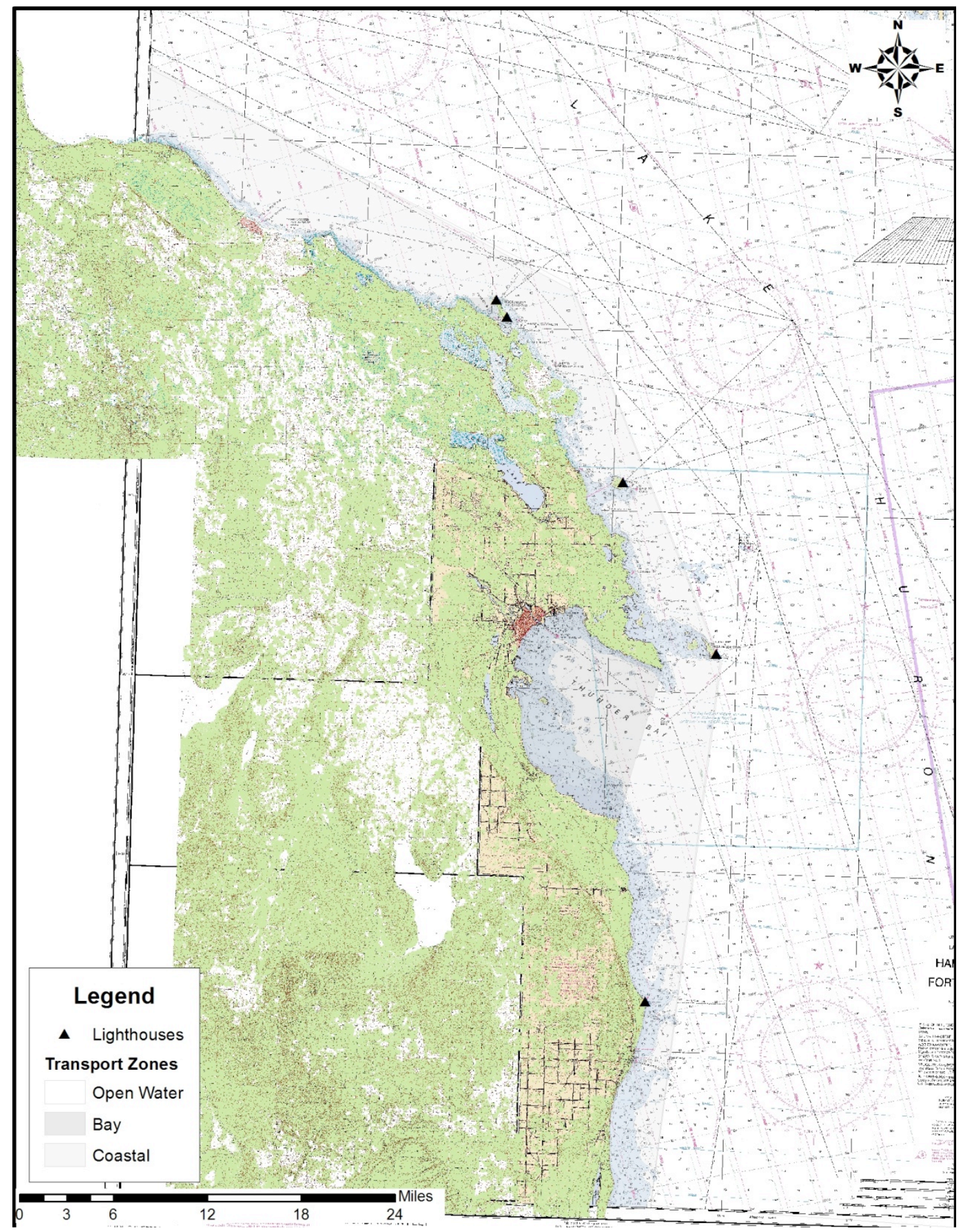

2.1 Bay and Coastal Maritime Transport Zones in the Vicinity of Thunder Bay 


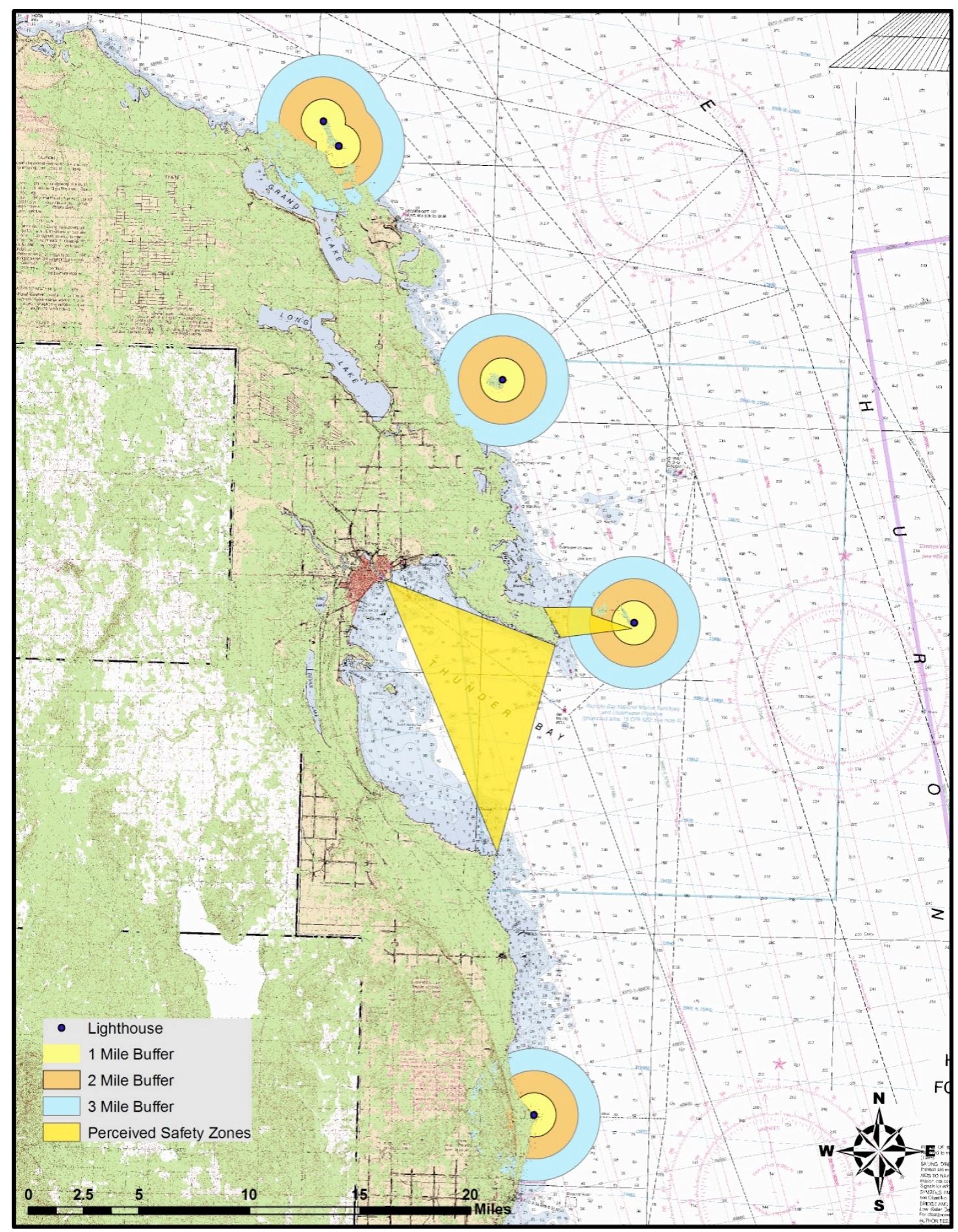

2.2 Potential Danger Zones within in the Vicinity of Thunder Bay 


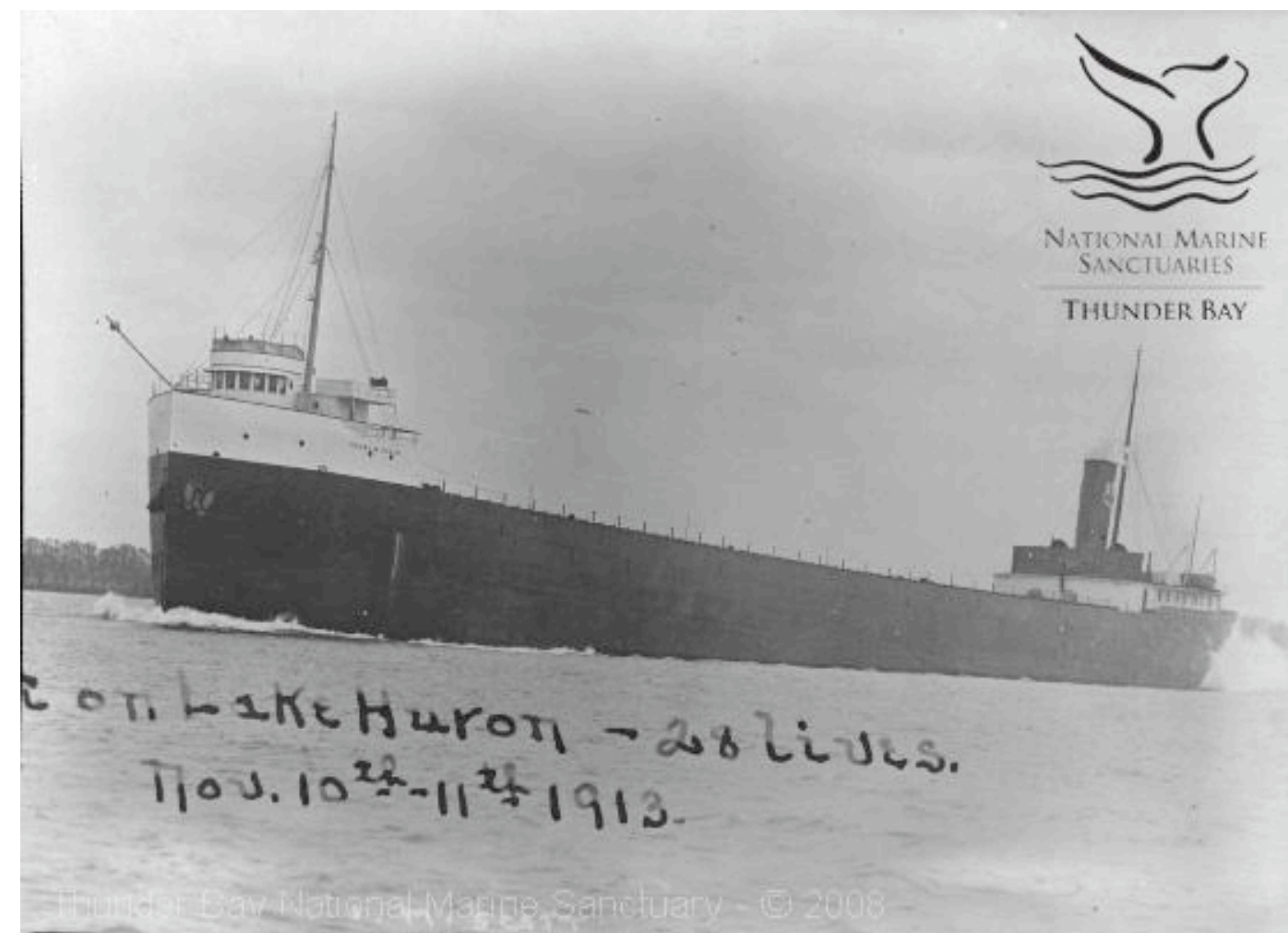

2.3a The Isaac M. Scott Underway (Courtesy Thunder Bay National Marine

Sanctuary) 


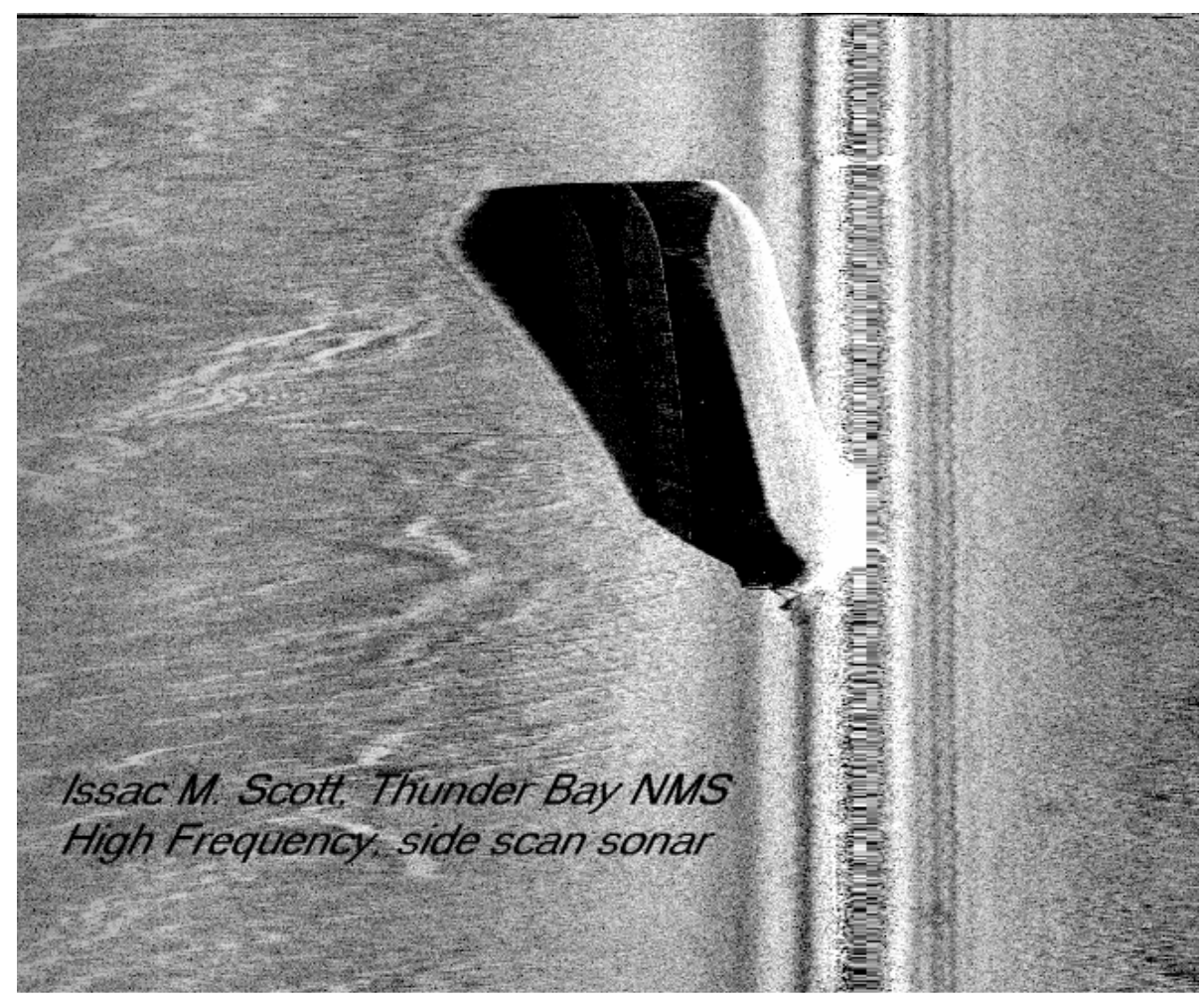

2.3b Side-scan Sonar Image of the Isaac M. Scott (Courtesy of the Institute for Exploration) 


\section{CHAPTER 3}

\section{ANTHROPOLOGICAL RISK AND THE MARITIME LANDSCAPE}

It is appropriate to introduce the concept of anthropological risk here because it is intimately tied to the total geographic landscape and cannot be separated from it. Since it is a very broad topic, the following will distill its fundamental aspects as they relate to the historic maritime landscape.

The Development of the Concept of Risk

The word risk, although seemingly simple and straightforward, is a temporally sensitive and culturally loaded term whose meaning cannot be considered exclusive of the scientific or social analytical context that attempts to describe or explain it. The concept of the analysis of risk as measurable phenomena was developed in the 17 th century in the context of gambling (Douglas 1992: 23). In this context, every aspect of risk was fully and discretely measurable as a function of a related set of probabilities inherent in a particular bounded game with a defined set of possible outcomes. Actual patterns of choice were irrelevant to the risk in question.

The application and analysis of risk marginally changed in the 18th century when it began to be used in the context of insurance against maritime disasters. The chance of a successful voyage with the ensuing financial gains for the involved parties was set against the chances of the ship being damaged or lost at sea. The presence of risk, as with the gambling games of the 17 th century, was still a bounded phenomenon. The 
process by which the outcome of the voyage was realized was irrelevant to its final result. The idea of risk was neutral, being recognized as purely a function of economics with no direct social connotations (Douglas 1992: 23).

The perception of risks as phenomena rooted in sociocultural reality was recognized in the 19th century; however, it was approached in a fundamentally different manner than today. Risk perception was tied to contemporary theories of perception in general. Risk was understood to only exist as an affective reality if it was realized. In the context of maritime voyages, this meant that embarking on a voyage was only considered a risky endeavor if the individual involved knew that there was a possibility for disaster at sea from any potential specific cause above and beyond the general understanding that sailing could be a hazardous profession. Hazardous and risky actions were not considered to be the same; risk could be discounted to the point of inaction. Thus, the probabilities associated with risks were only relevant if those involved understood them (Douglas 1985: 27).

In the 19th century, risk was perceived as being intrinsic with nature, or composed of discrete facts (Beck 1992: 20). The hierarchical social structure of European and American society was also thought of as a function of nature. The willing participation of the individual within his or her assigned social class in turn reinforced the foundation of the society's existence (Douglas 1992: 33); therefore, the burden of risk that weighed on an individual was perceived as natural.

Choice Selection and Blame Creation 
Although social position was predetermined in a hierarchical society, the individual faced a range of choices in any given situation. Hierarchical position prescribed what subset of choices was available to that individual. What modern society defines as risk would have been referred to as a set of relative dangers in the 19th century (Douglas 1992: 14). Measurable probabilities of possible outcomes of a bounded event might not have been known, but their existence was acknowledged. Risks therefore were inherently personal, even if the total number of affected individuals was unknown. The ramifications of a given outcome were discrete and physically real (Beck 1992: 21).

Blame as a result of risk was therefore guaranteed by an objective basis and was not enrobed in ideology (Douglas 1992: 7). Information accepted as true was linked to the particular authority that the person endorsed, be it scientific, anecdotal, or some other source; the rest was deliberately or unconsciously ignored (Douglas 1992: 19). Of course, this does not account for risks rooted in cultural and ideological logic. Overall, the 19th-century approach to risk management failed to take into account mythologized historic events that resulted in socially translated practices, for example, taboo behavior such as not whistling in the wheelhouse, else the sailor would conjure a storm.

The idea that choice selection was rooted in hierarchical position, it had real social ramifications, and individual choice was subsumed by the greater social reality faced by those without powers of social control. Individuals in the 19th century were bound to the conditions of industrial society and subject to the penalties of nonconformance within the labor system. Wage laborers were "engaged in constant 
struggle for [their] job[s]" and a range of prescribed rewards (Beck 1992: 47, 49).

Maritime sailors on the Great Lakes were members of this industrial social class.

Risks that come with reward can be either voluntary or involuntary; for example, one might prefer the risk of an accident or accept a certain degree of hardship rather than being unemployed. It may therefore be appropriate to approach risk as a function of choices made within a range of options controlled by the elite. At the local level, this would encompass choice proscribed by ship captains and, at the society level, by ship owners.

Hierarchical organization allows for the sacrifice of individuals to reinforce its structures. According to the theory of diffusion of responsibility, groups tend to make riskier decisions than individuals because this allows for mutual decision responsibility (Wallach et al. 1964). Reducing the risk for possible blame extinguishes possible response variety, potentially increasing associated risk. If risk behavior is inevitable, shifting responsibility may become more dangerous than weathering the consequences for some party, because the individual, usually someone with negligible social power, may be unaccustomed to the risk situation or may be more vulnerable to the changed conditions (Douglas 1992: 197). The more marginally situated the sacrificed individual, the less he or she is subject to directed public scrutiny (Douglas 1985: 69). Therefore, the effects on the individual are more or less ignored by the elite.

Risk Perception and Assessment 
To approach complex problems of risk, decision-makers use heuristics as a mechanism for simplification, sometimes to the point of distorting the issues in question, such as risk outcome frequencies. Contemporary scientific and social debates foster recognition of distorting heuristics, although they can emphasize insignificant issues while ignoring those that are more salient. A benefit of heuristics is that they allow prediction of what individuals and groups may do in a given situation (Douglas 1985: 80).

In addition to the attempt to create quantifiable risk assessments of physical phenomena, society creates social ideas of risk and the perception of risk behavior as a function of culture. In the context of risk, culture represents a formalized system of intra-societal consultation and negotiation. It provides recognition of established categories of phenomena, sets of culturally stored habitual behaviors for risk acknowledgment, information storage, and retrieval. Social pressure ensures that these structures will be maintained and remain uncontentious. New information is compared to often differentially evolving cultural standards, which act to justify behavior (Douglas and Wildavsky 1982: 6; Douglas 1985: 68, 80-81). According to Douglas (1992: 41), the question that arises from this process is: how safe is risk behavior for a particular social institution?

Institutions of social control create thresholds for acceptable behavior and phenomena. Development of thresholds, however, is deemed unacceptable if outcomes are unknown or poorly understood in practice, or if the cost is determined to be too expensive in relation to the potential benefits of the prescribed actions. The 
typical result is to do nothing or to keep debating without action (Douglas and Wildavsky 1982: 59). An example is the lengthy debates of the Lake Carrier's Association regarding the cost and necessity of different lifesaving equipment on Great Lakes boats (Brown 2004: 187).

In addition to socially created thresholds of acceptable risk, many individuals think that risks that are not technically manageable do not exist. These incalculable threats add up to an unknown residual risk, which becomes assigned to everyone and therefore deserves neither precautionary measures nor economic investment in prevention (Beck 1992: 29).

The process by which individuals perceive the temporal aspects of risk depends on the span of their attention. The idea of time associated with hazard potential is bounded with event anticipation and selective memory. Social conditions limit how far forward and backward one may consider (Douglas and Wildavsky 1982: 86).

Rules of Thumb

Individuals cannot comprehensively know the risks they face, but must act as if they do (Douglas and Wildavsky 1982: 1). Most people are not good judges of probabilities; they do not go out of their way to become informed of all possible risks and they typically do not incorporate uninvited probabilities of risky behavior. Often, individuals do not perform risk calculations they might be expected to make when approaching given situations. Remote potential outcomes of risk are ignored (Douglas and Wildavsky 1982: 74). So, how do people in a given set of bounded situations cope 
with issues of risk? Anthropologists recognize the social institution of "rules of thumb."

People respond to perceived risk as social beings that internalize social pressures and delegate decision-making processes to institutions in which they are members (Douglas and Wildavsky 1982: 80). This may explain why individuals seem to engage in irrational behavior, for example, when a captain embarks on a voyage in dangerous weather; the potential rewards of a late season cargo delivery could be perceived to balance expected risks. Rational behavior does not use elaborate calculations for making potentially critical decisions; rather it focuses on the infrastructure of everyday activity and social expectations, setting up conditions for success by constructing flexible and feasible aims for action (Douglas and Wildavsky 1982: 81). Those whose social positions, including their economic livelihoods, are dependent on an understanding of the physical factors that affect their environment create rules of thumb to reduce uncertainty. Historically, rules of thumb precede scientific inquiry in a given techno-environmental situation (Douglas 1992: 51)

For example, sailors use their experience with probabilism to assess their technological, social, and physical environments in order to predict the behavior of tides, wind, fog, and other important phenomena. They disregard inferences from small phenomenological samples and reference the "practical equivalent of statistical independence" (Douglas 1985: 32). If they were not capable of performing these functions, they would not be able to maintain their institutionalized position. This informal practice of probabilistic thinking is not inherently difficult (Douglas 1985: $32)$. 
It is possible to get a sense of socially created rules of thumb for dealing with inherently high-risk behaviors. In part, they can be derived indirectly from the historical record, by uncovering how sailors defined themselves and their occupation. Estellie Smith (1977: 11-12) interviewed Great Lakes sailors in the 1970s and obtained the following self-identifications in comparison to open-ocean mariners:

These lakes are the toughest, roughest waters in the world to sail and it takes a real sailor to handle the storms we get.

They got all the machinery that computes a ship from this to that place - but we still do it the way sailors do it.

Why, they even hire a pilot to dock the ships. Here, we have every licensed man on board able to pilot a vessel. A captain on the lakes is a real captain.

Those guys don't care; this ship, that ship, it's all the same to them. With us, we know every boat on the Lakes, every captain, every man almost. You got a reputation to worry about here. Makes you careful how you do your job because word gets out if you don't.

Hmpf! Iron ships and wooden men, that's all they are.

Applicable risk-related issues can be derived from such statements. Great Lakes sailors' diffuse perceptions of life aboard boats included positive factors: camaraderie; contacts with land-based individuals along familiar routes; piloting competence that reflected on the crew as a whole; egalitarian relationships among the crew; the possibility of working through the ranks, perhaps up to captain; and the integrating rivalry and competition between vessels that regularly encountered one another. An emphasis on interdependence and occupational competence indicates that focusing on these issues can alleviate risk-related concerns. These foci stress that acute awareness 
of the social and physical environment facilitates mitigation of high-risk situations (Estellie Smith 1977: 13).

These principles, which regulate institutional decision-making, are culturally bounded. Practitioners typically cannot translate informal rules of thumb outside of the context in which they are created (Douglas 1985: 32). This can include technological shifts within the same context such as the switch from sail to steam or from wood to iron and steel boats. A lag in the creation of rules of thumb inevitably occurs during technological shifts.

Risk and Maritime Technology

According to Petroski (1994), technological evolution is driven by perceived and expressed want as opposed to actual need. Basalla (1988) fleshes out this idea by including concepts of technological diversity, continuity, and novelty, and social selection processes that motivate individuals and social institutions to invest in new or improved products. In addition, individual experimentation, common in 19th-century maritime engineering, adds to the possibility for many unique concurrent technological forms in maritime industry (Souza 1998: 104). According to Souza, the state of technology and its relationship to contemporary economic systems foster support for the introduction of new technology. Souza (1998: 105) points out that, unlike developments in other industries, steam technology was introduced to maritime industry to augment current technological systems as opposed to replacing them outright. How then can the persistence of increasingly obsolete technology in maritime 
industry be understood? Two complementary theories allow us to address this issue: Gould's (1983b) theory of anticipatory recycling and Murphy's (1983) “one more voyage" hypothesis.

Anticipatory Recycling

According to Gould (1983b), industries and their investors attempt to prepare for a perceived future need of considerable stocks of infrastructure-related technology. Though Gould derived his hypothesis of stockpiling in the context of defensive isolation in situations of war, it is applicable to anticipatory issues in mercantile economic systems. The typical result of this behavior is that technological innovation and new industrial products enter the applicable markets while investment is made in a restricted number of technological forms. By the time the stockpiling is complete, the technology becomes outdated. However, real monetary investment is locked in the stockpiled material; therefore, it will be used and recycled in the system, despite its likely systemic inefficiency.

Nationally, in the mid-19th century, there was an overstock of new sailing vessels for which demand in an expected maritime shipping boom never materialized. Sailing vessels were overall much more costly to operate than steam vessels for relatively short voyages; early steamboats required copious amounts of cargo space for fuel for long voyages. Therefore, to allow for operational costs to successfully compete with steam vessels, sailing vessel owners would have had to operate at less than optimal conditions of both manpower and safety (Souza 1998: 106-107). The quality of 
experience and training of newly hired merchant marines markedly decreased during the 19th century, as more capable and seasoned sailors possibly would have refused the suboptimal working conditions (Souza 1998: 106-107). In addition, insurance policies varied by age of vessel, state of repair, type of cargo, and propulsion method. Some vessels that did not qualify for justifiable insurance continued to operate, with the number increasing through the late 19th and into the 20th century (Souza 1998).

\section{“One More Voyage”}

The longer a vessel is in service, the greater the potential economic return of its owner's investment. Insurance data show that it was often cheaper for an owner to bear the loss of an older vessel and its cargo than to pay for needed repairs. Insurance therefore could be irrelevant (Souza 1998: 129). Murphy (1983) has determined this behavior to be a function of the "one more voyage" hypothesis. This is defined as high-risk behavior taken by vessel owners when, upon the completion of a successful voyage, they try to eke out at least one additional voyage before investing in costly repairs or new technology. This thought process assumes that the success of each independent voyage is not mutually exclusive of the success of any previous voyage.

An excellent example of the deleterious effects of this practice is the sinking of the D. M. Wilson off North Point at Thunder Bay, Michigan. The D. M. Wilson, a wooden-hulled propeller driven vessel, was en route to Milwaukee from Cleveland on 27 October 1894, carrying a load of 1,000 tons of coal. While proceeding through Saginaw Bay in Lake Huron, the vessel opened a seam and began to take on water. 
Instead of putting into port for repairs, the crew used a bilge pump to handle the leak, a process that failed off North Point, causing the ship to founder and sink in $70 \mathrm{ft}$. of water. Interestingly, reports of the accident, including the Life Saving Station accident report and successive newspaper articles, incrementally increased the supposed cost of the loss of the vessel and cargo.

It is possible to correlate older and/or sailing vessels and relatively cheap bulk cargo such as lumber and coal during the late 19th century (Figure 3.1). These vessels may also show evidence of decreasing investments of money and labor in repairs. Souza (1998) also indicates that many of these geriatric vessels sailed overloaded as insurance concerns became lax over time. Additionally, on the basis of shipwreck data in the Dry Tortugas, Souza concludes that decreasingly competitive shipping systems encourage high risk sailing patterns such as cutting the time and distance of voyages by sailing in relatively more dangerous waters such as those in close proximity to shallow reef systems or in dangerous weather. There is a high probability that these high-risk behaviors should be visible in the patterns of shipwreck events and the resultant archaeological record at Thunder Bay.

Risk and the Archaeological Record

Typical characteristics of high-risk occupations are self-recruitment, strong traditions, and socially established norms of risk acceptance and behavior. These include ideas of fatalism, in which risk of danger is high, but is accepted as ever present (Hovden and Larsson 1987). This may account for observed patterns of 
behavior that may seem irrational to outsiders and that do not always result in successful outcomes. However, practitioners of high-risk occupations do take precautions to avoid danger. For 19th-century sailors, examples of these included increasing the frequency of depth soundings, posting additional watches in fog, reefing the sails in high winds, and ranging the anchor chain on deck and positioning bower and stream anchors for rapid deployment when sailing in shallow water (Souza 1998: 114-115). The latter can be observed in the archaeological record, in addition to patterns of anchor deployment. For example, if the engines were not strong enough to hold vessels in place, as was common for early 20th-century steamers, captains would order the anchors thrown to slow vessel drift and to orient the vessel with the bow facing into the waves, often leaving deep scours in the lake floor. If the lines broke, they can be seen in the archaeological record stretched straight in the direction of drift.

There are several additional risk mitigation practices that may be visible in the maritime archaeological record. Two that are relatively common in the Great Lakes include dealing with ice formation while in transit and beaching with bow flooding in heavy seas.

Lake ice and ice coat formation on vessels is a common and expected hazard on the Great Lakes. In winter, crews were supplied with a week's provisions, even for trips of only a few hours, in case they became stuck in ice and could not walk ashore. To prevent the ships from capsizing under the weight of ice buildup, crews would attack the ice with axes and sledgehammers, a practice that has lasted into relatively modern times. Evidence of this practice can be seen in the dented metal of the superstructures of wrecked vessels (Brown 2004: 38-39). 
Shipwrights began building iron and steel steam vessels in the late 19th and early 20th centuries. Engine evolution somewhat lagged that of hull design; shipwrights outfitted steel vessels with engines designed for wooden boats, which were insufficient for maintaining headway in heavy seas. If the engines became disabled or were otherwise unable to keep the vessel pointed into the waves, captains would order the bow beached. If the engines were also insufficient to keep the vessel beached, the captain would order the bow flooded. For example, during the White Hurricane of 1913, the steel propeller L. C. Waldo lost its rudder and the captain ordered it to be beached on the rocky Keweenaw Peninsula of Lake Superior. Additionally, the captain ordered that the L.C. Waldo be flooded to keep it from being pulled off the rocks and foundering (Brown 2004: 59). Many beached wreck sites, such as the L. C. Waldo and the schooner Maid of the Mist, have been identified near shore, while others may have a portion of the site on land such as the cut-down steamer-consort Joseph S. Fay, which broke from its tow in a gale on 19 October 1905.

\section{Conclusion}

Clearly, physical and social risks are difficult but very real concepts to consider in anthropology, and only grow more ungainly in archaeological discourse. It is possible, however, for discursive analysis to produce formidable results when dealing with the submerged archaeological record resulting from maritime transportation. Because maritime transportation, as sets of discrete events, is a bounded activity, physical risk is approached both in real time, with consideration of the state of the physical 
environment at the time of actual voyages, and as a set of averages that were variably understood by mariners and environmental forecasters. At the same time, social risk can be analyzed within the context of a bounded event. Also, like physical risk, social risk can be approached in the context of actual voyages and as a set of averages understood as an intrinsic part of the 19th-century social hierarchy. Involved social actors, however, understood the averages of social risk better than the complementary physical risks. This fact works to simplify the social matrix in which this type of archaeological discourse is embedded.

The difficult aspect of this analytical approach is for the archaeologist to determine the social environment in which 19th-century mariners lived and worked in order to fully understand the resultant archaeological record. Recognizing particularly common risk-related behaviors present in the archaeological record can orient anthropological analysis by providing a framework for teasing out other important but less visible aspects of risk-related activities in Great Lakes maritime transportation.

Accident mitigation by sailors during the White Hurricane well illustrates several of these behaviors and their resultant archaeological signatures. First, typical November maritime behavior addresses the fact that there are shipwrecks that are present as a result of this storm in the archaeological record. The captains of these ships chose to set sail when a storm was fully expected for two primary reasons. Storms in November were considered normal, sailors had weathered them in the past, and though sailing in November could be difficult, sailing in December was considered impossible. Secondly, there existed an informal system or custom of bonuses and promotions for captains who sailed after the traditional end of the 
navigation season (Brown 2004: 39). A secondary reason for the presence of these shipwrecks is that there was no institutional knowledge of hurricane-force storms on the Great Lakes. Though the storm had begun on the lakes prior to the embarking of most of the vessels, experience taught sailors that violent storms typically lasted for two days and better weather was expected by the third (Brown 2004: 79). In fact, to have accurately predicted the meteorological events that made up the storm, the Weather Bureau would have required knowledge of atmospheric physics that did not exist in 1913, for example upper atmospheric waves, fronts, and interactions (Brown 2004: 213).

An example of this behavior was the choice of the captain of the bulk freighter Henry B. Smith who had been given an ultimatum by the ship owner that if his cargo were not delivered on time, he would be fired. According to a local newspaper, he left the harbor without first battening down the cargo hold hatches (Brown 2004: 84-85). This is somewhat curious behavior as sailors considered it a given that if a hold flooded, a bulk freighter would sink. There was no profitable way that this defect could be corrected (Brown 2004: 195). To prove, presumably to his wary crew and perhaps to himself, that he was confident that the voyage would be successful, the captain mitigated potential risk by increasing the probability that a shipwreck would happen if the storm damaged the vessel, the sailing version of "going all in" so to speak.

Once the storm imperiled their vessels, sailors attempted to mitigate the danger of shipwrecking by carrying out actions that historically reliably saved both vessels and lives in the coastal transport zone. For vessels near rocky shores and shallow shoals, 
sailors would throw their anchors to prevent vessels from drifting ashore. If the anchors caught and held the vessel, this action would also keep the bow pointed into the waves by the force of the tailwind, preventing rolling and possibly flipping in the troughs. The Sylvania was able to prevent smashing upon the rocks at Whitefish Bay in Lake Superior because its anchor and 200 feet of chain was able to hold it in place (Brown 2004: 98). For vessels that wreck while attempting this mitigation, anchor lines can often be found stretched straight in the windward direction of the storm from the ship. If this did not work, as was the case with the Cornell at the Two Hearted River in Lake Superior, sailors would throw oil overboard. Sailors have done this practice for several thousand years to break the surface tension of the water supposedly reducing the force of the breakers. This practice however did not assist the Cornell (Brown 2004: 61).

For vessels caught under threat of wrecking close to a soft sandy shore, sailors would often purposefully strand vessels ashore in order to save the ship, cargo, and crew. This was the case of the Illinois. According to Captain John A. Stufflebeam:

"I saw only one safe solution. We drove into the land and forced the nose of the boat up on the beach. Then I kept the engines going slowly for 49 hours with the bow of the boat up on the beach. Thus we were able to ride the water, which continued to come against us with great fury. In that position we were able to throw a line ashore and this we fastened to a large tree. Then I stopped the engines and we rested there, fastened to the tree, for 23 hours more" (Brown 2004: 69).

The Illinois was lucky that it carried aboard a wireless radio and could report its location on South Manitou Island in Lake Michigan. A major concern for sailors stranded ashore with no communication systems was being lost in an unfamiliar or unknown location without accessible provisions (Brown 2004: 50-51). 
If a captain believed that his ship might be pulled from the beach or would wreck before it could be purposefully stranded ashore, he might order the vessel flooded, and in the latter case, sunk. The Waldo prevented foundering off of Keweenaw Peninsula by this method as it had lost its rudder crashing onto the rocky shore (Brown 2004: 59).

While these accident mitigation efforts could result in the recovery of the imperiled vessels, often they were too damaged to be profitably recovered, and subsequently they became part of the archaeological record. Evidence of the mitigation can be seen in the disposition of the shipwrecks. For example, this might include the orientation of the vessel relative to the shore, the deployment of the anchors, and open hatches to allow for purposeful flooding. Evidence can also be present relative to what might be missing from the site. For instance, a vessel may have been purposefully beached once losing an important structural component, such as the rudder, or an accessory such as an anchor.

All of the risk mitigation behaviors mentioned above were considered both typical and expected. At least 70 bulk freighters and manned barges were caught in the storm. Though twelve ultimately sunk and 31 stranded ashore, all of the vessels had to react to the danger of the storm. Nearly half of the vessels made it to a port. All of the survivors of the wrecked vessels were able to report their actions to save themselves and their ships. While sensational, these behaviors were normal. In fact, it was the report of the captain of the passenger steamer City of Hamilton on Lake Erie, whose decision to continue ahead rather than turning around as was considered appropriate mitigation measures, that appeared at the time remarkable. Though responsible for the 
vessels, the captains and sailors were not much considered in the structure of blame assignation found between the Weather Bureau and the shipping owners. 
Age of Vessel and Cargo at Loss, 1870-1899

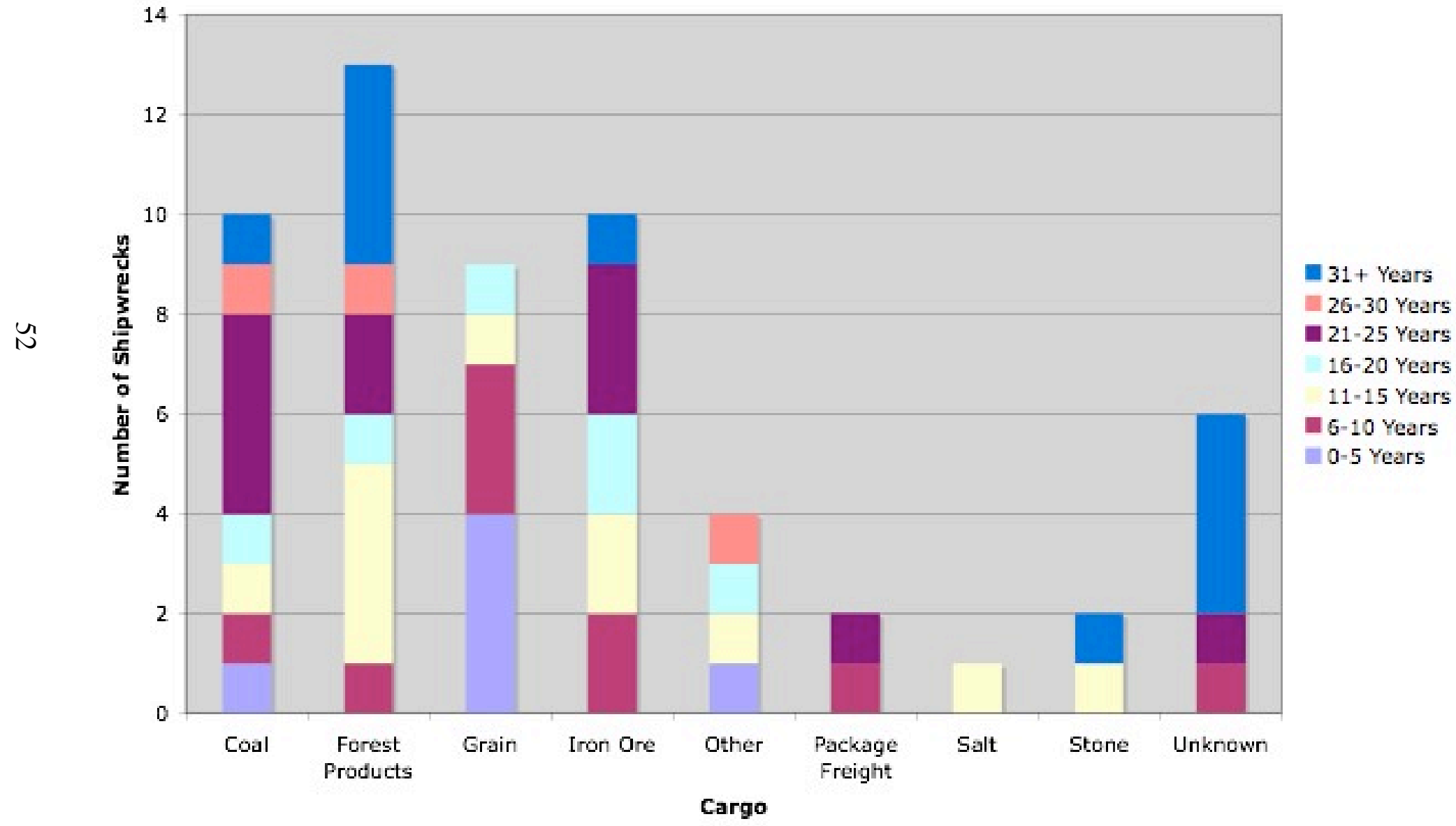

3.1 Age of Vessel and Cargo at Loss, 1870-1899 


\section{CHAPTER 4}

\section{THE PHYSIO-HISTORIC LANDSCAPE OF THUNDER BAY}

The goal of this landscape site formation model is to demonstrate how human behavior and the environment contribute to landscape dynamics from a long-term perspective. The research axes McGlade (1999) found useful and are applicable to this research include remote sensing and GIS, environmental dynamics, historical geography, and integrated community dynamics and social networks. To be able to consider each in turn, this section will concisely describe the geographic landscape parameters of important applicable geological and social geography to the formation model. They include: the topological, the geological/hydrographic, archaeological, the historic, and the modern landscapes.

The Geological Landscape

It is important to understand the three-dimensional geological and cultural stratigraphy of an archaeological site (Harris 1989). This includes both the layers of cultural material and the geological matrix into which it was deposited and/or incorporated. Extensive research has explored this on terrestrial archaeological sites (Stein and Farrand 2001). Understanding how the geological matrix was deposited allows for the determination of whether a given stratigraphic layer is likely to contain cultural material and if so, the likelihood of artifacts and features to be preserved 
within it. Geomorphological sequences, once deposited, are not static, and can continue to transform over time.

Relatively rapid geomorphological transformations occur regularly on inundated geological and archaeological sites. One of the most recent geologically active regions in North America was the changing glacial lake complex during the Late Wisconsinan glaciation, when human populations started to colonize what is now the Great Lakes region during the North American Paleoindian period. This has been explored archaeologically in both the Upper and Lower Great Lakes (Quimby 1963; Jackson et al. 2000; O'Shea and Meadows 2009).

Once the glacial history and geological processes that created and altered the region are understood, it can best be determined how to effectively search for inundated archaeological sites and how the current topography and geologic structure may affect the preservation of sites both buried and sitting atop of the inundated landscape.

\section{Late Wisconsinan Glacial Period}

The Quaternary is the most recent period in Earth's history dating from 1.8 million years ago. It is characterized by a generally cool climate compared with the previous 223 million years. The Quaternary Period experienced many short term warming and cooling events with as many as 21 glaciation cycles identified in the Oxygen-isotope record (Clark 1992). There is evidence locally for up to four of these episodes in the global geological record (Benn and Evans 1998). 
The most recent large glacial event on the North American continent was the Laurentide ice sheet advance of the Wisconsinan glaciation (Figure 4.1). It spread south from the Arctic Circle with the thickest ice at what is now Hudson's Bay (Erickson 1990). Near the southern extremity of the ice sheet, three major lobes advanced through the greater Michigan basin, including one directly through present day Lake Huron, depositing a series of end moraines and outwash plains in the basin and surrounding area (Fisher et al. 1988). At its maximum, circa 18,000 years ago (Clark 1992), the Laurentide ice sheet covered the entire Great Lakes region.

The Laurentide ice sheet advance/retreat system is the primary mechanism that shaped the geology of Lake Huron. It accounts for a complex resulting geology of glacial lake deposits, moraines, drumlins, eskers, and outwash plains (Fisher et al. 1988). Lake Huron was affected by both eustatic (water level) and isostatic (continental rebound) processes (Erickson 1990). Of the two processes, the former is more important. The removal of ice, erosion of continental crust, and sediment deposition are the variables that primarily affect isostatic equilibrium.

\section{Lake Huron Basement Geology}

Before continuing the discussion of the Wisconsinan glacial processes that affected the geology of Lake Huron, it is necessary to discuss the underlying bedrock topography on which the glacial processes acted. Cvancara and Melik (1961) assume that the prominent glacially derived topographic features are primarily controlled by 
the underlying bedrock. All Great Lake basins originate in pre-Wisconsinan bedrock valley systems (Larsen and Schaetzl 2001). Throughout the Michigan Basin, the bedrock is composed of various rock material including shale, limestone, chert, dolomites, anhydrite, salt, and sedimentary sandstones much of which dates to the Paleozoic era (Cvancara and Melik 1961, Larsen and Schaetzl 2001). There is no evidence of extant geological material that post-dates the Pennsylvanian super-period (324-295 million years ago) in the Michigan Basin save for a relatively small terrestrial Late Jurassic (160-144 million years ago) deposit (Dorr and Eschman 1970).

Cvancara and Melik (1961) identify three main types of basement topography in Lake Huron: gently sloping basins in Saginaw Bay, the South, and the Northwest; a long belt of linear topography oriented northwest to southeast; and a highly irregular topography of knobs and depressions in the Northeast. Three major erosion-resistant escarpments form the basin: the Niagara Scarp, capped by Upper Silurian dolomite, the Six-Fathom Scarp, capped by Middle Devonian limestones, and the Ipperwash Scarp, capped by Upper Devonian limestones. Bedrock forms the shoreline of several regions of Lake Huron including, in the northern half of the lake, immediately east of where the Niagara series Silurian dolomite that forms the islands which separate the North Channel and Georgian Bay and the Bruce Peninsula from the main lake basin intersects with the Presque Isle and Garden Peninsulas and parts of Manitoulin Island (Larsen and Schaetzl 2001).

Final Laurentide Ice Sheet Retreat 
The final advance of the Laurentide ice sheet created the extant Port Huron system of end moraines that surrounds the lake basin approximately 12 to 13 thousand years ago (Thomas et al. 1973). Following this time, the ice retreated relatively quickly, extending glacial Lake Erie to eventually fill glacial Lake Huron (Table 4.1). Possible deglaciation forcing factors include: bedrock rebound, iceberg calving, and moisture feedback (Peteet et al. 1992). Many of the small interstitial readvances resulted in extant regional end moraines (Larsen and Schaetzl 2001).

The cutting off of meltwater sources to the north, the erosion of drainage systems, and the removal of ice dams drained the basin to what is known as glacial Lake Algonquin which exhibited several lake level rises and falls until it stabilized at 184 meters above sea level for several hundred years (Figure 3.2). Many of the southern Lake Huron till and glaciolacustrine deposits result from this time (Thomas et al. 1973). Lake Algonquin eventually drained by approximately 10 to 11 thousand years ago (Thomas et al. 1973; Eschman and Karrow 1985; Farrand 1988; Larsen and Scheatzl 2001). Dating for lake level rise and fall has been accomplished primarily by looking at the Oxygen-isotope levels in invertebrate shells within the sediment (Rea et al. 1994). Post Lake Algonquin fossil assemblages are quite different from those of post-glacial lakes making their use as time indicators exceedingly useful (Eschman and Karrow 1985).

Post-Glacial Period 
The initial large post-glacial lake phase was named Lake Stanley with smaller confined lakes in the vicinity. Lake Stanley was relatively shallow at only 45 meters above sea level.

Between approximately 8.7 and 8.3 thousand years ago, with the continued retreat of the Laurentide Ice Sheet, Glacial Lake Agassiz was able to drain directly to the St. Lawrence River via the Ottawa River valley, bypassing the Great Lakes Basin. Lake Huron water levels fell over 20 meters below the available outlet at North Bay, becoming hydrologically closed. Pollen and stable isotope analyses indicate that a warm dry climate existed in which evaporation exceeded direct water inputs from precipitation and within basin drainage. There is evidence of now submerged tree stumps that date to this period. Lake Huron became once again hydrologically open at about 8.3 thousand years ago when the climate became wetter, and the atmosphere acclimated to the loss of glacial ice (Lewis et al. 2008).

As lands to the north were differentially uplifted due to isostatic rebound, the basin was progressively flooded, filling in deep scours and depressed areas, reaching a high-stand of 183 meters above sea level; the Nipissing Phase. This indicates that the glacial lakes in the Lake Huron basin consumed considerable amounts of meltwater from the north (Rea et al. 1994). These flooding episodes eroded glacial deposits and brought in a drape of sand and gravel that overlies many of the glacial deposits. Around approximately two thousand years ago, Lake Huron reduced to its present level of 176 meters above sea level.

The above summary of the last major retreat of the Laurentide ice sheet and the resulting glacial lake rises and falls is in no way exhaustive or even close to being so. 
Its primary purpose is to set a framework for understanding the glacial and post-glacial sedimentary history of Lake Huron. Rea et al. (1994) note that the general sequence of glacial and post-glacial sediments throughout all the Great Lakes is similar. In most of the lakes, till blankets bedrock with very-fine glaciolacustrine clays deposited atop it. During early Holocene lowstands, exposed glacial sediment was eroded and deposited in basin centers. Shallow water beach deposits also formed at the margins during the lowstands.

Current Lake Floor Geological and Sedimentary System

Thomas et al. (1973) sampled the sediment of the entire main basin of Lake Huron in 1969 (192 locations). Sediments are primarily composed of quartz, clay minerals, organic carbon, and carbonates (Figure 4.3). The percentages of quartz and clay in any given area show an inverse relationship. Organic carbon percentages parallel that of clay. Carbonates are generally low in percentage throughout the basin. Grain size generally decreases in a direction away from the inshore zones and other high topographic areas towards the small basins. From west to east in the Lake Huron basin, there is an increase in silt-sized materials. The Alpena basin, located due east of Thunder Bay, is not well defined by clay distribution patterns.

Three major units of surficial deposits were identified: till and bedrock, glaciolacustrine clay, and postglacial mud (Thomas et al. 1973). The latter occurs in basins of three distinct types. Type A basins have continuous post-glacial mud deposits. This could indicate a thorough erosion of glacially deposited materials; in 
fact in some areas, all till has been eroded exposing bedrock. Type B basins have glaciolacustrine clays, which outcrop, however; post-glacial mud covers more than 50 percent of it. Lastly, Type C basins are the same as Type B basins, but with less than 50 percent post-glacial mud coverage. A reflective boundary can be seen in echograms of the basin floor though the clay and mud are transparent (Thomas et al. 1973).

Lake Huron till is typically gray, light yellow-brown, and reddish-brown in color, composed of cobbles and pebbles in a sand, silt, and/or clay matrix. As mentioned above, much of this till is covered with a sand veneer (Thomas et al. 1973). The lakebed within Thunder Bay is primarily composed of undifferentiated till and with some bedrock outcrops. Acoustic research and visual inspection show that there are also many limestone deposits with cave systems and karst sink holes as well (Figure 4.4) (Black 1997; Coleman 2003).

Glaciolacustrine clay is found in areas intermediate between areas of till and the post-glacial mud within the relatively small, localized basins. The clay deposits are quite constrained by the lake floor topography. This material is stiff, gray to reddishbrown, and in places contains larger "rafted" pebbles. There is also evidence of lamination and seasonal varves within the clay (Thomas et al. 1973). Much of the area surrounding the small Alpena Basin is glaciolacustrine clay. The small pocket within the basin may be uncovered from the post-glacial mud due to currents and other localized water movement patterns.

In the deepest part of the Lake Huron basin, post-glacial mud has accumulated up to 18 meters. The Alpena basin has accumulation up to 2 meters. The mud is soft and 
easily disturbed. It is gray to black in color and ranges in grain size from silty-clay to clay. The black nature of the material is likely due to the presence of amorphous iron sulfides within it (Thomas et al. 1973).

Recent sedimentary erosion is a natural function of: the presence and height of uplands around the lakes, composition and erodability of shore-based materials, exposure to storm surges, fluctuating lake levels, the offshore hydrographic system, lake ice, and the rates of longshore transportation of sediment (Larsen and Schaetzl 2001).

The main source of sand into Lake Huron is bluff undercutting, a process which provides up to two thirds of sediments into the Great Lakes (Rea et al. 1994; Larsen and Schaetzl 2001). Sand primarily reaches the lake basin through movement to offshore bars and the presence of man-made obstructions such as dams and jetties.

Most of the surficial sediment of Thunder Bay and the extents of the National Marine Sanctuary consists of course sand and gravel (undifferentiated till) with occasional glacially derived boulders. Over ninety percent of the surficial sediment is composed of quartz. Less than ten percent of the material contains carbon or clay or silt size-fraction. It appears that much of the silt size-fraction, and most likely the carbon input, into the sanctuary inputs from the Au Sable River south of the sanctuary (Thomas et al. 1973: 244, 249-250). The above indicates that Thunder Bay and its immediate surrounding areas are high-energy regions of Lake Huron. It is likely that much of the small-size fraction particulates that input into the region are quickly transported into the main lake basin including the Alpena sub-basin. 
The Thunder Bay River does input small-size fraction particulates into the bay, with the potential of affecting submerged archaeological sites. This is evidenced by the presence of the shipwreck Shamrock, which sits in 12 feet of water just outside the mouth of the river. Sanctuary archaeologists have observed the shipwreck's eight-foot propeller, which sits on the lake floor, periodically buried, and at other times fully exposed (Wayne Lusardi, personal communication). It is likely that the massmovement of small size-fraction sediment is caused by periodic storm surges, which are common in the area.

The Social Landscape

The Prehistoric and Protohistoric Landscape

It is impossible to understand the patterns of lifeways in a given region without understanding that each new community construct in some way must pattern itself on the social knowledge and physical constructs that came before. For example, a social unit may inherit patterns of land use or communication network, or they may inherit the results of environmental and ecological manipulations that took place before the emergence of their local identity. It is therefore necessary in order to understand the historical landscape that included the maritime shipping industry of the Upper Great Lakes, to discuss the prehistoric and protohistoric environmental and cultural landscapes that preceded it in the region. 
Peopling the Great Lakes - The Paleo-Indians (9500 - 8000 BCE)

During the Paleo-Indian period of the Great Lakes region, life in Michigan and the Upper Great Lakes was harsh. Michigan was probably inhospitable before 10,000 BCE (Schott and Wright 1999: 61). The earliest evidence of a human presence in Michigan dates to approximately $9500 \mathrm{BCE}$, though the presence of the ice-front margin at what is now the Port Huron Moraine at first restricted occupation to the lower third of the state (Mason 1981: 104). The habitable terrain was tundra, or subarctic grassland with occasional wood stands that graded into dense boreal forest. Game animals likely included caribou, moose, wapiti, mammoths, and mastodons (Schott and Wright 1999: 65). Mason (1981: 104) postulates that the controlling factor for Paleo-Indian presence may have been the availability of game resources rather than the glacial ice margin or glacial lake levels. Although it is assumed that Great Lakes Paleo-Indians were hunting local megafauna, no sure evidence of a mammoth or mastodon kill have been found in the region (Mason 1981: 101).

Paleo-Indian communities were small, highly mobile groups of hunter-gatherers who covered large territory to extract resources as evidenced by the widespread use of exotic cherts though local sources were likely available. Most identified Paleo-Indian sites are located in the southern parts of Wisconsin, Michigan, and Ontario along the beaches identified with Glacial Lake Algonquin (Cleland 1992: 14). As at other contemporaneous Paleo-Indian sites in North America, representative material culture includes primarily lanceolate concave-based fluted bifacial projectile points (Fitting 
1970: 38). Fitting (1970: 57) states that many Paleo-Indian sites are now submerged as water levels rose to main stage Glacial Lake Algonquin.

Late Paleo-Indian through the Early Archaic (8000 - 6000 BCE)

Climatic and ecological conditions were not constant at the start of the Early Archaic period. Within the Hypsithermal Interval, average annual temperature was warmer and it was dryer than today. Vegetation transitioned from the boreal forests of the Paleo-Indian Period to a climax deciduous hardwood forest (Schott 1999: 72-73). The exploited animal community shifted to what is present today with deer, moose, wapiti, and small animals and birds, shifting the local resource economy and potentially rendering some areas, now devoid of megafauna, economically marginal (Fitting 1970: 65; Mason 1981: 133). Lake level fall during this period indicates that many Late Paleo-Indian and Early Archaic sites are now submerged (Mason 1981: 115). Extant Early Archaic sites in Michigan are widely scattered and concentrated in the southern end of the state (Cleland 1992: 16).

The transition between the Paleo-Indian and the Early Archaic periods in the Great Lakes region is difficult to identify. The start of the period is marked by an increase in projectile point varieties including the introduction of side or corner notching, however, the fluting of lanceolate points did not end abruptly, especially in the northwest Great Lakes region (Mason 1981: 101, 112, 114). Much of the lithic technology was made of exotic cherts though over time there is a trend for more localized sources, possibly indicating a restriction in territory utilization (Mason 1981: 
116, 129-130; Schott 1999: 76-78). Several major sites are located in caves or on ancient river terraces (Schott 1999: 73).

Middle Archaic (6000-4000 BCE)

In Michigan, the shift from the Early Archaic to the Middle Archaic is subtle. Mason views this period as a continuation of the transition between the Late PaleoIndian and the Late Archaic, with no markers to definitively categorize it as its own period in the Great Lakes region (Mason 1981: 126-127). The Middle Archaic saw climatic and ecological shifts significant enough to support intensive occupation, however, population levels in the Great Lakes region appear to have increased little (Mason 1981: 133; Lovis 1999: 86).

Nearly all sites identified as Middle Archaic in Michigan are located near the terminus of Saginaw Bay. Game resources include deer and wapiti, a variety of small mammals, fish and turtle. There is also evidence of nut and berry processing. Overall, there is evidence for small scale, highly mobile foraging populations (Lovis 1999: 8891).

Archaic sites in the Upper Great Lakes represent cultural groups identified as the Shield Archaic. Persisting through the Late Archaic, the Shield Archaic differed little from the Late Paleo-Indian - Early Archaic transitional period. Some copper implements appear though they were likely obtained from more technologically advanced neighbors. The most important game resources were caribou and fish. The local boreal forests provided few vegetal resources (Mason 1981: 136-138). 


\section{$\underline{\text { Late Archaic (4000-1500 BCE) }}$}

The Late Archaic Period in the Great Lakes region began as the Hypsithermal Period waned and glacial lake levels reached their maximum with lakes Nipissing and Algoma (Robertson et al. 1999: 95-96). During this period, population levels greatly increased and Late Archaic sites vastly outnumber all known sites dated to previous periods. These sites are also larger, deeper, and richer in archaeological materials. Cemeteries and ritual burial also became conspicuous (Mason 1981: 142-143).

A proliferation in projectile points occurred in the middle of the Late Archaic Period representing several cultural phases (Robertson et al 1999: 100). There is also an increase in carpentry tools, possibly indicating a canoe industry (Mason 1981: 146; 154). Many groups also had readily available copper (Mason 1981: 181-188). It is possible that most of the gear we associate with outdoor activities and industry were developed in the Late Archaic including snowshoes, fishhooks, traps, and woven basketry techniques (Cleland 1992: 16-17). Evidence for long-distance trade is apparent, with most exotic resources found in burial contexts (Robertson et al. 1999: 113).

The Late Archaic economy was varied and flexible, relying on several primary and secondary seasonal resources. Freshwater shellfish were newly utilized. An increased reliance on vegetal resources fostered at least temporary in-settling that likely promoted increased cultural divergence. Site specialization, such as game 
processing, also becomes more apparent in the archaeological record (Mason 1981:

143-145; Robertson et al. 1999: 105-106).

One Late Archaic site has been discovered and excavated in Alpena County, the Huron Beach Site (20AL36). Part of the Red Ocher Culture, the site produced 67 Pomranky-type projectile points covered in red ocher associated with a cremation burial (Robertson et al. 1999: 121). A second Lake Archaic site has been identified in Alpena at Bagley Street along the Thunder Bay River (Wayne Lusardi, personal communication, 2010).

The Archaic - Early Woodland Transition (1500 -100 BCE)

The introduction of the Early Woodland Period in the Great Lakes region marks the development of a bifurcation of cultures into distinct northern and southern traditions (Cleland 1992: 19). In the Upper Great Lakes, the Early Woodland period can be considered as more or less a continuation of the patterns and trends of the Red Ocher Culture (Mason 1981: 235).

Four major material innovations in this period include plant domestication and agriculture, thick-walled earthenware pottery, burial mounds with cremated internments, and new lithic and other artifact styles (Mason 1981: 202, Garland and Beld 1999: 126). Many of the Upper Great Lakes sites, however, lack pottery, and many of the cultigens at these sites were likely imported from southern Great Lakes groups (Garland and Beld 1999: 130). It is important to note that approximately 3000 
years pass between the introduction of cultigens to the Great Lakes region and the emergence of horticultural-based subsistence economies (Mason 1981: 205).

Throughout the Early Woodland period, Michigan communities continued patterns of seasonal mobility and most sites remain small and unstratified. Some sites in the lower half of the state contain earthworks. They may have functioned as tradecenters, ritual or ceremonial centers, communal meeting locales, or centralized burial sites. Archaeological evidence indicates that domestic activities also occurred at these prepared sites. Such a site might have supported between 150 and 175 persons (Garland and Beld 1999: 133-134; 140).

\section{Middle Woodland Period (100 BCE-500 CE)}

The Middle Woodland period in Michigan can also be divided into southern and northern tiers. The southern tier appears in the Saginaw River Valley and represents a manifestation of Hopewellian culture imported from the south. Evident in the associated mortuary complex is marked social stratification and monumental architecture (Kingsley 1999: 151, 169-171).

In the Upper Great Lakes, including the region around Thunder Bay, the Middle Woodland period is marked by the emergence of the Lake Forest complex. It is in this cultural context that the first local ceramic industry appears, though it is not stylistically uniform throughout the region indicating that it was not imported from elsewhere (Brose and Hambacher 1999: 173-176). It appears that there was little interaction, with regard to lithic toolkits and ceramic technology, between southern 
and northern cultures (Mason 1981: 260). Overall, population density was low and there is little evidence of the emergence of the social hierarchical development found to the south (Brose and Hambacher 1999: 191).

Lake Forest complex sites indicate aggregated population centers for the seasonal exploitation of resources. Many of these occur along waterways and lakes. These sites represent the first stages in lakeside adaptation centered on fishing. Several of these sites show repeated occupations. This developing fishery led to the Inland Shore Fishing Complex of the northern Late Woodland period (Cleland 1992: 23). Togglehead harpoons are characteristic artifacts at these sites (Mason 1981: 262-263).

\section{$\underline{\text { Late Woodland Period (500-1600 CE) }}$}

The Late Woodland period appears in the Great Lakes region at about $500 \mathrm{CE}$ and in the north-central Great Lakes at about $800 \mathrm{CE}$. Late Woodland sites are represented by moderate to large lakeside villages occupied during the summer months with small band regional dispersal to established hunting grounds the rest of the year. Site size indicates a possible overall increase in local population levels (Cleland 1992: 23-24). Overall, Late Woodland populations became increasingly dependent upon horticulture, though this pattern is not observed in the northern Great Lakes, however, trade for southern cultigens increased. Several localized cultures developed. Additionally, Hopewellian ceramic traits and elaborate burials disappear in the Great Lakes region (Mason 1981: 296-297). 
The Late Woodland period can be characterized as one of great economic systems change. Summer fishing at coastal sites intensified. Seasonal regionally dispersed local game and vegetal resources continued to be exploited by small mobile bands the rest of the year, but over the period there is an intensification in the trade for maize from the southern Great Lakes (Holman and Brashler 1999: 213-215). Established trade routes developed along major river networks and along lakeshores (Howey 2007: 1837).

The establishment of seasonal aggregation sites for the large-scale procurement of fish in the north and the growing of maize in the south promoted a greater formalization of residence patterns, territoriality, and individual roles to support economic efficiency (Krakker 1999: 229). Patterns of kinship alliance between communities become more apparent in local material culture styles and forms indicating an increase in matrilocality (Mason 1981: 350-351). These kin-based cultural groups in Michigan were the predecessors of Algonquian speaking groups such as the Anishnabeg (Ojibwa or Chippewa), Ottawa, Potawatomi, and Miami (Cleland 1992: 25).

During the Late Woodland, there is lithic and timber fortification evidence that violence greatly increased in both magnitude and frequency (Mason 1981: 325). After $1000 \mathrm{CE}$, boundaries between different cultural groups became more strictly delineated. This is evidenced through the use of earthworks and other stockade fortifications (Holman and Brashler 1999: 220). Sites with the greatest amount of fortification date to the centuries just before European contact (Zurel 1999: 244). 


\section{$\underline{\text { Prehistoric Fishery Development }}$}

The Upper Great Lakes prehistoric fishery is unique, as it survived mostly intact well into the historic era. Cleland (1982: 761) states that this fishery is the most important organizing concept for the understanding of regional cultural development, and is therefore worthy of closer inspection in this prehistoric landscape review. Seasonal availability of fish was regular and predictable. Material culture and faunal evidence indicates that Archaic peoples adapted spear-based fishing to their already established seasonal hunting cycles. It is in the Late Woodland that Upper Great Lakes communities developed a shore-oriented seasonal settlement system (Cleland 1982: 768, 772, 774).

The prehistoric fishery made extensive use of both the spring and fall spawning seasons. The spring spawning species of primary economic importance were the lake sturgeon, white sucker, northern redhorse sucker, northern channel catfish, black bullhead, brown bullhead, yellow perch, walleye perch, northern pike, and various members of the bass family. Important fall spawners include lake trout, whitefish, lake herring, chubs, and round whitefish. The spring spawning season lasted for at least two months, while the fall spawning season lasted a matter of weeks, usually in November, the most dangerous month of the year with regard to storms. Risk was compounded by the fact that fall fishing took place offshore. Fall spawning species were, however, of nutritionally higher quality than spring spawners (Cleland 1982: 766-768). 
Prehistoric peoples used a variety of technology types to fish. Spear fishing and angling were the first methods used and they persisted into the Historic period. Net fishing seems to appear in the Middle Woodland period. Weighted seines were used near shore, while weighted gill nets were used in deeper waters. Nets were made of basswood, nettle, and hemp fibers prepared by women, and sewn by men. Dip nets were used for concentrated fish runs such as at the rapids at the Sault. Barbed harpoons also became popular. Late Woodland fishing technology made the fishery efficient. Gill nets and harpoons were also used during the winter for ice fishing. The production of this technology and the processing of the increasingly large catches required much manpower creating opportunities for shifts in settlement patterns, the result of which persisted into the historic era (Cleland 1982: 762-779).

\section{Protohistoric Era (1500-1650 CE)}

The Protohistoric period refers to the absence of direct contact with Europeans in North America but the presence of European material culture introduced through indigenous trade networks. During the Protohistoric period, in general, the amounts of European trade goods in the Great Lakes region were small compared to amounts traded elsewhere through direct contact with European fishermen, explorers, etc. The first European goods in the Great Lakes region appear in a Huron site in present-day Toronto that dates to approximately 1500-1550 CE (Mason 1981: 375). In the Upper Great Lakes, it is extremely difficult to identify the ethnic or "tribal" affiliation of 
protohistoric sites because of the rapid replacement of culturally diagnostic ceramics with European metal (typically brass) pots (Mason 1981: 389; Cleland 1992: 29).

The majority of Michigan's Algonquian-speaking peoples are descendants of the pre- and protohistoric Anishnabeg. Anishnabeg communities in northern Michigan were hunter-gatherers who maintained ties with their horticultural relations to the south. They were patrilineal and patrilocal, followed the Iroquois kinship system, and practiced general polygyny and cross-cousin marriage. Family groups comprised several generations. Village size was likely 75 to 150 individuals, representing band organization, and was led by "Big Men". The northern Anishnabeg probably totaled between 10,000 and 15,000 individuals (Cleland 1992: 40-47, 51, 58-59).

Historic Era

Michigan and Great Lakes Colonial History

The five indigenous groups that spent time in Michigan in the early Historic period include: the Chippewa or Ojibwa (a generic term for a socio-linguistic group), the Ottawa who occupied the transition zone between the Carolinian and Canadian biozones, Algonquians (a generic term for a socio-linguistic group including the Mascoutin, Fox, Sauk, Potawatomi, and Kickapoo), the Miami, and the Huron. The latter were displaced from Upper Canada primarily by the Iroquois (Fitting 1970: 192201). 
The French made the first and most lasting impact on Indian communities in the Great Lakes region (Cleland 1992: 75). It is likely that the first European to see Michigan was Jean Nicolet who paddled through the Straits of Mackinac in 1634 (Heldman 1999: 294). The earliest archaeological sites in Michigan with evidence of French presence are primarily located within the vicinity of the Straits. In fact approximately half of the seventeenth-century historic sites in Michigan are in Mackinac County (Cleland 1999: 280).

Early trade between the French and Indian communities took place in the context of indigenous reciprocity, the act of trade indicating friendship (Cleland 1992: 108, 111). Indigenous cultures initially would have adopted tools and other trade goods that made life easier but would reject items in a context that challenged their worldview. For example, in the Upper Great Lakes, indigenous clay pottery was rapidly replaced with European copper pots (Cleland 1992: 77-78). According to Cleland (1999: 289), changes in material culture do not have to indicate cultural change in general, choices in material culture use are manifestations of choices made for cultural persistence. Choices in culture contact negotiation was conducted on the "middle ground", constantly created and recreated social space that allows for the creative interpretation of cultural constructs that allows for social exchange including trade goods, ideas and information, and social relationships (White 1991).

Warfare in the seventeenth century was essentially an elaboration of the prehistoric system (Cleland 1992: 121). In the middle decades of the seventeenth century, warfare with the Iroquois escalated, pushing Huron and Algonquian groups westward through the Straits of Mackinac (Heldman 1999: 294). Iroquoian raids were 
so destructive that Michigan's lower peninsula was practically abandoned (Fitting 1970: 236). By 1690, the French had established military trading posts at Green Bay, north of the Straits, the St. Joseph River, and several other locations that controlled interconnecting waterways north and west of Michigan (Cleland 1992: 93, 111). In 1701, the Great Peace of Montreal ended warfare between the Iroquois, the Algonquins and other Upper Great Lakes communities, and their European allies, allowing for the reestablishment of settlement in the lower peninsula of Michigan.

The eighteenth century in Michigan and the Upper Great Lakes can be characterized by intensification of indigenous identity negotiation, socio-cultural structural reformation, and constant reevaluation of both intra-Indian and European political and economic alliances. Colonial presence in the region, official, casual, and clandestine, increased in intensity and duration.

Alliance in warfare also expanded. During the eighteenth century, the geographical focus of colonial activity and conflict in the Great Lakes region moved southwest into central Ohio and eastern Indiana (Cleland 1992: 122). After the Treaty of Paris, which ended the French and Indian War and evicted the French politically from North America, alliances between Indian communities and between Indians and the British were quickly renegotiated. Indian communities in the Great Lakes region became increasingly upset because of the encroachment of Euro-American settlers into the southern Great Lakes and the restrictions placed on established IndianEuropean trading systems (Cleland 1992: 131). The British refused to conduct trade and intercultural negotiation on the "middle ground" established through contact and relationships with the French (White 1991). 
Disparate bands of Chippewa occupied the northern half of the lower peninsula of Michigan, including the Thunder Bay region, during the last quarter of the eighteenth century (Cleland 1992: 147). Further south, several Indian communities were locked in consistent conflict with illegal Euro-American settlers invading the southern Great Lakes region in ever increasing numbers (Cleland 1992: 131).

The Revolutionary War marked the first real interest of eastern colonial and subsequently congressional government in the Great Lakes region. The fledgling United States claimed the region north of the Ohio River in the Jay Treaty of 1794. Following peace between Britain and the United States, the 1795 Treaty of Greenville marked the first political agreements for peaceful relations between Congress and Great Lakes Indian communities. Though the Revolutionary War likely received little notice in the region, the rapid influx of American settlers west of the Appalachians pushed Indian communities to ally with the British during the War of 1812 (Cleland 1992: 144, 168).

After the wars with Britain, the United States pushed to purchase land in the Great Lakes region to facilitate territorial settlement and control (Michigan was organized as a territory in 1805). Treaties were made with Indian "communities" that were grouped and organized by the United States. These treaty parties often did not represent the realities of local political power regimes or cultural associations (Cleland 1992: 205). In some cases, Indian political identities were created for the purpose of signing specific treaties. Treaties that ceded the Thunder Bay region were the 1819 Treaty of Saginaw and the 1836 Treaty of Washington, both ratified with groups of 
Chippewa. Little was known of Michigan's lower peninsula north of Thunder Bay prior to the latter treaty (Landon 1944: 110).

Additionally, in the first decades of the nineteenth century the fur trade reached its peak in terms of value and total export. By the mid-1820s however, most of the prime fur-bearing species, including beaver, otter, and marten, were functionally exterminated. The growing popularity of silk instead of fur felt for hat construction also damaged the fur trade industry. The Great Lakes region exchange market shifted from one of male-dominated production of a few commodities to that of a femalecentered multi-product exchange centered on agriculture and local manufactured items (Cleland 1992: 179-180, 192).

Historical information for the early American territorial years is scarce and primarily limited to the southeastern portion of the lower peninsula and to the region of the Straits of Mackinac (Branster 1999: 320). Beginning in the late 1810s, American settlement into southern Michigan was encourage by the federal, territorial, and, after 1837, state governments after the ratification of the treaties that ceded Michigan land from Indian communities. By 1840s, most of the lower peninsula had been divided into townships, the precursor to legal settlement. However, land purchase and settlement was primarily restricted to lands south and west of Saginaw Bay. Settler perception of the poor quality of pine forest for agricultural improvement restricted immigrant influx into the northern half of the lower peninsula for the most part until the latter half of the nineteenth century after it was cleared by the lumber industry (Lewis 2002). Additionally, Landon (1944: 104) notes that, prior to demise of fur-bearing species, fur trading companies actively discouraged settlement, 
promoting the idea of roving bands of dangerous Indians, to protect wilderness areas from agricultural incursion.

\section{Lumber Industry}

The first large scale American landscape modification to the northern half of Michigan's lower peninsula was from logging white pine, beginning in earnest in the 1850s. Timber transportation from inland was at first dependent upon rivers, then railroads. Due to the marshy nature of many timber stands, logging was primarily a winter activity. By 1900, most of the white pine supplies were exhausted and efforts turned to hardwoods such as maple and beech. Logging companies also supplied younger species such as spruce and birch to the developing paper industry (Franzen 1999: 341).

The earliest archaeological evidence for lumber camps dates to the 1870s. They tend to be loose clusters of log buildings including a bunkhouse, cookhouse, stable, and often a storehouse. Many camps employed recent immigrants such as Scandinavians and Balkans. Archaeological evidence indicates that food procurement and production was the focal point of camp life. The small-camp centered logging industry in Michigan came to an end by World War II (Franzen 1999: 341, 345).

As timber interests moved northward into the pine region of Michigan, businesses developed to where logs could be floated or transported by rail for export by either log raft or schooner (Landon 1944: 106). Alpena, at the mouth of the Thunder Bay River, was one such location. 


\section{Alpena, Michigan}

Alpena was formed in 1840 and formally organized as a town in 1857 . Though the coastline of Thunder Bay, the Thunder Bay River, and the many islands just off shore had been often visited and in some cases purchased (after 1840) by fur trappers, traders, and fishermen, the first businessmen to successfully invest in the locale were George Fletcher and James Lockwood who, after securing timber rights in the vicinity, purchased several acres in what is now Alpena. The first permanent building, a home on River Street, was erected in the summer of 1857, shortly after the town was

incorporated. By the following year there were at least ten families living in Alpena. Two decades later, the population boomed to over 5000. Alpena developed as a destination of lumber from the interior with several prosperous sawmills. It also served as a transportation hub for lumber products moving out on Lake Huron (Boulton 1876). In the twentieth century, Alpena's focus shifted from the export of lumber to that of limestone (Landon 1944: 114), which remains an important local industry today.

\section{$\underline{\text { Historic Fishing }}$}

Though recognized as a stable and important local source for protein early in the Historic period, commercial fishing remained a small-scale enterprise until the early nineteenth century. At first fish resources were traded locally, with primarily part- 
time fishermen selling directly to consumers. Fish were considered an acceptable food source for many recent European immigrants. In larger population centers, such as Detroit and Toronto, some fishermen earned their livelihoods providing fish for wider distribution (Beattie Bogue 2000: 28, 32, 34).

Control of the early fisheries was variable. In 1787, the United States Congress enacted the Northwest Ordnance, which was interpreted to mean that the power of fisheries control was reserved for states under the Tenth Amendment of the Constitution; a system that remains today, the Great Lakes fisheries are controlled by nine state and provincial governments and two countries.

The 1830s saw the first major growth of the Great Lakes commercial fisheries. Beattie Bougue (2000: 29) proposes that this was due to the ability of growing commercial centers, such as Detroit, to provide a large-scale market. Fishermen recently established on Thunder Bay and Middle Islands supplied this market (Beattie Bogue 2000: 30).

Quick profit ventures characterized this early market growth. Fishing was viewed as a way for new settlers to raise capital to acquire farms and to quickly access "free" wealth (Beattie Bogue 2000: 31). It was also at this time that many of the structural aspects of the commercial fishing landscape formed. Market centers emerged for redistribution and a hierarchy of small-scale fishermen who worked to supply large fishing companies and merchant-dealers developed. It is also at this time that the United States and Canada had their first real troubles with international poaching (Beattie Bogue 2000: 32-33). 
The 1840s were characterized by continued expansion with intensification of harvests, growing markets, and better land and maritime transportation (Beattie Bogue 2000: 34). Following a short depression that lowered prices in the early 1850 s, the Civil War increased rapidly the need for fish as an important food resource making the industry quite profitable (Applegate and Van Meter 1970: 3). The 1850s also saw the widespread introduction of pound-net technology. First established in the western Lake Erie Basin in 1850 (Whitaker 1892: 173), they quickly spread to other shoal areas of bays and rivers in the Great Lakes, including at Thunder Bay (True and Kumlein 1887: 657).

The pound net was developed in Scotland and used in North America by the 1830s; it consisted of a leader net, a tunnel, and a pot (Figure 4.5). The leader was oriented 90 degrees to shore and guided fish to a heart-shaped enclosure from where they were directed through the tunnel and into the pot of the net. Leaders ran from 500 to almost 1500 feet in length and the pot was usually 20 to 40 square feet in area. A special flat-bottomed sailboat could enter the net for fishermen to scoop out the fish. At first, pound nets were typically used in 30 to 50 feet of water, but by the 1870 s were sometimes used in up to 100 feet of water (Beattie Bogue 2000: 38-39). Beattie Bogue (2000: 39) states that pound nets could not be used on hard, rocky lake bottom; however, True and Kumlein (1887: 127) indicate that this was the preferred bottom type for pound-net stations at Sulphur Island in Thunder Bay.

Pound nets were often set out in gangs up to three miles long (Whitaker 1892: 175). These rigs were expensive and often owned by an individual or company who hired workers to tend the nets. Nets would be set and removed twice each season in 
the spring and early fall. At the height of the season, pots would be emptied daily (Beattie Bogue 2000: 94).

Pound nets wasted tons of juvenile and undesirable fish. According to Whitaker (1892: 173) it was primarily responsible for the decimation of many species, especially in the 1870 s and 1880 s. Pound nets caught nearly all fish alive, however, most gear did not have a mechanism for releasing undesirable species. Delicate juvenile fish were crushed when the pots were lifted and undesirable species were left to rot (Beattie Bogue 2000: 101).

It appears that Thunder Bay and its nearby islands were known by the 1830 s as good fishing grounds. Commercial fishing centered at Alpena began in earnest in the 1850s. The most common fishing technology types were pound nets, trap nets, and gill nets. Pound net stations were located on the north shore of Thunder Bay between North Point and Whitefish Point, the latter so named because of its local abundance of its namesake. By 1879 , there were 15 net stations located in this region. Sulphur Island was also known for its favorable location of pound nets with 4 nets in 1879 . (Boulton 1876: 30-33; True and Kumlein 1887: 127). Pound net fishing was very profitable in Thunder Bay. In 1854, a Mr. Anthony established his first nets in about 33 feet of water. In 24 hours in one net, he caught 400 half barrels of whitefish and 100 pounds of other fishes (Whitaker 1892: 174). Pound net stakes are highly conspicuous in the archaeological record of Thunder Bay (Figure 4.6).

Though the Thunder Bay pound-net fishery produced thousands of barrels of fish per year, the gill-net fishery was even more prolific and important. According to Boulton (1876: 37-39), gill nets were not used in Thunder Bay proper, but lay off the 
coast between five and ten miles. The shoal reef between Middle and Thunder Bay Islands was known as a productive spawning ground, and Sugar Island was considered to have one of the best gill-net fisheries in Michigan. The preferred launches for gill net boats was from North Point, and Sugar and Gull Islands. In the 1870s, there were on average ten to 12 gill-net rigs working out of Alpena. Average yearly catch was between 4000 and 5000 barrels worth approximately $\$ 30,000$ (Boulton 1876: 30-33, 37-39).

Because of the success of its fisheries and due to its location on the maritime transportation network, Alpena developed a fish-packing and shipping industry. In 1879 , fresh-fish production, mostly whitefish and trout, was about 2.35 million pounds and salt-fish production, typically herring, about 100,000 pounds. Of this, Detroit fishermen and/or firms caught the most. Local producers could claim about eight percent of the fresh fish, but most of the salt fish. Fresh fish was sent to primarily either Detroit or Sandusky and salt fish was transported inland. Fish were also sent to Alpena for shipment. One Canadian dealer claimed that in 1879 he shipped over one million pounds of Canadian fish to Detroit through Alpena (True and Kumlein 1887: 657-658).

By the 1880s, abundance of commercial species had declined significantly. In addition to overfishing, habitat disruption was due primarily to the removal of boulders and rapids along log-drive routes, along-shore construction, flow-control structures, and the alteration of embayments and estuaries to accommodate ports and towns (Kelso et al. 1996: 15). All were likely present in Alpena. Pollution was also a major problem. Late nineteenth-century fisheries scientists Frederick True and 
Ludwig Kumlein (1887: 658) deduced that lumber-mill refuse decimated fish populations in Alpena.

As Alpena was considered an important port for fishing and fish processing, it was a focus of fishery rehabilitation in the late nineteenth century. By 1882, Alpena maintained two federal fish hatcheries. Restocking programs proved to be unsuccessful (Beattie Bogue 2000: 196, 199). Though some commercial fishing still occurs out of Alpena, ultimately, the Great Lakes fisheries collapsed with the devastating introduction of the exotic sea lamprey, which became firmly established by the 1940 s.

The Historic Maritime Landscape

\section{$\underline{\text { Maritime History }}$}

Mills (1910: 138) divides Great Lakes maritime traffic into several major periods: the Indian trade and the birch-bark canoe, the expanded fur trade with the bateaux and Mackinac boat, the schooner (dominant) and steamboat era in the first half of the nineteenth century ending with the rise of the railroads, and the schooner and steamboat (dominant) era of the latter half of the nineteenth century. The end of World War II could mark a fifth era, that of modern shipping.

The colonial period fur trade, exploration, and missionary activities utilized the indigenous technology of birch-bark canoes and bull boats for maritime transportation on the lakes and their connecting rivers until the mid-eighteenth century. Mills (1910: 
64) characterizes the locally developed bateaux, long and lean plank boats that appeared in the mid-eighteenth century, to be the first true "vessels" on the Great Lakes. Compared to the Ohio and Mississippi River valleys, Great Lakes transportation technology developed slowly due to the proximity of warring Indian communities discussed previously, as well as tensions between the French and English and likewise the English and Americans along their common North American border (Mills 1910: 65-66).

Besides the relatively small-scale transportation of fur trade and missionary personnel, there was little commercial transportation on the Great Lakes. The British Provincial Marine acted primarily as a transport and patrol service. A privately owned merchant marine was banned on the Great Lakes until 1785. Prior to 1785, port warehouses in Kingston and Niagara would fill up, and goods destined for Detroit would miss the navigation season. The new law allowed for private vessels manned by British naval personnel. In response, the Northwest Company built the 75-ton Otter in 1785 and the sloop Industry at Detroit the following year. At the beginning of 1788, British merchants were able to hire private crews. These small vessels were not meant to be especially durable. For example, the Onondaga, built in 1790, lasted eight years, which was considered good for a green wood vessel (Barry 1973: 23-24).

Though Lake Erie and Lake Ontario traffic grew rapidly prior to the War of 1812, commerce was nearly all fur trade related in the upper Great Lakes. Maritime transportation for the fur trade in the upper Great Lakes was also small with only five small vessels operating in all of Lake Superior (Mills 1910: 103, 133). The first 
American-flagged vessel in the upper Great Lakes, the sloop Detroit, was built in 1793 (Barry 1973: 25).

It is worth mentioning, briefly, some maritime aspects of the War of 1812, because it was the only North American war fought directly on the Great Lakes, and technological lessons learned helped to pave the way for local Great Lakes shipbuilding and rigging technology development (Landon 1944: 347). On June 18, 1812, the United States declared war on England. Ostensibly fought over issues of British Naval impressments of American citizens, other primary issues were economic tension created because the United States traded with both mutual rivals England and France, and the competition over American and European western expansion in North America. The war involved the United States Navy and Army, the British Royal Navy, British and Canadian military units, as well as the Northwest Company (Gough 2002: xi). The role of the latter was to man warships and impressed vessels and to transport artillery and sundries to upper Great Lakes forts, for example, at Fort Mackinac, when not directly engaged in fur trading activities (Landon 1944: 79-80). The fur trading company feared that the United States would remove them from the Great Lakes region as it expanded into its northwest territory. In addition to military regulars and fur trade employees, involved personnel included Indian patriot chiefs and their communities, Indian agents, shipbuilders, and national and local political strategists (Gough 2002: xiii).

The history of the War of 1812 on the upper Great Lakes was directly tied to the state and progress of the war on Lake Erie where the majority of the large military engagements took place (Gough 2002: xi). The English had the only one definitive 
warship, the impressed fur-trade merchant schooner Nancy, on Lake Huron. It was tasked with running supplies between posts on Lake Erie and the forts on the Upper Great Lakes. According to the ship's log, the Nancy followed the western shore of Lake Huron with Thunder Bay a noted waypoint on the voyage. During the navigable season, American vessels patrolled Lake Huron and several small-scale campaigns and engagements took place (Gough 2002: 59, 63, 88).

Like the Nancy, many merchant ships were bought, impressed, or captured into military service during the War of 1812 (Mills 1910: 72). These vessels included brigs, schooners, sloops, bateaux, and canoes, or in other words, anything that was available. Contemporary schooners were two-masted, less maneuverable than the later preferred three-masted schooners, and ocean-going brigs were large-rigged and top heavy. Many were lost during the war (Gough 2002: xii, xvi). Much was learned during the war about appropriate ship design for working on the Great Lakes.

The Treaty of Ghent ended the war in December 1814, though fighting persisted on the upper Great Lakes for several months. Immediately after the war there was not enough merchant commerce to warrant large expenditures in new boat building (Mills 1910: 89), however, shortly after peace was established $80 \%$ of American public lands were being surveyed and opened to immigration and settlement (Landon 1944: 157, Lewis 2002). The end of the war also reinvigorated the upper Great Lakes fur trade; Fort Mackinac posted its busiest period in the second decade of the nineteenth century (Landon 1944: 216). With the increase in immigration and the reestablishment of commerce between 1815 and 1825 there were almost too few vessels necessary for the Great Lakes traffic. Vessels shipped to the east carrying lumber products, fish, 
agricultural produce, and whiskey and returned west loaded with immigrants and their luggage (Mills 1910: 106).

During the War of 1812, hundreds of shipwrights moved to the Great Lakes (Thiesen 2006: 50). Immediately after the war, however, there was not enough commerce on the lakes to support local shipyard expansion in the development of new steam technology (Mills 1910: 89). Many of the early westbound vessels only sailed once, being broken up for material reuse at their destination (Hoagland 1917: 9). By the 1820 s, however, commerce almost exceeded available tonnage, approximately 42 vessels. These economic realities fostered the development of the Great Lakes sailing industry.

Most American shipbuilders of the nineteenth century were small-scale workingclass craft workers who inherited the "high" and "folk" craft techniques of England, combining the uses of basic math with models derived from natural forms (for example, a duck) (Thiesen 2006: 2). American shipwrights were responsible for all aspects of shipbuilding, making the profession highly specialized and requiring several years of apprenticeship training. This also fostered a conservative endogamous shipbuilding community characterized by intermarriage, a shared work ethic, and close ties between the shipwright and his laborers (Thiesen 2006: 46).

Thiesen (2006: 44-46, 52) defines the nineteenth-century American style of vessel design and construction as "practical" in nature. A shipyard's focus was to produce marketable ships using efficient and proven technology. One failed vessel could ruin a shipyard. The ramification of this process is that shipwrights spent their time perfecting already proven vessel types and technology using tools and methods that 
had been available for several centuries. This paradigm of shipbuilding persisted in the United States because of the plentiful and, therefore, cheap supply of forest products. Though this method of construction rendered most sailing vessels similar in form, the craft nature of production made each vessel unique.

One of the most unusual aspects of Great Lakes sailing vessel design was the organization of rigging. The War of 1812 taught shipwrights that fore-and-aft rigging was better on lake vessels than square rigging. Therefore, most lake vessels were schooners, brigantines, or barkentines. On the Great Lakes, the latter nomenclature was often shortened to brig or bark, and more commonly, sailing vessels were referred to simply as schooners regardless of the rigging (Barry 1973: 67).

As with sailing vessels, American shipwrights followed the practical method of building steam-powered vessels, referred to as steamboats, through trial-and-error. Though iron vessels were gaining popularity in Europe, American skepticism of iron's buoyancy and the cheap cost of wood promoted the development of wooden steamboats (Thiesen 2006: 54, 88). At first steamboats were only used on Lakes Erie and Ontario; however, by the 1830s they were voyaging to the extents of the lakes to Milwaukee and Chicago (Havighurst 1975: 121). The infrequent arrival of vessels at those terminal ports often created a carnival-like atmosphere as they arrived (Gjerset 1928: 17).

The first steamboat on the open water of the Great Lakes was the Ontario built in 1817. The first commercial steamboat on the Great Lakes was the Walk-in-the-Water, built in 1818. It was 135 feet in length, 32 feet wide, with eight-foot depth of hold. The paddlewheels were located amidships with the machinery below deck. The vessel 
could travel at up to 10 knots; however, it had to be towed against the strong current of the Niagara River.

Steamboats were very expensive compared to comparably sized sailing vessels, costing up to $\$ 60,000$ (Mills 1910: 86 ). Though vessels were crafted in the method of sailing vessels, using proven forms and methodology, the expense of the propulsion machinery fostered large-scale experimentation in steam technology and the frantic search for "superior" steamboats (Mills 1910: 107). Not all early steamboat technology was successful. For example, the side-wheeler Michigan, built in 1833, had individual engines for each wheel. The wheels did not function correctly in swell, often leaving one out of the water, giving the vessel a waddling appearance (Mills 1910: 111-112).

Because of the high cost of steam machinery, unsuccessful steamboats were often converted into sailing vessels and their machinery placed in new, better designed, or larger vessels. Likewise, engines, boilers, and machinery were, if possible, recovered from wrecked or derelict vessels to be placed in new ones (Mills 1910: 100,102).

Unsurprisingly, the lucrative nature of designing and selling successful steam equipment fostered considerable competition between engineers to develop the best engine. Several new types appeared in the early nineteenth century, including the walking-beam engine, the square engine, and the horizontal engine. This spirit of competition continued to the operation of steamboats, which often led to races and tests of speed. The first steamboat to port often acquired preferred available business. Winning speed races was also an accepted mark of prestige for steamboat owners (Mills 1910: 120-123). 
By the 1840s, settlements had been established on the shores of every Great Lake save Lake Superior, where economic focus remained the wilderness fur trade. Paddlewheel steamboats thrived in this immigrant transport (Barry 1973: 53). Steamboats loaded with immigrants traveled newly established transport routes, the longest from Buffalo to Chicago. The largest steamboats carried up to 1500 people, most undocumented deck passengers (Mills 1910: 145). In 1840, there were eight steamboats dedicated to the immigrant passenger traffic (Havighurst 1975: 128).

New agricultural settlement, primarily along Lake Michigan, sent increasing amounts of grain eastward. A grain elevator was built in Chicago in 1839, in Buffalo in 1843, and shortly thereafter in Oswego and Kingston, Ontario. By 1840 the total traffic in bulk grain was only a few thousand bushels, but by 1846 , Buffalo alone received over 500,000 bushels from points west (Hoagland 1917: 9). The grain trade at most ports was still a local, small-scale operation. Most towns had no harbors. Vessels had to anchor offshore and lighter in the cargo (for example, at Presque Isle, Michigan) (Gjerset 1928: 11; Landon 1944: 111). By 1841, the largest steamers on the upper Great Lakes were employed in bulk grain shipment (Mills 1910: 119).

In the first half of the nineteenth century there were no fixed rates for grain transport. On the same day in the same port, two vessels could secure very different rates for the same cargo (Gjerset 1928: 14). This lack of regulation and an overproduction of cargo vessels led to a crash in freight rates in 1842. All attempts to regulate the system were unsuccessful (Mills 1910: 121). This may be one reason for the boom in production and size of comparatively cheaper sailing vessels over 
steamboats for the grain, coal, and lumber trade, a role they dominated through much of the nineteenth century (Mills 1910: 124).

The early 1840s also saw the development and use of the screw propeller on the Great Lakes. The first vessel so equipped, the Vandalia built in 1841, operated on Lake Ontario. Like most steamboats at this time, the Vandalia was sloop-rigged. The first screw propellers all had double screws powered by individual shafts (Mills 1910: 129). Screws were less expensive to operate than paddlewheels, which cost approximately $\$ 150$ per day and used 100 to 300 cords of wood daily, and therefore quickly replaced paddlewheels in bulk cargo shipment. Paddlewheels, however, continued to be popular for passenger and package freight transport (Mills 1910: 120, 130-131).

By 1845, shipping needs and prospects improved (Mills 1910: 123). Copper was discovered in the Lake Superior basin in 1843, resulting in a boom in immigration to the upper Great Lakes. New technological innovation included the introduction of the compound engine, first appearing in the steamboat Oregon. Also, the busy shipyards began producing iron steamboats up to 1000 tons, the largest wooden steamboats being only about 350 tons maximum (Mills 1910: 139-140).

The 1850s and 1860s saw the continuation of practical shipbuilding; however, at the same time, shipyards quickly and continuously adopted new modern industrial methods for building sailing vessels and steamboats. The primary motivation for shipyard industrialization was to reduce costs (Thiesen 2006: 60-61). In addition to shipyard mechanization, manufacturing costs were reduced through labor division and subcontracting. They also expanded the use of piecework production, allowing 
shipwrights to work in multiple yards. These new labor practices meant the disappearance of the master craftsman and a focus on manufacture specialization. (Thiesen 2006: 61-63). Specialization fostered deskilling and a decline in shipwright apprenticeships, decreasing the possibility for upward mobility within a shipyard (Thiesen 2006: 65).

Many mid-century master shipbuilders of iron vessels were educated primarily in wooden-ship design and construction. This allowed for the survival of many superfluous wooden-ship technologies in iron ships such as the shifting butt pattern and the protruding keel (Thiesen 2006: 86-87). Thiesen (2006: 91-93) surmises that a complete transfer of craftsmen and laborers from wooden to iron shipyards never took place in the nineteenth century, as wooden shipbuilders and specialists would have faced a reduction in craft prestige and possible unemployment.

The 1850s saw a continuous increase in size of Great Lakes vessels. New technological features also appeared including closure joiner work on the forward main deck to the stem, the mechanical appliance for the direct application to the hull of propellers, and more efficient propulsion systems (Mills 1910: 148-149). Another first, in 1852, the first steamboat to enter the Thunder Bay River, the Julius D. Morton, carried supplies to newly established fisheries.

The mid-nineteenth century also saw a marked increase in shipping and transportation competition. Large transportation companies headed by wealthy owners could undercut competition. Small-scale competitors ruined their businesses by overworking vessels and slashing freight rates (Mills 1910: 150). Major competition for both large- and small-scale Great Lakes shipping operations came 
from the rapid expansion of several railroads, beginning with the completion of the Cleveland-Toledo route in 1852. The first commodities affected were passengers and perishables because the railroads could travel much more quickly than vessels. Additionally, railroads were not subject to the Great Lakes navigation season and could operate an additional four months per year. As freight rates declined, small sailing vessels were restricted to local traffic, replaced by larger brigs and schooners. Steamboats relinquished the package freight traffic. Lastly, railroad companies began to construct their own ships including rail car barges and luxurious passenger liners (Mills 1910: 153-155).

The boom years of the 1850s made it seem as if there was enough business for both shipping lines and railroads to be profitable. Palace steamers ran regular routes, railroads expanded, the Crimean War provided large markets for American products, and California gold production and American infrastructure development circulated a lot of money. However, money was locked in these enterprises leaving little available cash. When the Ohio Life Insurance Company failed in 1857, outfall led other financial institutions to collapse leading to the Panic of 1857. Business on the Great Lakes came to a standstill. Few vessels operated in 1858 , and when the market improved the following year, the railroads took up an increasingly large majority of the freight. This marked the increasing importance of propeller-driven steamboats (Barry 1973: 80; Brehm 1998: 13).

The advent of the Civil War reinvigorated the Great Lakes shipping industry, but only in the short term. Owners, desperate to make their vessels profitable, developed a 
new shipping method indigenous to the Great Lakes, the steam barge and consorts (Figure 4.7).

Towing on the Great Lakes at this time was not a new phenomenon. Sailing vessels had always faced hazards in the narrow confines of harbors and rivers connecting the Great Lakes. Hazards included too strong or too light winds, winds from unmanageable directions, strong currents, obstructions, and congestion. From as early as the 1840 s, captains could hire local tugs to aid them through problem passages, the most notable location for towing being the Detroit and St. Clair Rivers. By the mid-1860s, there were nearly 250 registered tugboats on the lakes (Warner 1998: 45-46).

The steam barge with towed consorts was the most inexpensive mode of shipping to date. Many obsolete schooners were converted to consorts. They were typically manned and carried some sail power. At times up to six vessels were towed in tandem. According to Mills (1910: 188), the steam barge and consort system was the most dangerous form of transportation on the lakes. The consorts were sometimes poorly loaded and top heavy, overloaded, unwieldy, and would likely wreck if separated from the towline. That said, by 1869, there were over 100 unpowered barges operating on the Great Lakes (Thompson 1991: 31).

Though it was evident by the mid-nineteenth century that steam power was the future of maritime transportation, 1869 marked the year with the greatest number of sailing vessels on the Great Lakes with 1,855 registered. Though their number began to decline afterwards, aggregate tonnage actually increased (Figures 4.8 and 4.9). This time also marked the appearance of a new sailing vessel type, the Lake Schooner, an 
inexpensive sailing vessel that could pay for itself in just one or two seasons by focusing primarily on the grain and lumber trade (Figure 4.10). Lake Schooners were typically owned by their captains (Mills 1910: 184). The primary reason sailing vessels were able to remain profitable in the grain and lumber trade was that steamboats were becoming increasingly focused on the iron ore trade.

More than 5000 vessels were built on the Great Lakes between 1869 and 1900. The greatest number of vessels operating on the Great Lakes was approximately 5600 in 1874 , decreasing to approximately 3000 in 1900 , however, total tonnage was double that of the peak vessel period. In 1896, more tonnage was launched on the Great Lakes than anywhere else in the world (Figure 4.11). That year, there were 19,387 recorded passages at Detroit, many of which likely also passed Thunder Bay on their way to destination ports (Thompson 1991: 23-24).

By the 1870s, the Great Lakes schooner had achieved its penultimate form. It was shoal, flat-sided, and had a fitted centerboard. Usually three-masted, it was as efficient as a barkentine, but easier to sail and cheaper to build. As the barkentines disappeared on the lakes, the term "bark" was often used to describe Great Lakes schooners with square sails (Barry 1973: 119-120).

Another Great Lakes sailing vessel form that appeared at this time was the scow schooner. Used in the trade of lumber remainder lots, it was rigged as a lake schooner but was square-ended and slab-sided. Some had schooner bows grafted onto scow hulls. After the development of the motor truck in the 1910s, these vessels disappeared from the lakes (Barry 1973: 136). 
The last true Great Lakes schooner, the Cora A., was launched in 1889. Pressure from the growing tonnage of bulk propellers, their lack of maneuverability in tight quarters, and their dependence on the vagaries of wind power, made schooners less cost efficient than steamboats. Additionally, work for seamen aboard steamboats was easier than on sailing vessels, therefore, labor costs rose steadily for the latter (Barry 1973: 143).

In 1884 , steamboats accounted for approximately $75 \%$ of all newly constructed vessels, and in 1886, steamboats surpassed the number of sailing vessels on the Great Lakes (Thompson 1991: 36). Great Lakes seamen, however, maintained an affinity for wooden vessels, believing in their greater longevity and strength of wood versus iron hulls and its purported greater buoyancy (Mills 1910: 181). Steam propulsion, however, was one of the eventual undoings of wooden vessels because the vibrations from the increasingly larger and more powerful engines loosened hull fastenings and promoted dry rot (Thiesen 2006: 82). It is surprising, then, that insurance firms initially hesitated to underwrite iron hulled vessels. It was assumed that wooden sheathing would increase life expectancy of the vessel. Though this was superfluous, wooden sheathing did aid the vessel in cases of grounding. Built with closely spaced iron frames, oak planking, and iron sheathed in wood from the waterline to the main deck, the first composite freighter, the Fayette Brown, was launched in Detroit in 1887 (Barry 1973: 136).

In the late nineteenth century, the term "modern freighter" had no constructive meaning for Great Lakes shipyards (Thompson 1991: 38). The high level of creativity, especially in iron shipbuilding, is likely due to the fact that the private 
sector was the primary pioneer in new vessel design (Thiesen 2006: 81). Investors rarely specified more than cargo or passenger capacity and speed for their new vessels (Thiesen 2006: 115). Great Lakes shipyards converted from wood to iron shipbuilding used the same craft specialists in vessel design. Except for riveting, yard work was under the control of the master woodworkers (Thiesen 2006: 89, 103). Additionally, longitudinal design and the use of engineering drawings were not used for iron hull design until the 1880s (Thiesen 2006: 88, 119).

The year 1871 marked the first real boom in Great Lakes freight traffic (Hoagland 1917: 13). Most of the cargoes were destined for Lake Erie or Lake Ontario ports (Thompson 1991: 132). By 1872, the top three ports by size were Buffalo, processing 140,000 tons, Oswego with 102,000 tons, and Chicago with 101,000 tons, the latter with 740 vessels discharging this tonnage. Sailing vessel tonnage was also profitable in this year, for example, the schooner White Mary received net earnings of over $\$ 6000$ (Gjerset 1928: 15).

After the Great Chicago Fire in October 1871, there was great demand for vessels to carry supplies and building material. Freight rates almost doubled at this time. By 1873 , however, rates and therefore wages dropped to unprofitable amounts. This economic depression lasted through most of the 1870s. Recognized causes of the depression include excessive building of vessels, the Chicago Common Council's decree that buildings within city limits had to be constructed of non-combustible materials, the overall financial panic of 1873 , and the increased competition between sailing vessels, steamboat lines, and the increasingly affordable Grand Trunk Railway 
lines. Great Lakes shipping interest also recognized during the depression the inevitable obsolescence of sailing vessels (Gjerset 1928: 89-93).

The 1890s marked the nadir of the Canadian Great Lakes shipping industry. Because of the American dominance in the shipping of iron ore, the Canadian fleets focused on the shipping of grain. Between 1896 and 1914, grain shipments on the Great Lakes doubled every five years, with the average being more than three million tons (Salmon 1998: 110, 130).

The American dominance in iron ore shipment was fostered by the recognition in the 1890s that large mine owners, such as Andrew Carnegie and John D. Rockefeller, would financially benefit by owning their own shipping fleets rather than contracting with outside shipping companies (Barry 1973: 175). This new focus on vessel ownership, and therefore design, fostered new creativity in shipbuilding. The 1890s saw record fleet sizes, in total approximately 2700 to 3000 vessels, and also the greatest diversity in fleet composition. Only the commercial fleets of England and Germany were larger. Steel was increasingly used for hull plates, and propulsion systems also achieved greatest diversity in design (Thompson 1991: 209-210). Highly inventive vessel forms appeared such as the steel "whalebacks" designed especially for the Great Lakes iron ore trade (Figure 4.12) (Mills 1910: 219).

The 1880s saw the peak in development of the Great Lakes lumber and forest products trade, especially along the western coast of Lake Huron. Throughout the decade, intensification in the industry grew steadily northward along the coast. Major lumber towns included Bay City, Saginaw, Cheboygan, and Alpena. By 1890, Buffalo had 132 lumber dealers and finishers who handled the lumber products 
(Havighurst 1975: 87, 93,95). There were two primary modes for the shipment of lumber, sailing schooner and log rafts.

Lumber carrier vessels were called lumber hookers. Many schooners were built especially for the lumber trade and several existing schooners were modified for its transport. Cut down schooners carrying lumber products were often towed in tandem by large steambarges (Barry 1973: 147-148). There was a particular technique developed for loading lumber schooners, both in the vessel's hold and on deck (Mills 1910: 107). This makes identifying lumber schooners in the historical and archaeological record relatively simple.

The second method for transporting lumber was the use of the log raft (Figure 4.13). Either constructed into an actual raft that could be sailed, or collected as a loose conglomerate of logs, large amounts of timber could be moved with little man or steam power. Some of the largest rafts were eight to 25 acres in area and were towed by upwards of three tugboats (Barry 1973: 159).

Rafting timber was relatively cheap but very hazardous to navigation. In storms they could be broken from their tows and easily pulled off course. Often they were poorly lit at night. For example, in August of 1890, the steam propeller Jewitt ran into a raft and broke all of its propeller blades (Barry 1973: 159). Another example, a raft being towed from Alpena to Chicago broke up in a storm on Thunder Bay scattering four million feet of timber along the shore, creating a navigation hazard for several seasons (Havighurst 1975: 118). By 1890, the Michigan lumber boom ended. Additionally, in 1898, Canada required that all timber cut on government property be 
processed in Canada, effectively ending the American log rafting business (Barry 1973: 148, 162).

Schooners and other sailing vessels that did not participate in the lumber trade had few options to remain viable. Small schooners were sometimes outfitted to act as traveling stores operating at small towns. Many were little more than decked fishing boats and were usually owned and operated by a single family (Barry 1973: 120). As the target viability of wooden ships was typically 15 to, at most, 25 years (Barry 1973: 149), many schooners were not repaired when damaged, abandoned after being driven ashore in storms, or left to rot in harbors (Gjerset 1928: 98). Mills (1910: 186) estimates that by 1910 , there were fewer than 200 sailing vessels from the late nineteenth century still operating in any capacity on the Great Lakes.

Passenger traffic did increase in the late nineteenth century. Side-wheel steamboats were still produced for this industry (Mills 1910: 181). Illustrated brochures and pamphlets appeared catering to passenger service and there was a perception by travelers that the more sophisticated the promotional flyer, the more superior the shipping line (Barnett 1992: 1). Luxury liners catered to the increased interest in the passenger vessels themselves. For example, the excursion steamboat Theodore Roosevelt had exposed engines allowing them to be viewed and admired (Mills 1910: 243). Interest by passengers did not necessarily mean that there was an increase in focus on vessel safety. In 1870, the passenger/packet steamboat Japan sailed its first season without a trial voyage or having its compass adjusted (Barry 1973: 11). Another example, in 1894, the luxury liner North West had 28 Belleville boilers that had a tendency to explode. According to several accounts, men regularly 
had to be "shanghaied" from waterfront saloons to maintain the vessels full compliment of firemen (Barry 1973: 163).

At the beginning of the twentieth century there were major shipyards present all along the Great Lakes including at Alpena. Between 1901 and 1910, these shipyards built nearly 300 new vessels (Landon 1944: 46). Over 200 of these vessels were bulk freighters built for owners switching from wooden to steel ships (Barry 1973: 176). Wooden steamboats were built as late as 1903. However, by the twentieth century, most of the supply of new timber had been exhausted (Mills 1910: 217). There were many new "firsts" in the development of the steel bulk freighter in this decade including the first vessel built without main deck beams or hold stanchions, 12-foot hatch spacing, and steel hatch covers (Augustus B. Wolvin), the first vessel with a 60foot beam (William G. Mather), the first 600-foot vessels, and the first vessels to carry 11,000 tons (Landon 1944: 46-48). Luxury passenger steamboats were also being built, including the City of Cleveland that cost over 1.25 million dollars (Mills 1910: 280). There were also a few lasts during this decade. The last unpowered consort, the Alexander Maitland, was built in 1902, and by 1910 the steambarge and consorts disappeared from the Great Lakes (Mills 1910: 221; Landon 1944: 49).

The 1920s also saw a number of firsts in the shipbuilding industry. The first diesel-powered vessel, the Henry Ford II, was launched in 1924 though diesel engines did not appear in large numbers until the 1970s. The year 1925 saw several firsts including the first one-piece or patent hatch covers (William C. Atwater), and the first vessel built with a steam turbine engine (T. W. Robinson). The T. W. Robinson was also the first to have mechanical coal-stokers (Thompson 1991: 60-61) 
A new type of transport vessel also appeared in the early twentieth century, the railroad car ferry. The period from 1910 to 1929 was the "golden era" of rail car ferries (Barry 1973: 184). Rail cars were either loaded onto the ferries with cargo or cargo was dumped into hoppers and reloaded into new cars at port. In 1911, the Ann Arbor Railroad was the first line to operate a rail car ferry across open water (Barry 1973: 181). All rail car ferries operated throughout the winter season and could function as icebreakers, crushing the ice with their massive weight. This practice, however, was not without associated dangers. In winter, rail car ferries were provisioned with at least a week's worth of food in case they became stuck in ice (Thompson 1991: 214). In some cases, as with the 1910 accident of the Pere Marquette 18, cars had to be jettisoned in order for the vessel to maintain stability and remain seaworthy (Barry 1973: 183). According to Mills (1910: 215), rail car ferries became the most hazardous of commercial transport services.

A revolutionary technological innovation that appeared in the twentieth century was the development of self-unloading vessels. The Wyandotte, built in 1908, was the first true self-unloader. It had a system of double hoppers that emptied cargo from the hold onto pan conveyors, which delivered it to the main deck and a conveyor boom that unloaded the cargo to the dock. The system was immensely successful (Lafferty 1998: 157). Some small vessels were cut down, such as the Adriadic and the John Lambert, for which in 1912, tracks were added to the deck on which a clamshell bucket was mounted (Thompson 1991: 49; Lafferty 1998: 157). The 1920s saw additional innovation in self-unloading equipment such as the tunnel scraper (Lafferty 1998: 165, 174-188). Self-unloaders were not immediately popular with vessel 
owners as they posed a dramatic departure from standard port practices (Landon 1994: 43). However, after 1930, economic conditions made the increasingly large bulk freighters ideal candidates for the equipment (Lafferty 1998: 187).

After 1900, transport of bulk commodities represented the largest percentage of cargo transported on the Great Lakes (Lafferty 1998: 155) and the shipping companies who plied these waters were highly efficient (Thompson 1991: 26). Ninety percent of the bulk tonnage was, in order by size, iron ore, coal, grain and flour, and lumber products. By 1910, one third of all American tonnage was on the Great Lakes. At the Detroit River, through which most bulk carriers passed, one vessel went through every six minutes. All bulk commodity rates were based on that of iron ore and total-lake commerce was worth over one billion dollars. Seventy-one percent of these products were processed through only 12 ports (Mills 1910: 294, 347, 350, 353, 357). In the first three decades of the twentieth century, iron ore shipments rose from 15 million to 73 million tons (Thompson 1991: 26).

Though the amount of iron ore shipped increased steadily during the early twentieth century, the total number of bulk carriers on the Great Lakes decreased. In 1918, for the first time, the number of bulk carriers numbered less than 500 (Landon 1944: 360). Without impediments to navigation, the modern freighters could make approximately 30 round trips between Lake Superior ore docks and Lake Erie ports in a season carrying over 400,000 tons of ore (Mills 1910: 302). The large tonnage of these vessels made Great Lakes shipping highly economical. By 1909, shipping by available railroad lines cost seven times as much as over water (Curwood 1909: 8). 
Grain was also shipped in increasingly large amounts, much of it shipped by Canadian companies. Between 1907 and 1914, the Montreal Company shipped an average of 15 million bushels, nearly three times as much as in 1900 (Salmon 1998: 120). Stone shipments also increased as limestone provided the flux material for the production of steel. Investment in road construction also promoted the production of stone products. Between 1915 and 1929, stone shipments on the Great Lakes increased 530 percent (Lafferty 1998: 162).

By 1932, the Great Depression had seriously damaged the Great Lakes shipping industry and shipbuilding stopped. Additionally, the Coast Guard acted at this time to enforce load line regulations in order to reduce overloading and the chances of foundering in large swells. This resulted in up to 300 tons less cargo a vessel could carry in a trip (Thompson 1991: 26, 63).

World War I and World War II had significant impacts on Great Lakes shipbuilding and shipping. During World War I, many lake vessels were impressed into war service, primarily small Canadian packet freighters. Commerce boomed for the vessels remaining on the lakes as need for iron ore in the war effort dramatically increased. Also, because of the large number of sailors called to war, many vessels worked with shorthanded crews. Ship technology benefited greatly from the war. New available tools included the gyrocompass, the radio direction finder, and radio communication. Surprisingly, many vessel owners felt that radio communication would undermine their authority with ships underway and it was banned on the lakes between 1924 and the early 1940s (Thompson 1991: 55-57). 
According to Landon (1944: 366), World War II came to the Great Lakes immediately after it began, with "every" cargo vessel impressed into service. Great Lakes shipyards built hundreds of vessels for the war effort. Among these were "Maritime Boats". Because of war-related material shortages, these vessels were powered by old steam reciprocating engines. Great Lakes shipping companies were allowed to trade their old bulk carriers for new Maritime Boats on a ton-per-ton basis (Thompson 1991: 64). Many of these vessels did not return to the Great Lakes from war service, but were either destroyed at sea or scrapped (Devendorf 1995).

\section{Historic Accident and Safety Landscape}

The Great Lakes are some of the most dangerous waters upon which a sailor or seaman can set out, yet they are historically, one of the most heavily trafficked waterways. It is not surprising therefore, that of the hundreds of thousands of Great Lakes voyages, tens of thousands resulted in some sort of accident, ranging from bumping a dock to boiler explosions, and thousands of catastrophic shipwrecks. According to Curwood (1909: 77), "If all the ships lost upon [the lakes] were evenly distributed, there would be a sunken hull every half-mile over the entire thousand-mile waterway between Buffalo and Duluth.” In fact, the losses on the Great Lakes are, in proportion, greater than those of any of the oceans (Curwood 1909: 106). As a dramatic example, between 1878 and 1898, the U.S. Commissioner of Navigation listed 5999 accidents on the Great Lakes with 1093 of them total losses. There was a one in 12 chance that a vessel would be wrecked in the navigable season (Thompson 
1991: 145). This section sets out to briefly explore the general trends in these Great Lakes shipping losses and wrecking and the actions taken to increase safety on the water. The shipwrecks and associated archaeological assemblages at Thunder Bay National Marine Sanctuary will be discussed in Chapter Six.

There are many ways a vessel can wreck upon the Great Lakes. They include: stranding or grounding, foundering, collision with another vessel, fire and/or boiler explosions, and abandonment. Blame for wrecking can include operational error, incompetence, poor maintenance of vessels and equipment, and force majeure, however, all losses from shipwrecks are a direct result of patterns of behavior within the maritime landscape that evolved with the shipping industry over the course of its history (Thompson 1991: 150).

The first true ship on the Great Lakes, Le Griffon, was probably the first shipwreck on the Great Lakes. It disappeared somewhere either on Lake Michigan or Lake Huron in 1679. Early corporate vessels faired little better. For example, by 1829, three of the four Northwest Company and Hudson's Bay Company fur-trade schooners had wrecked in Lake Superior. In general, however, records of wrecking events for the first half of the nineteenth century are diffuse. Official records of shipping accidents were not kept until after the disastrous 1870-1871 season.

Gjerset (1928) compiled a record of Great Lakes shipping losses for much of the mid-nineteenth century (Table 4.2). Note that the missing years, 1857 to 1859 , was a period of severe financial recession with little shipping activity on the lakes. It is possible that the spike in shipping accidents and large increase in loss of life in 1856 could have resulted from two potential behavioral causes. The financial boom 
preceding the recession may have resulted in an attempt by captains to make up for less competitive shipping rates by taking increased risks in course and speed. Additionally, at this time there was marked increase in the competitiveness of steamboats, and the majority of these accidents may have been with sailing vessels whose owners attempted to make them more profitable through increased risks in course and speed, spending less money on vessel maintenance, or hiring less experienced and therefore cheaper crews. The rapid rise in shipping disasters in the late 1860 s reflects the corresponding increase in the number of vessels in operation.

Because the number of vessels operating on the Great Lakes increased rapidly during the 1860 s and the tonnage shipped continued to increase throughout the century, it is unsurprising that large-scale multi-vessel catastrophes appear to become more prominent as a result of violent storms. For example, the 16-19 November 1869 gale wrecked 93 vessels with vessels and cargo valued at nearly 1.3 million dollars (Gjerset 1928: 80). Wooden vessels that wrecked in storms on reefs or rocky shores were seldom salvaged (Mills 1910: 333).

On Lake Huron's northwestern shore, only Thunder Bay and the nearby islands offered potential safe haven for vessels in distress, including those endangered by storms (Wright 1980). Ninety-five percent of groundings or strandings in the vicinity were the result of vessels being carried off their course by storm-induced or intensified currents, currents that would have been difficult to predict by vessel masters and pilots (Landon 1944: 341).

The most catastrophic storm on the Great Lakes was the "White Hurricane" of 611 November 1913. As a result of this storm, 12 vessels sank, eight on Lake Huron, 
an additional 31 were stranded, and approximately 250 people were killed. Post-storm investigations showed that for the most part, captains and crews had practiced typical expected behavior such as how they had secured the vessels and the believed appropriate ways to ride out a storm (Brown 2004).

Most of the wrecked vessels were relatively new and therefore those who advised setting out may have falsely expected the vessels to perform above their capabilities. For example, Landon (1944: 332) reports that vessel owners were "appalled that the products of the best shipyards in America were unable to withstand the force of this storm." Many of the losses were modern straight-deck bulk freighters, and it had been believed that their wide-flat bottom could not flip in heavy seas (Landon 1944: 333), as did several of the vessels, including the Isaac M. Scott, which sank near Thunder Bay with all hands. An additional technological contribution to the fate of these bulk freighters was the use of engines too small to maintain adequate speed-made-good in the head sea produced by the storm (Brown 2004: 24).

A false expectation of the performance of technology still endangers shipping. For example, Ramsey's (2006) analysis of the foundering of the Edmund Fitzgerald in November 1975 on Lake Superior indicates that inappropriate upscaling of the bulk freighter's architecture from smaller vessel designs caused unexpected multi-axial structural loadings resulting in hull failure.

In the late nineteenth and early twentieth century, in addition to storms, and in the winter, ice, a great hazard to navigation is fog. Fog is typically heaviest on the Great Lakes in the spring. The most typical accidents attributed to fog is grounding and collision between vessels, especially on open water and where traffic converges such 
as the mouth of rivers and where traffic changes course such as north of Thunder Bay off Presque Isle (Landon 1944: 339-342). For example, the bulk freighter D. $R$. Hanna collided with the Quincy A. Shaw, flipped, and sank in May 1919 approximately six miles from the Thunder Bay lighthouse. In May 1923, the Edward U. Demmer collided with the Saturn in the same location and sank. The crew claimed that the fog was so thick, they could not identify the Saturn (Landon 1944: 339). Additionally, the hurry to make up lost time due to fog might pose increased risk in crew behavior.

Collisions did not have to be the result of an obscured vision caused by fog. The most famous clear-day collision at Thunder Bay was between the passenger/packet freighter Pewabic and its sister ship Meteor in August 1865. Traveling in opposite directions, the vessels passed close to exchange news and packages. The vessels collided, sending the Pewabic to the lake floor, killing approximately 125 passengers and crew. After this disaster, there was a general push for the development of shipping lanes for upbound and downbound vessels, though they were not established until 1911 (Thompson 1991: 149).

A related issue to fog is the presence of smoke lingering over the water. The source of smoke could be forest fires, coastal town fires, and the smoke from passing vessels. This was primarily a concern for shipping in the last decades of the nineteenth century. Alpena had five major town fires in the span of ten years in 1862, $1863,1867,1869$, and 1871. Smoke was reported to have blanketed the Thunder Bay River and Thunder Bay (Havighurst 1975: 108). It is unclear if any of these fires caused any of the known wrecks in or around Thunder Bay. In general, fire was a 
major safety concern for Great Lakes vessels, especially for wooden steamboats. Fire could endanger a vessel on the water as well as while tied at a dock.

Clear-day accidents could also occur due to technological failure. For example, the D.M. Wilson, a wooden propeller, was en route to Milwaukee from Cleveland, 27 October 1894, carrying a load of 1000 tons of coal. While proceeding through Saginaw Bay in Lake Huron, the vessel opened a seam and began to take on water. Instead of putting into port for repairs, the crew used a bilge pump to handle the leak, a process that failed off North Point causing the ship to founder and sink in seventy feet of water.

The United States and Canada have made considerable effort to increase safety at sea on the Great Lakes. The first steps taken were to increase knowledge of the lake systems themselves through charting the lake coasts. The first general survey of the Great Lakes was by Gother Mann in 1787. Mann toured the lakes gathering navigational information that the British might find useful in war. Henry Wolsey Bayfied conducted the first systematic surveys of Lake Huron in the 1810s. Bayfield's charts represented a rapid reconnaissance of known coastal hazards. In 1823 , the federal government appropriated the first monies for the improvement of navigation. Major harbors were surveyed; however, the work did not follow a specified procedure and often the work took years to complete (Woodford 1991: 1214).

The United States Lake Survey was founded in 1841 (incorporated into the Army Corps of Engineers in 1863, and the National Oceanic and Atmospheric Administration in 1970) to undertake hydrographic surveys of the Great Lakes. This 
motivation for the agency's formation was the large influx of settlers into the Great Lakes region (Woodford 1991: 1). The first general survey of all the lakes, save Lake Superior, was completed in 1845. It focused on harbors with established regular steamboat service. The Lake Survey completed a full survey of Lake Huron between 1857 and 1859 . The inshore survey extended out to about half a mile or to four fathoms depth. Offshore survey was conducted by steamboat and extended out up to 12 miles. Each chart set out sailing courses and included a list of authorities, a water table, a table of magnetic variations, a list of lighthouses, sailing directions, and a statement of known hazards (Woodford 1991: 56, 62). Charts were issued free to ship masters and were distributed by the thousands.

In 1882, the Great Lakes hydrographic survey was officially completed and had published 76 charts. By the 1880 s, however, the Lake Survey began to realize that the charts were inadequate for the current maritime technology and did not recognize recent major harbor improvements. Additionally, the charts did not indicate channel depth greater than 18 feet, a depth appropriate at the start of the survey. Also, recent lake-level studies showed that the level of the lakes had fluctuated by 1891 by as much as five feet (Woodford 1991: 69-70). Over the course of the next several decades, the Lake Survey continually resurveyed needed areas within the Great Lakes and updated charts, finding new navigational hazards with each survey. A new total Great Lakes survey was initiated in 1907 and completed in 1936. An outcome of the project was that major waterways, harbors, and connecting rivers would be resurveyed on a triennial basis (Woodford 1991: 131). Throughout the twentieth century until today, 
survey technology has continued to improve, rendering navigational charts increasingly accurate and precise.

Pilot books for Great Lakes Navigation were also produced beginning in the last decades of the nineteenth century. The earliest comprehensive pilot books date to the late 1860s and 1870s; the best known was Thompson's Coast Pilot. New pilot books appear to have been issued approximately every ten to 20 years. Information in the pilot books include sailing directions with reference to harbors, manmade structures, navigational aids, soundings, and coastal landmarks, harbors of refuge, local pilots, potential obstructions and hazards, and docking and tonnage fees in port (Thompson 1878).

The first lighthouses erected on the Great Lakes were at Presque Isle on Lake Erie, at Buffalo, and at Niagara in the 1810s. Two lighthouses were erected in the vicinity of Thunder Bay, at Presque Isle, established in 1840 and refitted in 1857, and one on Thunder Bay Island, established in 1832 and refitted in 1857. Though these lighthouses were continually manned, their upkeep at times was minimal. In an 1838 survey of lighthouses west of Detroit, James T. Homans stated of the Thunder Bay Island Light: "the buildings are in danger of washing away, the house requires considerable repairs, and the plaster is falling off' (O'Brien 1976: 15). In general, lighthouse keepers and their families were the first responders to marine accidents (O’Brien 1976: 22). The Lighthouse Service was also responsible for aids to navigations such as beacons, buoys, and fog signals.

In the early nineteenth century, most captains in the coastal trade navigated by coasting or sailing close to shore, looking for landmarks to fix their position. This 
posed a very real danger of grounding, especially in heavy seas (Noble 1994: 16).

After several years of petitions in response to coastal marine disasters, in the $1850 \mathrm{~s}$ Congress authorized funding to begin building life-saving stations; however, no money was appropriated to man or inspect the stations. Throughout the decade, small funds were granted to build the service. For example, in $1854, \$ 12,500$ was given to purchase metallic lifeboats for the Great Lakes stations. Each step Congress took to build the safety network was in response to a major maritime disaster (Noble 1994: 22). Little real progress was made, however, through the 1850 s and 1860 s.

Life-saving institutions and infrastructure along the American coasts were intensively reorganized after the disastrous 1870-1871 navigation season. Over 200 sailors and seamen lost their lives just on the Great Lakes. These deaths proved the ineptitude of the system in place at the time to render aid effectively. Issues included untrained and/or incapable personnel, inadequate stations and equipment, and too long of distance between stations (Noble 1994: 24). To remedy the situation, Congress appropriated $\$ 200,000$ for training, better pay, new equipment, and station refurbishment (O’Brien 1976: 34). Reorganization of the Life-Saving Service took place under the authorization of Sumner Increase Kimball who headed the agency for several decades. The expansion of the Life-Saving Service was aided and justified by the 1874 Life-Saving Service act, which required all maritime accidents, no matter the severity, to be reported (Noble 1994: 31).

On the Great Lakes, it was assumed, based on accident reports, that most maritime incidents occurred at or near harbors and in sheltered areas where vessels might try to ride out storms (Noble 1994: 88). Consequently, most Great Lakes life- 
saving stations were located within their vicinity. Near Thunder Bay, stations were built on Thunder Bay Island in September of 1876 and on nearby Middle Island in November of 1881 . This was a high traffic yet dangerous area, known as a lee harbor in most foul weather, but very close to the shoal reefs along North Point. By 1928, aid could be rendered up to 25 miles from shore (Gjerset 1928: 163). Until its incorporation into the Coast Guard in 1915, the Life-Saving Service saved thousands of lives and millions of dollars of property (Stonehouse 1994).

\section{The Modern Landscape}

The modern landscape of Thunder Bay is dominated by the city of Alpena,

Michigan. Covering 23.5 square kilometers, the municipality is home to over 11,000 residents (www.alpena.mi.us, accessed April 28, 2010). Most of the population clusters around the Thunder Bay River and Lake Huron coast.

Thunder Bay is heavily utilized for coastal and marine recreation including boating, snorkeling, and scuba diving. Lake-based economic activities include relatively small-scale commercial fishing, including tribal fishing off Middle Island. Cement barges operated by the LaFarge Cement Company dominate commercial transportation within the bay. Heavy commercial traffic operates in open water, much more removed from the coast than historic shipping lanes. 
Tables

\begin{tabular}{|l|l|l|l|l|}
\hline \multicolumn{1}{|c|}{ Date (ka) } & \multicolumn{1}{|c|}{ Direction } & Glacial Lake & $\begin{array}{l}\text { Height above Sea } \\
\text { Level (ft) }\end{array}$ & \multicolumn{1}{|c|}{ Outlet } \\
\hline 18 & Glacial Max & & & \\
\hline 14.5 & Retreat & Early Saginaw & 730 & Grand River \\
\hline 13.5 & $\begin{array}{l}\text { Mackinaw } \\
\text { Interstade }\end{array}$ & Arkona & $710-695$ & Grand River \\
\hline $13-12$ & $\begin{array}{l}\text { Pt. Huron } \\
\text { Advance }\end{array}$ & Saginaw & 695 & Grand River \\
\hline $12.5-12$ & Retreat & Warren 1, 2 & 690,682 & Grand River \\
\hline & Retreat & Wayne & 655 & Grand River \\
\hline 11.8 & Retreat & Warren 3 & 675 & $\begin{array}{l}\text { Grand River or } \\
\text { Indian River }\end{array}$ \\
\hline & Retreat & Grassmere & 640 & $\begin{array}{l}\text { Grand River or } \\
\text { Indian River }\end{array}$ \\
\hline & Retreat & Early Algonquin & 605 & $\begin{array}{l}\text { Port Huron and } \\
\text { Schomburg }\end{array}$ \\
\hline & Two Creeks & Kirkfield Algonquin & $<580$ & $\begin{array}{l}\text { Kirkfield and } \\
\text { others }\end{array}$ \\
\hline
\end{tabular}




\begin{tabular}{|l|l|l|l|l|}
\hline \multicolumn{1}{|c|}{ Date (ka) } & \multicolumn{1}{|c|}{ Direction } & \multicolumn{1}{|c|}{ Glacial Lake } & $\begin{array}{l}\text { Height above Sea } \\
\text { Level (ft) }\end{array}$ & \multicolumn{1}{|c|}{ Outlet } \\
\hline 11 & Retreat & $\begin{array}{l}\text { Algonquin } \\
\text { (draining) }\end{array}$ & Fluctuating & $\begin{array}{l}\text { St. Clair River and } \\
\text { Chicago }\end{array}$ \\
\hline $10.5-10$ & Retreat & $\begin{array}{l}\text { post-Algonquin } \\
\text { (draining) }\end{array}$ & Fluctuating & $\begin{array}{l}\text { Kirkfield, Fossmill, } \\
\text { and others }\end{array}$ \\
\hline $10-9.8$ & Advance & Stanley, Hough & 180 & North Bay \\
\hline $8.7-8.3$ & Retreat & $\begin{array}{l}\text { Unnamed } \\
\text { Lowstand }\end{array}$ & $<100$ & None \\
\hline $8.3-8$ & Retreat & $\begin{array}{l}\text { Nipissing } \\
\text { Transition }\end{array}$ & Fluctuating & North Bay \\
\hline $6-4$ & $\begin{array}{l}\text { Absence of } \\
\text { Glacier }\end{array}$ & Nipissing & 605 & $\begin{array}{l}\text { North Bay, St. } \\
\text { Clair River, }\end{array}$ \\
\hline $3.5-2$ & $\begin{array}{l}\text { Absence of } \\
\text { Glacier }\end{array}$ & Algoma & Fluctuating & $\begin{array}{l}\text { St. Clair River and } \\
\text { Chicago }\end{array}$ \\
\hline $2-0$ & $\begin{array}{l}\text { Absence of } \\
\text { Glacier }\end{array}$ & Lake Huron & 580 & \begin{tabular}{l} 
St. Clair River \\
\hline
\end{tabular} \\
\hline
\end{tabular}

4.1 Final Laurentide Ice Sheet Retreat (after Farrand 1987)

Red: Thunder Bay ice covered

Blue: Thunder Bay inundated

Green: Thunder Bay exposed

Purple: Unknown status of Thunder Bay 


\begin{tabular}{|l|l|l|l|}
\hline \multicolumn{1}{|c|}{ Year } & \multicolumn{1}{|c|}{ \# Disasters } & \multicolumn{1}{c|}{ Loss of Property } & \multicolumn{1}{c|}{ Loss of Life } \\
\hline 1850 & & $\$ 558,926$ & 431 \\
\hline 1851 & 263 & $\$ 730,537$ & 79 \\
\hline 1852 & 229 & $\$ 992,659$ & 296 \\
\hline 1853 & 266 & $\$ 874,143$ & \\
\hline 1854 & 384 & $\$ 2,189,825$ & 119 \\
\hline 1855 & & $\$ 2,797,830$ & 118 \\
\hline 1856 & 597 & $\$ 3,126,744$ & 407 \\
\hline 1861 & & $\$ 867,347$ & 116 \\
\hline 1862 & 300 & $\$ 1,162,173$ & 154 \\
\hline 1863 & 310 & $\$ 2,600,517$ & 123 \\
\hline 1864 & 599 & $\$ 654,100$ & \\
\hline 1865 & 421 & & 175 \\
\hline 1866 & 621 & $\$ 675,000$ & 211 \\
\hline 1867 & 931 & & 331 \\
\hline 1868 & 1164 & & \\
\hline 42 Compilat & & & \\
\hline
\end{tabular}

4.2 Compilation of Great Lakes Shipping Disasters for the $19^{\text {th }}$ Century (Gjerset 1928). 
Figures

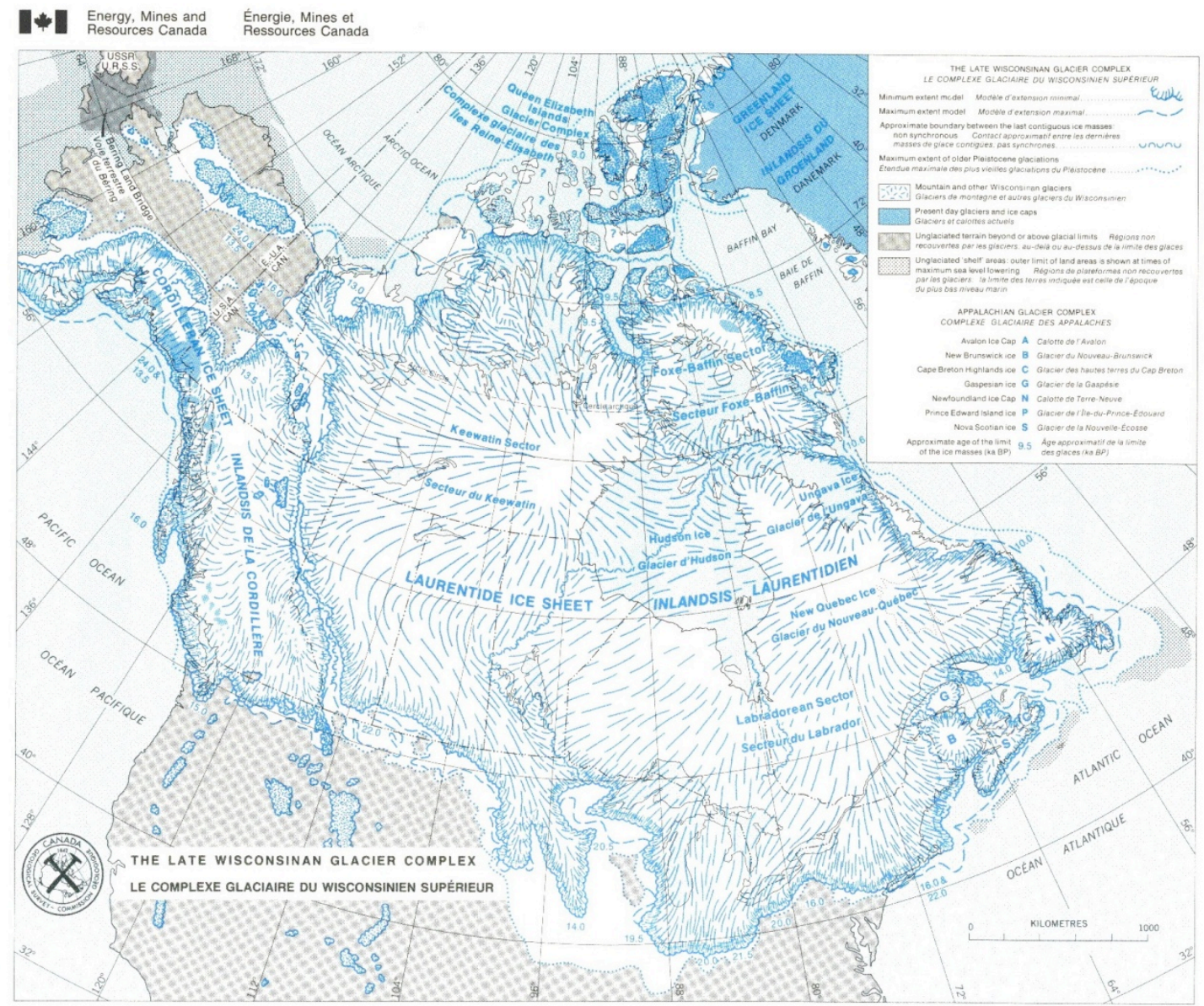

\section{Canadàa}

\subsection{The Late Wisconsinan Glacier Complex (Energy Mines and Resources Canada}

n.d.) 

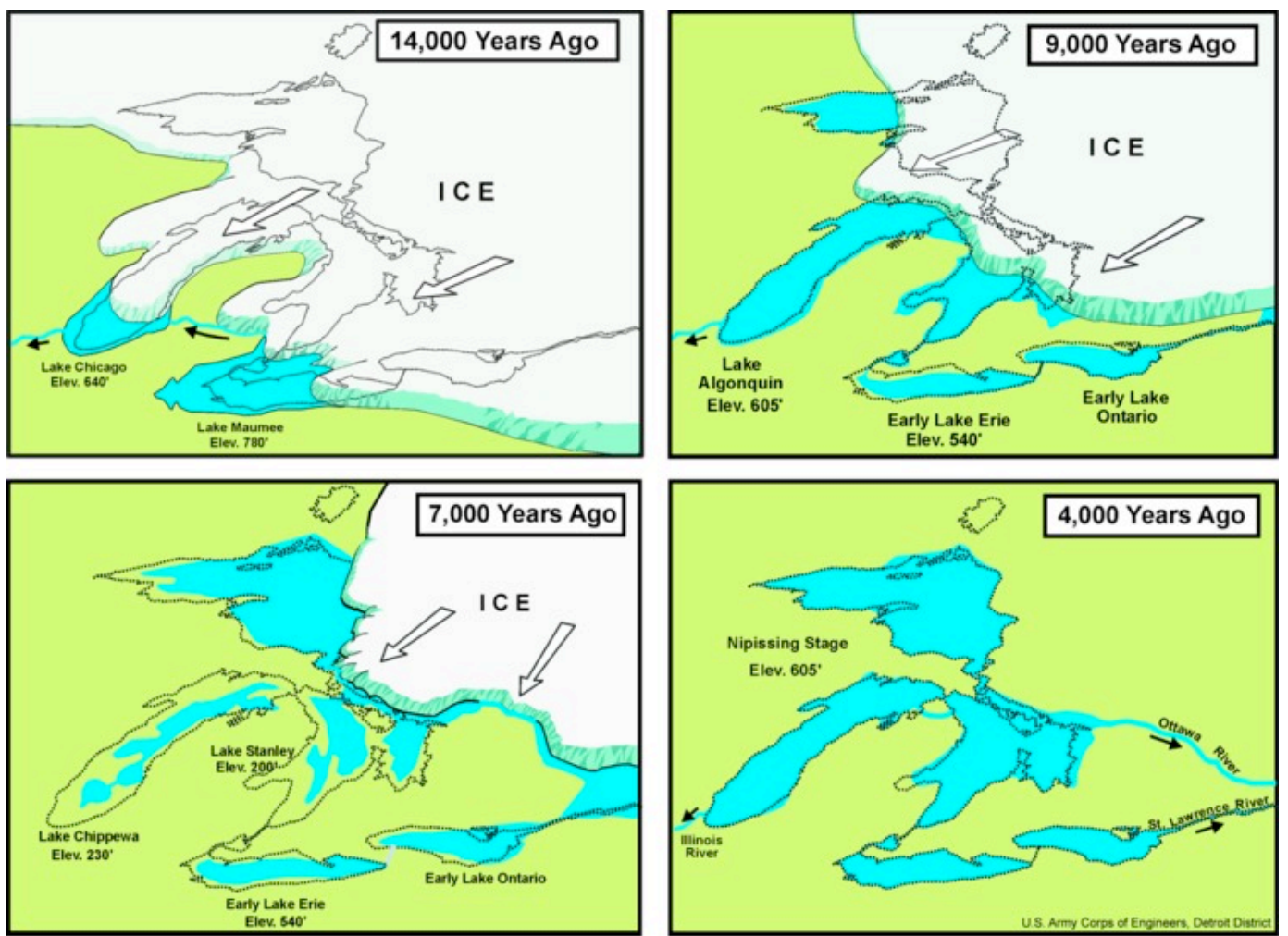

4.2 Glacial Lakes in the Great Lakes Basin (US Army Corps of Engineers, Detroit

District n.d.) 


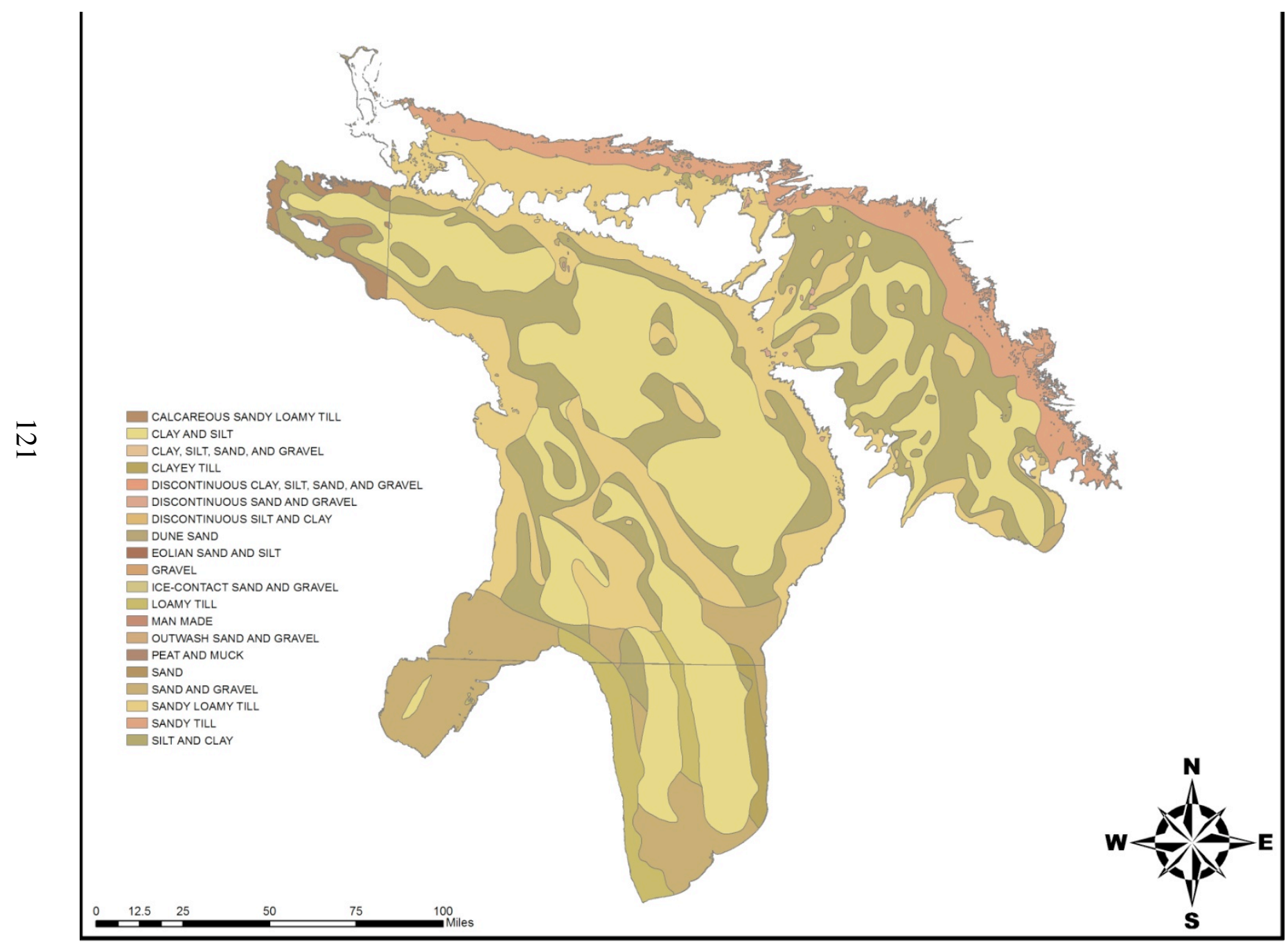

4.3 Lake Huron Basin Sedimentary System 


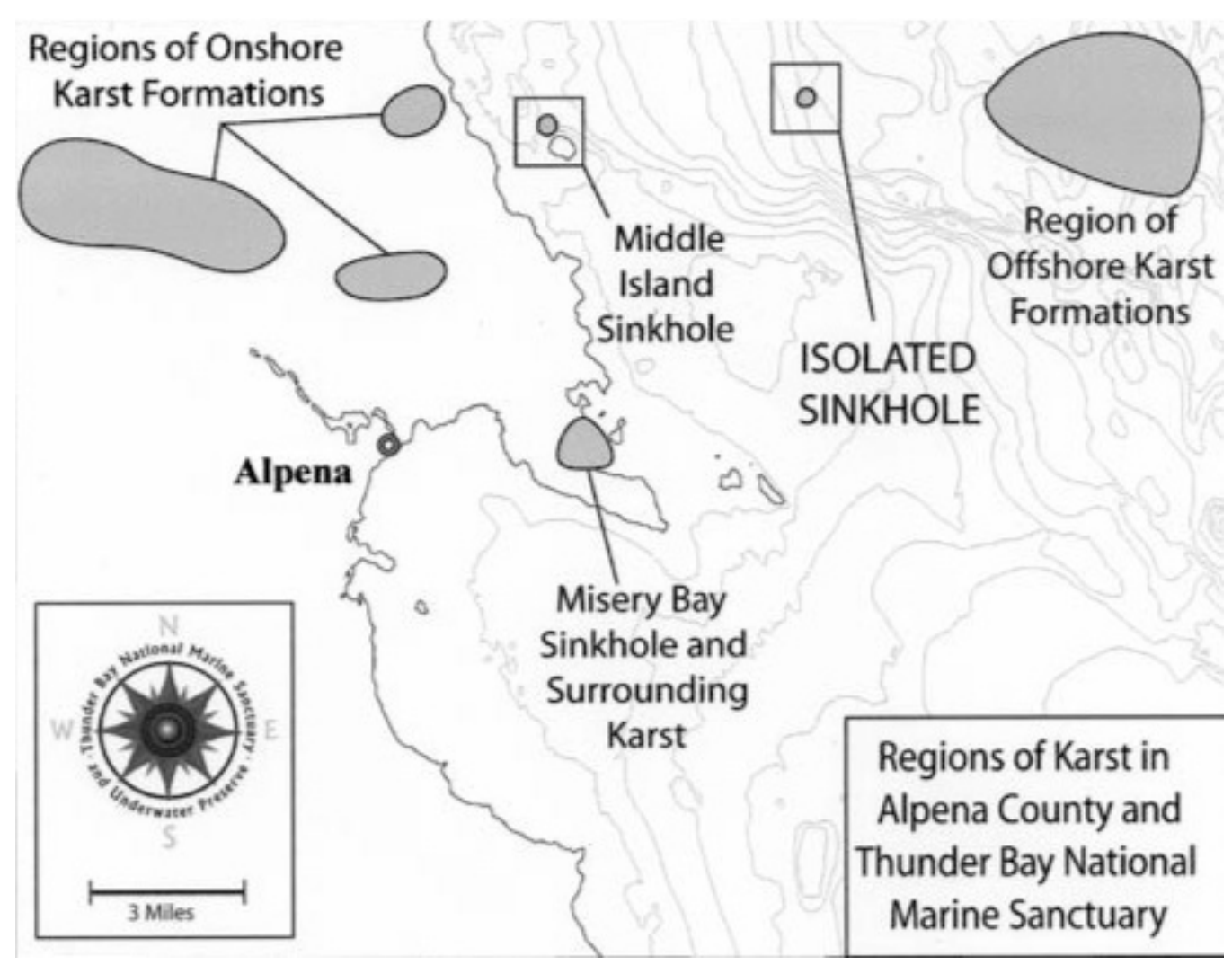

4.4 Karst Sinkholes in the Vicinity of Thunder Bay (Biddanda et al. 2006)
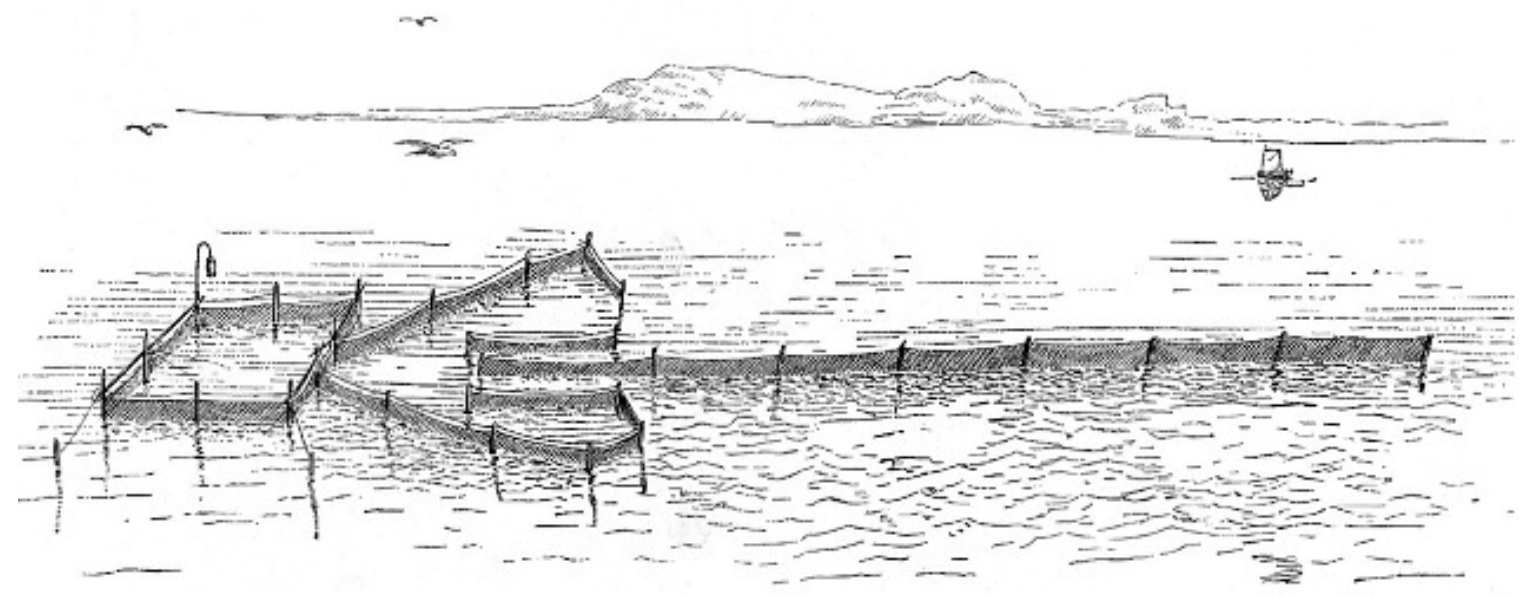

4.5 Pound Net Fishery (Smith and Snell 1889) 


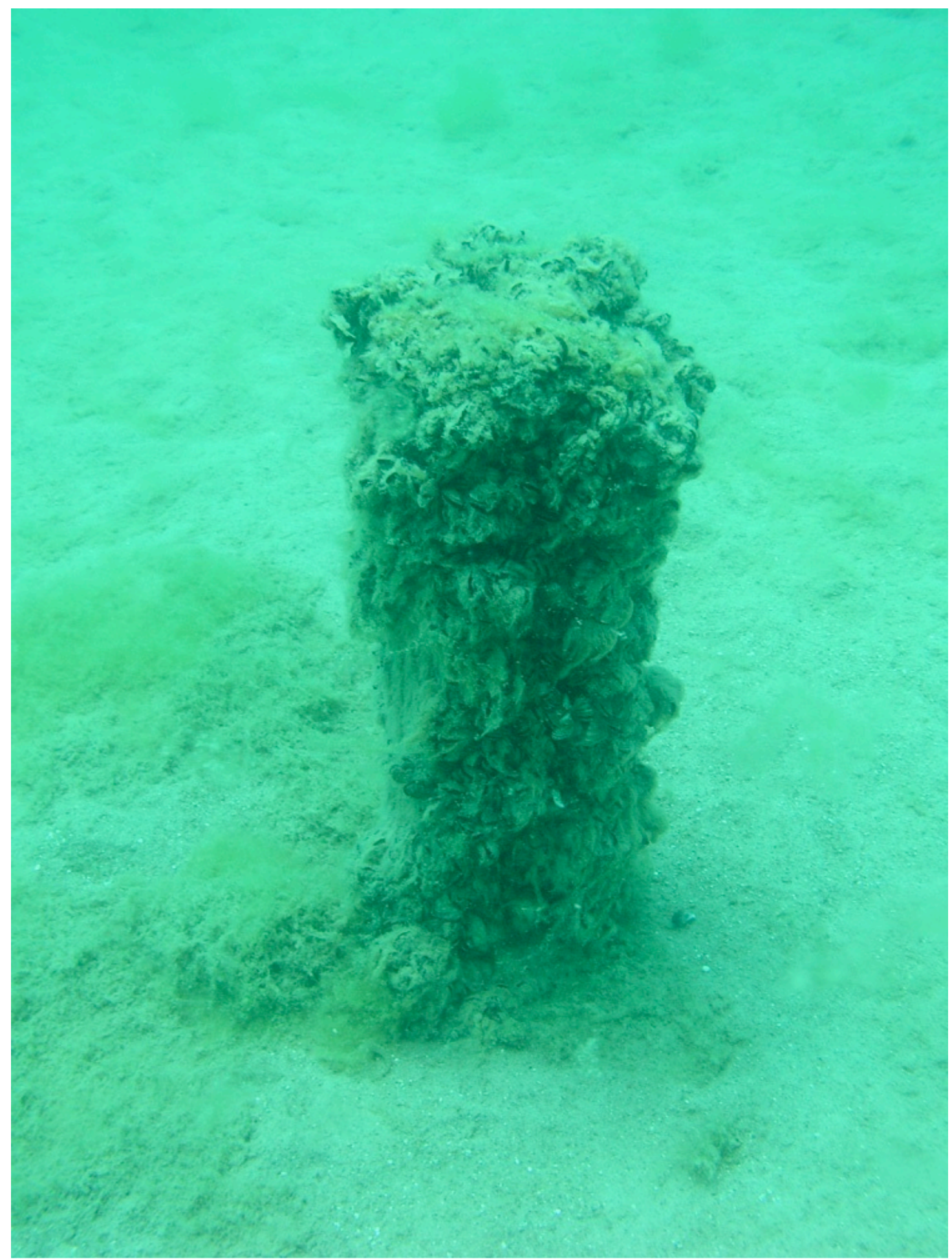

4.6 Pound Net Fishery Net Stake in Thunder Bay 


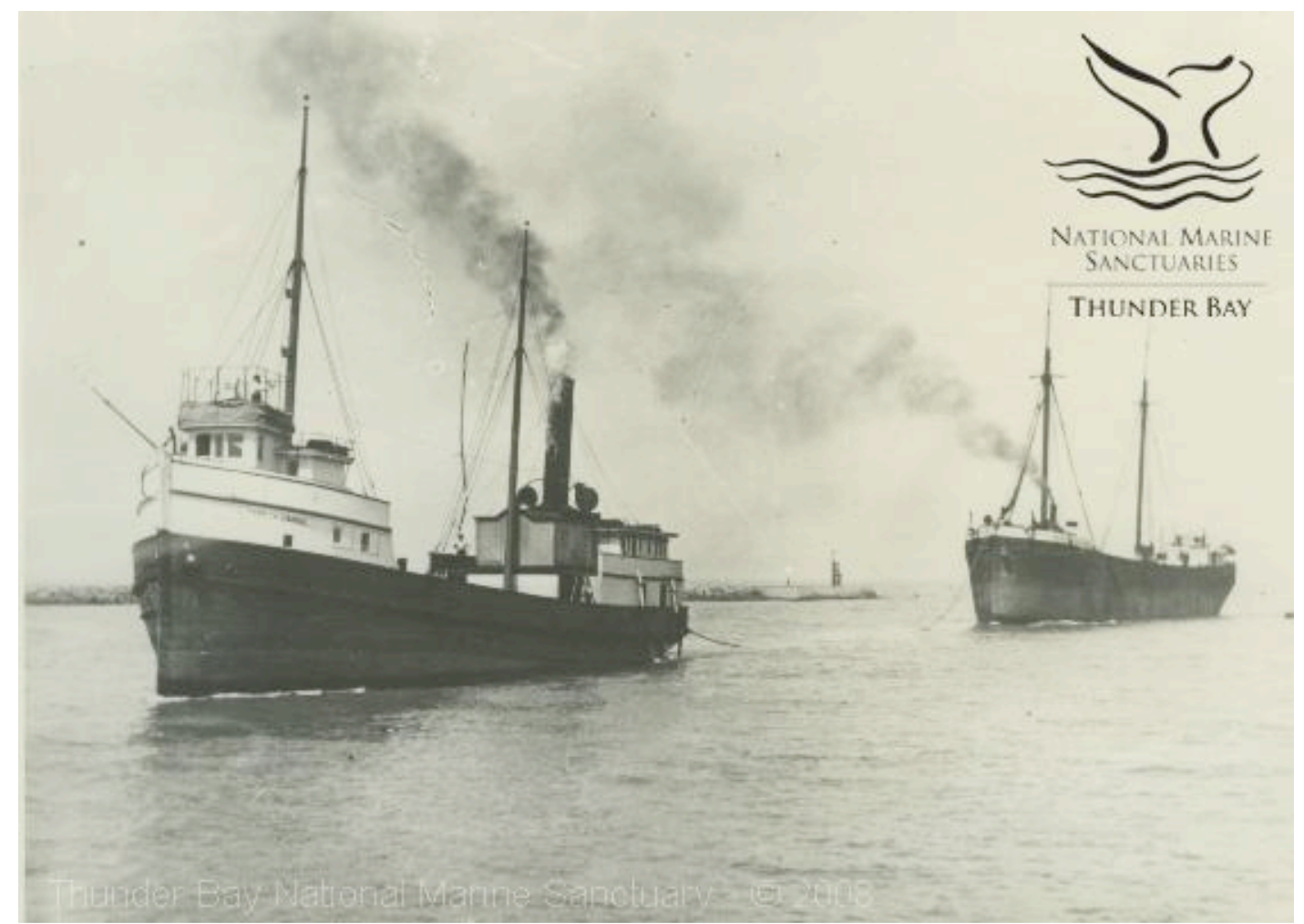

4.7 The Wooden Propeller Isabella J. Boyce with a Consort in Tow (Courtesy Thunder

Bay National Marine Sanctuary) 


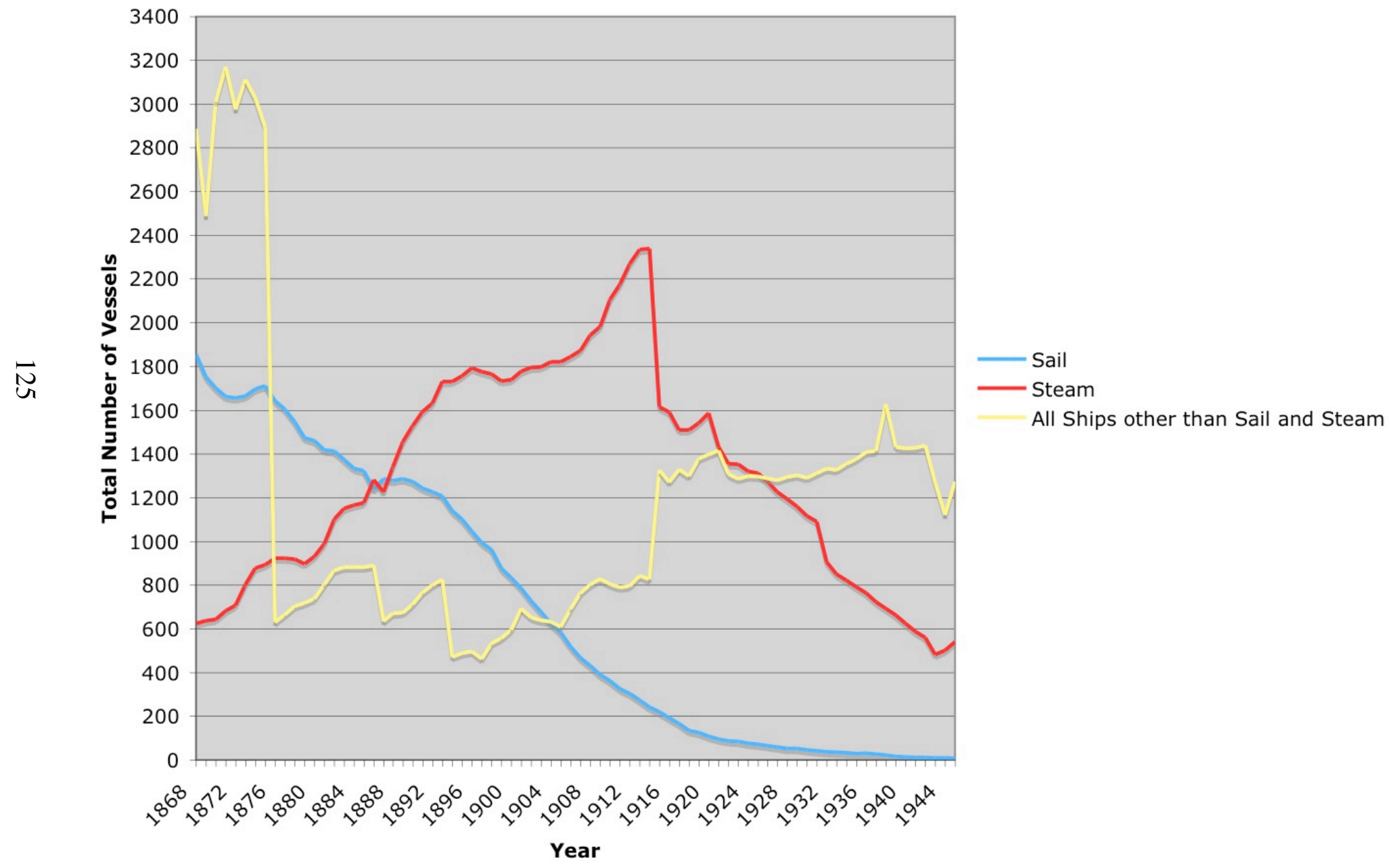

4.8 Commercial Sail versus Steam-Powered Vessels on the Great Lakes (after Barnett 1992: 147-149) 
Total Tonnage

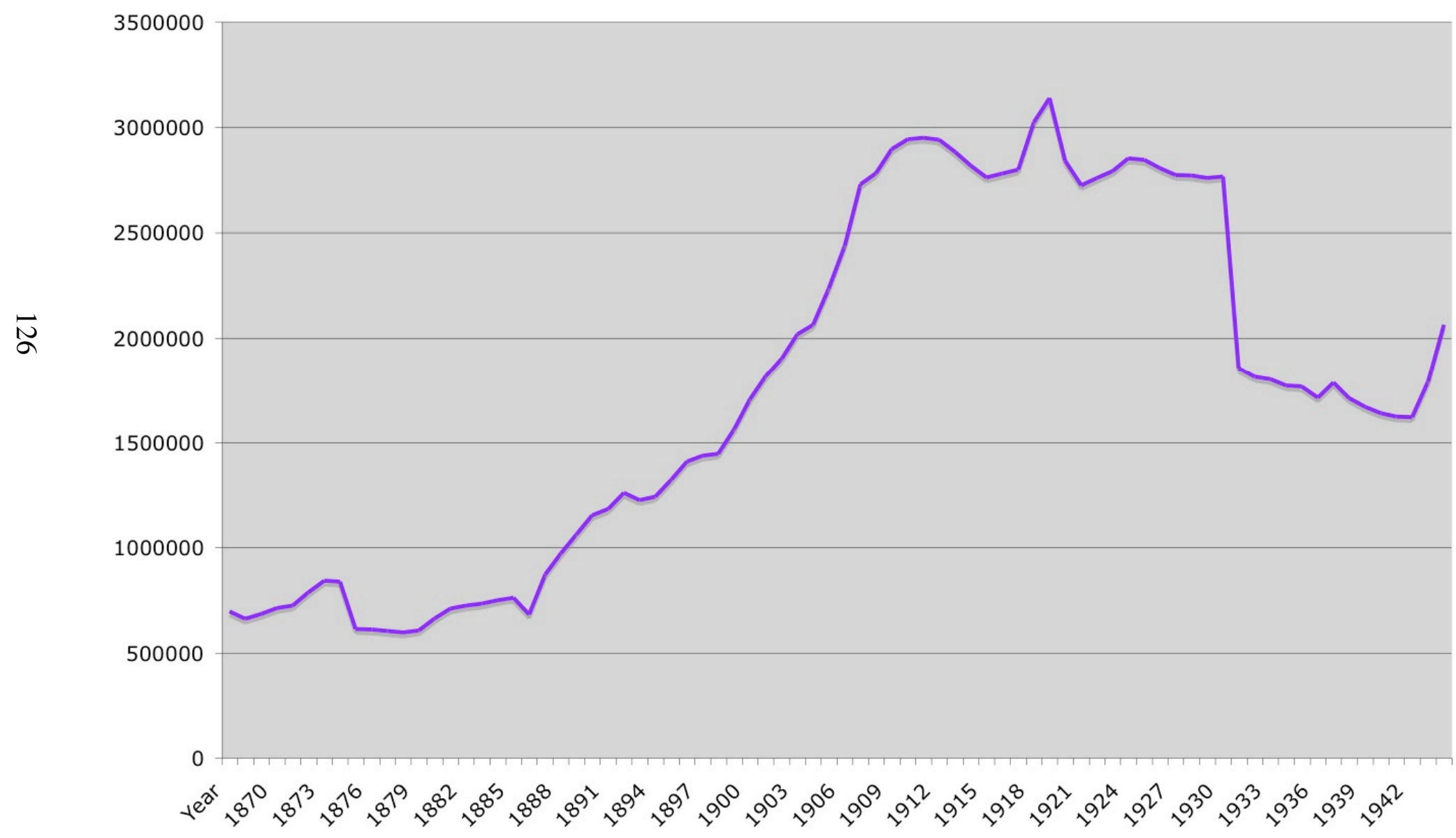

4.9 Total Tonnage on the Great Lakes (after Barnett 1992: 147-149) 


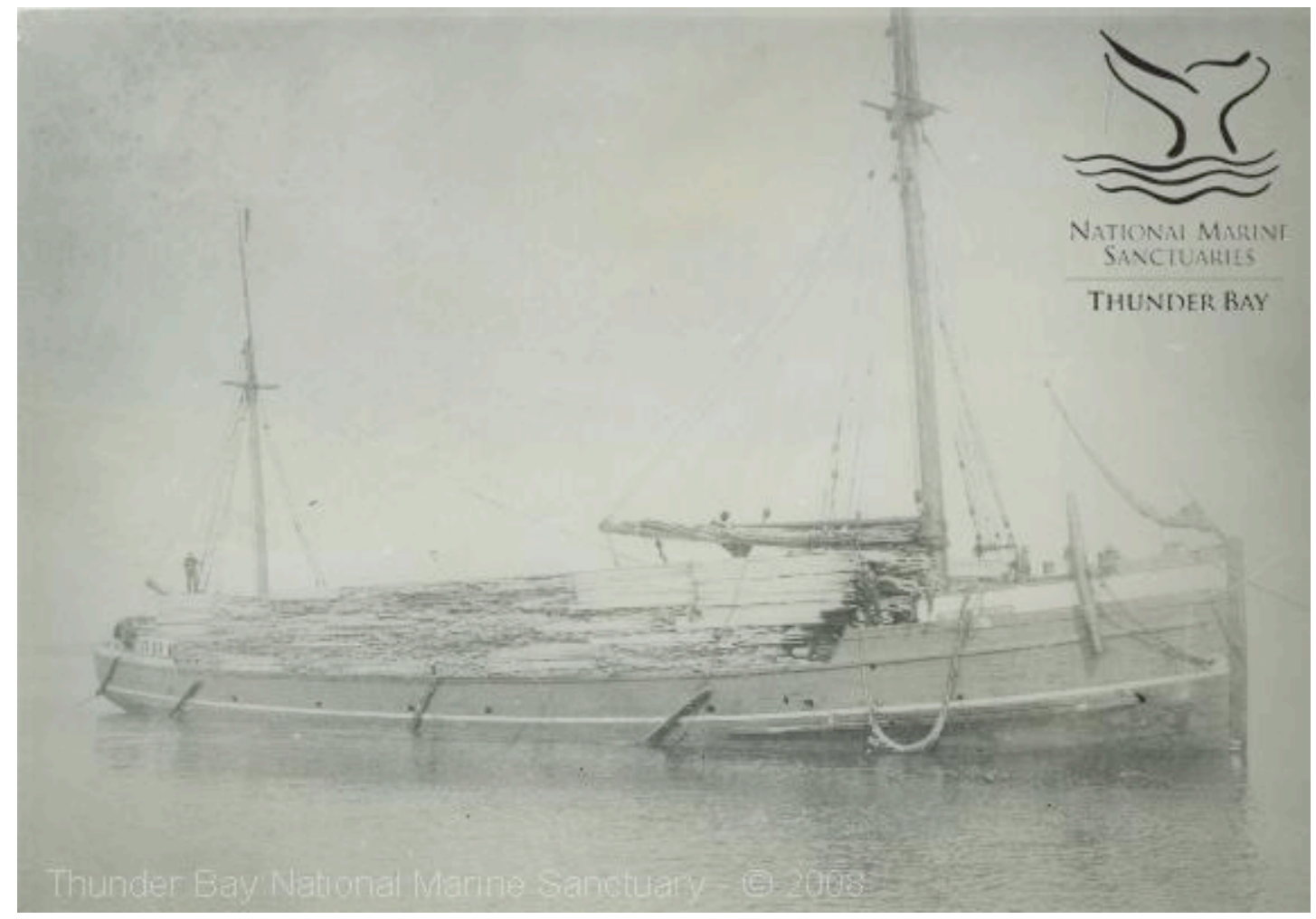

4.10 A Typical Great Lakes Schooner, the John T. Johnson (Courtesy Thunder Bay

National Marine Sanctuary) 


\section{Number of Vessels per Type Normalized by Total Tonnage}

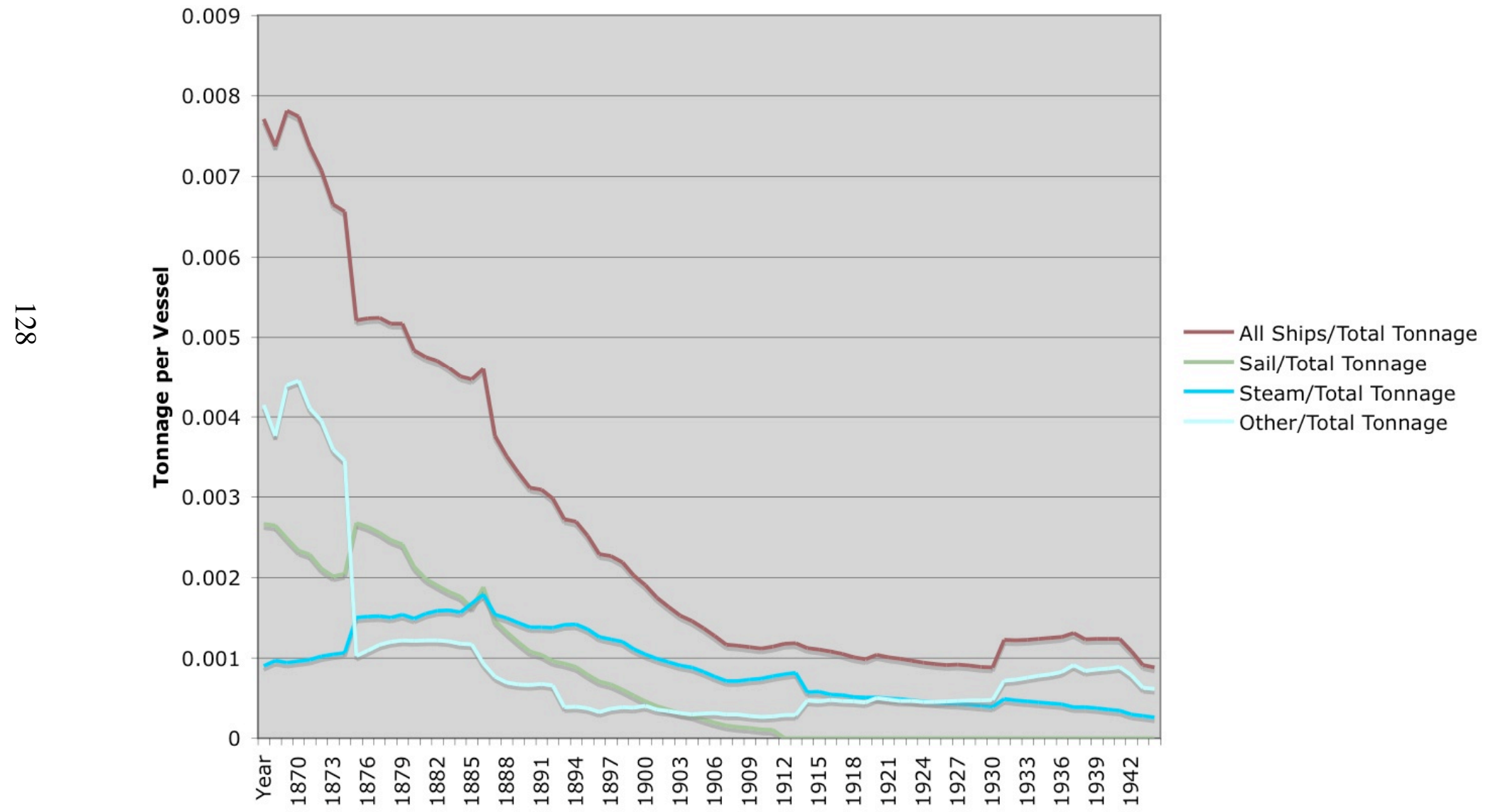

4.11 Commercial Sail versus Steam Powered Vessels Normalized by Tonnage (after Barnett 1992: 147-149) 


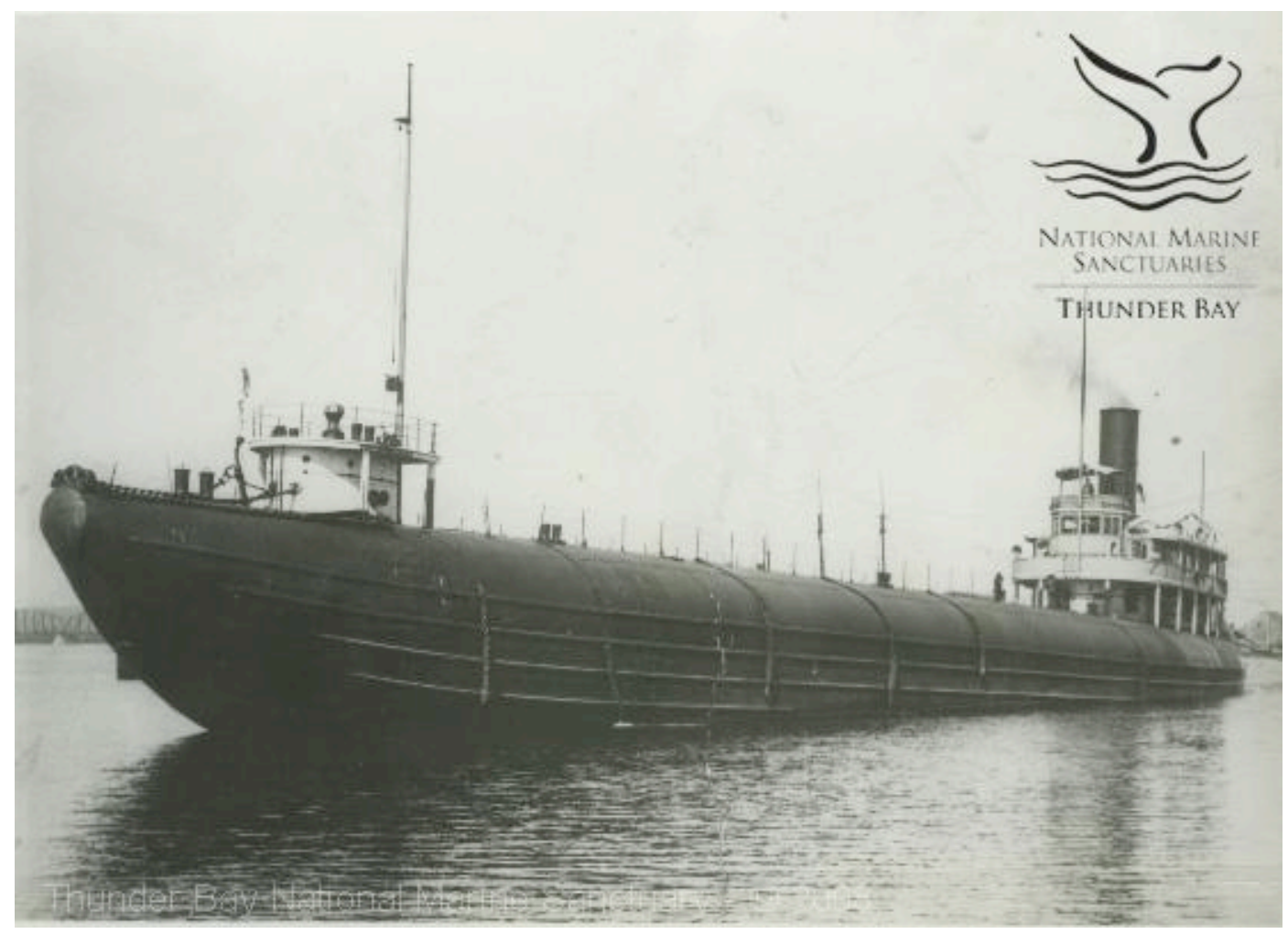

4.12 The Whaleback Clifton (Courtesy Thunder Bay National Marine Sanctuary) 


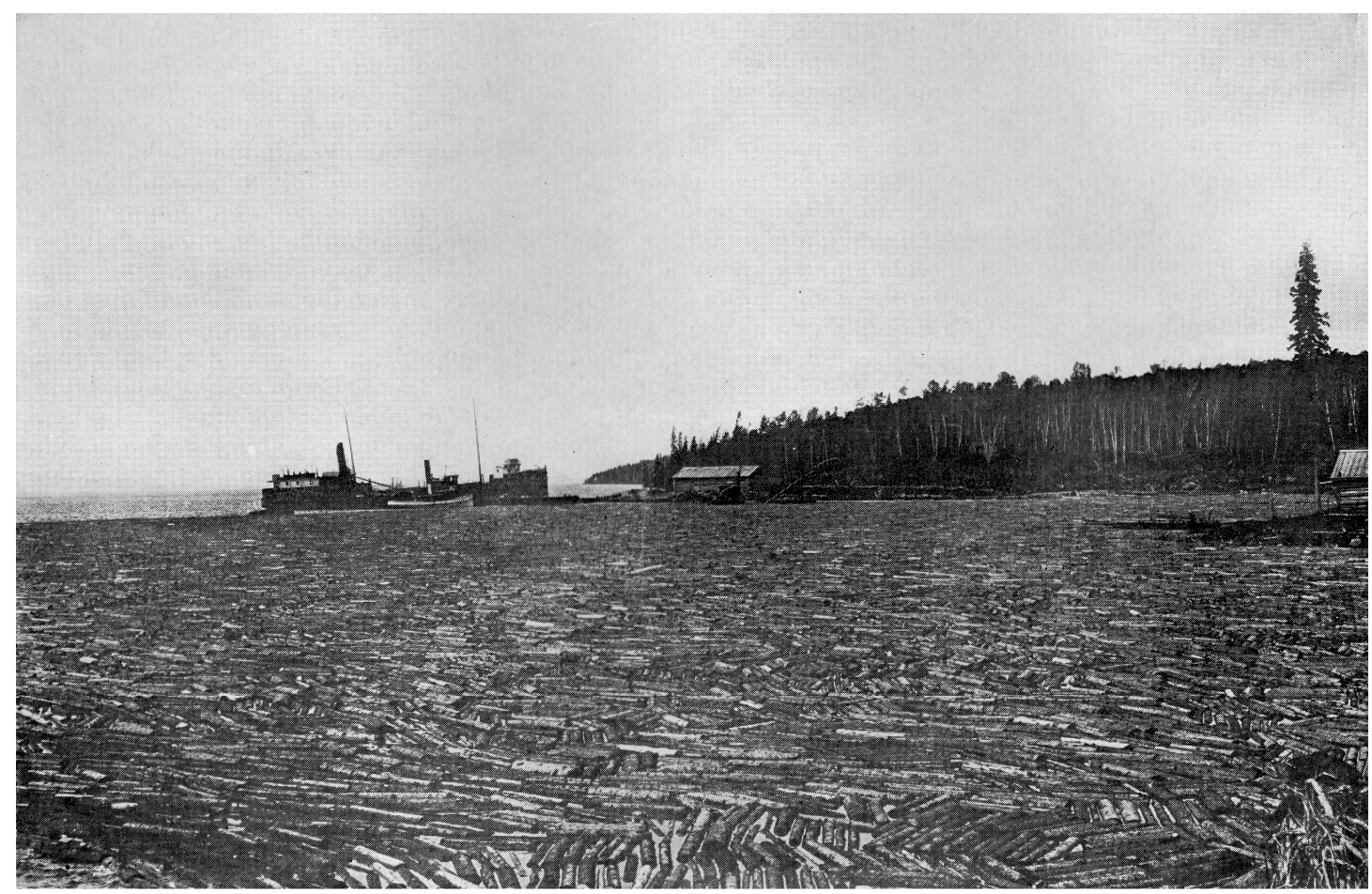

4.13 A Towed Log Raft on Lake Michigan (Curwood 1909) 


\title{
CHAPTER 5
}

\section{ARCHAEOLOGICAL INVESTIGATIONS AT THUNDER BAY NATIONAL MARINE SANCTUARY AND UNDERWATER PRESERVE}

\begin{abstract}
All known or presumed archaeological materials in Thunder Bay are individually listed in Appendix 1.
\end{abstract}

Previous Archaeological work at and around Thunder Bay National Marine Sanctuary

1972 Inventory of Shipwrecks in Michigan Waters

In 1972, the Michigan Department of Natural Resources, Office of Planning Services, funded a study to determine concentrations of shipwrecks in Michigan waters (Wright 1980). The study endeavored to assist in identifying areas with the greatest number of coastal shipwrecks. This was the first investigation of spatial clustering of shipwrecks in the Great Lakes.

References to approximately 6000 shipwrecks were scanned from primarily Detroit and Chicago newspapers. A list of 2166 shipwrecks was extracted as potentially lying in Michigan waters. Wright notes that there were few data for shipwrecks from 1800 to 1850 , and the study ignored vessels under 50 feet in length. Of the 2166 listed shipwrecks, 1316 were determined to very likely rest on the bottom in Michigan's Great Lakes waters, 418 of them in Lake Huron. Most of these shipwrecks were sailing vessels, followed by propellers, and lastly other 
mechanically-propelled vessels. Off the coast of Iosco, Alcona, Alpena, and Presque Isle Counties, the study predicted that there are 56 propellers, two side-wheel steamboats, two steam yachts, 13 tugs, 85 schooners, three scows, nine barges, two dredges, two fish tugs, five brigs, five barks, and one sloop. These numbers are further categorized by loss type.

1975 Thunder Bay Shipwreck Survey

Between 15 and 29 June 1975, The Recreation Research and Planning Unit of Michigan State University conducted a survey off the coast of Alpena County, Michigan in order to provide information on local shipwrecks and to propose recommendations for potential protective reserve boundaries (Warner and Holocek 1975). Data collected included shipwreck location, general site condition, and recreational diving condition and potential. Twenty-six shipwrecks were identified and 17 mapped and photographed. Information provided on shipwreck condition is referential and not suitable for scientific analysis. Additionally, locational information is incorrect for most shipwrecks. The survey also mapped the limestone ridge that runs along the southwestern edge of Thunder Bay Island at a depth of 20 to 60 feet. Wreckage debris was observed along the base of the ridge. The authors postulate that it derived from vessels that struck the ridge.

2001 University of Minnesota Multibeam Survey 
In summer 2001, archaeologists from the University of Minnesota conducted a multibeam survey over nine well-known shipwrecks in and around Thunder Bay including the Carbide Barge, E. B. Allen, William P. Thew, Grecian, Montana, Oscar T. Flint, Shamrock, Lucinda van Valkenburg, and William Rend. The sonar data set was processed with CARIS and images produced with SURFER. During the survey, the sonar transducer head impacted the William Rend resulting in poor imagery (Wayne Lusardi, personal communication 2010).

2001 Side-scan Sonar Deep Water Survey

In June 2001, the Institute for Exploration conducted deep-water (i.e. greater than 15 meters depth) in and just north of Thunder Bay National Marine Sanctuary (Coleman 2002). The goal of the project was to produce base-line archaeological reconnaissance data in advance of potential intensive investigations. The survey utilized a custom-built duel-frequency $(400 \mathrm{kHz}$ and $100 \mathrm{kHz})$ deep-towed CHIRP side-scan sonar built by Woods Hole Marine Systems, Inc. for the Institute for Exploration. In addition to side-scan sonar, the towfish carried an acoustic transponder, pressure transducer, altimeter, and pitch/roll/heading sensor. Incoming data were recorded with Triton-Elics International, Inc.'s ISIS software.

Over 250 square kilometers of the lake floor were acoustically mapped within Thunder Bay National Marine Sanctuary and nearly 100 additional square kilometers were mapped just north of the sanctuary (Figure 5.1). Seventeen shipwrecks were identified including two previously unknown vessels. Several other sonar targets were 
tentatively identified as cultural in origin. Additionally, scour marks in the lake floor were identified within the side-scan sonar mosaic. It was proposed that these were the result of historic salvage attempts of valuable shipwrecks and their cargoes.

2002 Remotely Operated Vehicle (ROV) Deep Water Survey

In August and September 2002, the Institute for Exploration conducted ROV visual reconnaissance survey of shipwreck targets identified during the 2001 deepwater side-scan sonar survey (Coleman 2003). The ROV used was the open-frame unit Little Hercules, developed by the Institute for Exploration. Several hours of reference video of the shipwrecks were produced as part of this survey project.

2004 Archaeological Investigation of the Shamrock

In Summer 2004, members of the National Marine Sanctuaries Maritime Heritage Program recorded the remains of the steambarge Shamrock. This project resulted in a site plan of the exposed section of the shipwreck.

2004 Archaeological Investigation of the Monohansett

In June 2004, the Maritime Studies Program at East Carolina University conducted a Phase II pre-disturbance survey of the wooden steamer Monohansett to provide baseline data for site management and monitoring (Dappert 2006). Previous 
investigations of the shipwreck include a 2001 preliminary site identification report by the State of Michigan and 2003 side-scan sonar site survey by Thunder Bay National Marine Sanctuary. The 2004 survey plotted the site location and produced a scaled drawing of the shipwreck. Photographic and visual assessment of vessel integrity was conducted.

2005 Investigation of the Middle Island Life-Saving Station

In July 2005, the state of Michigan Office of the State Archaeologist and the PAST Foundation partnered on the documentation of the structural remains and surface artifacts of the Middle Island Life-Saving Station. Project objectives included creating a detailed site map, architectural drawings of the extant structures, excavation of the privy, cistern, and trash midden, and test excavation units to determine the extents of the site (http://www.pastfoundation.org/MiddleIsland/Objectives.htm).

2005 Deep Water Shipwreck Survey

In August 2005, Thunder Bay National Marine Sanctuary created high-resolution photomosaics of two deep-water shipwreck sites, the Pewabic and an unidentified schooner. The latter is known as Target \#7 in the Institute for Exploration 2001 sidescan sonar survey. Target \#7 is likely the remains of the Corsican, lost by collision in 1893. 
2005 North Point Survey

Between 8 and 28 September 2005, The Maritime Studies Program at East Carolina University and Thunder Bay National Marine Sanctuary conducted a Phase I and Phase II archaeological survey of North Point Reef (Pecoraro 2007). The primary objective of the survey was to assess previously recorded archaeological sites to determine if one of them was the remains of Congress, and to photograph and map each site. Either a scale drawing or a sketch map and a written summary were prepared for each site.

In total, the survey located the remains of 55 individual shipwreck sites, isolated finds, and historic debris over an area of 1.5 x 0.5 linear miles (Figure 5.2). Consolidation of related sites reduced the total number of unique sites to 32 , with approximately 12 individual vessels. Nineteen were sections of associated wrecks, and 13 were isolated finds. Only six of the 32 sites were correlated to specific vessels and wrecking events. Vessel components and isolated finds were assessed for material composition, weight, and size to determine likelihood for mobility and spatial distribution. Key determinants for mobility were presence of iron and accumulation of sediment on the site. The 32 sites are incorporated into the current Thunder Bay Shipwreck Database.

2006 Bathymetric LiDAR Survey 
In 2006, the NOAA National Geodetic Survey, Remote Sensing Division conducted Light Detection and Ranging (LiDAR) and aerial photogrammetric surveys of the Thunder Bay National Marine Sanctuary and surrounding coastline. Several shallow-water shipwreck site locations were confirmed (Thunder Bay National Marine Sanctuary 2006).

2006 Investigation of the New Orleans

In August 2006, members of the National Marine Sanctuaries Maritime Heritage Program recorded the remains of the steamer New Orleans. This project resulted in a site plan of the exposed section of the shipwreck.

2007 Archaeological Investigation of the Joseph S. Fay

In June 2007, the PAST Foundation administered the Michigan Environmental Education Summer Camp for high school students in conjunction with the Michigan Office of the State Archaeologist and the National Marine Sanctuaries Maritime Heritage Program (http://www.pastfoundation.org/2007MichiganEnvironmentalEducation/SitePlan01.ht $\mathrm{m})$. This project documented the terrestrial and submerged remains of the shipwreck of the Joseph S. Fay. Photographic documentation and scale drawings of the site components were produced. 
2007 Archaeological Reconnaissance Survey

During the summer of 2007, archaeologists and students from the National Marine Sanctuaries Program, Yale University, the University of West Florida, East Carolina University, and the University of Georgia conducted archaeological investigations on several shipwreck sites within Thunder Bay National Marine Sanctuary (http://thunderbay.noaa.gov/research). Photographic documentation and scaled drawings were produced for each site. Investigated shipwrecks include: Oscar T. Flint and John F. Warner. Additionally, reconnaissance dives were conducted on the sites of the shipwrecks of the F. T. Barney, Florida, Lucinda van Valkenburg, and William H. Stevens.

2007 Aerial Coastal Photogrammetry Survey

In May 2007, Thunder Bay National Marine Sanctuary conduced an aerial coastal bathymetric photogrammetry survey using NOAA's remote sensing Cessna Citation II aircraft. Aerial film cameras were used to detect submerged shipwrecks (http://thunderbay.noaa.gov/research/fn_may07/fn_aerial.html).

2008 Experimental Autonomous Underwater Vehicle (AUV) Survey

During the summer of 2008 the University of Michigan Perceptual Robotics Laboratory deployed an Iver2 AUV with side-scan sonar to test the feasibility of 
extremely shallow (i.e. less than five feet) and deep-water archaeological mapping in Thunder Bay National Marine Sanctuary with this technological system. A shipwreck in 180 feet of water was surveyed.

The University of Rhode Island Archaeological Investigations (2005-2008) in and around Thunder Bay National Marine Sanctuary

2005 University of Rhode Island Pedestrian Survey

Systematic pedestrian shore surveys on selected beaches bordering sanctuary waters were conducted. The area chosen for this survey was along the tip of North Point Peninsula, a remote, privately owned rural expanse of land with thick-forested growth bordering the beaches. This land is primarily used for intermittent hunting trips with little visitation to the survey area. It was confirmed that practically all of the wood that the owner had collected from the beaches was true driftwood and did not derive from shipwreck debris.

The walkable shoreline at the time of survey and the timberline of the beach formed the boundaries of the survey area and were recorded with GPS. The total area surveyed was approximately 0.15 square kilometers along the eastern shore of North Point and 4100 square meters along its northeastern tip (Figure 5.3). Surveyors attempted to follow the contours of the beach so as to maintain a consistent coverage of about thirty percent. Artifacts encountered include: whole and fragmented ship timbers, iron ship fasteners, and coal scatters, as well as modern wooden structural 
debris. All artifacts and scatters were mapped using a GPS, capable at best of onemeter resolution, and a digital camera. In total, 130 artifacts and three artifact scatters were identified.

University of Rhode Island Shallow Water Side-Scan Sonar Survey

$\underline{2005}$

In June of 2005, directed by Rod Mather, the University of Rhode Island, conducted a systematic Phase I remote sensing survey of the North Point Reef section of the sanctuary. This region of the bay is relatively shallow with water depths of 0.6 to 0.9 meters in some areas. It was chosen as a survey area because historical sources suggest high cultural resource concentrations. Survey lines intentionally overlapped to make sure no areas of the lakebed were missed and to mitigate any small navigational errors arising from difficulty in controlling the boat at the low speeds required for the survey. The survey was controlled using a differential global positioning system (DGPS) and a suite of computer software for data acquisition, post-processing, and hydrographic survey including HYPACK, SonarWiz, and CARIS.

The side-scan sonar towfish used in this survey was a modified Edgetech 272 system with signal frequency centered at $500 \mathrm{kHz}$. It was designed as an analog system but used with a digital converter to produce digital output. When possible, the towfish was flown at an altitude of ten percent of the swath width to obtain highly detailed images of shipwreck debris and other submerged cultural resources. The 
system is rated to a maximum depth of 200 meters; however, most of the survey area was less than thirty meters deep.

Though this system worked well for the purposes of this research, it did pose a few problems for data interpretation. First, the sonar data were recorded on highfrequency bandwidth $(500 \mathrm{kHz})$ and low-frequency bandwidth $(100 \mathrm{kHz})$ though

identified targets of possible interest were only seen in the high frequency range. The bathymetry of the area posed problems as well, since the depth of the lake floor changed rapidly across and along the survey lines. This required the towfish to be raised and lowered as the survey progressed to try to maintain a constant altitude. Also, because at times the towfish was necessarily close to the surface in shallow water without benefit of a depressor weight, it is likely that small movements of the ship altered its trajectory somewhat over the course of the survey lines. Upon completion of the side-scan sonar survey, the raw data were post-processed and mosaics of the acoustic images were created.

After survey lines were completed, several targets noted during the survey as being potentially significant archaeological remains were ground-truthed by University of Rhode Island and sanctuary staff divers. Photographs were taken of each diver-observed target.

The Phase-I side-scan sonar survey was continued in August 2006, focusing around North Point, following the procedure and using equipment and software 
established for the 2005 survey. Similar conditions and constraints prevailed during data acquisition. Coverage of data gaps evident in the 2005 survey was completed. In addition to archaeological debris, the 2006 survey identified two previously unknown wrecks within the study area (Figures 5.4 and 5.5). Because the arrangement of the sonar equipment was highly sensitive to sea state, on 14 and 17 June, days of poor weather and heavy seas past the mouth of the bay, survey was conducted within Thunder Bay in the vicinity of South Point.

After survey lines were completed, several targets noted during the survey as being potentially significant archaeological remains were ground-truthed by University of Rhode Island and sanctuary staff divers. Photographs were taken of each diver-observed target. Additionally, video footage was collected from a selection of these targets.

$\underline{2007}$

On 29 and 30 August 2007, side-scan sonar survey was conducted within Thunder Bay along South Point and to its east. Sea state past the mouth of the bay prevented further survey along the eastern shore of North Point Peninsula. The survey procedure used followed that of 2005 and 2006, however, a Klein 3000 towfish system with signal frequency centered at $500 \mathrm{kHz}$ was used. The Klein 3000 towfish system can be towed at faster speeds than the Edgetech 272 system allowing for better control of direction and speed of the boat. The undulating bathymetry of the lakefloor posed the same difficulties with the Klein 3000 system as with the Edgetech 272 system. 
Additionally, the lack of depressor weight may have affected the trajectory of the towfish in a similar manner as the previous system.

In August 2008, the University of Rhode Island and Thunder Bay National Marine Sanctuary partnered with the crew of the $R / V$ Laurentian to conduct side-scan sonar survey along the historic shipping corridor between Middle Island and Presque Isle, and between Presque Isle and Rogers City, to the northeast of Thunder Bay. The sanctuary's Klein 3000 side-scan sonar system was deployed from the stern winch, using a coupled pulley-rigged system, directly behind the ship. The 80-foot, steelhulled Laurentian was capable of consistently maintaining the 5-knot speed required for optimal use of the Klein 3000 system. Layback was determined using an analog cable-out counter. Additionally, because the Laurentian could host a large scientific party, data acquisition occurred 24 hours per day. Survey lines intentionally overlapped to ensure full coverage of the survey area. The survey was controlled using a DGPS and HYPACK, SonarWiz, and CARIS for data acquisition and postprocessing.

Because this survey area is deeper and the bathymetry less undulating than the shoal areas around North Point, and because altering cable-out was mechanized, maintenance of a constant altitude of approximately ten percent of the swath width was not as difficult as in previous surveys. Interruption of survey did occur in the 
southwest corner of the survey area near Middle Island in order to avoid deployed tribal fishing nets whose buoys could be seen on the surface.

\section{$\underline{\text { Survey Coverage }}$}

Eight general areas were surveyed as a part of the 2005-2008 University of Rhode Island Side-Scan Survey Project (Figure 5.6a and 5.6b). From northeast to southwest they are as follows: 33 square kilometers along the historic shipping route between Rogers City, Michigan, and Presque Isle, Michigan; 196 square kilometers along the historic shipping route between Presque Isle, Michigan, and Middle Island; 14.5 square kilometers east and the shoals surrounding Thunder Bay and Sugar Islands; 14 square kilometers between the shoals east of North Point and the shoals to the south and west of Thunder Bay and Sugar Islands; three square kilometers along the shoals southwest of North Point; seven square kilometers across the mouth of Thunder Bay; 4.5 square kilometer along the axis of Thunder Bay; two square kilometers northeast of the shoals surrounding Partridge Point and Sulphur Island; and 3.5 square kilometers along the shoals north of Scarecrow Island. All measurements are approximate. In this description, shoal areas are those defined as bathymetrically hazardous according to current Federal nautical charts. In total, approximately 278 square kilometers of lake floor were surveyed and 919 targets were identified (Figure $5.7 \mathrm{a}$ and $5.7 \mathrm{~b})$. 


\section{$\underline{\text { Survey Quality Assessment }}$}

The quality of the side-scan sonar data varied according to the sonar equipment, towing vessel and apparatus used, and equipment handling. Data were also variably impacted by the characteristics of the sea state, bathymetry, and temperature variations within the water column. System-user issues present include heave-induced images "stretching", the presence of propwash in the image, and inconsistent image size due to the inability to control sonar altitude (primarily an issue during the 2008 survey). Sensor issues include occasional navigation loss (these files were discarded resulting in data gaps), and positioning error that rendered the spatial resolution of the 20052007 surveys to approximately one meter. The primary environmental issue was the presence of a strong summer thermocline.

Variations between the survey areas indicate that the ability with which it is possible to identify targets with confidence is variable. This was taken into account when identifying the presence of archaeological materials, their associated formation processes, and the human activities by which they were formed. However, though variations in survey quality to exist for the survey areas, these variations appear to be negligible and survey results are sufficient to begin to analyze the submerged archaeological record and subsequently use these data to inform a new maritime archaeological landscape formation model. 
Figures

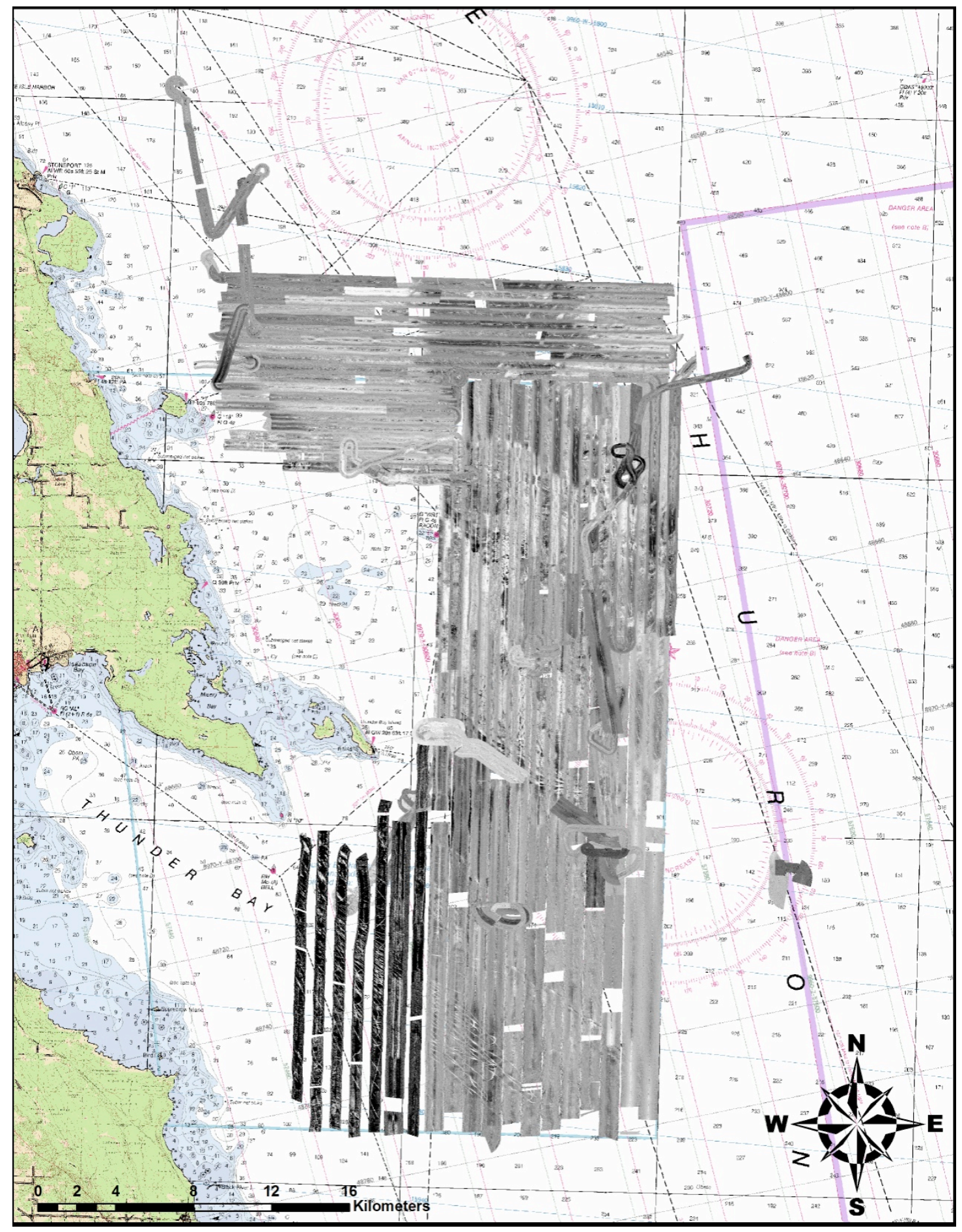

5.1 The Institute for Exploration 2001 Systematic Side-scan Sonar Survey 


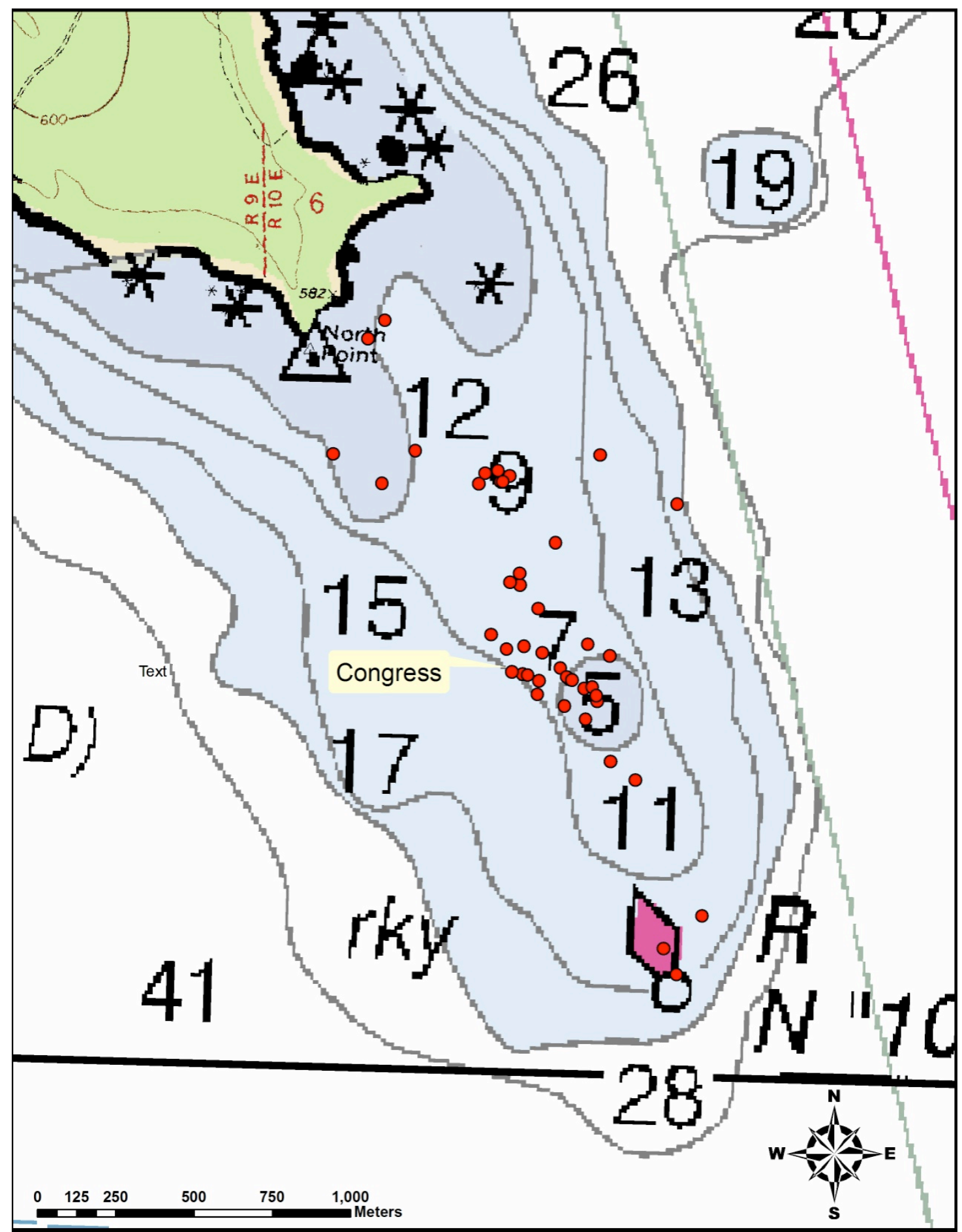

5.2 2005 East Carolina Survey Targets 


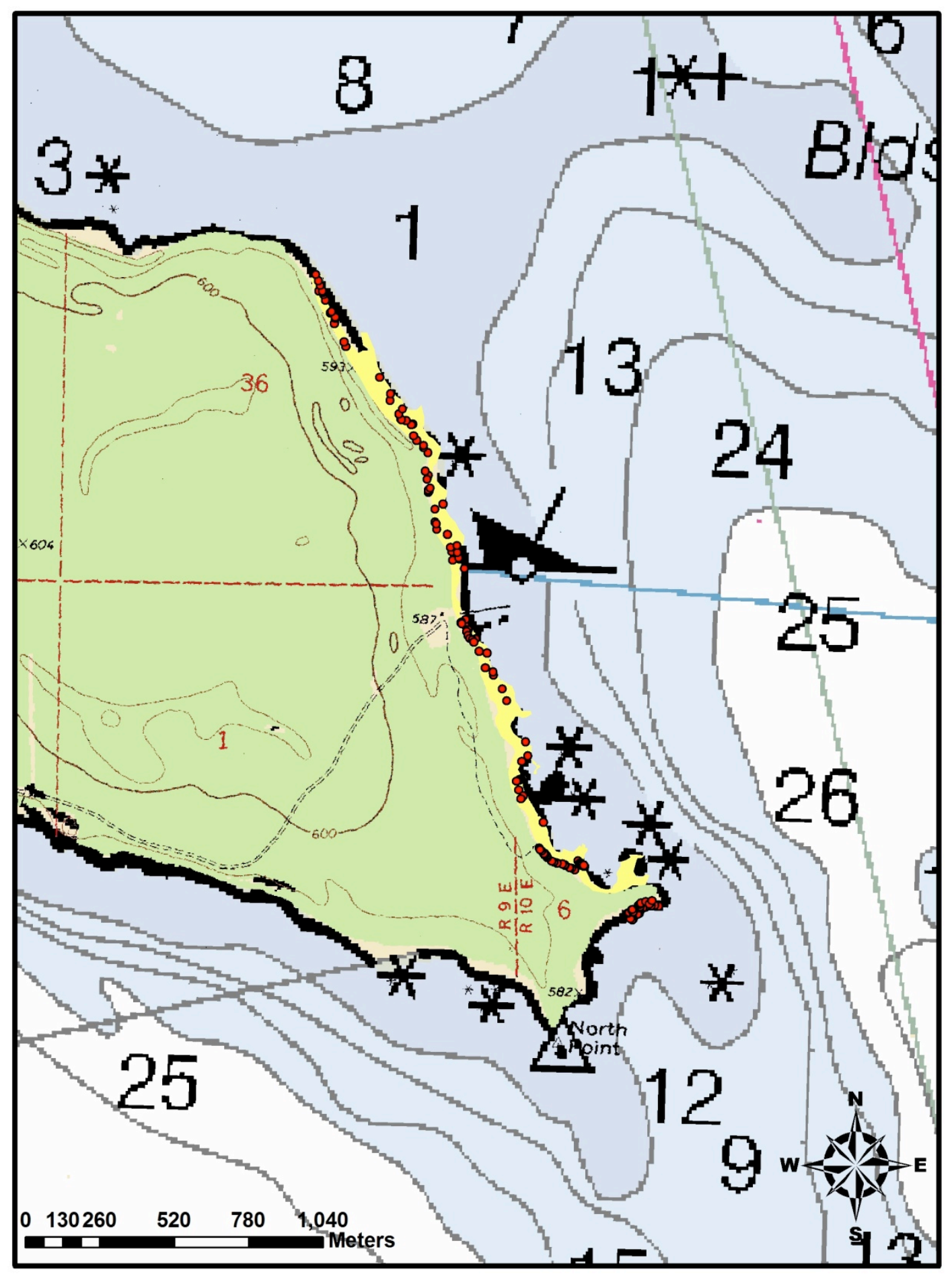

5.3 2005 University of Rhode Island Pedestrian Survey and Targets 


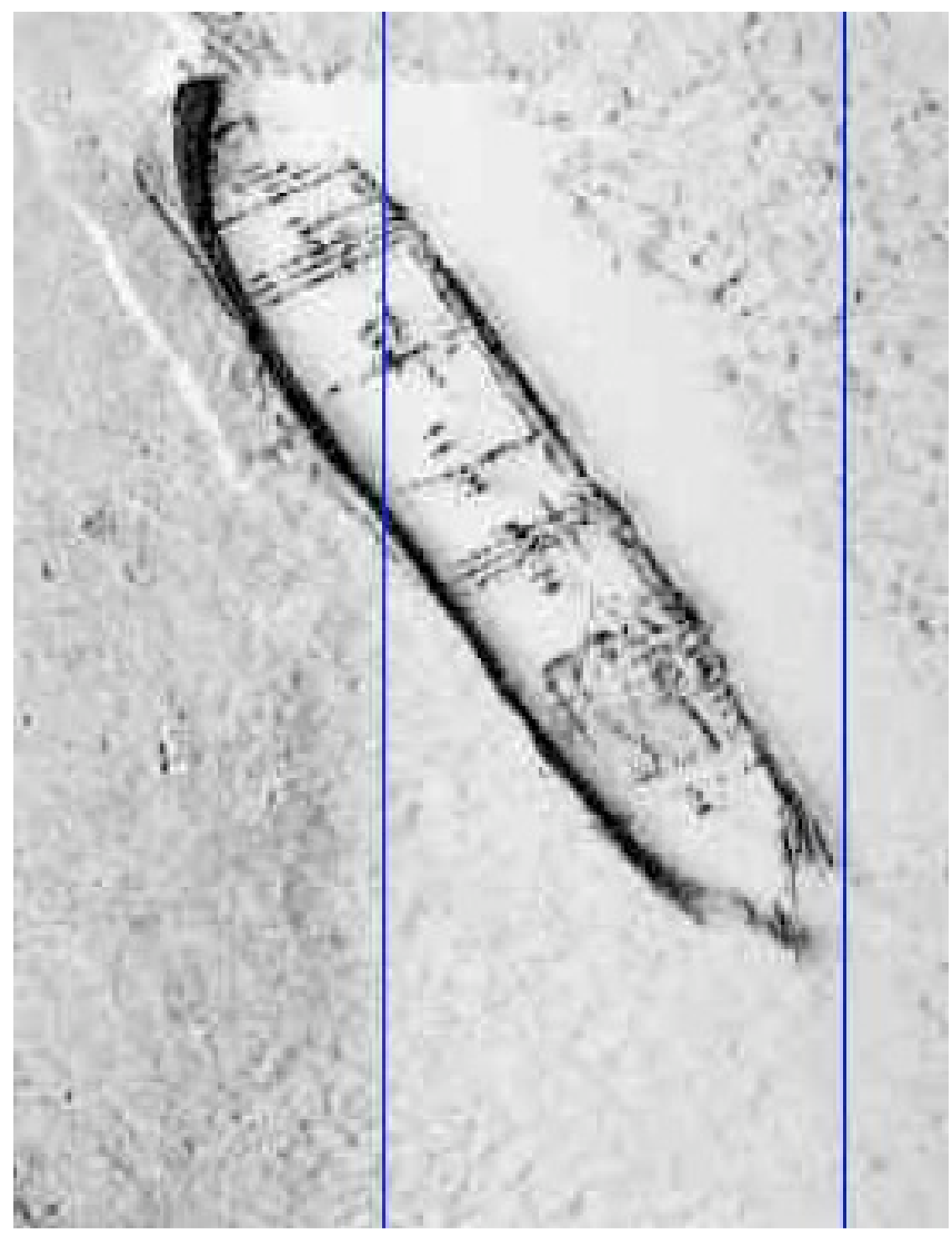

5.4 Side-scan Sonar Image of the D. M. Wilson 


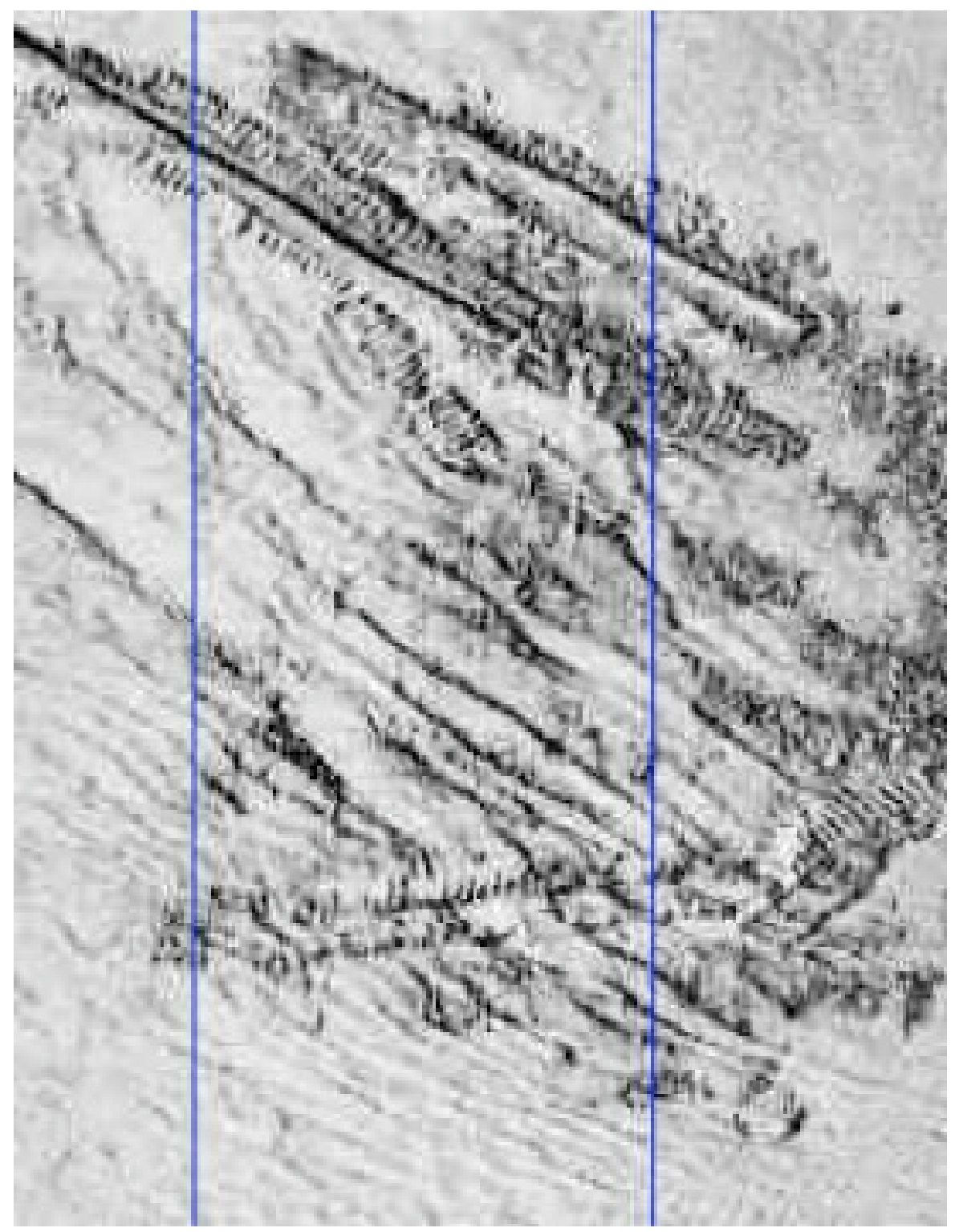

5.5 Side-scan Sonar Image of the O.E. Parks 


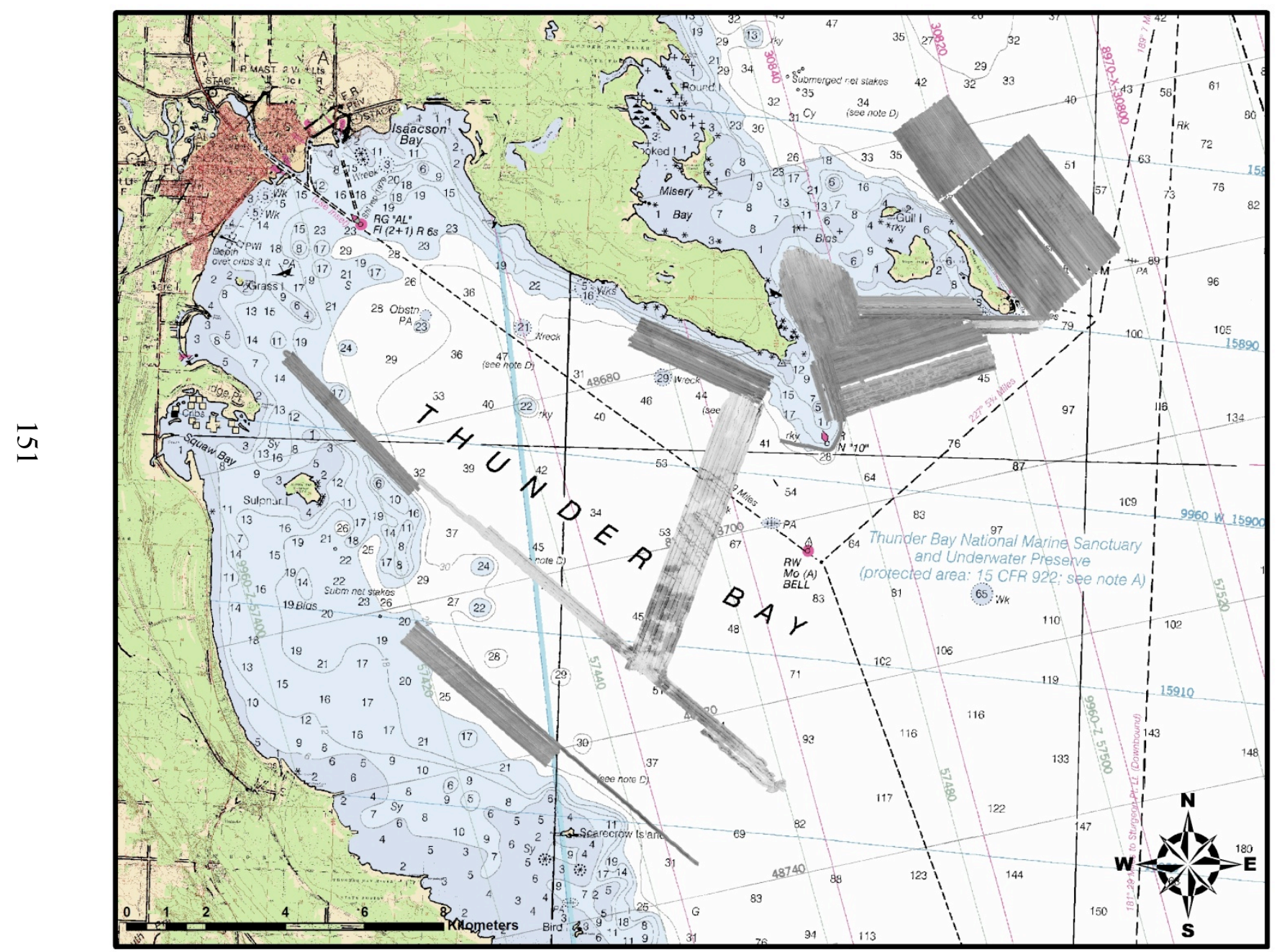

5.6a 2005-2007 Side-scan Sonar Survey Coverage 


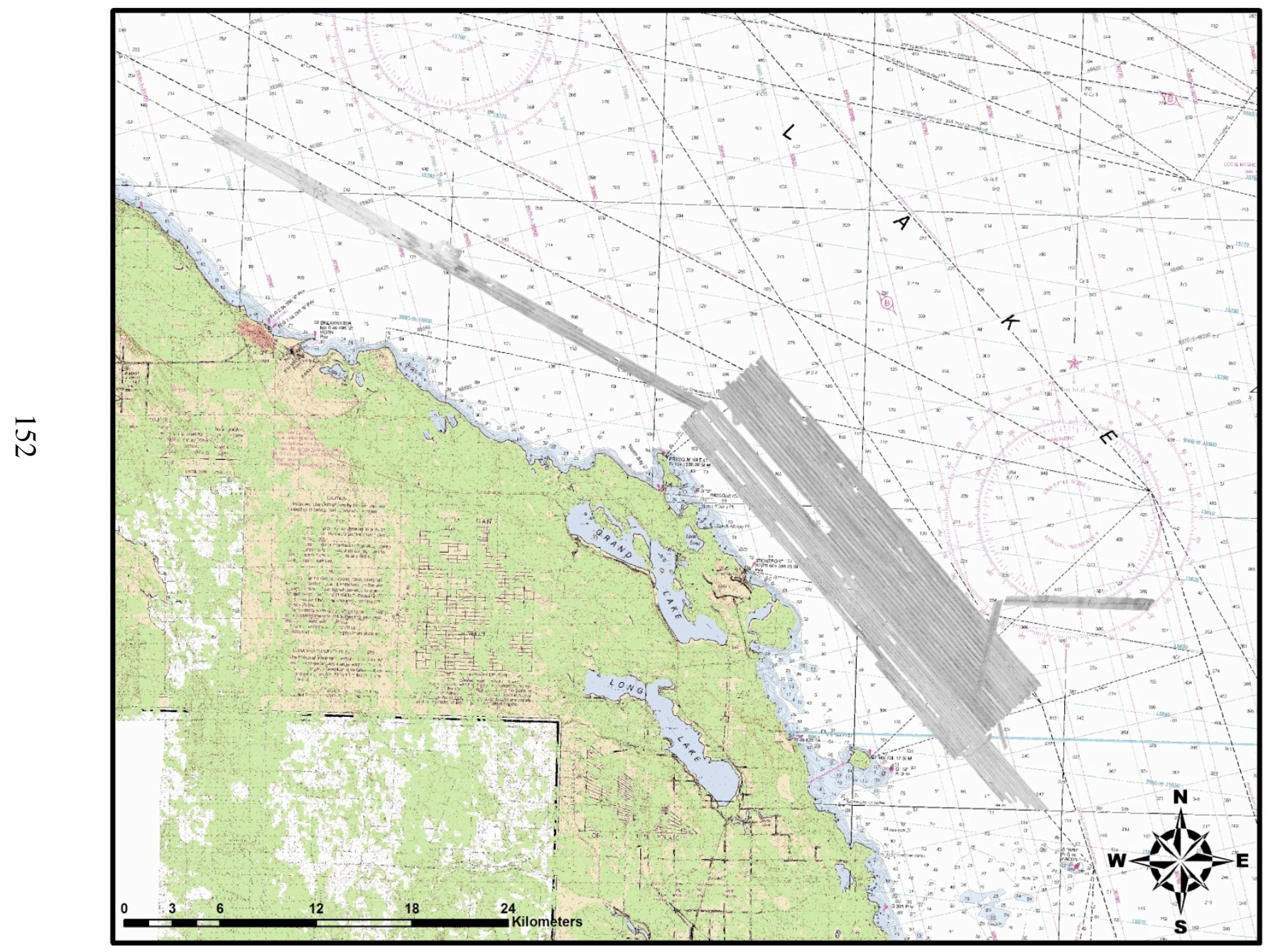

5.6b 2008 Side-scan Sonar Survey Coverage 


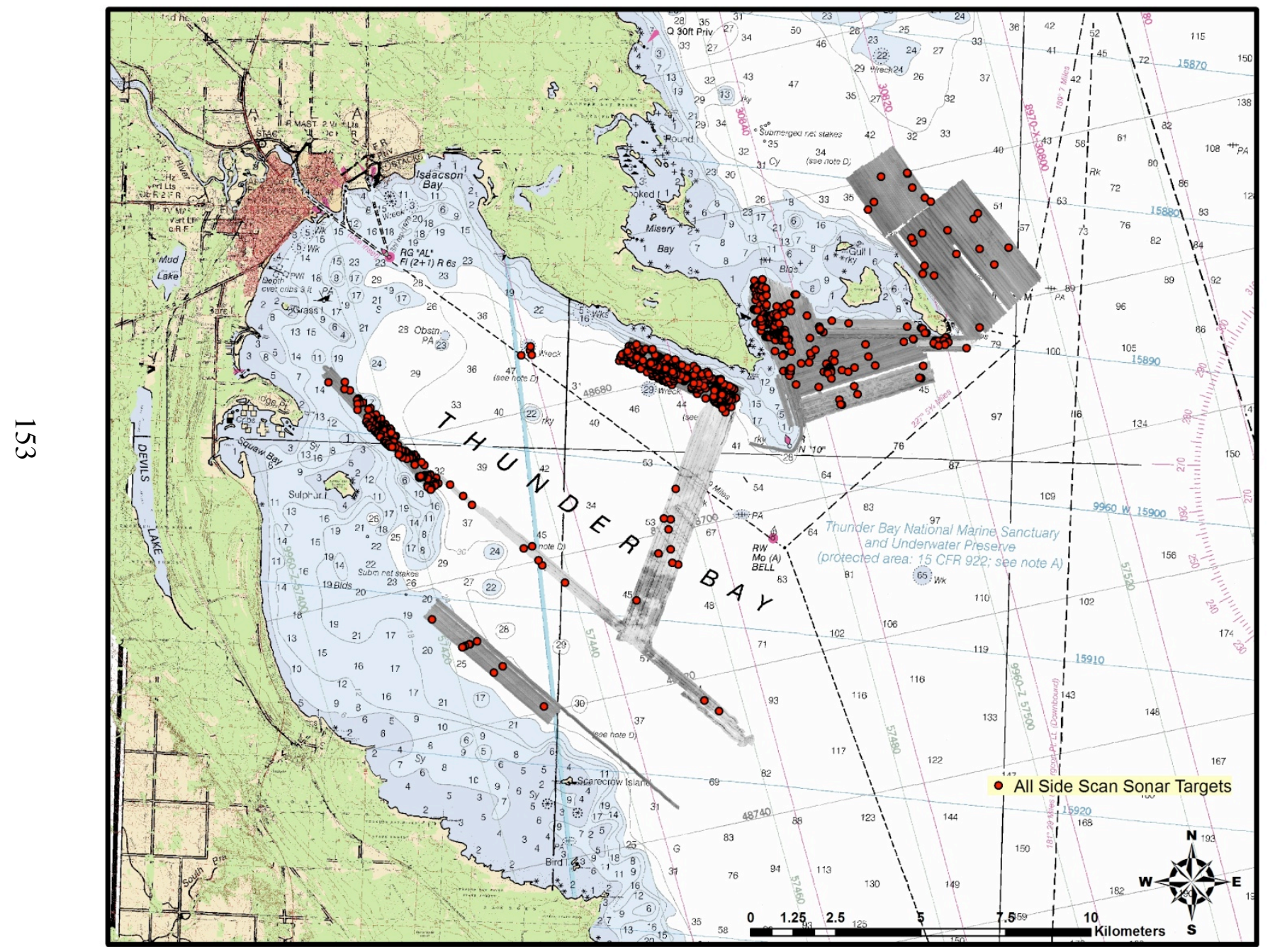

5.7a 2005-2007 Side-scan Sonar Targets 


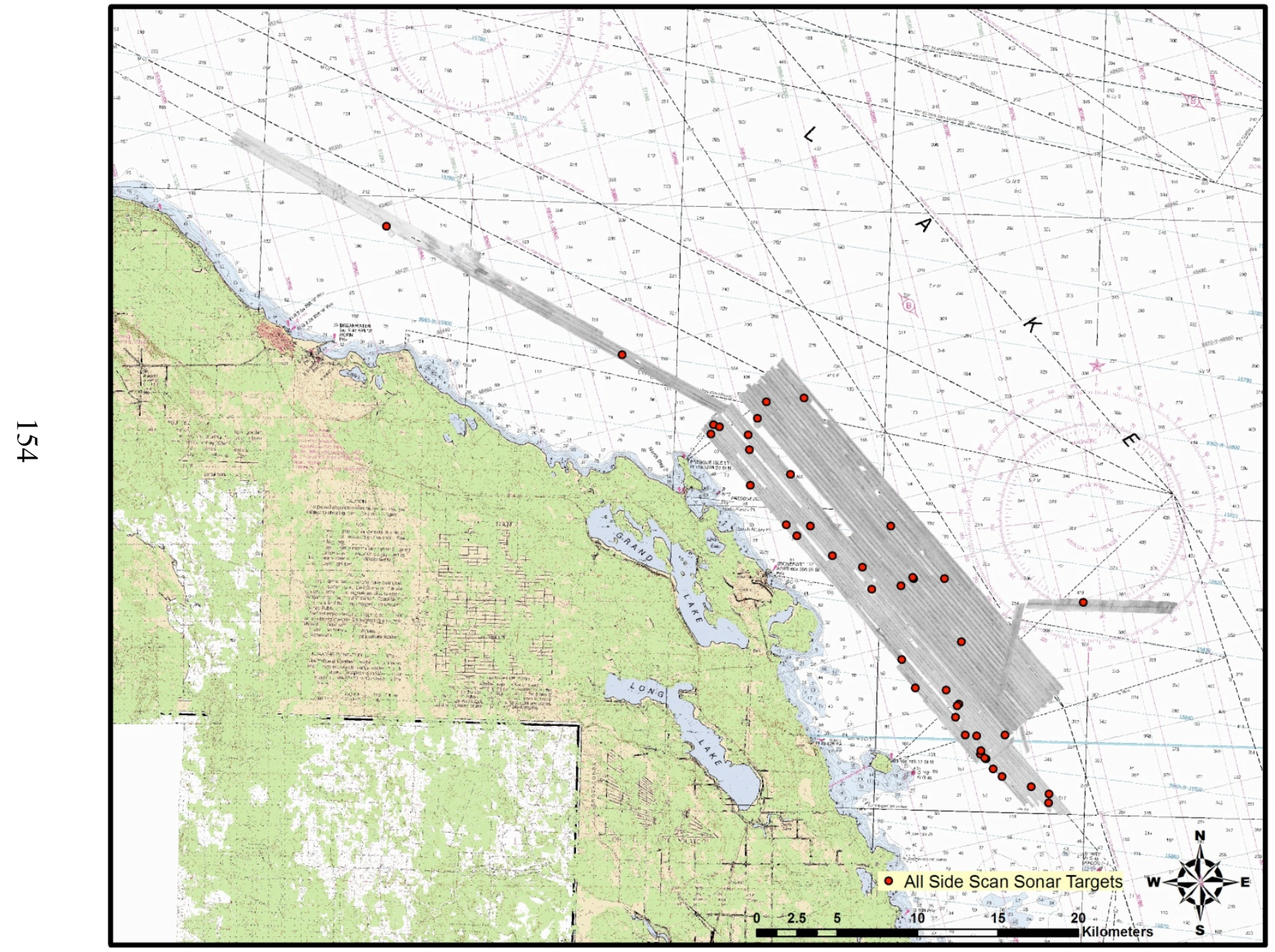

5.7b 2008 Side-scan Sonar Targets 


\section{CHAPTER 6}

\section{A NEW MARITIME ARCHAEOLOGICAL LANDSCAPE FORMATION MODEL}

Formation processes of the archaeological record have been a concern of terrestrial archaeologists for much of the second half of the twentieth century, and constitute one of the tenets of the New Archaeology paradigm developed in the 1960s (see Binford 1983). Hypotheses about formation processes were developed in the late 1960s-1970s through the application of the concept of entropy to archaeological sites; i.e., that potential site-derived information degrades over time. During the 1970s, the idea of transformation processes recognized that there is discontinuity between human activities, artifact deposition, and preservation and archaeological recovery or the creation of sampling bias. Recent work has shown that formation processes:

transforms, sites, and regions formally, spatially, quantitatively, and relationally, can create distortion and artifact patterns unrelated to past human behaviors, but exhibit regularities that can be studied and expressed statistically (Schiffer 1987: 9-11).

Work in model development for the understanding of shipwreck formation processes has lagged its terrestrial counterpart, but has continued to slowly evolve since Muckelroy first proposed his "evolution of a shipwreck" in 1978. All discourse on shipwreck formation processes understand that the environment and other natural factors contribute to the creation and, to some degree, modification of the archaeological record. Formation theory provides structure for applying information that is derived from the site (O’Shea 2002: 10). Gould (1983a: 18) points out that many maritime and nautical archaeologists state that they implicitly include all the 
steps of "archaeological reasoning" in their research, including site formation, but that there is a need to be explicit in how the rules of science are applied to explanations of past human behavior. This "implicit" inclusion leads to inconsistent application of environmental factors in research and contributes to "the illusion of site uniqueness" (O'Shea 2002: 3). Though recent research on specific shipwreck sites has at times been able to pinpoint specific natural events that have contributed to the wrecking of individual vessels or groups of vessels, scientists are just beginning to understand how the environment affects submerged cultural materials and vice-versa (see Jordan 2003; Forsythe et al. 2000; among others). At both the local and regional levels, this is necessary "to develop a reasonable perspective in the rational utilization of the [archaeological] resource base" (Murphy 1983: 80-81).

Even the latest models of site formation processes, those that include the oceanographic or limnological aspects of the formation process, fail to provide a thorough understanding of archaeological formation and preservation when one considers a maritime landscape. They oversimplify or ignore the movement of archaeological materials. This is not to say that this problem has yet to be addressed. Regional studies of shipwrecked materials, which take into account environmental factors, have been carried out both in the United States and abroad (for example Wheeler 2002; O’Shea 2002, 2004). These studies, however, do not explicitly delineate a model that that can be applied generally to most or all maritime landscapes. They also only lightly touch upon the probability that environmental regimes may have quite specific preservation potentials which carries with it regional archaeological management significance (Wheeler 2002: 1151). 
The proposed model attempts to ameliorate this deficiency by starting with the marine landscape and its environment so as to take into account all of the archaeological materials contained within it. Included in the model are three levels or stages of analysis: that a vessel will wreck in a given location; that wreck material will arrive at a given location; and that wreck material will survive at a given location.

\section{Site Formation Modeling History}

To fully understand the proposed landscape formation model, it is necessary to derive its evolution through previous modeling attempts. Muckelroy was the first to explicitly put forth that shipwreck phenomena contain common features. This implies that when evidence can be ascertained and tested on sites where historical evidence is present, it can also be applied where historical evidence is lacking. Therefore, archaeological evidence is inherently homogenous with at least some degree of cohesion and the assemblage can be approached as a system defined by the characteristics of a ship which may have gone through a series of transformations through time (1978: 157-159). Muckelroy's shipwreck evolution model (Figure 6.1) interprets the site formation process as a closed system with only the ship as an input. There are extractive (salvage, disintegration, dissolution, etc.) and scrambling devices, which include the wrecking process itself and seabed movement.

Based on review of studies that attempt to measure the quality of archaeological remains through parallel biological and geomorphological marine studies, Muckelroy (1978) characterizes what he considers to be relative environmental attributes that 
contribute to material extraction and scrambling. He determined that the geomorphology or nature of the sea-bed deposit is the most important control for determining site scrambling and cohesion (survival) of archaeological remains underwater. The most deterministic forcing factors are: maximum offshore fetch, sea horizon or open water, average slope of the sea bed, recent underwater topography, and coarse versus fine sediment as deposit matrix. Less relevant attributes are tidal stream speed and depth of site.

Muckelroy's attempt to classify well-known shipwreck sites according to cohesion, presence, and amount of extant archaeological material with the dominant factors listed above is descriptive and not causal. He states that these factors cannot predict the likelihood that remains will be found in a location known to have been a wrecking site, that it does not address variability between sites of similar geomorphology, and that it looks at the wrecking process as a single event (1978: $165)$.

This formation model is rather simplistic, as it does not consider inputs that are themselves defined in the present as archaeological such as floral and faunal attraction to the site (as habitat) or post-"shipwreck" anthropogenic input such as salvage process debris, memento deposition, net snags, etc. It also does not allow for extraction due to non-"floating away at time of wrecking" means. There are other extracting filters besides salvage and disintegration once the site has reached “stabilization" such as storm surges, currents, waves, ice movement, etc., especially in lacustrine environments. 
While in general there is little cause to dispute Muckelroy's deterministic factors affecting material extraction and site scrambling, it is erroneous to believe that they can neither predict the probability that archaeological remains will be found in a given location, nor that they can address site variability. The probability that remains might be found in a given location is inherent in Muckelroy's process of wrecking if the deterministic factors are taken into account. Both site location and intersite variability can be addressed if the model is expanded to include the material once it has been extracted from the primary archaeological site, or in other words, if archaeological material is recognized to remain a tangible part of the landscape. In addition, O'Shea (2002: 8) notes that the use of "scrambling device" as a term for material movement implies a randomization or pattern diminishing effect (entropy), which is inaccurate.

Nearly a decade after Muckelroy proposed his site formation model; Schiffer (1987) more precisely defined how to characterize site transformation processes by dividing them into two categories, cultural and natural, termed in turn c-transforms and n-transforms, and breaking down process effect components to three levels: the artifact, the site, and the region. While Schiffer was considering terrestrial archaeological deposits and does not appear to intend the work to be considered a model per se, it can be used to define both physical and spatial inputs into an underwater formation process model. Most importantly, it is understood that sites are open systems and, therefore, one should include inputs other than the initial deposit and materials once they have left the immediate site area (1987: 151).

C-transforms are defined as the processes of human behavior that affect or transform artifacts after their initial period of use in a given activity and are 
responsible for retaining items in a systematic context to form the historic and archeological records as well as for any post-depositional modification. N-transforms are any natural (i.e. biological, chemical, geological, or physical) processes that effect archaeological deposits by deterioration, decay, alteration, or other modification and can add environmental material to the site. Unlike c-transforms, they are to some degree continuous. Resulting transformation/modification for both types of transforms are both regular causally and consequently making the processes and their effects predictable and thus able to be statistically modeled (Schiffer 1987: 7, 21-22, 143).

Schiffer (1987: 199) also shows how when approaching the archaeological record, c- and n-transforms can be invariably linked. Non-cultural processes will affect behavior that potentially causes c-transforms to occur. For example, environmental factors might keep sailors from venturing into certain places due to historically understood geological, physical, or other concerns (shoals, cross-currents, whales, etc.).

$\mathrm{N}$-transforms must also be taken into account when approaching an archaeological landscape. They can affect both site visibility and accessibility. They can also bias survey and sampling regimes, for example, sedimentary processes may variably expose or cover some or all of an archaeological site rendering its identification in a side-scan sonar survey dependent on the sedimentary conditions on the day that the survey takes place. Identifying formation processes in the archaeological record implies that they occurred. It is necessary; therefore, to be explicit as to their effects and without extensive analysis it may be impossible to 
separate the archaeological remains from them. This is especially true when one considers that there can be much variability in the effect of transforms (Schiffer 1987: 265-267, 302).

In any case, it is important to identify formation processes before behavioral and environmental inferences are made so they can be filtered from the anthropological phenomena of interest (Schiffer 1987: 303). Gould (1990: 21, 53-54) terms these as first-order and second-order variables. First-order variables are the constraints of the environment (n-transforms) as well as anthropological limitations, such as the state of technology at a given time. Second-order variables are the "human factor" or specific behaviors (c-transforms) that will aid in a better understanding within a culturalhistorical context (i.e., desired anthropological information). In other words, formation process controls must be ordered. The need for second-order variables defines Gould's “Operational Theory”, which assumes cultural uniformitarianism and a form of middle-range theory (contemporary and historical) to derive c-transforms that can be applied to and/or filtered from the archaeological remains $(1990: 49,55)$. Examples of operational theory are the "One More Voyage Hypothesis" (Murphy 1983) and "Technological Trend Innovation". The latter is the perpetual improvement, including increased complexity and cost, of a traditional industrial system that over time is rendered increasingly obsolete. At least one segment of the social hierarchy has a stake in the perpetual production of the system (Gould 1990: 170-189).

Ward et al.'s (1999: 561) processual site formation model was the first to incorporate dynamic natural transforms into the core of the model (Figure 6.2). It is 
predictive, process-oriented, and scale independent. Shipwreck degradation is characterized by the sum of direct and indirect affective environmental processes plotted against the local sediment budget (considered a first-order control) over depositional history (1999: 563). The environmental processes are physical or hydrodynamic, biological, and chemical. It is clear that most, if not all, of these processes are interrelated and cannot be considered apart from one another. This model is excellent for characterizing site formation processes within the context of an individual archaeological site.

The sediment budget is defined as the rate of net supply or removal of different types and sizes of sediment grains to the site area. Ward et al. (1999: 564-565) recognize the link between sediment budget and hydrodynamic forcing; however consider it separately because one does not assume the other bi-directionally. The sediment budget influences the extent of development of reduction-oxidation zones within the sediment. For many sites, it may be possible to examine sediment profiles to determine the history of the sediment budget.

The nature of the hydrodynamic environment is variable in time. Physical effects have greater impact in high-energy environments and biological and chemical effects have greater impact in low-energy environments. The site can transition to and from high-energy environments to low-energy environments and at any stage, material can be lost. There are an infinite number of different process paths a site could progress through to reach the "present" state (Ward et al. 1999: 565, 568).

Ward et al. (1999) approach the visual interpretation of the model as a revision of Muckelroy's (1978) flow chart. This flow chart adds the sediment budget and the 
hydrodynamic environment as inputs into the process of pre-stability site formation, therefore, the wrecking process is no longer a single unidirectional path towards site stability (1999: 564). Obviously, different site types degrade or are affected in dissimilar ways, but it is clear that these factors have a greater influence on the modification of the site than if one only considers the ambient "steady-state" environment (1999: 564). This equilibrium environmental characterization can be used to normalize the forcing factors when comparing sites and/or loci.

The most recent dynamic site formation model assumes Ward et al.'s (1999) natural transformational process, expanding it to include the range of cultural processes, before, during, and after a shipwreck and the long-term relationships between people and shipwreck sites (Gibbs 2006: 4-5). Gibbs (2006: 7) argues that cultural transforms should be structured, not as pre-depositional, depositional, and post-depositional, but around the nature of the event and the sequence and range of potential responses at each stage of the event.

Using Leach's five major stages of a physical disaster, a shipping disaster follows the following processes (Gibbs 2006: 7-13):

1. Pre-impact: the pre-impact stage comprises a period of recognized potential threat and a period of warning in which evidence indicates that an accident is likely to occur. A threat may be real, manufactured, or imagined (Duncan 2004: 15) and it may or may not be understood. During the warning period, mitigation can be physical and or spiritual and successful mitigation can result in an arrest in accident progression.

2. Impact: the impact stage is the moment of a disaster event through the realization that the event has occurred and mitigation must take place. Disaster studies 
have shown consistent trends within groups during the impact stage with only a small proportion of the group able to respond immediately and effectively. The remainder is often bewildered or behaves inappropriately. Mitigation may include jettisoning cargo or fixtures, patching a leak, or intentionally grounding a vessel.

3. Recoil: the recoil stage commences when the immediate threat to life has receded or that the primary disaster event has been survived. This does not mean that involved individuals are out of danger. It is possible that a vessel can be successfully mitigated out of both the impact and recoil stages resulting in no shipwreck archaeological site. Other event-related materials might be retained to form the archaeological record (e.g. flotsam, jetsam, etc.).

4. Rescue: the rescue stage commences when the person or group involved in the disaster has been removed from danger. Often, this is where many of the first documentary accounts of the event are generated such as in Life-Saving Station logs or rescue vessel logs.

5. Post-trauma: post-trauma is the medium- and long-term response to the event. Most primary documentary accounts of an event are produced at this time. This can include insurance reports, newspaper articles, etc.

Gibbs (2006: 14-15) also recognizes the importance of salvage as a key formation process of archaeological sites and rightly recognizes the variability in the methods and effects of salvage in different disaster stages. Salvage can begin during the recoil stage and continue long after the disaster participants are no longer actors in the life of the shipwreck. Salvage is variable over time and is dependent on site accessibility, the time and effort required to salvage, the perceived benefits versus cost, and the legality 
of the endeavor. Opportunistic and organized salvage can occur in several cycles and in either order. This also applies to mobilized wreckage such as cargo, other materials, and even corpses that wash ashore.

Gibbs arranges the pathways of his processual model by modifying Muckleroy's flowchart to include explicitly defined c-transforms present in terms of the five stages of the shipwreck event (Figure 6.3). In other words, it follows the process of the associated human activity. Ward et al.'s (1999) natural transformation model is the continuation of the dynamic formation processes that affect the site apart from human interference (represented in a 'black box' format in the model) and therefore does not overlap with the cultural transforms.

Though it acknowledges archaeological materials distributed off-site through human activity, the model is designed to specifically address the formation of a single archaeological site; it only implicitly assumes the presence of removed material elsewhere. This in itself is not a failing of the model, but rather the model assumes that what is of interest is the formation of the immediate site location of the shipwrecking event and that associated materials would be included when investigating the particulars of associated activities. Gibb's (2006) model does, however, only include purposeful cultural transforms; it does not include inadvertent or incidental human activity that affects shipwreck sites such as channel dredging or snagging towed gear.

A New Maritime Archaeological Site Formation Model 
While the Ward et al. (1999) and Gibbs (2006) models appear to be excellent for a rigid site definition, they do not allow at all for site parameter flexibility. The site must derive from a single event and is therefore strictly locational. It is not useful for characterizing an archaeological landscape and all the archaeological materials contained within. Additionally, the preceding models in general do not allow for the inclusion of many types of archaeological materials located with the maritime archaeological landscape. This includes wreckage that has broken away from shipwreck sites, either in the process of wrecking, or after the archaeological site has initially formed. Archaeological material can derive also from other, non-ship types of maritime transportation such as towed log rafts, which in the Great Lakes could be up to several acres in area. One such log raft broke up in a storm in Thunder Bay scattering four million feet of timber along the shoreline and underwater, imperiling local shipping for several seasons. Fishing and other non-transportation activities also can leave submerged remains such as net stakes and discarded gear. All of this cultural material is an integral part of the maritime archaeological landscape.

To create a useful maritime archaeological landscape formation model, archaeological space and time must be analyzed in three dimensions, including the surface and water column in addition to the sea floor. There are three levels or stages of analysis within this system upon which variables can act. In terms of a vessel these are: (1) that a vessel will wreck or become irrecoverable in a given location at the surface; (2) that wreckage will arrive at a given location; (3) and that wreckage will survive at a given location. Each shipwreck or wreckage must go through each of these stages of transformation. Additionally, once reaching the third stage, mobile 
wreckage may become re-entrained within the system, due to c- and/or n-transforms, and continuously cycle through stages two and three. While in stage three, the Ward et al. (1999) model is applicable for all submerged archaeological remains. The model is generalized in order to be applied to any definable maritime landscape.

Formation transforms are defined as environmental inputs that can be characterized or measured in space. They can be both variable and non-variable and exist at different scales. These transforms can be measured directly in the environment, derived from historic data, or inferred from historic accounts. Depending on the area and scale studied, different transforms will have more influence than others.

The role of scale in characterizing affective formation transforms is best understood in the context of a Stommel Diagram (Stommel 1963). Different components of the spectral distribution of cultural and natural transforms that have a formative effect on the maritime archaeological landscape are plotted on a logarithmic-logarithmic scale with the effect of the transform plotted in the z-axis. This three-dimensional representation of formation transforms at all scales allows for the quantitative analysis of the interaction of the transforms, as well as aids in the determination of the total effect of transforms on the landscape. It allows for informed selection of relevant transforms in the analysis of a specific research hypothesis.

In order to approach the maritime landscape as a human ecodynamic system, it is impossible to separate anthropogenic and natural phenomena (McGlade 1995: 359) as with the models of Ward et al. (1999) and Gibbs (2006). The former treats ctransforms as an arbitrary initial input and the latter does not incorporate n-transforms 
into the socio-cultural model except to assume the forcing of behavioral constraints over time. Additionally, neither allows for positive feedback from landscape events over time to affect the continual cycling of landscape formation processes. The total landscape is not merely a sum of the events that take place within it.

To combine anthropogenic and environmental processes into a single landscape formation model, it is necessary to treat the total landscape as an irreducible socionatural system (McGlade 1995: 359). Additionally, though previous formation cycles inform human behavior, individual shipwreck and other internment events are essentially mutually exclusive. It is a non-linear system where behavior cannot be reduced to a mathematical algorithm. What is needed is a model that acts as an abstract dialogic resource that can carry multiple analytical arguments through a variety of model scenarios and various temporal and spatial scales (McGlade 1995: 361). This approach allows for the combination of different types of data including descriptive, deductive, and interpretive data sets.

McGlade (1995: 361-366, 384) has developed an organizational structure in which this approach is possible. A framework is required in which empirical data are situated within an interpretive as opposed to a deductive frame of reference in order to facilitate an interrogative dialogue between qualitative and quantitative data. Instead of a model as a representation of real world phenomena, the model becomes a dialogic resource constructed around the potential interaction between model sets within which multiple possible arguments can be formed. Each problem set or inquiry requires appropriate sub-models to address different aspects of observed phenomena within different boundary domains. Instead of a single predictive model, inquiry leads to a 
series of potential evolutionary pathways to which a system is prone. The model allows for selective component access to address specific problems related to the dynamics of the system. The modeling process provides an "experimental arena" within which different interpretations are possible hypotheses that can be tested.

The new model is presented in graphic form in Figure 6.4. Unlike all previous models, all human behavior associated with maritime activities is incorporated with the landscape formation model, because they fundamentally take place within it. This includes behaviors that are not directly included in the wrecking process such as successful maritime voyages and modern salvage activities.

Each stage in the model can be construed as a "black box" which represents an infinite number of potential c- and n-transforms that are bounded by the unique conditions present at a given time and that evolve over time. Except for "Maritime Behavior", which can be construed as being continuous throughout all or limited to a part of the landscape, every stage within the model is associated with a particular location on the landscape. As people and materials move between stages, this location may stay the same or change.

Once materials arrive at Stage 3, on the sea floor an archaeological site is formed. There are two pathways through which this can occur, through an accidental internment (Stage 3a) or through a purposeful internment (e.g. pound net stakes, wharf pilings, etc.; Stage 3b). On the landscape, these sites are contingent on the moment of observation. While some archaeological sites persist through their initial formation to the present, others may have a finite lifespan controlled through time-dependent c- and n-transforms. 
Both cultural and natural forces drive the system through the three stages. These forces are time dependent. For physical changes on the landscape, these can be either unidirectional or bidirectional. The bidirectional forces create cycles within the system. The dominant cyclical physical process is the entrainment of archaeological materials from an established site into the water column, essentially returning it to Stage 2, where it will then be deposited elsewhere creating a new site. Environmental forces involved might include storm-induced currents and waves or ice scouring, and human forces might include purposeful activities such as dredging and dumping of spoil.

An accumulation of input into any stage may split and continue the formation model at different locations ultimately forming unique archaeological sites within the landscape. For example, cargo may be jettisoned during accident recoil; a portion of the crew may leave the vessel in a lifeboat; wreckage may differentially disperse on the surface; a portion of material may become entrained into the water column and be carried from an archaeological site; etc.

What makes this model truly a landscape formation model, as opposed to an archaeological site population model with mutually exclusive site formations taking place intra-site, is the creation of positive feedback that drives the continuous flux of human behavior, which in turn drives the entire system as it affects the primary input: maritime behavior. This feedback can initiate from several stages, may not be the same at different stages, and may affect the overall system differentially. Both the feedback itself and the effects of the feedback are contemporarily unpredictable. It 
may be ignored, misunderstood, perverted, or dismissed, and disparate groups or individuals might use and respond to it differently.

Additionally, because maritime behavior and environmental forces occur as parts of the landscape as a whole, areas within the landscape that do not contain archaeological materials retain their importance within the system and cannot be discounted or ignored. Just as dynamic behavioral and physical processes are deterministic factors in the creation and presence of archaeological sites, they equally inform the lack of sites and any given place.

The continuous cycling of the dynamic formation of the landscape creates a system that can absorb the effect of force inputs. Systemic steady state is not synchronous between the landscape and processes occurring intra-site. Perturbations within the system at any stage may affect or may not affect a particular location or site but always affect the landscape. Because the formation of the landscape is tied to both time and place, different parts of the model can be accessed to address specific questions posed to it. Understanding every possible input into the model is not required for it to function as a dialogic resource for inquiry.

Thunder Bay as a Model Exemplar

Thunder Bay National Marine Sanctuary is an excellent location for the development of this maritime archaeological landscape model. There is archaeological material related to all four transport zones: the Thunder Bay River, within Thunder Bay proper, along the coast of North Point and nearby islands, and 
open water. Shoal areas of the sanctuary, such as at the tip of North Point, provide traps for mobile wreckage, and there is evidence for other commercial activities such as pound-net fishing. Additionally, shipwreck, debris, and fishing materials spatially overlap on the landscape.

There are also present in the archaeological record many forms of maritime technology including small sailing schooners, side-wheeled steamboats, wooden propeller-driven steamships, and large iron and steel steamships. These ships also carried a wide variety of cargoes including passengers, package freight, agricultural products, stone, forest products, and iron ore.

Thunder Bay is also an ideal laboratory for model development, because its natural environment is relatively homogenous. For example, the sedimentary surface of the lake floor is primarily coarse, glacially derived sand and boulder reefs indicating a rather uniform energy regime. Additionally, the waters are generally oligotrophic, limiting primary production and biological activity within the water column. Compared to other regimes, this environment promotes relative ease in identifying spatially distinct regions on the landscape. 


\section{Figures}

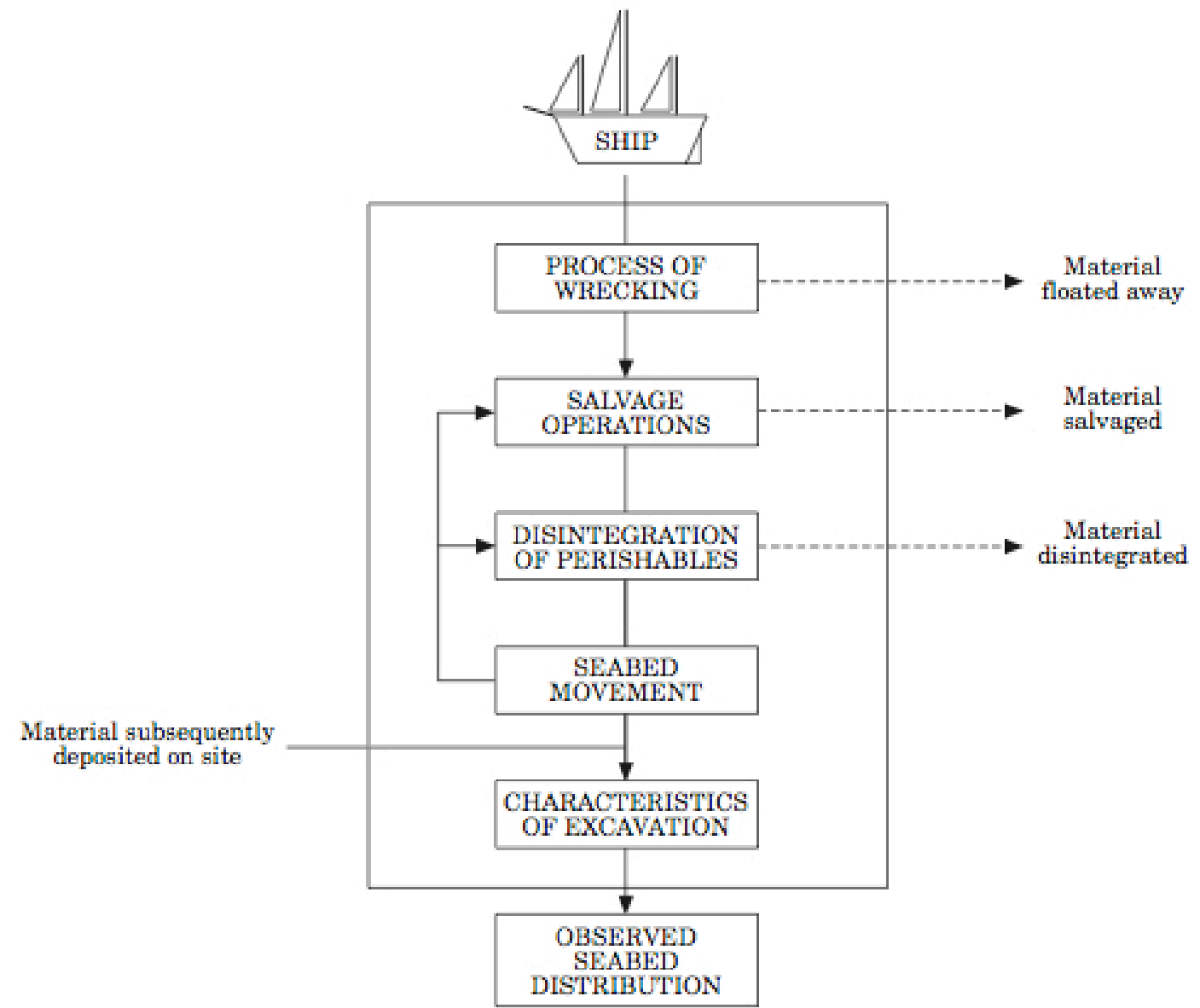

6.1 The First Shipwreck Site Formation Model (Muckelroy 1978) 


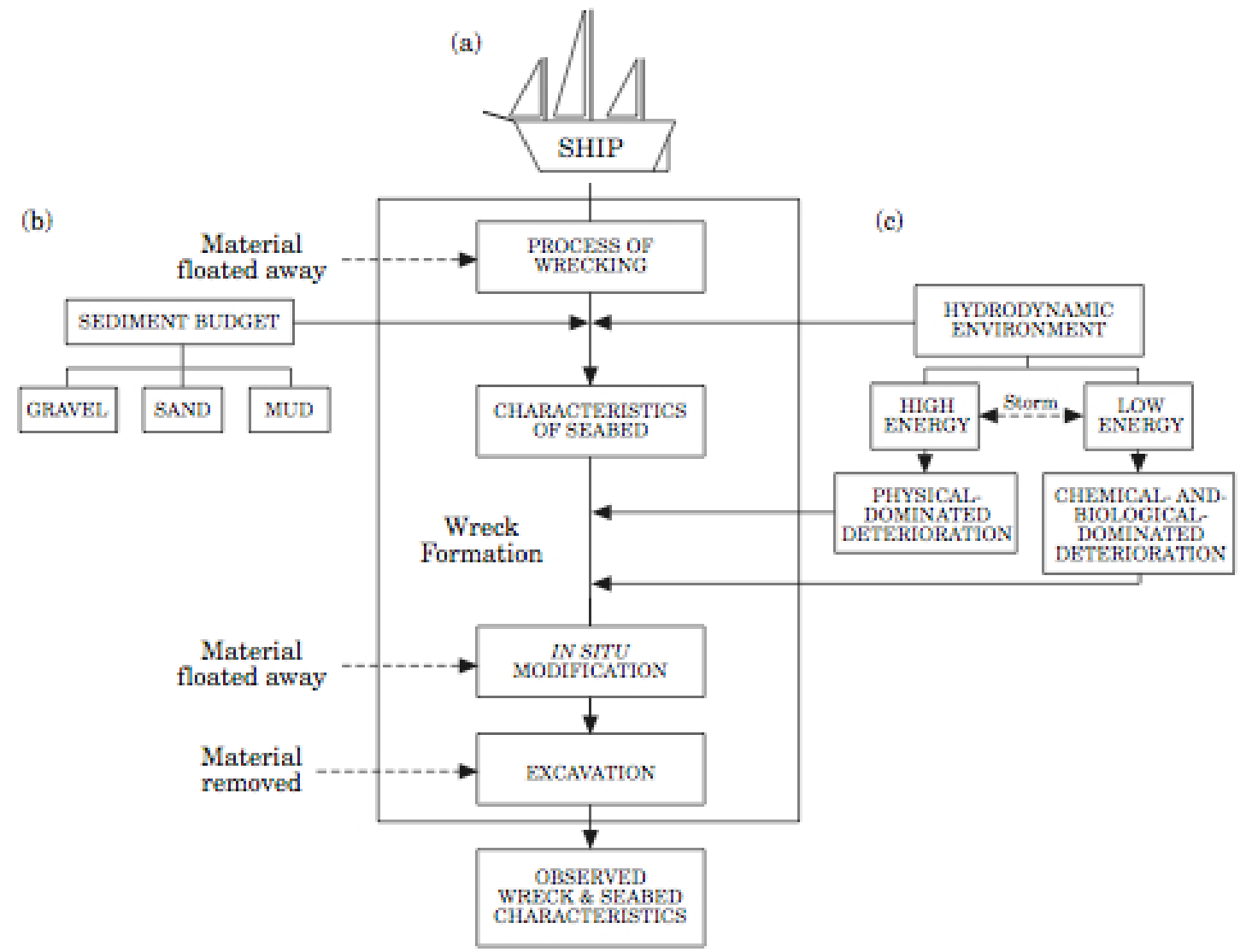

6.2 Dynamic Processual Shipwreck Site Formation Model (Ward et al. 1999) 


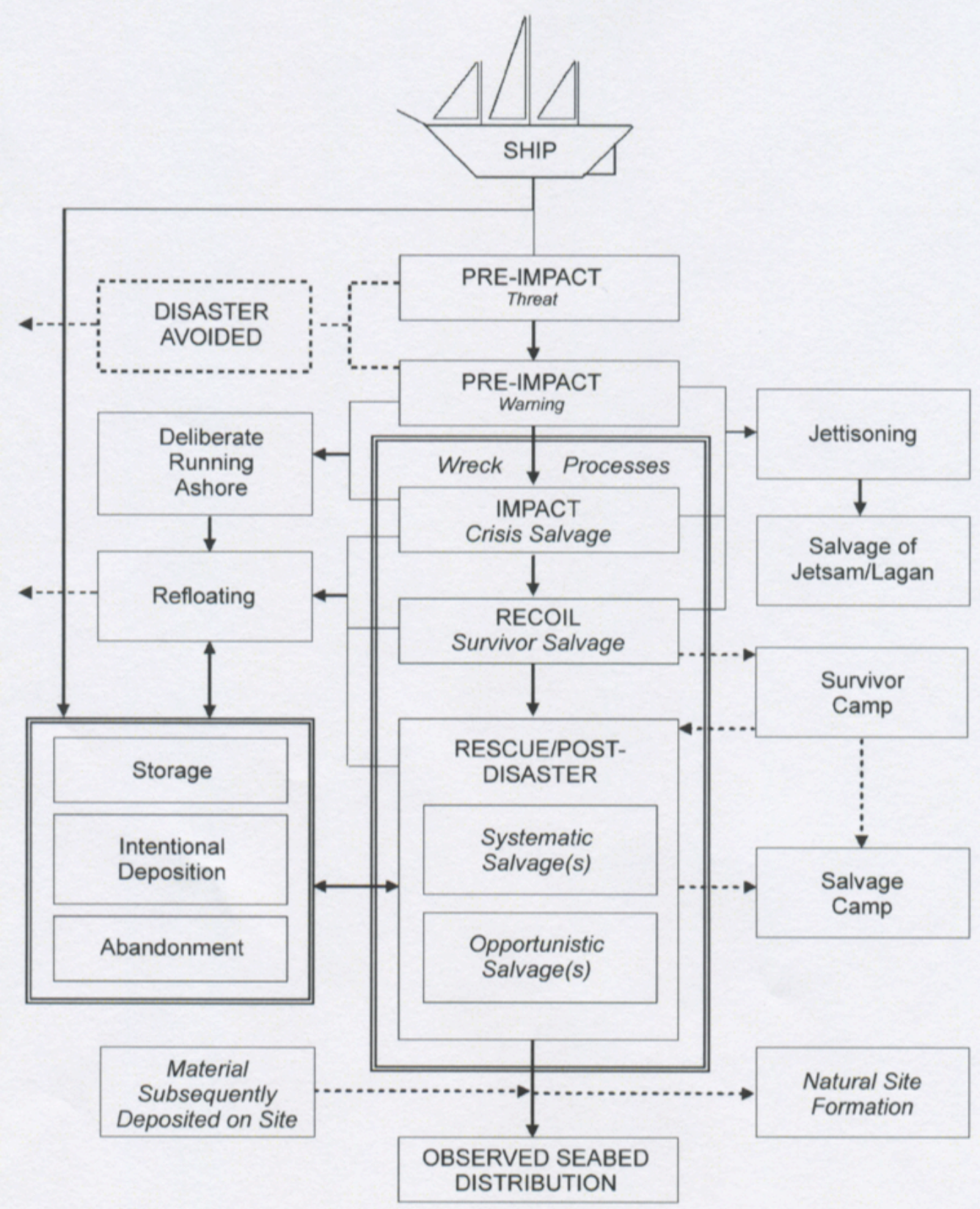

6.3 Dynamic Cultural Processes in Shipwreck Site Formation Model (Gibbs 2006) 


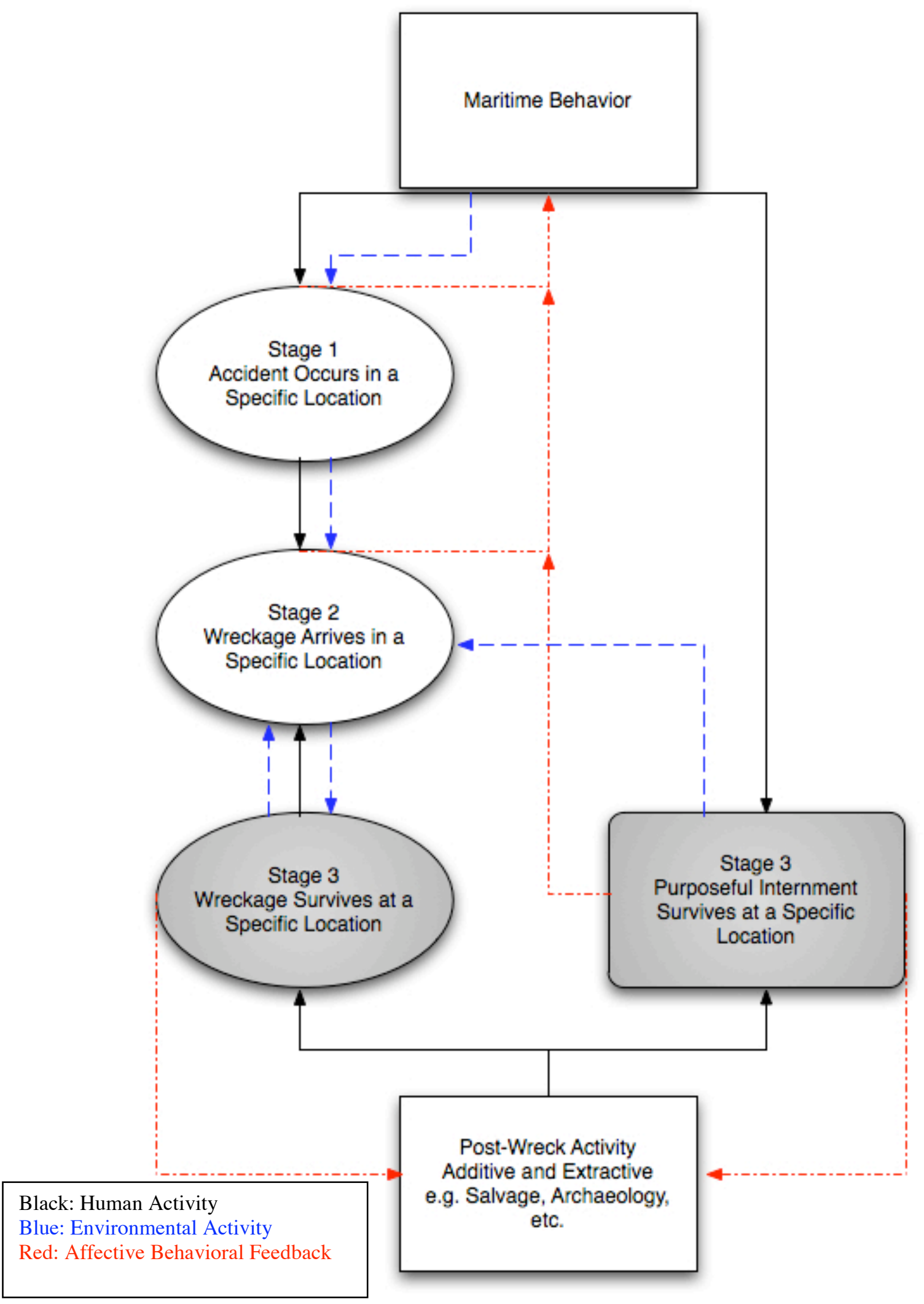

6.4 Dynamic Processual Maritime Archaeological Landscape Formation Model 


\section{CHAPTER 7}

\section{THE SHIPWRECKED LANDSCAPE OF THUNDER BAY NATIONAL MARINE SANCTUARY}

Through the use of the new maritime archaeological landscape formation model, patterns and trends in commercial shipping and associated human behavior become readily apparent in the submerged archaeological record of Thunder Bay and the northwest Lake Huron coast. As a whole, the spatial patterning of shipwrecks in the region is not random. Nearest neighbor analysis of all historic shipwrecks (Figure 7.1) indicates that there is a less than one percent likelihood that the pattern is the result of random chance, further supporting the model theory that formation processes do not begin with an archaeological site's initial deposition on the lake floor. Additionally, taken as a whole, the spatial mean and median of shipwrecks in the region occurs at North Point (Figure 7.2). Historically, Thunder Bay was considered to be the only major refuge of safety in northwest Lake Huron. This chapter aims to explore how the social conditions of the period between 1830 and 1930 informed the maritime behavior that best explains the qualitative historical and spatial distribution of archaeological materials, in the context of the maritime archaeological landscape formation model, associated with primary shipwreck sites. Note that no known shipwrecks occurred in the region prior to 1830 and shipwrecks that occurred after 1940 can be considered modern in the context of associated maritime behavior.

As the model is time dependent, it is best to look at the patterns and trends in the archaeological record chronologically. Patterns exist when analyzing the historical 
and spatial attributes of the shipwrecks by decade, therefore each shipwreck has been assigned to a decade of loss. The following discussion will consider each decade in turn. Following the decadal discussion, trends in the archaeological record will be discussed in the context of the entire maritime archaeological landscape, especially in the context of transport and perceived safety zones. Though much historical information is available for most of the shipwrecks, analysis will focus on the primary attributes of decade of loss (Figure 7.3a-b), month of loss (Figure 7.4a-c), propulsion type (Figure 7.5), loss type (Figure 7.6a-d), cargo at loss (Figure 7.7a-c), and age at loss (Figure 7.8). Other attributes may be described as part of particular exemplars.

Data are expressed and analyzed both graphically and spatially. Spatial statistical cluster/hot spot analyses were performed for select data categories and will be discussed in the context of the maritime archaeological landscape. In only a few analyses were the results statistically significant, which is not unexpected for anthropological phenomena; however, those that are statistically significant are, therefore, exceedingly meaningful.

$1830 \mathrm{~s}$

Only two known vessels sank in the vicinity of Thunder Bay in the 1830s, a Passenger Paddlewheel (Don Quixote) and a Schooner (Utica). Both stranded on coastal shoals, the schooner during an October snowstorm. Little is known about either wreck and it is likely that the loss date of the paddlewheel is potentially inaccurate as it is unlikely that it was at sea in mid-January when Lake Huron is 
typically iced over; however, it may have been attempting to take advantage of a break in the winter weather. Both vessels carried package freight, the primary cargo of the 1830 s, and were only a few years old.

The small number of shipwrecks and the vessels' young ages are representative of several historic conditions. Most early upper Great Lakes vessels at this time were new and costly, representing a significant investment for their owners. This is especially true of steamboats, which were essentially still technologically experimental throughout this decade. Commercial shipping in the region was relatively new, there were few vessels, competition was low, and freight rates were high. Both owners and sailors would be unlikely to take large risks during this decade. Additionally, because sailors were still learning the coastal transport zone of northwest Lake Huron, they would have remained quite close to shore making the likelihood of stranding high relative to other loss types.

$1840 \mathrm{~s}$

Newly opened frontier settlements and increased production in Midwestern grain greatly increased overall commercial shipping and subsequent construction and investment in vessels in the upper Great Lakes in the 1840s. The Thunder Bay region was one such immigrant destination; Alpena was initially settled in 1840 , not as a farming community, but as a lumbering site, therefore the rate of settlement growth was not as great as in the plains to the southwest. Alpena, however, would have started to receive commercial shipments at this time. Most commercial shipping 
consisted of immigrants and package freight moving northward and grain and other food products moving southward in northwest Lake Huron.

Because steamboats were more costly to operate than sailing vessels, the inconsistency of freight rates led many steamboat owners to focus on the more stable passenger and package freight transport. The shipment of food products was, therefore, dominated by sailing vessels in the 1840s. Though few shipwrecks occurred in the region in this decade, this trend is mirrored in the archaeological record.

Four vessels sank in the vicinity of Thunder Bay in the 1840s: a passenger paddlewheel with a cargo of package freight (New Orleans) and three schooners (Arnoline, Havre, and Henry Hubbard), at least two of which carried food products. Two vessels (New Orleans and Henry Hubbard) sank in the vicinity of Thunder Bay Island in the month of June, the latter in a relatively rare summer storm. The New Orleans stranded on the North Point shoals and the Hubbard foundered to the east of the island. Though standard pilot books were not likely available for the upper Great Lakes at this time (Thompon's earliest pilot book for the area that could be verified was published in the 1860s), it appears that the lee shore of Thunder Bay and Sugar Islands may already have been considered by this time as a safe haven for vessels caught in storms within the coastal transport zone in the vicinity of Thunder Bay. The Havre may have also been attempting to reach this perceived safety zone during a more common October storm when it was blown ashore. It is also possible that these two strandings may have been partially the result of a continuing lack of knowledge of the coastline. Lake Huron was not fully surveyed until the late 1850s making 
experience and skill at sounding key to a successful voyage within the coastal transport zone.

Though no known shipwrecks occurred in the vicinity of Presque Isle during this decade, the first of its two lighthouses was built in the 1840s. On a clear day, this $40-$ foot light had a visibility range of approximately 13 miles. Its construction, where the coastal route towards Lake Michigan and Lake Superior changes direction, indicates that this area was perceived to be increasingly dangerous for collisions as commercial traffic between the northern lakes grew. It is intriguing that no known collisions resulted in shipwrecks in the area until the following decade. This may be due to a traffic volume threshold being surpassed, but this is merely speculation.

Little is known about the fourth vessel, the Arnoline. As it purportedly sank within Thunder Bay, it may have been a local vessel or associated with the early settlement of Alpena.

$1850 \mathrm{~s}$

Competition in commercial shipping increased rapidly throughout the 1850 s. The Great Lakes trade saw the growth of wealthy shipping companies and the marginalization and spatial restriction of individual vessel and small-scale shipping owners. Railroads also became commercially viable at this time, rail iron being shipped by boat to the northern plains. It is during this time that a disparity develops between large- and small-scale owners in vessel maintenance and other support 
expenditures. Small-scale owners were also likely to take more risks to secure profitable rates that wealthier owners could afford to absorb.

Eight vessels sank in the vicinity of Thunder Bay in seven accidents. They include two passenger paddlewheels (Benjamin Franklin and Albany) and seven sailing vessels (John J. Audubon, Defiance, Harwich, Northampton, Northwestern, and Agate). All vessels sank in September, October, or November, the three most dangerous months to sail due to unpredictable weather events. The steamboats both carried package freight; the Franklin stranded on the shoals of Thunder Bay Island and the Albany on the shoals of Presque Isle. The Franklin probably wrecked under the same conditions and constraints as vessels that had previously wrecked in this location. The presence of the Presque Isle lighthouse transformed the small bay at Presque Isle into a perceived safety zone, which the Albany was trying to reach. Both of these vessels wrecked early in the decade, symptomatic of the competition by and eventual takeover during the decade of the package freight shipment by railroads.

The 1850s saw the first instances of collisions resulting in shipwrecks in the Thunder Bay region. All three shipwrecks resulting in this decade from collisions were sailing vessels, and all three accidents took place near the boundary between the coastal transport zone and open water. Two of these shipwrecks resulted from the same accident, the collision in fog between the northbound Audubon with a cargo of rail iron and the southbound grain transport Defiance. The brig Audubon sank immediately. The distribution of rail iron on the lake floor indicates that the vessel was overloaded and top heavy, an example of increased risk-taking by owners of an 
increasingly obsolete vessel type. The third vessel that sank from collision with another vessel, the Northwestern, carried a cargo of salt and was likely southbound.

The two vessels that stranded (Agate and Northampton) both carried food products southbound and wrecked during storms, the former just south of the Presque Isle lighthouse and the latter at Thunder Bay Island. Both appear to have been attempting to reach the safety of the nearby bays. The Northampton is the only vessel to have sunk in February in the region. It is unclear as to why it attempted to ship food products and rail iron during the winter, but as the vessel had aboard government lifeboats, aspects of this particular voyage are likely more complicated than they appear. The only shipwrecks in the region with cargoes of rail iron date to this decade.

The Panic of 1857, brought on by the failure of several insurance companies and banks that year, brought shipping to a near halt during 1858; therefore, it is quite interesting that the lumber hooker the Harwich set sail at this time with a load of lumber during the dangerous month of October. The vessel foundered in the vicinity of False Presque Isle during a storm. It is possible therefore that this cargo was local in origin and destined for a local market making the expected voyage relatively short.

$1860 \mathrm{~s}$

The 1860s saw a boom in commercial shipping with the onset of the Civil War, as well as a significant increase in the total number of shipwrecks in the vicinity of Thunder Bay. In fact, the 1860s had the highest number of shipwrecks, second only to 
the 1900s, with 26. Because of this major increase in the number of vessels, the particulars of every vessel will not be described here and can be reviewed in Chapter Six. Though in the 1860 s there were three times as many sailing vessels as steamboats, sailing vessels make up nearly $85 \%$ of the decade's shipwrecks. This discrepancy is not due to the development of the consort-and-tow method of shipping as no consorts sank during this decade. It is possible that the consort and tow system was at this time only in use on the lower Great Lakes. The 1860s also saw the first marked discrepancy in the relative age of vessels at the time of wrecking.

Overall, competition between railroads and lake shipping, and sailing vessels and steamboats decreased during the 1860s. While the railroads focused on shipping package freight, sailing vessels focused on the grain and lumber shipments and steamboats on the rapidly growing iron ore shipments. This bifurcation increased throughout the decade. Note that these are all southbound commodities. It is likely therefore that there was increased competition and subsequently risk-taking behavior for northbound transportation.

There is a noticeable concentration of shipwrecks in the vicinity of Forty-Mile Point at this time as is a shift for collisions from the vicinity of Presque Isle northwestward. This may be due to the newly increased traffic during the $1860 \mathrm{~s}$ towards Lake Superior. This is also the area where vessels sailing from Lake Michigan and Lake Superior merge to form a single southbound corridor.

Of all of the southbound sailing vessels, 12 carried cargoes of grain and two carried lumber products. The majority of these 14 vessels sank in two primary locations: off of Forty-Mile Point and within three miles of the Presque Isle 
lighthouse. Additionally, one schooner stranded at Middle Island in a storm and one in a collision in open water off of Sturgeon Point. Three of the four vessels at Presque Isle stranded on the shoals during a storm and the fourth in a collision at night along the boundary between the coastal transport zone and open water. One of the vessels, which sank at Forty-Mile Point foundered in a storm while the two others were victims of collisions. There is no information as to whether visibility was obscured at the time.

Surprisingly, the three ore-carrying Schooners all sank in the latter half of the decade. All three stranded, one of them in a storm. The two vessels that stranded in high summer, one at Middle Island and one at Black River, were subsequently salvaged indicating that the vessels may have been abandoned at these locations.

Five likely southbound steamboats sank in the vicinity of Thunder Bay in the 1860s. All vessels wrecked during quite different events. The Portsmouth, with a cargo of iron, stranded off of Middle Island during a November storm, likely attempting a final trip before the close of the navigation season. The Congress, the first vessel in the area to succumb to the ultimate cause of fire, was purposefully stranded off of Thunder Bay Island. The Avon sprung a leak while being towed and sank stranded on Forty-Mile Point. The vessel would have been lightered off the reef but it was destroyed during a storm. Little is known about the passenger propeller Waterwitch, which sank with a cargo of copper at Au Sable River. Lastly, perhaps the most famous shipwreck in the vicinity of Thunder Bay, the Pewabic sank in a collision with its sister ship due to piloting error. The Waterwitch and the Pewabic were the only ships to wreck with cargoes of copper in the region. 
Three northbound schooners sank in the 1860s with cargoes of coal; all in October and November indicating an attempted last run of the navigation season. The Anna C. Raynor stranded off of Middle Island in a storm. The F. T. Barney sank in a collision between Rogers City and Forty-Mile Point. Lastly, the Syracuse foundered after springing a leak off of Forty-Mile Point.

Overall, the 1860s saw the first known shipwreck on the maritime landscape south of Thunder Bay and an increased clustering of shipwrecks at Middle Island, Presque Isle, and Forty-Mile Point. The locations of shipwrecking events became less random. This may be due to a newly perceived safety zone at Middle Island, an institutionalized perceived safety zone around the Presque Isle lighthouse, and the new directional change node and shipping corridor merge in the vicinity of Forty-Mile Point. Random stranding accidents may have also decreased due to the completion of the first Lake Huron coastal survey and the publication of readily available coast pilot books. Lastly, the 1860 s had the highest percentage of November shipwrecks. One might speculate that the increased risk-taking behavior was directly tied to the needs of the war effort.

$1870 \mathrm{~s}$

Several changes to the worldview of maritime commercial shipping participants occurred in the 1870s. The need for materials following the Great Chicago Fire of 1871, as well as continued immigrant settlement of the Great Plains, led to a boom in shipping in 1871 and 1872. It was at this time that the culture of working on sailing 
versus steam-powered vessels diverged. Most newly built vessels were steampowered. A disparity in operating costs developed; the best sailors demanded higher pay to work the more labor intensive but less efficient sailing vessels. Additionally, vessel owners were increasingly recognizing the obsolescence of sailing vessels. This led to the overall gradual deskilling of sailing vessel operators.

Additionally, the clustering of shipwrecks in the vicinity of Presque Isle and the recognition of dangerous sailing conditions at Sturgeon Point led to the erection of new lighthouses at these locations. The new lighthouse at the northern end of Presque Isle was nearly twice as tall as the older structure. These two new lighthouses created new perceived safety zones on the maritime landscape. It is curious, however, that lighthouses were not erected at Forty-Mile Point until the 1890s and at Middle Island in the 1900s, as clustering of shipwrecks also clearly occurred in these locations as well.

The 1870s saw the first wrecks of a consort; the Kate L. Bruce foundered within three miles of the Thunder Bay lighthouse and the Gold Hunter stranded north of the new Sturgeon Point lighthouse, both after parting their towlines in storms. The glut of new vessels, plus the financial panic of 1873 , led to a depression of freight rates and an overall decrease in commercial shipping throughout the decade.

As with the 1860s, most shipwrecks in the 1870s carried the southbound commodities grain, lumber products, and iron ore, and $81 \%$ of the 26 shipwrecks were of sailing vessels. Six of the seven vessels carrying grain were sail-powered, as was one of the two vessels carrying lumber products. A third sailing vessel, the D.R. Braman, a scow likely also carried lumber products. There is no apparent clustering in 
the location of these vessels; however, the Dixon stranded on Middle Island, the Portland within five miles of the Presque Isle lighthouse, and the Maid of the Mist between Middle Island and Thunder Bay Island in storms. All of these vessels were likely trying to reach perceived safety zones when they were blown ashore. Three of the grain carrying vessels, which foundered did so in the open water transport zone. One collision occurred at the boundary between the coastal and the open water transport zones and the other in open water.

Only three of these vessels sank during the boom years of 1871-1872. This is to be expected, as there was enough freight business that vessel owners did not have to risk dangerous sailing conditions to ensure securing a cargo. Those that sank during the depression did so either in summer storms or late in the navigation season.

Surprisingly, all of the southbound shipwrecks with cargos of iron ore were schooners, not steamboats. One, however, the Gold Hunter, was a consort of a steamboat. It is difficult to explain of the lack of shipwrecks of ore-carrying steamboats during the depression. All sank during storms, five stranded, one in the immediate vicinity of the Presque Isle lighthouse and another at the Sturgeon Point lighthouse. The other three vessels appear to have been attempting to reach the relative perceived safety zone of False Presque Isle and Thunder Bay. Three of the five ore carriers sank during the boom years and two during the depression. This may possibly be explained by a deficiency in available cargo space in steamboats for iron ore during the boom years. One of the two vessels, which sank during the depression, the Empire State, was the oldest vessel to wreck during the 1870s. Perhaps its owners 
felt that the relatively low financial risk of loss of such an old vessel justified a trip in November, so late in the navigation season.

The three southbound steamboats, which wrecked while carrying commercial cargo, sank during the boom years of the decade. The barge Galena foundered with a cargo of lumber products on the North Point shoals, likely trying the reach the perceived safety of Thunder Bay. The barge Detroit, also carrying lumber, was stranded in a storm near Harrisville. Lastly, the passenger propeller R. G. Coburn, with a cargo of grain, foundered well into open water during a storm. As the two barges were both near shore and in close vicinity to primary lumber ports, it is possible that the two vessels were conducting local trade at the time they wrecked, their cargoes destined for southbound sailing vessels.

The single northbound vessel, which sank in the vicinity of Thunder Bay, a coalcarrying schooner, the Marion Egan, wrecked in a collision. This accident occurred during the depression. As coal was typically shipped northward in vessels whose primary freight were the southbound commodities, perhaps it is not unexpected that few coal-laden vessels would sail to the west if it were unprofitable to secure freight to send back east.

The remaining two steam-powered vessels that sank at Thunder Bay were local vessels. The tug Philo S. Bemis sank after catching fire, and the Nellie Brampton, a pleasure yacht, stranded on the North Point shoals.

$1880 \mathrm{~s}$ 
The trends in commercial shipping on the maritime landscape and the worldview of its participants that appeared in the 1870s continued and became more established during the 1880 s. By the mid-1880s, $75 \%$ of all newly constructed vessels were steam-powered, however the total number of sailing vessels versus steamboats were essentially equivalent. Additionally, the 1880 s is the first decade in which the total number of losses of sailing vessels is about equal to that of steamboats. This explains why, in the 1880 s, there is a clear split between the average ages of vessels at loss by approximately ten years. All vessels lost had wood hulls. None of the steamboats lost exceeded the expected use life of 15 to 25 years; however, half the sailing vessels were older than this range illustrating the rapid aging of the available sailing fleet. Overall, fewer losses in the 1880 s compared with the 1870 s indicates that fewer risks were taken to secure profitable cargoes as the recession of the 1870 s waned.

The 1880 s also was the peak of the lumber trade in northern Michigan. In addition to the use of barges, tow-and-consort systems, and lumber hookers, timbers were also floated down the lake in very large rafts, towed by up to three tugs. These floating islands provided additional hazards to navigation, especially at night.

At least seven sailing vessels sank with southbound cargoes. Though at its maximum level of trade, only three southbound schooners wrecked with cargoes of lumber products. The Acontias was stranded off of Presque Isle and the Colonel Hathaway was stranded off of Harrisville. Neither appears to have wrecked in a storm. The third schooner, the New Hampshire, wrecked while tied to the Alcona pier, was towed from the harbor, and foundered on a nearby reef. The Acontias and 
the New Hampshire were two of the oldest vessels to wreck during this decade, well over their expected use lives.

Two schooners wrecked with cargoes of stone products: the Venus, sank at the mouth of the Black River in a storm and the M.F. Merrick sank off of Presque Isle in a collision in fog within two miles of the boundary between the coastal and open water transport zones. As it is unlikely that a vessel would venture out in a storm, it is likely the Venus was attempting to entire the river at the time.

As with the 1870 s, the only southbound vessel to wreck in the 1880 s with a cargo of iron ore was a schooner, the Harvest Queen, which foundered well offshore in open water. The insurance company questioned the accidental nature of this wreck; it is not surprising that it is so far outside of the historic shipping corridor, as if it was truly a case of insurance fraud, the perpetrators would not want to be seen.

Beginning it the 1880s, Canadian law decreed that all grain grown in Canadian provinces had to be processed through Canadian ports, therefore it is expected that shipwrecks of grain transport would significantly decrease at this time. This is borne out in the archaeological record. Only one southbound schooner wrecked with a cargo of grain in the vicinity of Thunder Bay. The Nellie Garner stranded just south of South Point

Compared with the 1870 s, the archaeological record indicates that either more cargoes of coal were moving north, or increased risks were being taken with northbound cargoes in the 1880s. Three of the four coal carrying vessels that wrecked were steam-powered and two of the three were bulk freighters that stranded in late season storms: the Anna Smith wrecked in the vicinity of the Cheboygan lighthouse 
and the James Davidson at Thunder Bay Island. The Davidson was towing a consort and, therefore, would have had restricted maneuverability in the dangerous shoals of North Point. The barge Belle Wilson foundered after springing a leak in a storm and was likely attempting to reach the harbor at Harrisville when it succumbed. The only coal-carrying schooner to wreck was the Lucinda van Valkenburg, which wrecked in a collision in heavy fog on the boundary between the coastal and open water transport zones.

Several of the steam-powered vessels that wrecked in the 1880 s most probably participated in local trade. The appearance of local tugs increase dramatically in the archaeological record beginning at this time. Two tugs with cargoes of package freight wrecked after catching fire. The third wrecked tug stranded off of Presque Isle in a storm. A yacht, the Aimee, was stranded at Presque Isle after breaking from its moorings.

In general, the spatial trends in shipwrecking events seen in the 1880 s are very similar to those of the 1860 s. Shipwrecks are clustered near lighthouses at Presque Isle and Thunder Bay Island. Interestingly, there are no shipwrecks within three miles of the Sturgeon Point lighthouse; however, there are several just north and south of it along the coast. This may represent the growing importance of this area as a coastal node in local transport coupled with an unfamiliarity of local sailing conditions, as was the case in the 1860 s at Forty-Mile Point. In the 1880s, however, clustering represents both the recognition of perceived safety zones and an increase in local traffic, especially for tugs, which would be expected near lighthouses and in harbors. 
All shipwrecks due to collisions were sailing vessels and took place near the boundary between the coastal and open water transport zones.

1890 s

While the types of commercial commodities remained the same is in past decades, the total tonnage of cargo shipped on the Great Lakes increased dramatically by over two million tons in the 1890 s, the majority of the increased tonnage being iron ore. There were also several significant changes in the overall Great Lakes commercial fleet. The 1890s was the first decade where steam-powered vessels shipped a greater tonnage of cargo than sailing vessels. Overall the number of steamboats increased while sailing vessels decreased. The average age of vessels at loss continued to increase for both sailing and steam-powered vessels, however the former was at a much greater rate as sailing vessels, once removed from service, were not being replaced. In general, there were few commercially viable options for sailing vessels other than in the shipment of lumber products. Many sailing vessels were converted to local package trade as store ships. The shipwrecks of sailing vessels in the vicinity of Thunder Bay had a variety of north and southbound cargoes potentially indicating that the above commercial restrictions were more prevalent in the lower Great Lakes. Slightly more sailing vessels wrecked in the region than steam-powered vessels indicating that a higher percentage of the total number of sailing vessels wrecked than steam-powered vessels. 
At least six of the 13 sailing vessels that wrecked in the vicinity of Thunder Bay carried southbound cargoes. There is no pattern in the month of loss for these wrecks. The Newell A Eddy, a consort with a cargo of grain, foundered in a storm near Bois Blanc Island in open water. Two schooners wrecked with cargoes of iron ore: the Millard Fillmore foundered north of Rogers City and the Fred A. Morse in a collision southwest of Thunder Bay Island in open water. Two carried lumber products: the Reindeer stranded off of Rogers City in an October storm, possibly in an attempt to reach the safety of the harbor, and the J.H. Magruder foundered off of the Harrisville dock in a storm. It does not appear that this vessel was underway at the time.

Two additional consorts wrecked at this time: the Ironton with a cargo of package freight in a collision in open water and the John F. Warner, which was abandoned near the mouth of the Thunder Bay River. The vessel with which the Ironton collided, the southbound bulk freighter Ohio, also sank at this location. The abandonment of the Warner at this location set a precedent for later abandonment events at this site.

Two northbound sailing vessels with cargoes of coal wrecked in collisions: The Corsican southeast of Thunder Bay Island in open water and the Typo at the transition between the coastal and open water transport zones between Presque Isle and Middle Island.

No steam-powered vessels wrecked by stranding in the 1890 s. In fact, in the twentieth century, only six mechanical propulsion vessels stranded, in many cases due to piloting error. Additionally, none wrecked with cargoes of iron ore. Shipwrecked cargoes mirrored those of the sailing vessels with grain and lumber shipped to the east 
and coal and package freight to the west. There is no pattern in the month of loss for steam-powered vessels.

Two southbound steam-powered barges foundered while towing multiple consorts decreasing their maneuverability. The Oswegatchie foundered off of Sturgeon Point in a storm within three miles of the lighthouse. Two of its consorts also sank but were recovered. It would be interesting to know which of the vessels started the chain reaction of foundering. The second barge, the Charles C. Ryan, foundered north of Port Austin after springing a leak.

Two of the three northbound vessels wrecked with cargoes of coal: the barge Mackinac and the bulk freighter Egyptian both wrecked after catching fire. The third vessel, the D.M. Wilson foundered off of Thunder Bay Island. Its case is unique, as the sailors knew that the vessel was damaged shortly after undertaking the voyage, yet did not terminate for repairs. The third steam-powered vessel that burned was the Messenger, which caught fire in the Rogers City harbor.

The two northbound steam-powered vessels with cargoes of package freight both wrecked in collisions in the same location as the Typo, the Florida and the Norman, at the boundary of the coastal and open water transport zones. Both were accidents early in the navigation season. The Norman represent a first for the Thunder Bay maritime archaeological landscape. It was the first steel vessel to wreck in the region and the only in the decade. Iron vessels had been in production for several decades, however their high value likely led to less risky behavior, especially in the nineteenth century. 
There was an additional first and only for the archaeological record. The tug Acme, while towing a log raft foundered in a storm while attempting to reach the perceived safety of Thunder Bay.

All but three of the sailing vessels that wrecked in the 1890s were well over their use-life expectancies. The $E d d y$, the only young vessel, had specifically been built as a consort, a type that was still in production at this time. Though all of the steampowered vessels were within the range of expected use life, most would have been considered old vessels. It appears that the number of vessels that wrecked while leaking, at least four in the 1890 s, increased at the end of the nineteenth century, which is probably linked to the increasing age of the fleet.

$1900 \mathrm{~s}$

The turn of the twentieth century saw a major shift in the production of Great Lakes vessels. No new commercial sailing vessels were built, and after 1903 no new wooden steamboats were built. In the first decade of the twentieth century, $65 \%$ of all new vessels were steel bulk freighters, and approximately 300 new vessels were launched. The 1900 s was also the last decade in which consorts were regularly towed. Bulk commodities represented nearly all cargos shipped on the Great Lakes with iron ore the primary commodity as it still is today. The last vessels that wrecked with cargoes of iron ore in the vicinity of took place at this time.

The 1900s marks the first decade in which more steam-powered vessels sank in the vicinity of Thunder Bay than sailing vessels, as well as the first decade where most 
of the steam-powered vessels that were not abandoned as derelicts were bulk freighters. It was also the last decade with a significant number of sailing vessel losses and the first of two decades with significant numbers of abandonment of derelict vessels.

All southbound sailing vessels that wrecked in the region had cargoes of lumber products. Only the Westside appears to have been a full schooner. The Westside foundered well out in open water after fighting a storm for two days. It is probable that the initial accident occurred much closer to the historic transport corridor. The other four lumber carriers all appear to have been modified as tows; however only the John T. Johnson, which was stranded along with its tow, the barge B. W. Blanchard, on North Point, and the Thomas P. Sheldon, which collided with its tow off Au Sable Point, both wecked in storms. The Jupiter foundered off of Alpena and the $G$. W. Wesley purposefully stranded off of Presque Isle after springing a leak. It appears that most of these vessels were trying to reach perceived safety zones when they wrecked.

The three northbound sailing vessels all had cargoes of coal. The Ogarita sank after catching fire between Middle and Thunder Bay Islands, the Ishpeming and the $W$. H. Rounds were stranded on Black River Reef, the latter in a storm. By the 1900s, it is difficult to state that vessels containing package freight were destined for western ports; therefore, it is unclear what were likely the historical conditions of the loss of the Cascade, which sank off of Harrisville.

Five steam-powered vessels wrecked while southbound. The B. W. Blanchard was mentioned previously, and the fish tug William Maxwell stranded on Thunder Bay Island in a storm. The last two iron-ore carriers to wreck in the region were the bulk 
freighters Joseph S. Fay, which stranded on Forty-Mile point and the Kaliyuga, which foundered well into open water during the "Great Gale of 1905". It is likely that the Kaliyuga was forced off course by the harsh winds of the storm. Lastly, the Oscar T. Flint sank in Thunder Bay after catching fire. It is likely that the first three of these vessels were attempting to reach perceived safety zones.

As with the sailing vessels, all northbound steam-powered vessels had cargoes of coal. Two, the P. H. Birckhead and the Monohansett attempted to seek the perceived safety zones of Alpena Harbor and Thunder Bay Island respectively after catching fire. The Baltimore foundered off of Au Sable Point. Lastly, the Etruria and the New Orleans wrecked in collisions in heavy fog in open water, the latter near the boundary between the coastal and open water transport zones.

The 1900s is the first decade in which there are shipwrecks of vessels that wrecked without a return cargo and empty holds. Both vessels with no cargoes, the barge William Peter Thew and the schooner barge Bay City, wrecked in collisions, the former off of Thunder Bay Island in heavy fog and the latter at the Alpena piers during a gale.

Though there is little clustering of shipwrecks in the 1900s there is a significant shift in the general location of wrecks away from north of Presque Isle and south of Sturgeon Point. All sailing vessels that were abandoned in the region were all sunk in the 1900s and all three were abandoned at Whitefish Point. Two of the abandoned steam-powered vessels were also abandoned at Whitefish Point. It is unclear as to why this location was chosen. The only other shipwreck at this site, the schooner barge $G$. W. Wesley, was stranded at this location several months after these vessels 
were abandoned. The Shamrock was abandoned in the same location as the Warner in the previous decade. Their associated wreckage is currently jumbled. The Emerald was abandoned at Thunder Bay Island, a later recognized location for derelict abandonment. Though vessels were abandoned year round, most of the summer shipwrecks are of this loss type skewing the pattern of loss month for vessels lost while underway.

With regard to risk, the predominance of coal and lumber cargoes in wreckage indicates that greater risks were being taken to ship these commodities. Freight rates must have been highly variable for coal and lumber as these wrecks took place year round. The 1900s also saw the greatest increase in total tonnage, primarily of iron ore, shipped on the Great Lakes indicating that rates were likely stable and there was enough business for all making high risk taking behavior unnecessary.

$1910 \mathrm{~s}$

By the 1910s, the total tonnage of cargo shipped by sailing vessels was negligible. While tonnage remained steady throughout the decade, the number of vessels on the Great Lakes decreased indicating rapid growth in the capacity of new vessels and nearly all newly constructed vessels were steel bulk freighters. In addition to iron ore, stone became a major commodity shipped by American vessels. A new type of vessel in this decade was the rail car ferries, owned and operated by railroading companies. 
The decrease in the total numbers of vessels on the Great Lakes and the onset of World War I in the latter half of the decade would have kept freight rates steady and plentiful available shipments would have necessitated less high-risk behavior in its shipment. In fact no vessels sank in the vicinity of Thunder Bay after 1910 with cargoes of iron ore.

Only one sailing vessel wrecked while under its own power; the Julia Larson stranded on Thunder Bay Island in a storm with a cargo of lumber products. The Larson was a relatively small vessel and may have participated only in local trade. A second schooner, the James H. Hall, sank at Alpena after catching fire. It remains in a location where previous vessels had been abandoned.

Though rare at this time on the Great Lakes, the only other two sailing vessels that wrecked in the region in the 1910s were both in tow as consorts. The northbound William A. Young foundered at the boundary of the coastal and open water transport zones south of Middle Island in a storm and the Southbound Exile stranded south of Sturgeon Point after parting its towline in a storm and drifting ashore. All of the above vessels were well over their expected use life.

The 1910s saw the last shipwreck of a grain carrier in the region. The bulk freighter D. R. Hanna wrecked in a collision off of Thunder Bay Island in heavy fog in open water. This is curious as grain production increased at this time. This may indicate that Canadian fleets and ports began to specialize in grain transport and that railroads were taking a larger portion of this commodity.

Though essentially all of the new bulk freighters built in the Great Lakes were steel vessels, five of the eight mechanical propulsion vessels that wrecked in the 1910s 
had wooden hulls. In addition to the Hanna, the northbound New York foundered off Thunder Bay Island in open water in a storm with a cargo of coal, the locally famous Barge No. 1 foundered on the North Point shoals with a cargo of lumber products and chickens, the steam barge Montana burned and while attempting to reach the perceived safety of Thunder Bay, and the William P. Rend stranded on the North Point shoals in a storm with a cargo of stone. The vessel is now located near Whitefish Bay indicating that the wreckage must have been relocated for disposal.

Two of the three steel bulk freighters to wreck in the area did so in collisions, the Choctaw in heavy fog near the boundary between the coastal and open water transport zones. The third steel bulk freighter to wreck near Thunder Bay, the Isaac M. Scott, was a victim of the White Hurricane of 1913 mentioned previously.

World War I had significant impact on Great Lakes commercial shipping activities. May vessels and their crews were requisitioned for the war leaving a shortage of available trained crews for the remaining vessels. It is unclear what, if any, role inexperience played in this decade in the wrecks that occurred at this time. The vessels, the yachts Tu Jax I and Tu Jax II wrecked as a direct result of wartime activities. The owner of the vessels purposefully burned his ships rather than allowing them to be requisitioned for the war effort.

As with the 1900s, the majority of the shipwrecks of the 1910s, with both sail and mechanical propulsion, are in general located in the vicinity of North Point and Thunder Bay Island and within Thunder Bay. This is likely due a shift in perceived safety zones, especially for mechanical propulsion vessels, away from the corridor between Thunder Bay Island, Middle Island, and North Point, which would have been 
considered unsuitable for larger vessels, towards Thunder Bay as the preferred shelter. Additionally, directional shipping lanes were charted and used during this decade decreasing the likelihood for collisions at directional nodes within the historic shipping corridor. The institution of shipping lanes, and the demise of the sailing vessel in profitable commercial shipping, are probably the key reasons for the precipitous decline of the total number of shipwrecks in the vicinity of Thunder Bay after 1910.

$1920 \mathrm{~s}$

The overall trends in commercial shipping on the Great Lakes in the 1910s continued into the 1920 s with the tonnage of iron ore remaining relatively steady and the tonnage of stone dramatically increasing. The total number of vessels on the lakes continued to decrease as new bulk freighters grew increasingly larger and one new vessel could replace several smaller ones.

Only five of the 13 vessels that sank in the region in the 1920s did so while transporting bulk cargoes. This includes the only two steel bulk freighters that wrecked: the northbound Edward U.Demmer, which wrecked in a collision in heavy fog well into open water with a cargo of coal and the whaleback Clifton, which foundered after its cargo of stone shifted in open water. The other three vessels were much older including the oldest vessel to wreck in the region; at 68 , the mechanized sloop J. H. Stevens caught fire and sank in the vicinity of the Presque Isle lighthouse with a cargo of lumber products. The only sailing vessel to wreck in this decade was 
the consort Mary Woolson, which foundered off of Sturgeon Point in open water after colliding with its tow.

The 1920s saw the second major period of derelict abandonment in the vicinity of Thunder Bay. Three wood-hulled tugs, all past their expected use life were abandoned, two at Rogers City and the third at Alpena. Because of the few vessels that wrecked in the region with commercial cargoes, except for the locations of derelict abandonment, there is little clustering of accidents on the landscape. The four vessels, however, that wrecked within two miles of a lighthouse (J.N. Dewey, Dottie, O. E. Parks, and Wanderer) appear to have been attempting to reach the perceived safety zones of the lighthouses while in distress, indicating the persistent recognition of lighthouses as hazard mitigation zones.

1930s

Two events of the 1930s had a significant impact on Great Lakes commercial shipping. First, the Great Depression dropped total shipped tonnage by approximately one million tons from the previous decades leaving a glut of available cargo space. Additionally, the Coast Guard began enforcing load line regulations to reduce incidences of foundering in rough seas, meaning that the largest vessels lost up to 300 tons of cargo per trip.

Given these conditions, it is not surprising that, of the 12 vessels that sank in the vicinity of Thunder Bay in the 1930s, only four were Great Lakes vessels that carried bulk commodities. The bulk freighter B. H. Becker foundered off of Greenbush in a 
storm with a cargo of oil, the barge William H. Simons wrecked after catching fire in Thunder Bay with a cargo of carbide, the bulk freighter W. C. Franz wrecked in a collision in open water in heavy fog with a cargo of mixed freight, and surprisingly, a schooner, the Bertha May, foundered off of Sugar Island with a cargo of lumber. It is curious that lumber was both being shipping at this time on the water and on such a relatively small vessel. It was undoubtedly used for local transport. A fifth vessel, the ocean freighter Viator, wrecked in a collision in open water with a cargo of pickled herring and other fish products; these are not regional products. The crew of this vessel may have been unfamiliar with shipping conditions in the upper Great Lakes. Several barges with unknown cargoes also wrecked during the 1930s. Though little is known about these vessels, such as their age and in most cases their loss type, each of these vessels wrecked within two miles of a lighthouse, indicating that they were seeking the shelter of perceived safety zones.

Relative to the earlier decades of the twentieth century, the vessels lost by fire in the 1930s significantly increased. This may indicate an unwillingness to maintain vessels if the likelihood that, during the Great Depression, the costs would likely not be recouped during the shipping season. Three of the four vessels that burned were tugs whose local towing opportunities were surely restricted and who could not compete with other vessels, especially older wooded freighters and barges for regional business. It is interesting to note that all of the losses due to fire occurred during the summer, the height of the shipping season.

Trends and Patterns in the Maritime Archaeological Landscape 
It is clear that, at a decadal scale, there are trends and patterns in the archaeological record that represent changes in maritime behavior on the landscape. These will be examined in the contexts of decade of loss, month of loss, type of loss, and cargo at loss. Attention will be given to the social constructs of maritime transport and perceived safety zones. Additionally, the effects of the competing maritime activity, pound-net fishing in and around Thunder Bay will be considered.

\section{Decade of Loss}

The total number of known shipwrecks in the vicinity of Thunder Bay in the 1830 s through the 1850 s is relatively low due to the small number of vessels on the upper Great Lakes at the time, little commercial activity around Lake Superior, and possibly because of limited recording of shipwreck accidents, though as they would have been rare and costly, any severe accident would likely have been noted. Because steam-powered vessels were costly, fewer risks would have been taken with their use; therefore, it is unsurprising that only four wrecked during these decades. A lack of spatial patterning of shipwrecks during these decades indicates unfamiliarity with the coastline as the coast had yet to be surveyed and pilot books were unavailable. All shipwrecks before 1860 , however, took place within or immediately adjacent to the coastal transport zone either in shoals or within the historic shipping lane. It appears at this time that the corridor between Thunder Bay and Sugar Islands and North Point and the lee side of Presque Isle were becoming recognized as a perceived safety zones 
for imperiled vessels, as several wrecks occurred in these locations. This informal designation was probably the primary motivation for the construction of the region's two earliest lighthouses, one at each location.

The period of 1860 through 1900 saw a significant increase in the total number of shipwrecks in the vicinity of Thunder Bay with sailing vessels making up at least half of the wrecks for every decade except 1900. This indicates that, as the ratio of new steam-powered to sailing vessels increased, sailing vessels became increasingly marginalized as a profitable method of shipping, and variable risks would have been taken by sailing and steam-powered vessels owners. It also explains the split in the rates growth of the average ages of shipwrecks of these two propulsion systems throughout this period. The percentage of sailing vessels that shipwrecked compared with the total fleet also increased throughout this period while the percentage of steam-powered vessels that wrecked remained stable. The latter is not unexpected as, overall, fleet size grew with tonnage availability even as cargo capacity became increasingly larger.

An interesting spatial patterning of shipwrecks occurred between 1860 and 1900 . The 1860s saw significant clustering of shipwrecks at three primary locations: at Forty-Mile Point, Presque Isle, and Middle Island. The perceived danger zone at Presque Isle was mitigated by the construction of a new lighthouse. As stated above, it is curious as to why this was not also the case at the other locations. The 1870s saw no apparent overall clustering. This changed in the 1880 s, with apparent clustering at Thunder Bay Island and Presque Isle and also north and south of the new lighthouse at Sturgeon Point. As few wrecks had occurred previously at Sturgeon Point, this 
indicates that the lighthouse became a perceived safety zone on the maritime landscape at this time. Also, new pilot books in the 1860s and 1870s had formalized the North Point corridor as a perceived safety zone on the landscape. Again, there was little clustering in the 1890s, then again, clustering in the 1900s around Thunder Bay Island. It is also at this time that shipwreck events in general, with some exceptions, become more restricted to the immediate vicinity of Thunder Bay.

This cycle of clustering over a 50-year period likely represents a behavioral reaction on a decadal scale of the maritime community to perceived dangers on the landscape. When apparent clusters of shipwrecks occur in a recognized period of time, both the perceived and real risks are mitigated, through coastal survey, the distribution of pilot books, and the erection of lighthouses, and in the later half of this period the institution of life-saving stations. While accidents do occur at these locations afterward, the pattern of shipwreck location becomes much more diffuse. Over time the institutionalization of their presence and their associated risk mitigation, or a laziness factor of risk recognition, coupled with changes in maritime technology and general maritime transport and commercial shipping conditions, forces the cycle to begin anew with new patterns of clustering that fit the new maritime landscape conditions.

The number of shipwrecks in total fell precipitously between 1910 and 1930 . Few wrecks of sailing vessels illustrates their essentially complete marginalization in commercial shipping indicating that the vessels that did wreck were probably restricted to local activities. All new commercial vessels built during this time were iron, the majority steel freighters, yet most of the shipwrecks of steam-powered or 
other mechanized vessels at this time were old wooden-hulled boats. Only a small percentage carried bulk commodities and those that did carried relatively non-valuable cargos compared with iron ore, therefore it is likely that these vessels were for the most part competing in regional trading activities. A preponderance of tugs indicates that many accidents occurred in a local context. Throughout this period, the spatial distribution of shipwrecks continued to contract in general towards Thunder Bay.

Hot-spot analysis of shipwrecks of sailing vessels in the region reveals some interesting patterns (Figure 7.9). Hot-spot analysis measures the standard deviation in spatial clustering of an attribute relative to other individual points, point clusters, and attribute clusters. A hot spot will have points of closely clustered attributes spatially restricted from other points or clusters. A cold spot will have clusters of points but with mixed attributes. Lastly a neutral spot will have either clusters of an attribute in close proximity to clusters of another attribute or a diffuse collection of points. In the vicinity of Thunder Bay, shipwrecks northwest of Presque Isle form hot spots from the 1860s and the 1890s. Moving southward along the coast, there are neither hot nor cold spots between Presque Isle and North Point indicated that clusters of shipwrecks in any given decade do occur; however, they are in close proximity to other clusters of shipwrecks and shipwrecks that are diffuse on the landscape. This is not unexpected in an area with a large overall number of shipwrecks compared with the rest of the region. There are cool spots located around Thunder Bay Island and North Point indicating clusters of wrecks from several decades. South of South Point, shipwrecks from several decades are highly clustered in proximity to one another. There are no hot or cold spots with regards to steam-powered vessels. 
Month of Loss

Vessels were lost in every month of the year but, the preponderance of shipwrecks occurred in the late summer and fall. Additionally, the pattern of monthly losses differs considerably between the nineteenth and twentieth centuries. Overall, hot-spot analysis does not indicate any statistically significant locations for month of loss.

In the nineteenth century, accidents occurred at the opening of the navigation season in April and May. Few shipwrecks occurred during the early and middle summer. The vast majority of shipwrecks occurred in September, October, and November with differences between these three months per decade. While the majority of shipwrecks occurred overall in October, November saw many more wrecks in the 1860 s than in other decades. All of these shipwrecks carried southbound cargoes of primarily grain or lumber products. It is likely that this is a direct result of the Civil War. Greater risks would have been expected to be taken in order to secure last shipments of supplies for the Federal Army before navigation became impossible.

Shipwrecks in the twentieth century became more evenly spread out over the course of the year with the highest number of accidents occurring in November. This represents improvement in ship-building technology, an institutional over reliance on naval technology in risk mitigation, the greater number of steel compared with wooden vessels, and the use of the largest vessels as icebreakers. For example, the Isaac M. Scott had engines too small to make headway in the large swells of the great 
November storm that ultimately flipped the vessel and sank it. Additionally, because many of the new steel vessels could successfully mitigate many of the conditions that wooden vessels typically could not, it is not surprising that the majority of shipwrecks at this time were wooden vessels attempting to compete with steel vessels during this dangerous month.

An approximately equal number of sailing and steam-powered vessels wrecked in September. All but three were likely southbound cargoes. Interestingly, most September accidents occurred within Thunder Bay or the coastal transport zone. September also appears to be the only month in which vessels wrecked at Whitefish Point, though an explanation for this phenomenon is elusive.

Shipwrecks occurred throughout the region in the month of October, but with a greater number of wrecks occurring in perceived safety zone corridors and in the vicinity of lighthouses than in earlier months. The majority of October losses, $78 \%$, were by stranding or foundering, $60 \%$ of these in storms.

Interestingly, all but three shipwrecks in the month of November occurred outside of the coastal transport zone, and these three vessels all wrecked in the later twentieth century. This indicates a recognition that sailing during November was highly dangerous and all of these vessels were likely attempting to make one final voyage before the close of the navigation season. Additionally, the majority of the wrecks cluster around five primary locations: Forty-Mile Point, Presque Isle, Middle Island, Thunder Bay and Sugar Islands, and the tip of North Point. Nearly all of these vessels either foundered or stranded in storms indicating that the vessels in these five locations wrecked while attempting to mitigate danger in perceived safety zone. It was 
expected that the majority of the vessels lost in November would be older vessels with which owners would be willing to take on increased risks; however, this is not the case with a more or less even spread of vessel ages represented in the month's shipwrecks.

Type of Loss

Loss type is dependent on several factors: the location on the lake in which the accident occurs, the state of the weather and water, the condition of the vessel, knowledge of the coastline, risk mitigation by the vessel's owner and sailors, and the presence and condition of other vessels in the region. Vessels were lost in the vicinity of Thunder Bay through accidental collisions, fires, foundering, stranding, and purposeful abandonment. The patterning of each loss type will be looked at in turn.

Collisions occurred throughout the entire 100-year period of historic shipwrecking in the region. In the nineteenth century, collisions typically involved a sailing vessel with 21 accidents compared with four collisions sinking steam-powered vessels. This can be explained by the greater number of sailing vessels, especially in the 1850 s and 1860 s participating in the bulk commodities transport of grain, rail iron, coal, and lumber products. This trend reverses by the 1890 s with nearly all bulk transport conducted by steam-powered vessels.

While only three collisions occurred during storms, nearly half of the collisions occurred in heavy fog. This exacerbated dangers posed by the lack of shipping lanes until the 1910s, in fact only seven collisions occurred after 1910, and two of these by ocean vessels with crews unfamiliar with the area. Collisions occurred year round 
indicating that sea state (storms) had little to do with the likelihood of an accident to take place.

Collisions tended to occur in close proximity of the boundary between the coastal and open water transport zones. In other words, most collisions occurred within the historic shipping corridor. This indicates that sailors would have known that, on any given day, especially in fog, the likelihood of an accident to take place by collision was high and appropriate mitigative behaviors should be carried out. Additionally, collisions cluster within the historic shipping corridor approaching three turning nodes: at Thunder Bay Island, at Presque Isle, and at Forty-Mile Point. Collisions occurred often in open water. The majority of the open water collisions though took place south of Thunder Bay Island. Why this is the case is unclear.

Loss by fire tended to occur close to the homeport of the lost vessel or as the burning vessel attempted to reach the perceived safety zones of a harbor or lighthouse. Homeports with fire losses include Alpena, Harrisville, and Rogers City. Half of all tugs and yachts not abandoned were destroyed by fire, two vessel types for which the use is restricted to a local area. Approximately $45 \%$ percent of steam barges not abandoned were also destroyed by fire. It is probable that something in the design of these vessel types rendered them more prone to fire-related accidents than other vessel types. Unlike the tugs, all of the burned steam barges were well over their expected use lives. Only two sailing vessels were lost to fire during the entire 100-year study period.

Fifty-two vessels wrecked by foundering, with approximately an equal number of sailing and steam-powered vessels succumbing by this method. It was the primary 
manner of wrecking in the twentieth century. While founderings occurred year-round, nearly two-thirds occurred between September and November. Twenty-three vessels, or $44 \%$, foundered during a storm. It does not appear that sailing direction determined the likelihood of wrecking by foundering, though all but six or so (there are several unknown cargoes) carried bulk commodities indicating that, except for those with cargoes of lumber, danger mitigation likely commenced while the vessels were in the shipping corridor. This is evident in the spatial distribution of the foundered vessels.

Founderings occur in the region in three primary areas: in open water, near the inner boundary of the coastal transport zone (near shore), and in a perceived safety zone, in the vicinity of a historic perceived safety corridor or in the vicinity of a lighthouse. In open water, outside of the historic shipping corridor, a vessel could be at any location when an accident is imminent. Therefore, it is understandable that there is no patterning of the location of founderings in open water. All open water foundering are, however, south of Presque Isle. Often, steam-powered vessels would attempt to purposefully strand vessels on a "soft" beach to prevent foundering; therefore, one might expect many of the founderings of steam-powered vessels to be near shore. In the region this is not the case with only three such possibilities based on location. Most steam-vessels appear to have been attempting to reach a perceived safety zone when they wrecked. The apparent pattern for sailing vessels is more diffuse; however, more sailing vessel founderings took place near shore.

Not surprisingly, stranding occurs on shoals and beaches and, therefore, all strandings, save hazard shipwrecks that were towed offshore, are clustered within the near-shore area along the entire length of northeastern Michigan. Interestingly, there 
are more strandings at and south of Presque Isle than along the northern shoreline. This likely is a function of shore orientation with northerly winds producing insufficient fetch to force vessels ashore. All but two of the vessels, however, along this shore wrecked during storms. Clusters of stranding occur at six locations: Presque Isle, Middle Island, Thunder Bay Island, the tip of North Point, north of Sturgeon Point, and south of Sturgeon Point. In the first four cases, it is probable that vessels were attempting to reach the perceived safety zones of the lee corridors between the islands and the mainland shore, the lighthouses, or Thunder Bay. The strandings south of South Point indicate that this is a dangerous stretch of coast to sail, especially in heavy easterly winds.

All but seven strandings took place between September and November with two in January. All but three of the November wrecks occurred at a lighthouse or at the tip of North Point. This shows recognition of these locations as a primary target when there is a threat of wrecking during this month. If it were otherwise, it would be expected that the distribution of strandings would be more diffuse.

Abandonment of derelict vessels is the only type of purposeful internment, except for insurance fraud, of vessels in the vicinity of Thunder Bay. Abandonment of derelicts is the only loss type with shows high clustering and high probability that abandonment occurs in one of the clusters (Figure 7.10). The primary locations for abandonment are just outside Alpena Harbor, at Whitefish Point, and just outside Rogers City Harbor. It is safe to assume that these locations were chosen for causing the least interference with maritime activities, as well as representing a place that 
required the least amount of effort at which to locate or relocate vessels. All abandoned derelicts were well past their expected use lives.

Cargo at Loss

The tendency for the loss of a specific cargo type coincides in general with the tonnage of that cargo type in any given decade, excepting iron ore that in this context is underrepresented in the archaeological record. The majority of cargo losses in the nineteenth century were, in decreasing order: grain, lumber, iron ore, coal and package freight. The majority of grain and iron ore losses were in the 1860s and 1870s, likely representing the needs of the Civil War effort. In the later decades of the century, the number of grain and iron ore losses decrease as the losses of coal and lumber increase. This can be explained by the growth of the lumber industry and immigrant settlement at this time in the region as the shipments of iron ore become restricted to larger steam-powered vessels and Canadian grain became restricted to Canadian ports.

In the twentieth century, the losses of lumber carriers as well as coal carriers dramatically increase, especially in the 1900s and 1910s. This represents the marginalization of old sailing vessels as they attempted to take advantage of the rapidly dwindling lumber trade. Heavy competition between sailing vessel owners would encourage higher risk taking activities; approximately half of the lumber hookers, which wrecked in this century did so in late season storms. Most of the twentieth-century wrecks of coal carriers were bulk freighters indicating that these vessels were northbound expecting a return cargo of iron ore. The twentieth century 
also saw a significant rise in the number of vessels that wrecked with no cargo. This can partly be explained by the significant increase in the losses of local tugs and the 1920 s period of derelict abandonment. Only three vessels in this century were lost with cargos of grain or iron ore indicating the lack of commercial interest in the former and the lack of high-risk behavior for the latter.

There is little spatial patterning in the location of shipwrecks with specific types of cargo save one. Lumber carriers, except for two vessels, all wrecked within or very close to the coastal transport zone. As most of these shipwrecks are near shore, it is unsurprising that only a single lumber carrier wrecked in a collision. The same is true for the few shipwrecks of iron ore carriers, only a single schooner carrying iron ore wrecked in a collision. Iron ore losses tended to take place near shore or well into open water. Most collisions were by grain and coal carriers though why this is the case is unclear.

The Effects of Pound-Net Fishing on the Location of Shipwrecks at Thunder Bay

There are two primary locations for historic pound-net fishing within Thunder Bay and one just outside of the bay proper: along the edge of the shoals northeast of Sulfur Island, along the edge of the shoals just inside of Thunder Bay along North Point, and within the shoals west of Sugar and Thunder Bay Islands within the perceived safety corridor. Any shipwrecks that occurred in these locations prior to their use as prime fishing grounds in the 1850 s and 1860 s would have been removed before the stakes and nets were installed. 
Accidents in the fishing grounds would have produced costly damages to both the vessels and the fishing apparatuses. Therefore, vessels in general would have avoided these areas while sailing under normal conditions, as they are along the shoals, and while mitigating danger. If wrecks did occur in these locations, they would have been quickly removed and the fishing gear repaired. After the use of the fishing grounds ended and the nets removed, the stakes would have remained a danger to vessels in the area and would have been avoided during risk mitigation. There are no shipwrecks within the three clusters of net stakes. This is not surprising within the bay, but it is quite interesting that it is also the case within the perceived safety corridor west of the islands, as they would have been hard to avoid for wrecking vessels in this area. In fact, the three closest shipwrecks to the net stakes at this location are from the New Orleans, which predates the fishing activities and two vessels from the 1930s. 
Figures

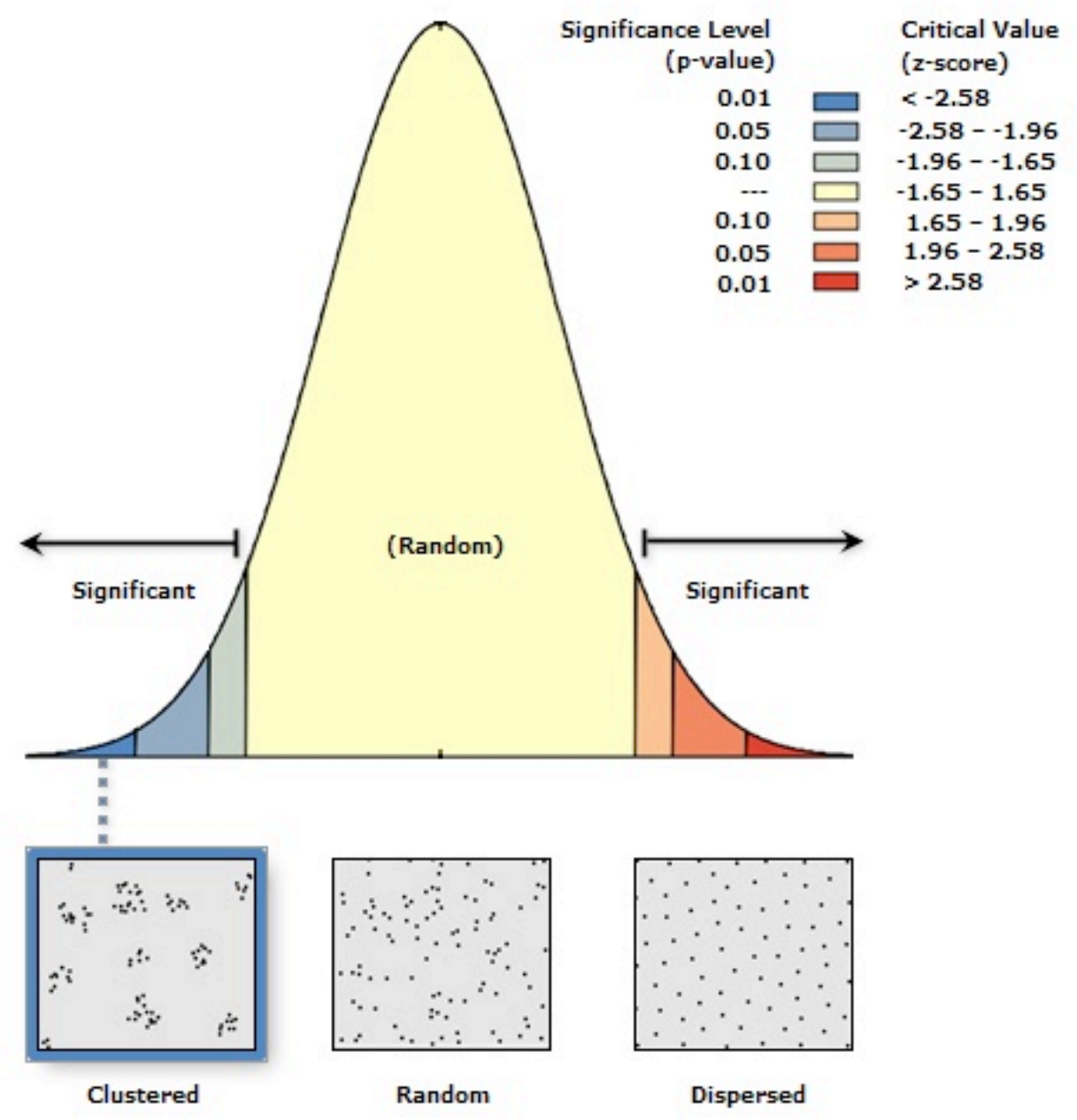

7.1 Nearest Neighbor Analysis of Shipwrecks in the Vicinity of Thunder Bay 


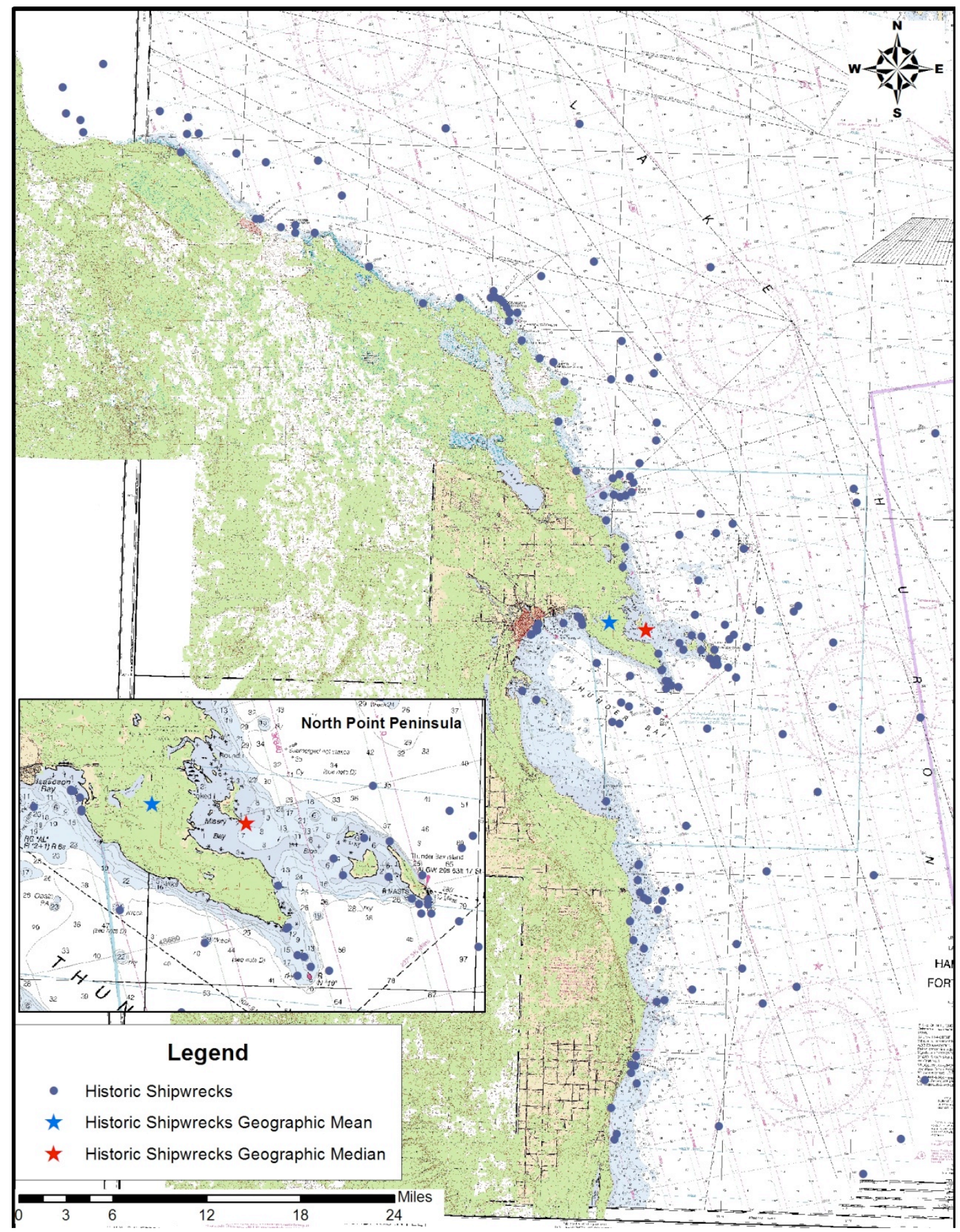

7.2 The Spatial Mean and Median of Shipwrecks in the Vicinity of Thunder Bay 
Sail versus Mechanical Powered Shipwrecks per Decade

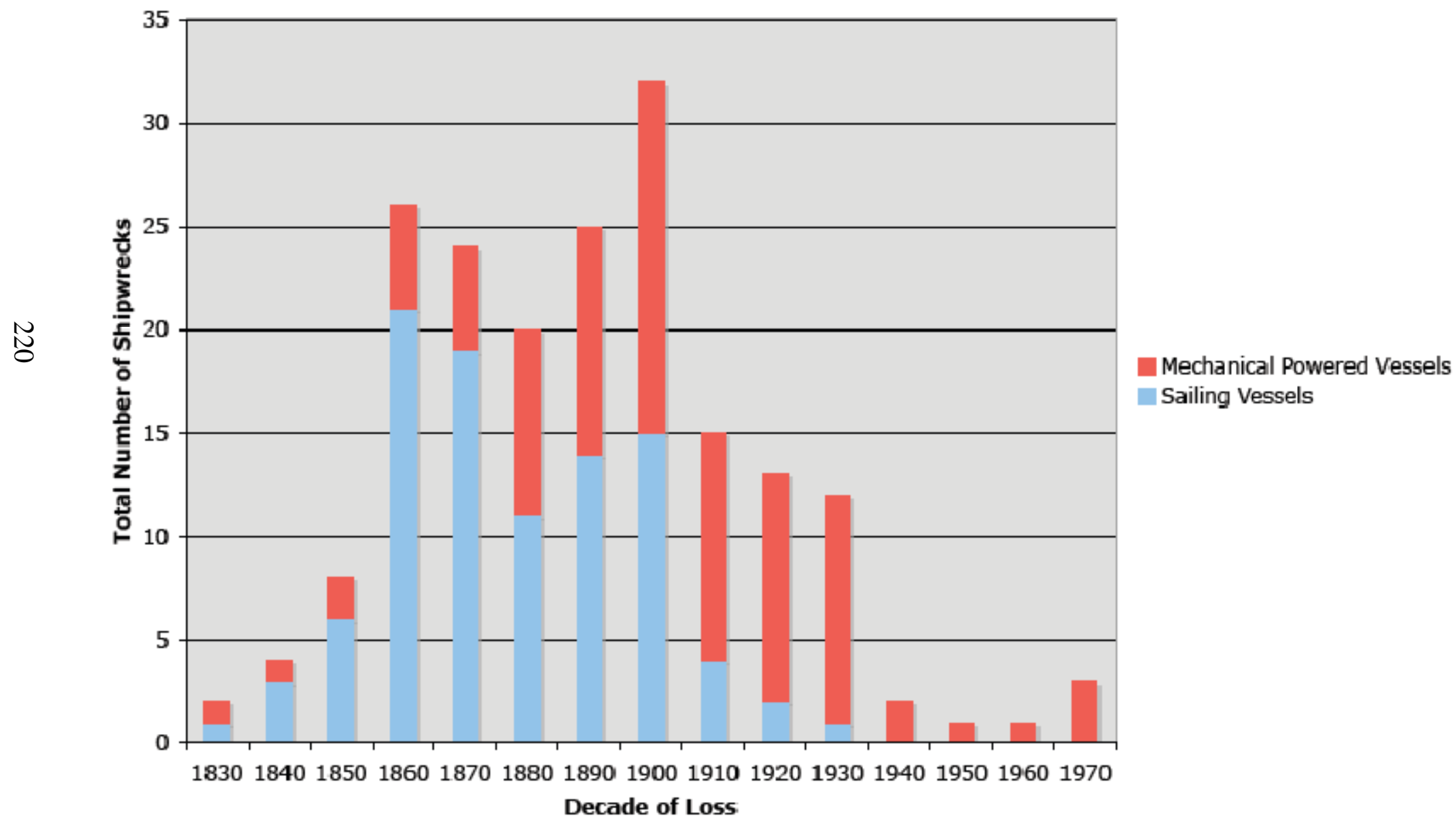

7.3a Decade of Loss (Graphical) 


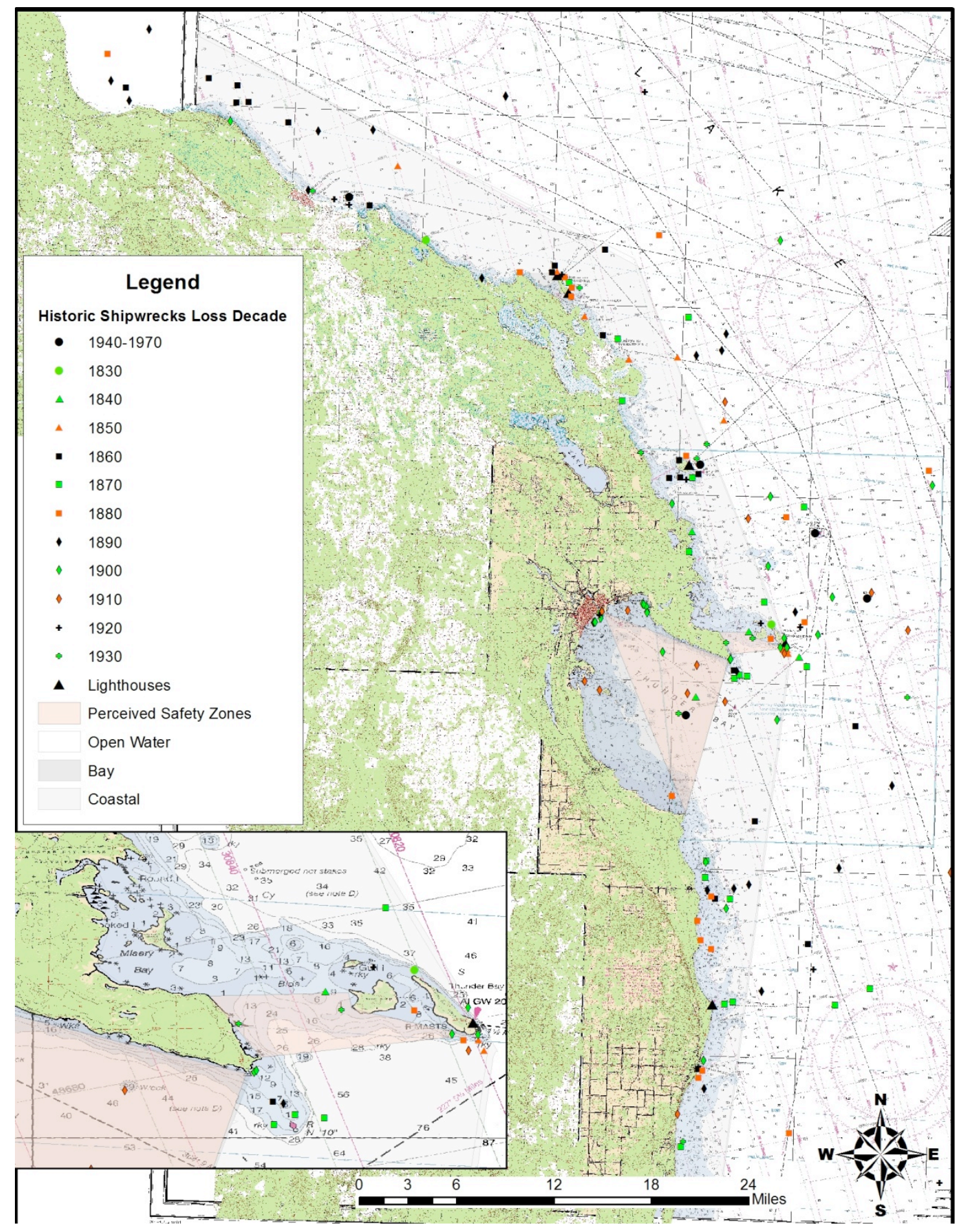

7.3b Decade of Loss (Spatial) 


\section{Nineteenth Century}

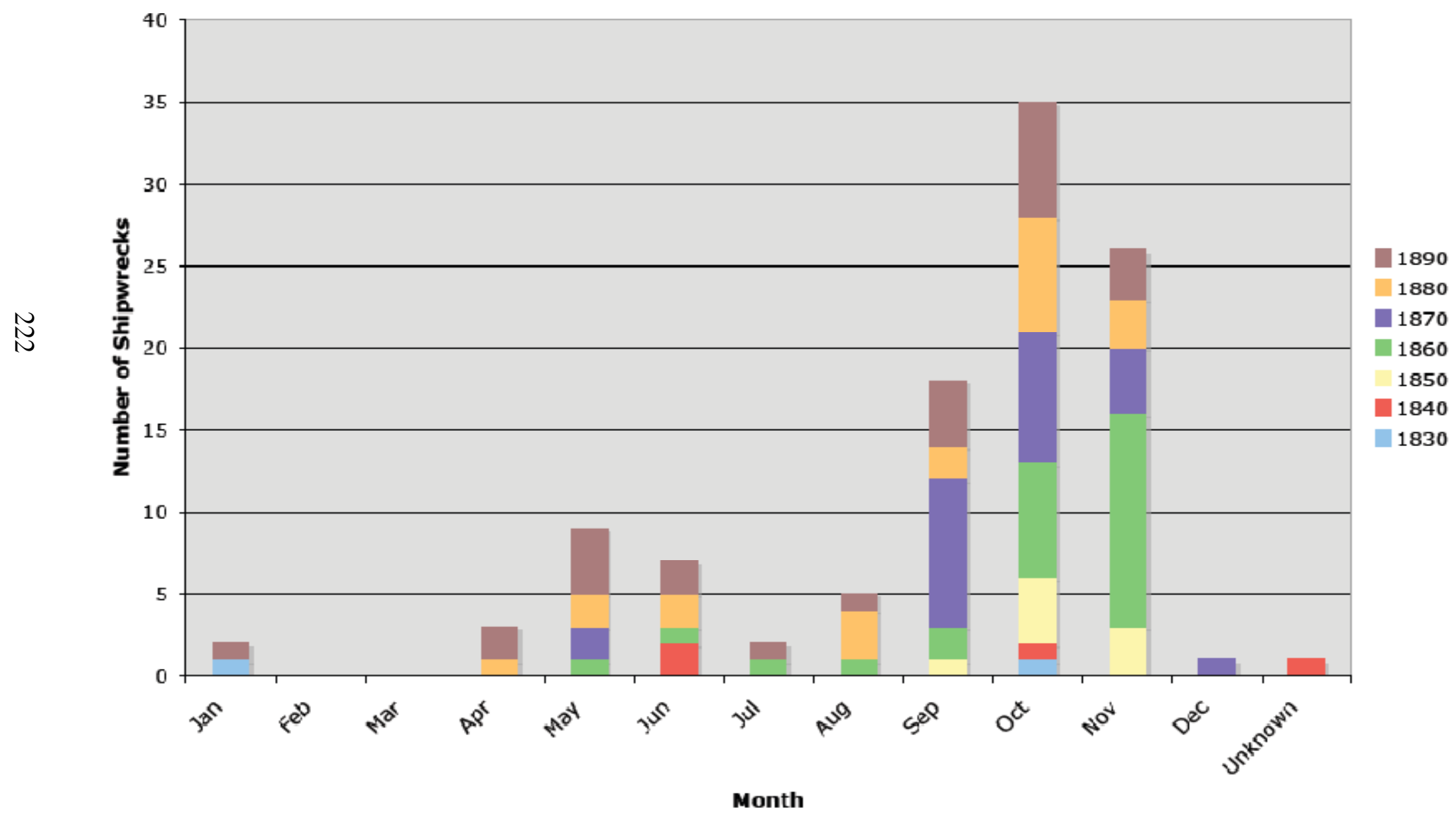

7.4a Month of Loss, Nineteenth Century (Graphical) 


\section{Twentieth Century}

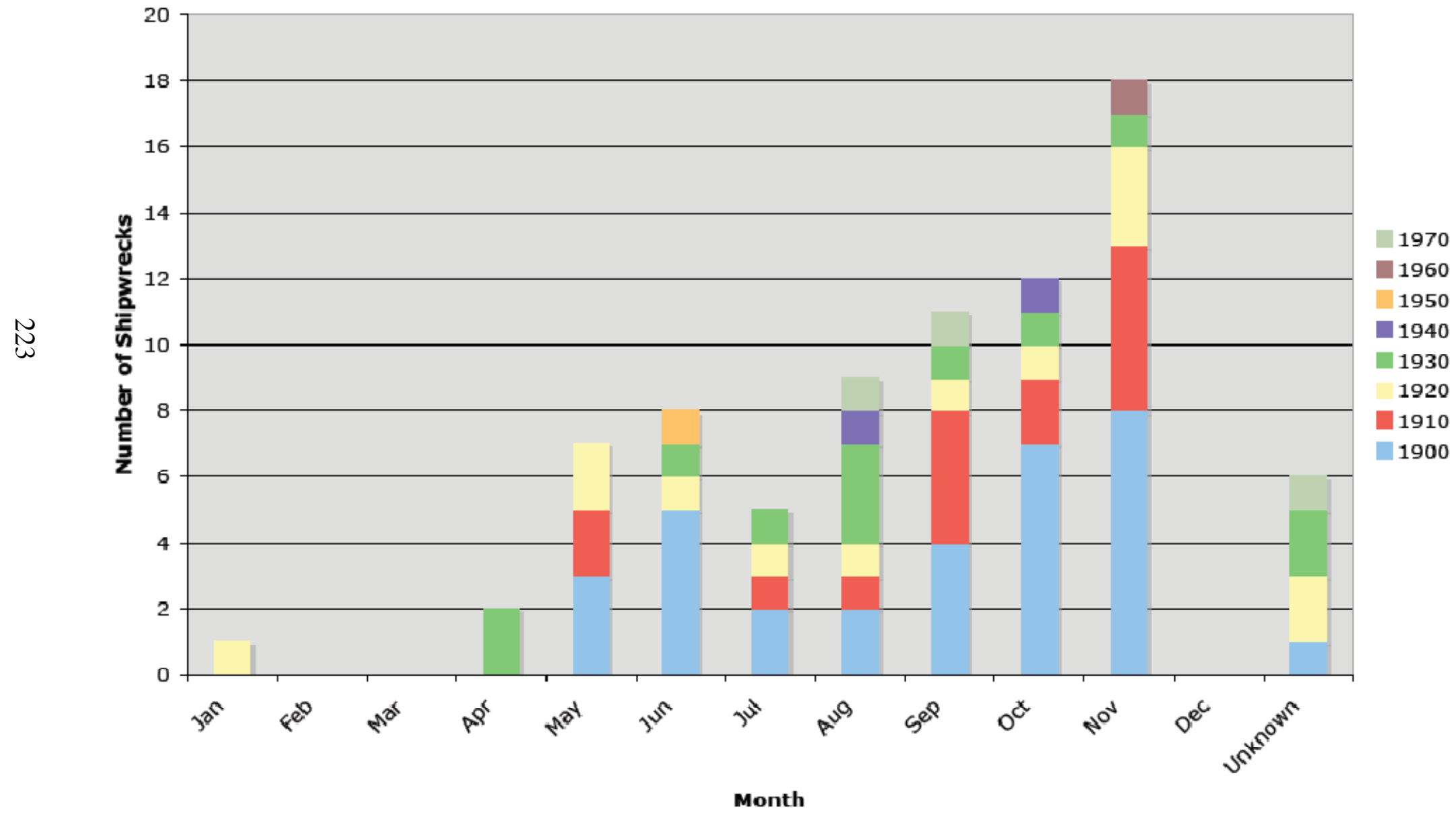

7.4b Month of Loss, Twentieth Century (Graphical) 


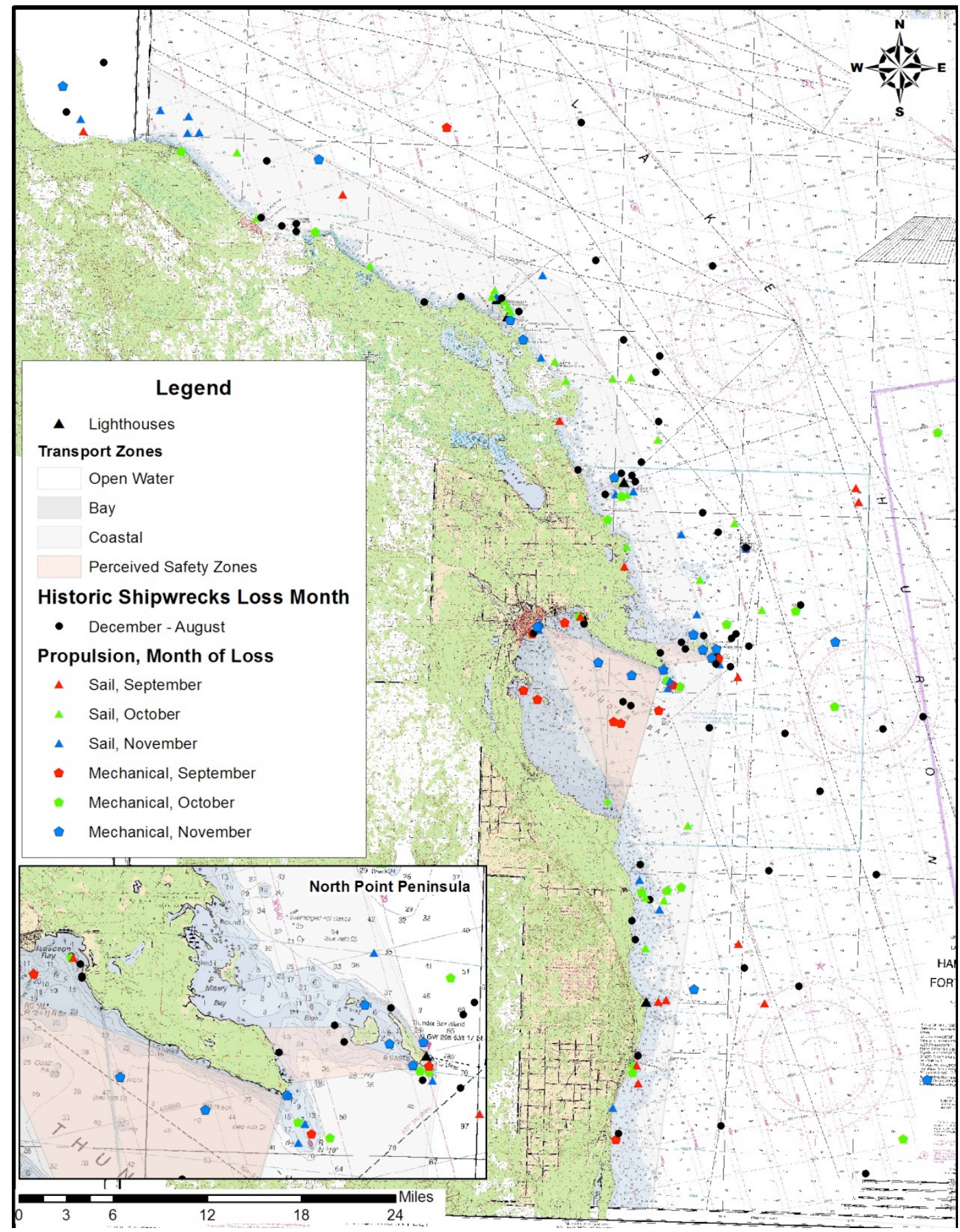

7.4c Month of Loss (Spatial) 


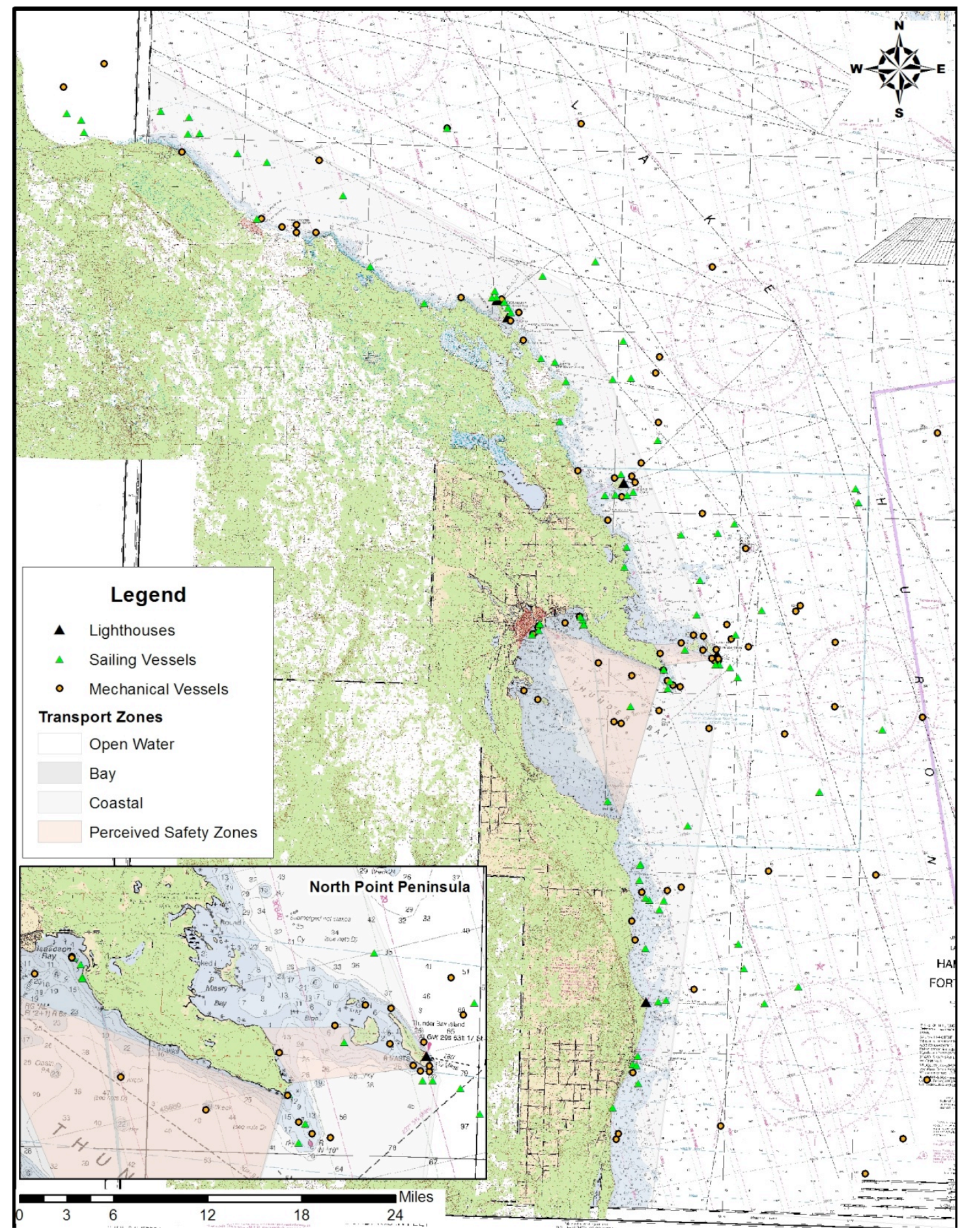

7.5 Propulsion System at Loss (Spatial) 


\section{Nineteenth Century Loss Type per Decade (Sail)}

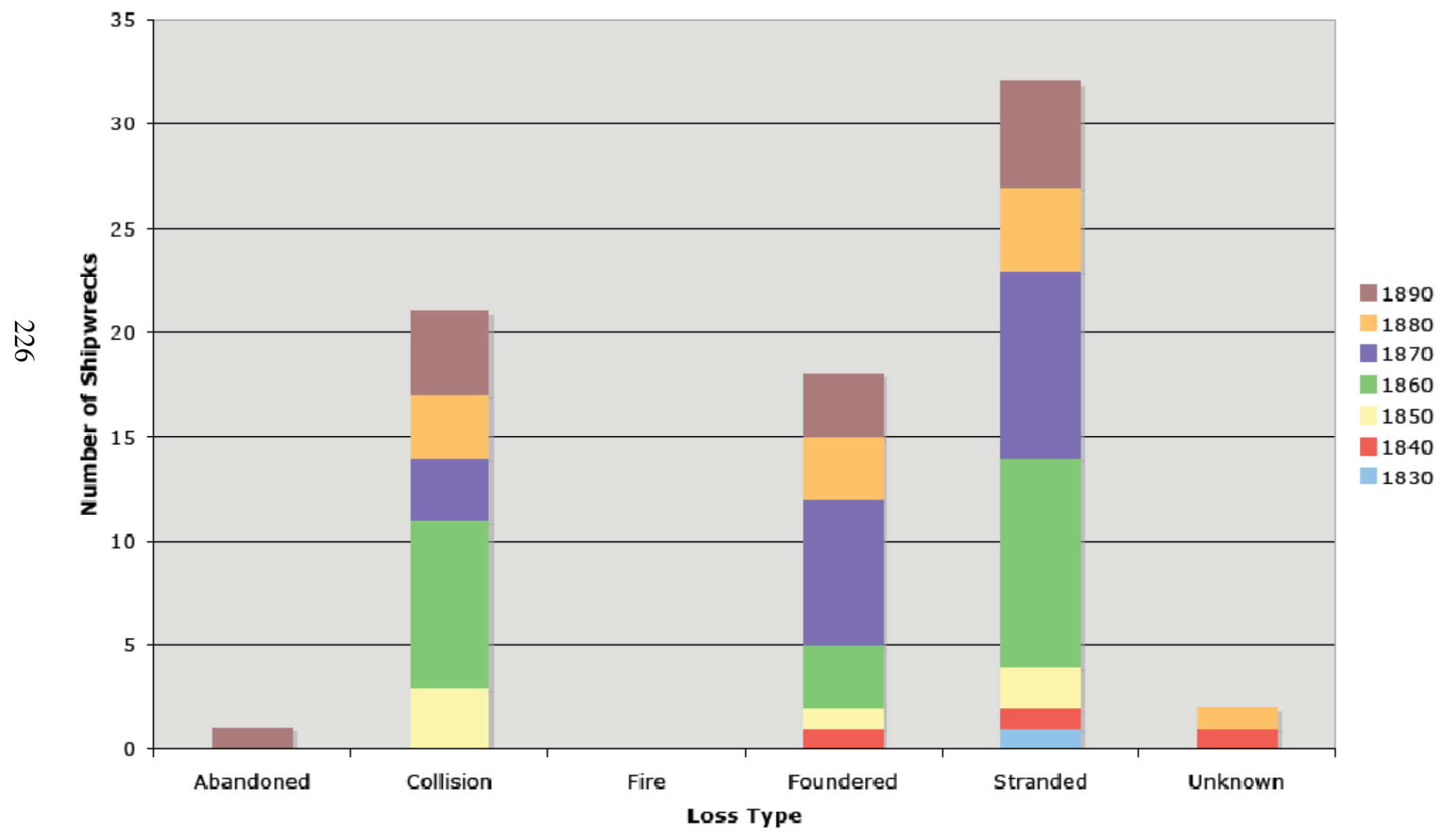

7.6a Type of Loss (Sail), Nineteenth Century (Graphical) 
Nineteenth Century Loss Type per Decade (Mechanical)

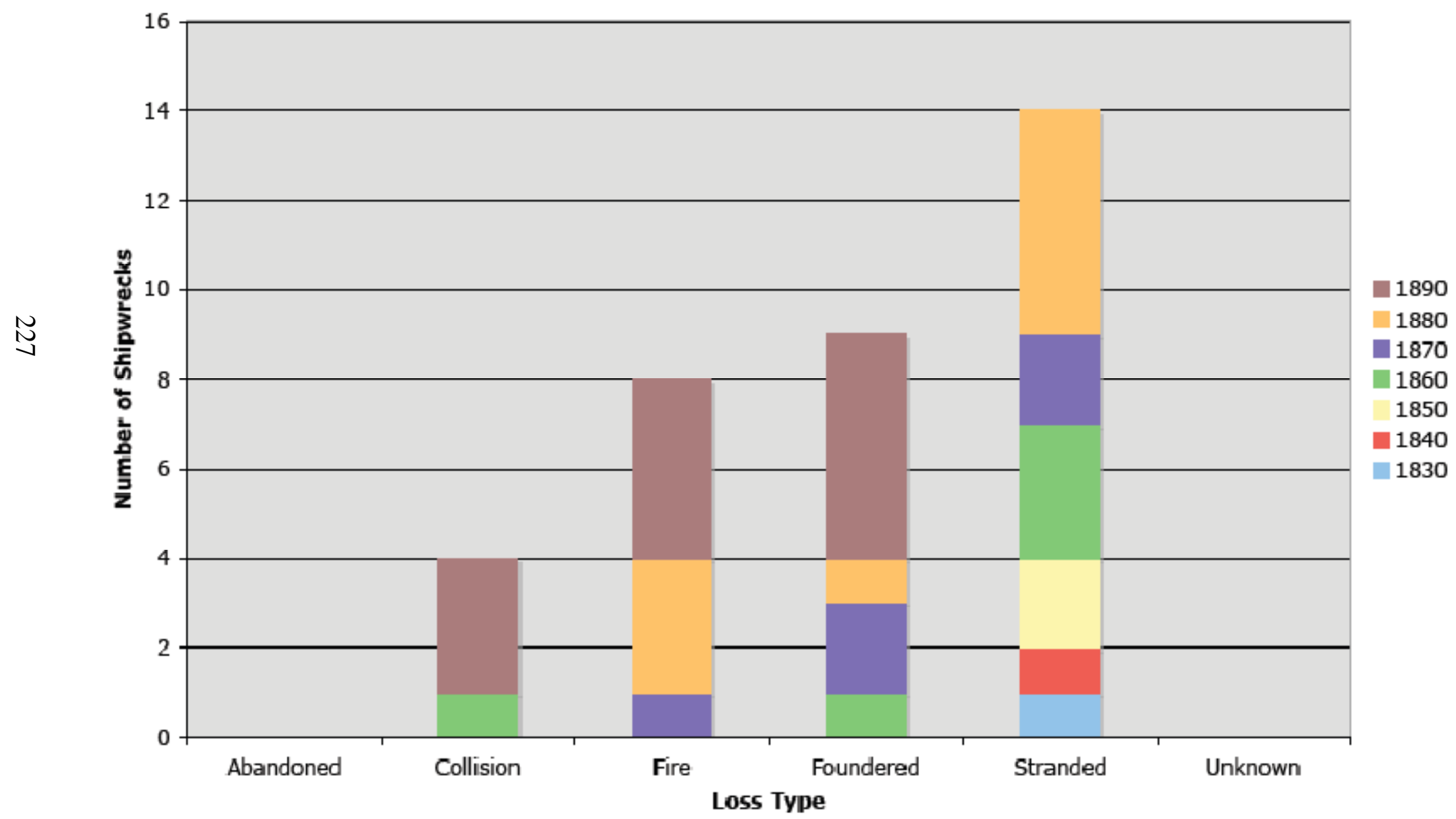

7.6b Type of Loss (Mechanical), Nineteenth Century (Graphical) 
Twentieth Century Loss Type per Decade (Sail)

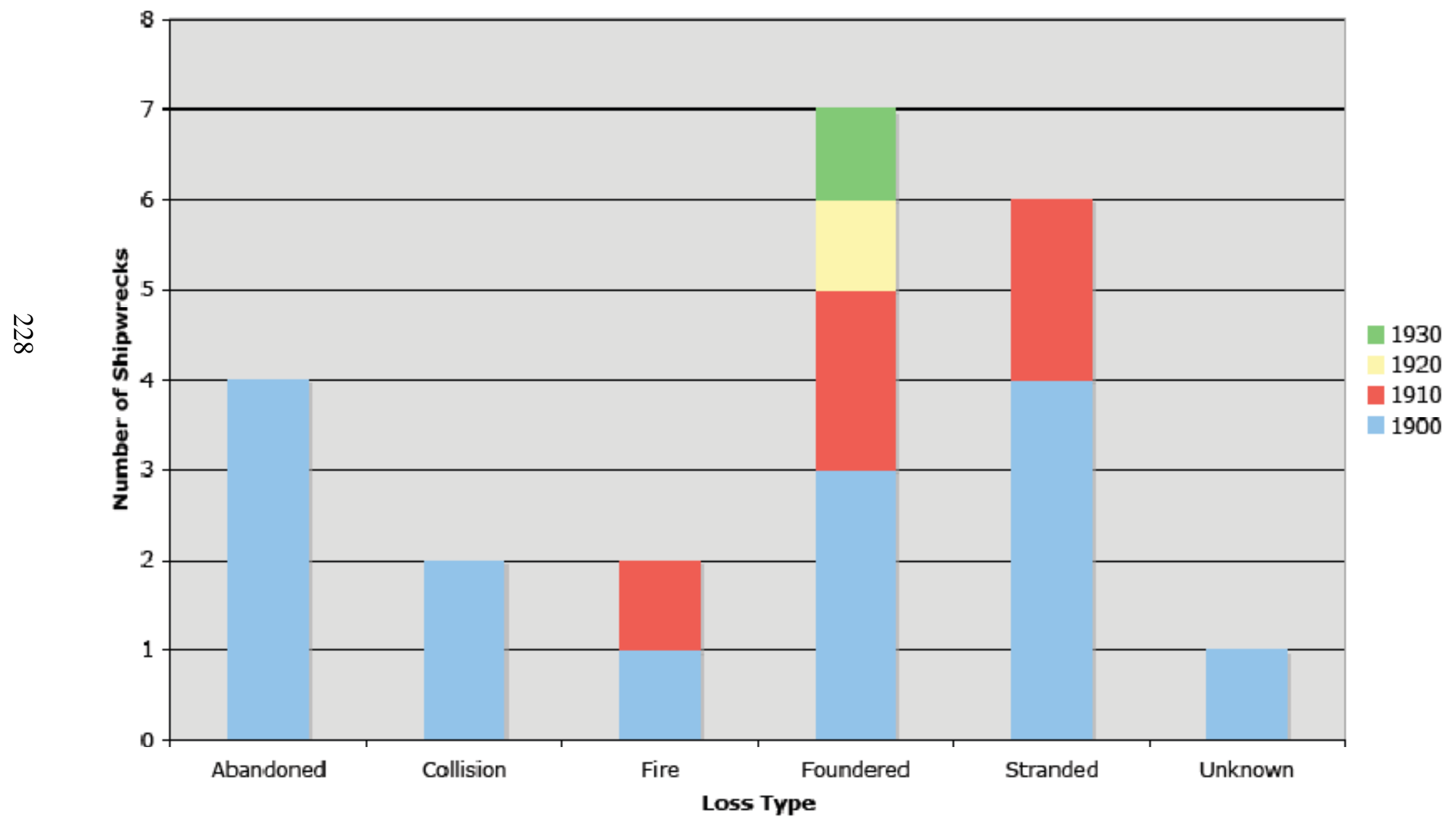

7.6c Type of Loss (Sail), Twentieth Century (Graphical) 
Twentieth Century Loss Type per Decade (Mechanical)

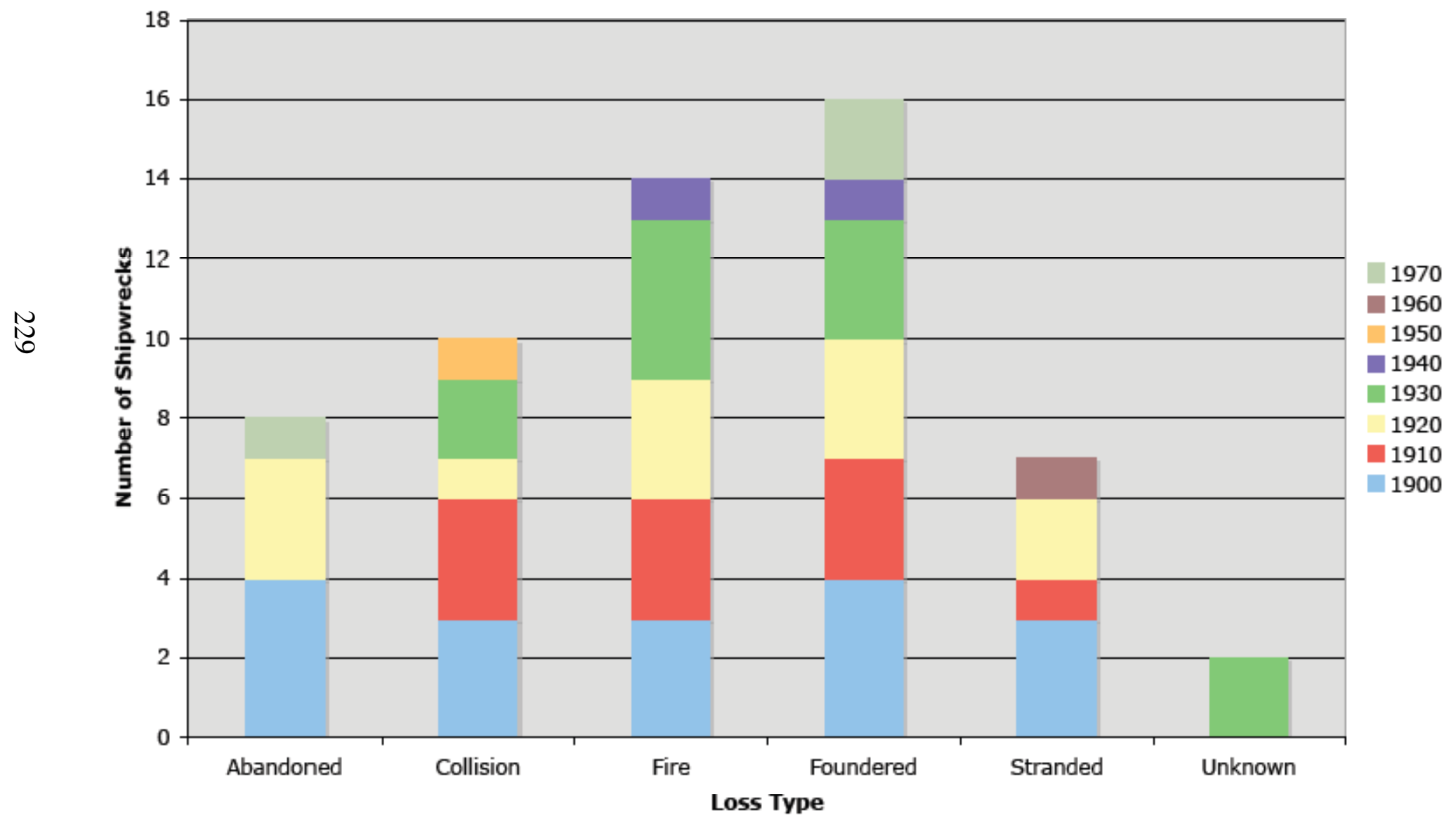

7.6d Type of Loss (Mechanical), Twentieth Century (Graphical) 


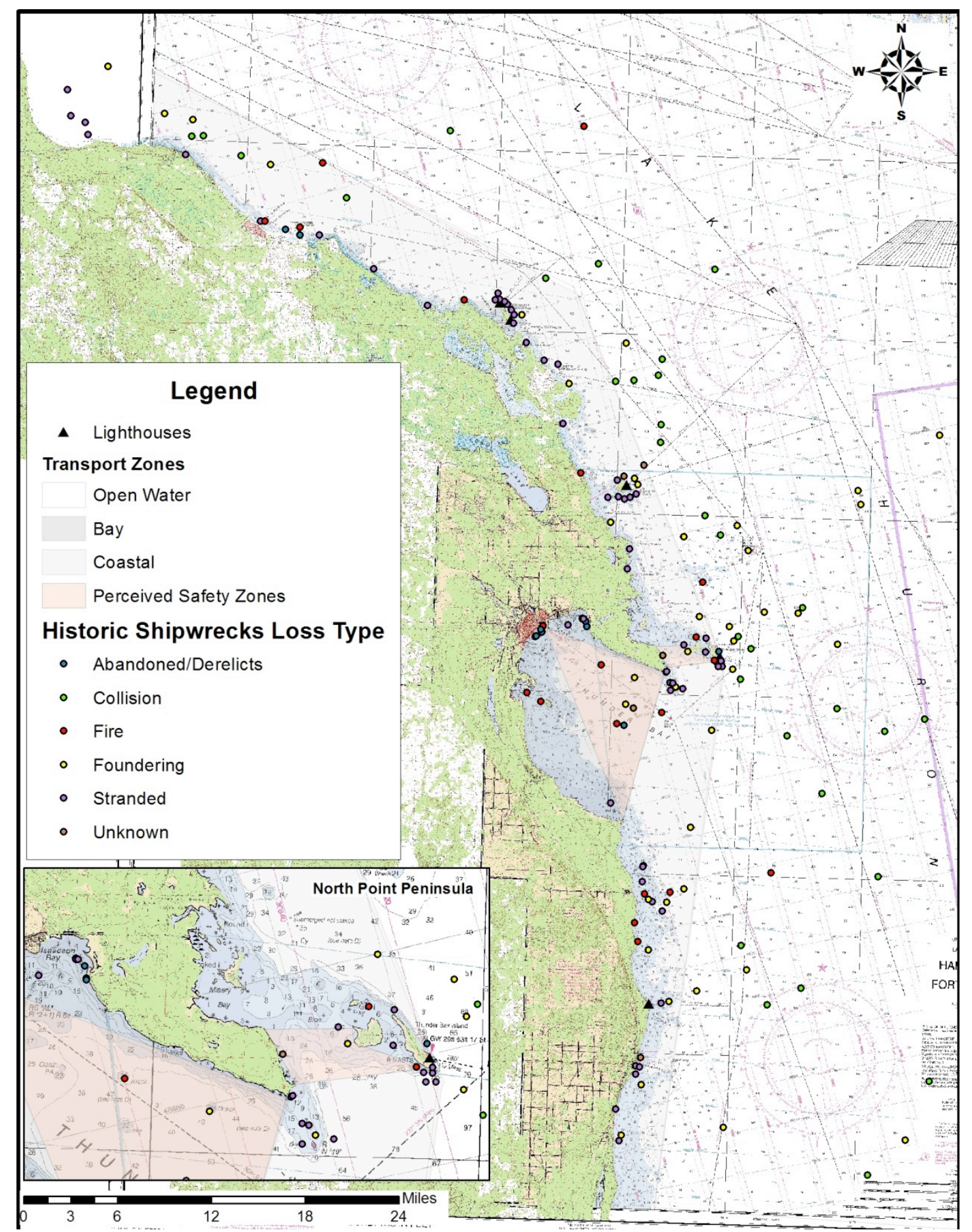

7.6e Type of Loss (Spatial) 


\section{Nineteenth Century Cargo at Loss per Decade}

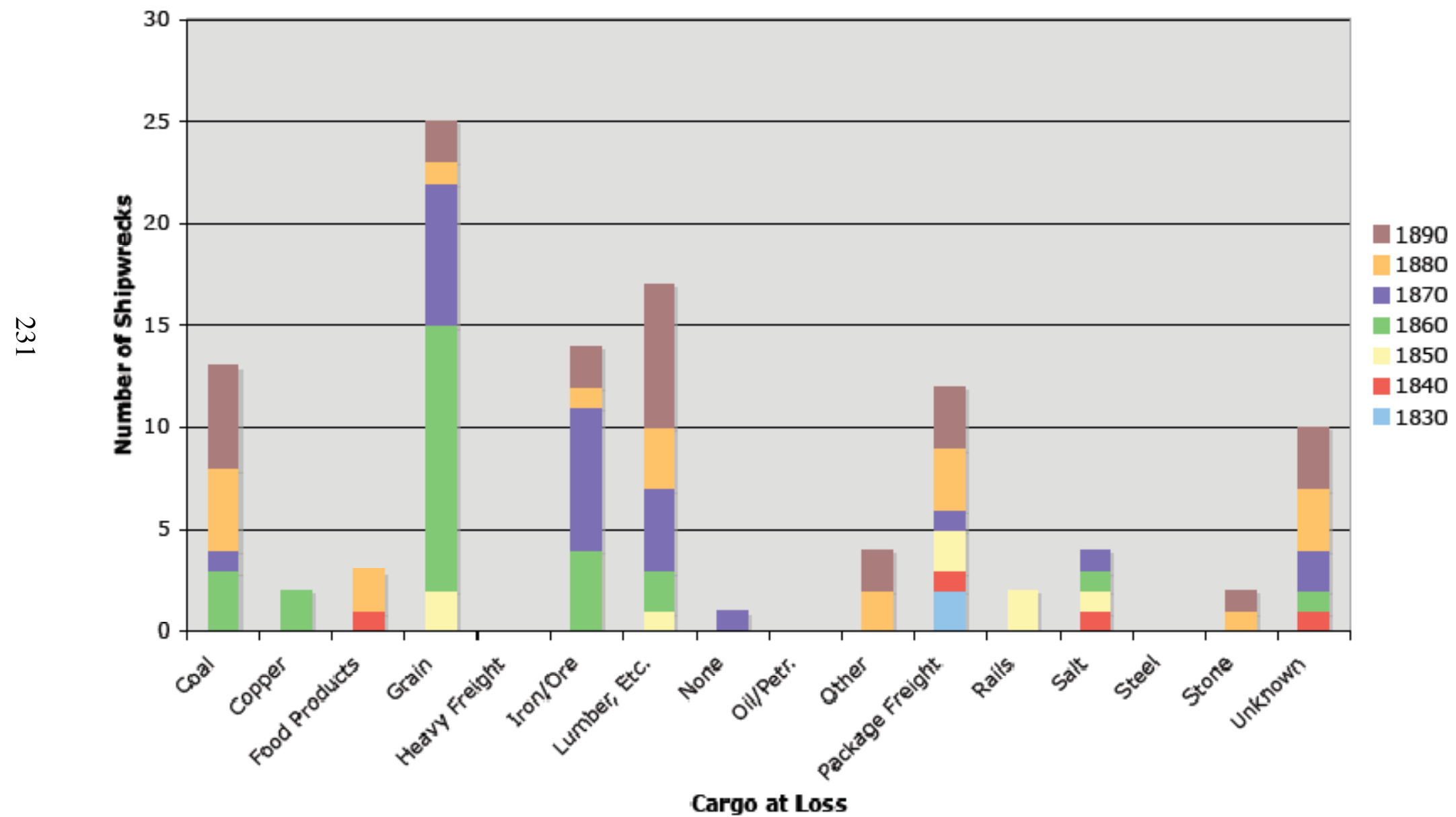

7.7a Cargo at Loss, Nineteenth Century (Graphical) 
Twentieth Century Cargo at Loss per Decade

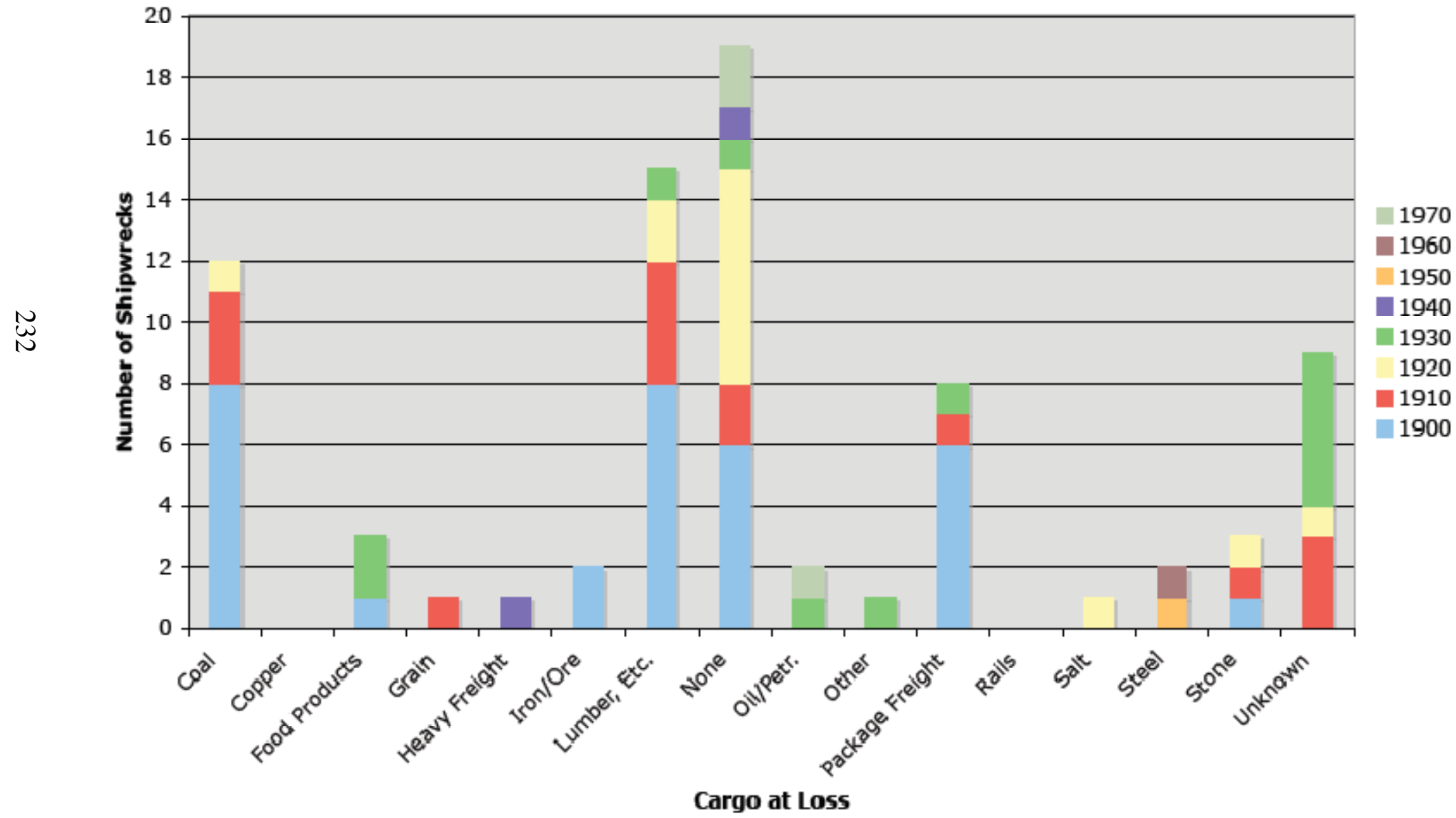

7.7b Cargo at Loss, Twentieth Century (Graphical) 


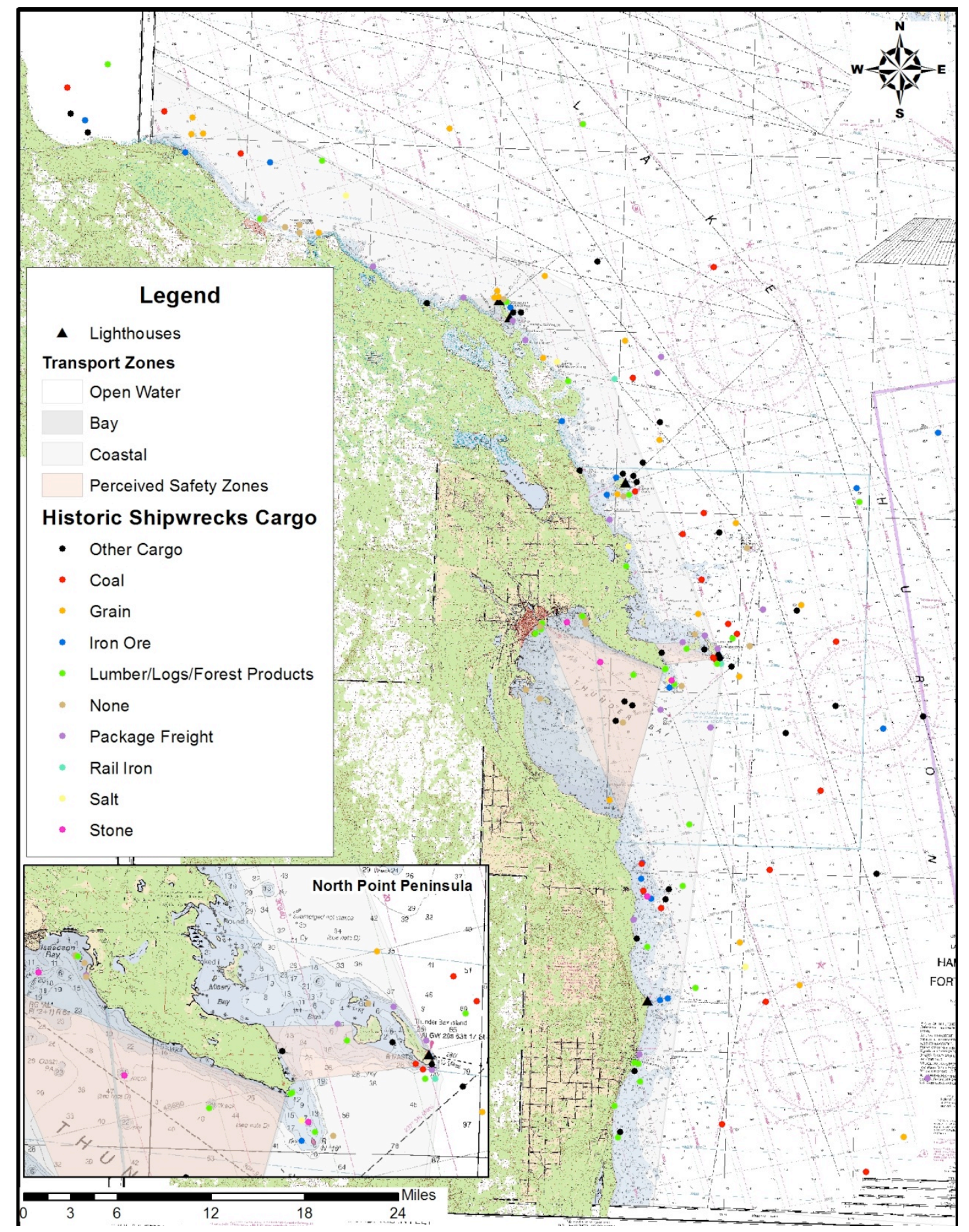

7.7c Cargo at Loss (Spatial) 


\section{Age of Vessel at Loss per Decade}

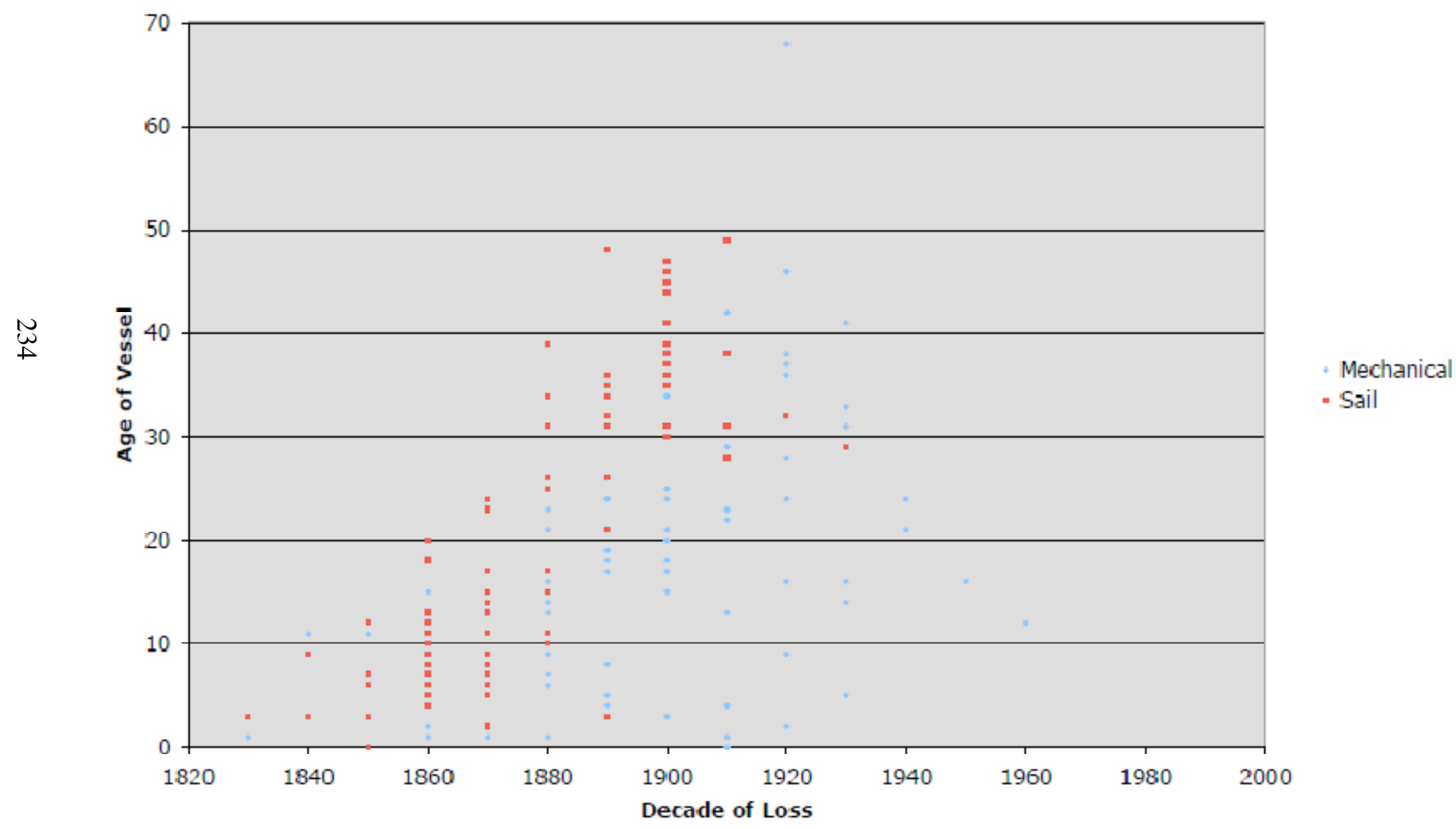

7.8 Age at Loss 


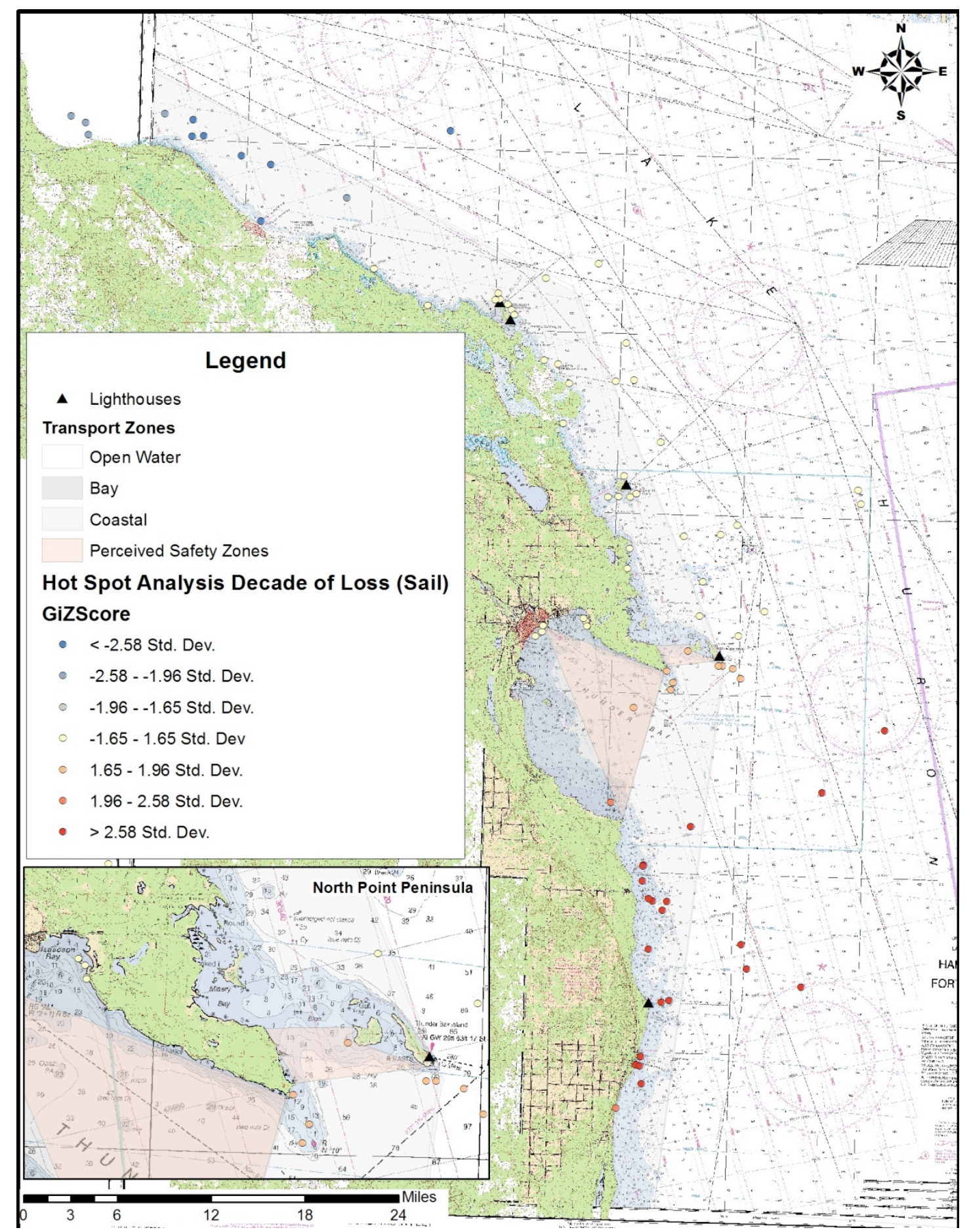

7.9 Hot Spot Spatial Analysis of Decade of Loss (Sail) 


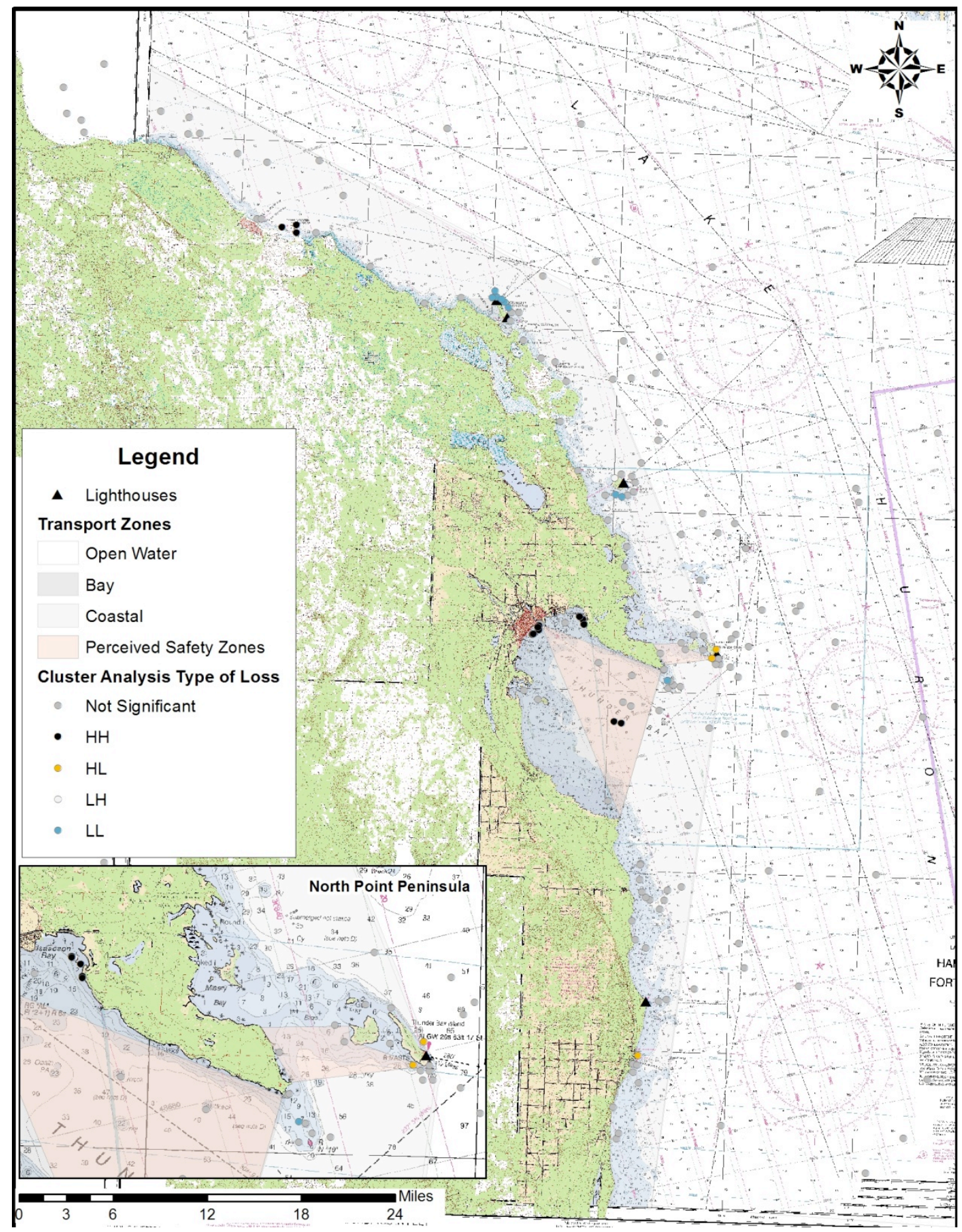

7.10 Cluster Spatial Analysis of Type of Loss 


\section{CHAPTER 8}

\section{THE MOBILIZED ARCHAEOLOGICAL LANDSCAPE OF THUNDER BAY NATIONAL MARINE SANCTUARY}

In addition to shipwrecks and the events associated with their immediate loss, the mobilization of associated wreckage could cause both excitement and serious concern within the maritime community. The appearance of recognizable mobilized wreckage could be the first, and perhaps only evidence of a disaster. For example, the fate of the bulk freighter Kaliyuga, believed to have foundered off of Presque Isle in the "Great Gale of 1905", was determined upon the appearance of the corpse of a crew member ashore at Kircardine, Ontario. Nearby at Southampton, Ontario, several pieces of decking, the cabin, and the name board also washed ashore (The Alpena Evening News, Tuesday 10/31/1905: 3). At the same time, prior to the widespread use of marine radios, it was common for vessels to be erroneously reported as lost. For example, a Chicago news source reported that the Waldo had been lost with all hands, though it was stranded ashore and its crew rescued, after the pilothouse washed ashore near Marquette, Michigan (Brown 2004: 58, 139).

The identification of remobilized wreckage also served to keep the events of maritime disaster fresh in the psyche of the maritime community long after the initial accident, potentially with the power to affect maritime behavior. Wreckage could appear months after the loss of a vessel. For example, wreckage from the passenger paddlewheel Albany, which stranded in a storm above Presque Isle, was spotted by a passing vessel at Port Huron, Michigan five months after it wrecked (Detroit 
Advocate, Buffalo Daily Republic, Thursday 4/20/1854; Cleveland Morning Ledger, 4/21/1854). Note that the three papers that reported this accident are from cities far from the accident location. The identification of mobilized wreckage did not just affect the local maritime community but the community of the entire Great Lakes maritime landscape.

The reporting of mobilized wreckage also illustrates the ability of the lakes to move the wreckage over long distances. The wreckage of the Kaliyuga, discovered ashore across Lake Huron, was not an isolated event. This explains why the appearance of mobilized wreckage would be considered important news in distant ports. It could take the entire Great Lakes maritime community to identify the provenance of the wreckage.

The Efficacy of the Analysis of Mobilized Wreckage

As with the distribution of shipwrecks, the location of mobilized wreckage in Thunder Bay National Marine Sanctuary is not random. Mobilized wreckage is here defined as materials that derive primarily from shipwrecks, but can also include other maritime infrastructure such as log rafts or timber cribbing, that are removed from the location of primary deposition and are transported and deposited through either natural or human forces. In most cases, the identified location of these materials is temporary as they can be entrained into the water column and set down elsewhere. Therefore, the location used in this analysis is that identified at the time of the side-scan sonar survey. 
In nearly all cases, it is impossible to determine either the specific vessel/structure or the event from which the mobilized wreckage derives. It is, therefore, difficult to analyze these archaeological deposits as sites in the context of human behavior. It is possible, however, to incorporate the analysis of mobilized wreckage as a part of the maritime archaeological landscape through the use of the new maritime archaeological landscape formation model by introducing it to the overall structure of the landscape in Stage 2 with an analytical "Time 0" of wreckage arriving at a specific location and creating a site. "Time 0 " is recognized as being the moment that the wreckage is discovered at a given location.

Once a given area is mapped, it is the locations of the mobilized wreckage on the landscape, and not the individual pieces of wreckage, that are important when analyzing landscape formation. This is because it is impractical, and also functionally impossible to track each individual piece of wreckage as it moves through the landscape. Subsequent periodic mapping of the area elicits overall changes in the landscape including where wreckage survives, where it rests temporarily, and where it is absent, all of which can be quantitatively measured.

The survey and archeological site identification in this research represents "Time 0 " for the presence of mobile wreckage in Thunder Bay in the immediate vicinity of North Point Peninsula. While this precludes the study of change on the landscape, it does allow investigation into what environmental parameters encourage at least temporary preservation at a given location. This analysis will focus on the relationship of the mobilized wreckage to the local geology and presence of 
shipwrecks in the context of average reported currents constrained by coastal landforms.

Of the 919 square kilometers surveyed, this analysis will focus on the 31.5 square kilometers surveyed in the immediate vicinity of North Point Peninsula and Thunder Bay and Sugar Islands. Not only is this area identified on the maritime landscape as the nexus of three transport zones (bay, coastal, and open water) it contains three perceived safety zones (Thunder Bay Island lighthouse, the lee passage between Thunder Bay Island and North Point, and Thunder Bay). It also contains two of the three identified grounds for pound-net fishing, the third located in the vicinity of Sulfur Island. Lastly, it contains every type of mobilized wreckage identified through survey.

The Mobilized Wreckage of North Point Peninsula

Within this area, the mobilized wreckage consists of material identified through the side-scan sonar survey and mobilized associated and unassociated articulated wreckage and isolated finds identified during the ECU diving survey of the North Point shoals off the tip of the peninsula. Only wreckage identified through the sidescan sonar survey that have assigned values of one of two are included as targets with a value of three are likely not archaeological in origin. This collection of mobilized wreckage includes: 49 pieces of identifiable wreckage, 11 isolated finds, 8 debris, 203 linear targets, and 2 unknown targets. 
Most of the survey area does not contain any identified mobilized wreckage. In fact, the survey area east of Thunder Bay Island contains only five total targets in 14.5 square kilometers. Nearly all of the mobilized wreckage is concentrated in four primary locations within the survey area (Figure 8.1). From east to west these locations are: the southern end of Thunder Bay Island (location 1), along the edge of the shoals east of North Point peninsula (location 2), within the North Point shoals off the tip of North Point peninsula (location 3), and along the edge of the shoals southwest of North Point peninsula (location 4). Additionally, formerly mobilized wreckage, primarily consisting of ship timbers, iron parts including strapping and davits, and scattered coal, are continuously scattered along the beach on the eastern coast of North Point peninsula. This stretch of coastline runs parallel to the area surveyed between the peninsula and Sugar Island.

Shipwrecks occur in two of the four locations of mobilized wreckage concentration, locations 1 and 3. Nearly all of the vessels wrecked by stranding, a typically highly destructive process that often produces considerable loose wreckage. Shipwrecks also occur within the survey area east of Thunder Bay Island in which there was very little mobilized wreckage. Additionally, shipwrecks have been identified out side of the survey areas in both open water and within the North Point shoals. Any of these shipwrecks may have contributed to the mobilized wreckage identified through the surveys; however, an analysis of the spatial relationship between locations of types of wreckage, the depth of wreckage, and the location of shipwrecks illustrates the likelihood of shipwreck origin. Explanations for this spatial patterning of the mobilized wreckage might include a combination of physical traps 
for mobilized wreckage, current patterns, wave activity, and purposeful removal and/or dredging.

Spatial Patterning of Mobilized Wreckage

Distribution of mobilized wreckage by type of wreckage is highly patterned (Figures 8.2 and 8.3). All articulated wreckage and isolated finds are confined to either location 1 or 3 . Both locations have shipwrecks that wrecked by stranding in the immediate vicinity. In location 3 , several of these sites have been identified as associated with a particular vessel. There are no other types of mobilized wreckage identified in location 3, however this may be an artifact of the unsystematic 2005 ECU diving survey. Location 3 is very shallow. All wreckage was identified in water less than approximately ten feet in depth. In addition to articulated wreckage and isolated finds, location 1 also contains linear artifacts. The water in location 1 is quite shallow, as well, and the sites of the relatively larger articulated wreckage is more inshore than the both the isolated finds and linear artifacts.

Alternatively, locations 2 and 4 contain only linear artifacts and a few unidentifiable targets. While the depth of location 4, ranging from approximately 20 to $30 \mathrm{feet}$, is artificially constrained by the extent of the survey, the distribution of sites in location 2 is restricted to depths between approximately ten and 25 feet. As this depth range is essentially equivalent in locations 2 and 4, it is possible that the area surveyed in location 4 represents the actual distribution of linear artifacts. For all of the wreckage in locations 2 and 4 it is impossible to assign a shipwreck of origin. 
An explanation for the observed spatial patterning of mobilized wreckage can be postulated to include a combination of physical barriers or traps, prevailing or average currents, and historic maritime activity. A fifth explanation is likely the role of nearshore ice scour; however, local data have not yet been analyzed to account for this parameter. It was hoped that it would be possible to quantify the effects of physical environmental parameters (surficial geological, chemical, and biological); however, the spatial resolution of available data sets is not sufficient to be able to analyze differences between sites within the survey area. Additionally, a sediment budget has not been quantified in the vicinity of North Point. In other words, every location has essentially the same value for different environmental parameters. The following set of potential explanations is therefore based upon observed phenomena and function as hypotheses worthy of future testing.

\section{Physical Barriers or Traps}

There are two types of physical barriers or traps present within the four concentrations of wreckage: pocketed shoals of highly variable shallow bathymetry and densely packed pound net stakes. Other physical traps present in the vicinity of Thunder Bay, with concentrations of mobilized wreckage, include the karst sinkholes located north of North Point near Middle Island (Coleman 2003). Location 3 is composed of very shallow, highly variable bathymetry with small pockets in which wreckage and isolated finds have settled. While it is possible that this wreckage may have washed into the trap from elsewhere, all wreckage associated with a particular 
vessel is from a shipwreck located in the immediate vicinity. It is therefore likely that the unassociated wreckage also derived from one of the vessels wrecked within the trap.

This wreckage may have broken away during the initial process of wrecking. Alternatively, because the vessels that wrecked in the North Point shoals are relatively easily accessible in calm seas, the wreckage may have been created and deposited during salvage activities for which the vessel in question was not to be recovered. While individual components such as timbers or cargo elements might have broken from the articulated wreckage and could have washed out of the trap, the average circulation and local weather induced wave action must not be powerful enough to transport the articulated wreckage from the shoal pockets.

Location 1 is similar to location 3 in that it contains a mix of articulated wreckage and isolated finds, but also contains individual timbers. This mobilized wreckage is also co-located with several shipwrecks, including those that wrecked due to stranding and abandonment. While the bathymetry does not contain pockets within the shoals, it is possible that the steep slope of the lake floor on the lee side of Thunder Bay Island impedes the entrainment of the wreckage. It is likely, therefore, that this wreckage derives from shipwrecks in its immediate vicinity. At the same time, the steep slope and presence of the island would be expected to create turbulence in local bottom stream flows promoting the entrainment of mobilized wreckage. Perhaps the shipwrecks themselves in location 1 serve as breaks to stream flow and effectively create virtual bathymetric pocket traps. 
Locations 2 and 4 are very similar in structure. Both occur on the lee side of landforms and both contain concentrated nests of pound-net stakes at depths between approximately 20 and 30 feet (Figure 8.4a). Additionally, except for a couple sites, all mobilized wreckage in these locations is linear wreckage components, such as timbers. Many of these linear components are in physical contact with netstakes (Figure 8.4b). It appears that the netstakes serve as both a trap and a break in the current flow regime. Additionally, the consistency in the depths at which the concentration of timbers coupled with the regularity in the slope of the bathymetry at these locations indicate that some combination of physical processes maintain entrainment of mobilized wreckage until the wreckage arrives at these locations. Evidence for this is seen in the group of linear components found just outside of the concentration of netstakes near location 2 that lie at the same depth and on a similar slope. The netstakes indicate productive historic fishing grounds. It is likely that the physical processes that encouraged the presence of fish at these locations are the same processes that delivered and deposited there the mobilized wreckage.

Within both locations 2 and 4 there are distinct concentrations of linear components. While the density of netstakes in a given location may act as small traps within the fishing grounds, another possible explanation is that articulated wreckage may have washed into the netstakes, pounded upon them, and broke up with the individual timbers remaining in close proximity to each other. Whichever the case, it is highly probable that the arrival of wreckage within locations 2 and 4 date to after the fishing grounds were abandoned. Wreckage in the area would have been removed during the installation of the net stakes and any wreckage arriving after the rigs were 
installed would have been cleared as it could damage fragile nets, impede the collection of fish, and pose a hazard to the specialized pound net boats.

\section{Currents}

Currents in the Great Lakes are not regular and as persistent as they are in the oceans. In the lakes, current direction and temporal cohesion is dependent primarily on wind direction, fetch, vorticity, surface heat flux, and the Coriolis effect. In Lake Huron, net surface (less than 10 meters depth) circulation consists of a large counterclockwise gyre within the northern two-thirds of the lake with generally persistent southward flow along the Michigan shore (Figure 8.5). Observed speeds of this flow in the summer range from two to four centimeters per second (Sloss and Saylor 1976: $3069,3072,3074-3075)$. The average direction of the southward coastal flow is consistent at all depths throughout the year with currents somewhat stronger in the winter, up to approximately seven centimeters per second (Beletsky et al. 1999: 84).

The coastal boundary zone is defined as the area between the surf and swash zone and open water in which bottom friction impedes geostrophic flow. Though coastal flow regimes are highly complex and episodic, in general, during the summer, when the water column is highly stratified with the presence of a strong thermocline, down welling occurs within the coastal boundary zone when the shore is to the right of the net current flow, with offshore transport occurring within the bottom layer (Rao and Schwab 2007: 207). This should be the case along the Michigan coast in the vicinity of North Point east of the North Point shoals and Thunder Bay and Sugar Islands. 
Persistent down welling throughout the year suggests an explanation for the paucity of mobilized wreckage in the area surveyed east of Thunder Bay and Sugar islands. Though there are at least five shipwrecks within the area, there are only five identified sites of linear mobilized wreckage. Additionally, the distribution of this wreckage appears to be random. Most of the vessels in this area wrecked through either collisions or by foundering. While the degree of disarticulation of the shipwrecks is dependent on the unique characteristics of each accident, collisions and founderings typically produce less immediate mobilized wreckage than stranding accidents, especially if they are not subsequently salvaged. What wreckage is entrained from the lake floor is likely washed out of the area towards the east into the large, deep mid-lake basin. The coastal boundary zone is located at approximately the same spatial location as the confluence of the coastal and open water transport zones, an area in which are found many shipwrecks. It is expected, however, that, because of the current regime, most of this zone, along the Michigan coast between Presque Isle and past Sturgeon Point, contains little mobilized wreckage.

Wave Action

As with currents, wave action in the Great Lakes is dependent upon wind direction, speed, and fetch. The greatest effect of wind waves occurs in surf and swash zones inshore of the coastal boundary layer. Geostrophic flow is impeded with the coastal zone and nearly all circulation is driven by forces derived from the dissipation of breaking waves (Rao and Schwab 2007: 205). It is the effect of this 
wave action, which provides the power to entrain wreckage from traps that impede movement from currents. It also provides the energy to remove mobilized wreckage from the marine environment depositing it onshore. Such is the case for the shipwreck and cribbage related material located along the beach on the eastern shore of North Point Peninsula.

Wreckage stretches along the entire length of the beach along the eastern shore of North Point Peninsula. While some along the water line has the possibility of entrainment during storms from wave action or even the effect of seiches, most of the material has been incorporated into the terrestrial archaeological record.

While none of the wreckage ashore at North Point, save a single beached steel barge and associated scattered components, could be identified as to the shipwreck of origin, it is possible to determine the likely direction from which the materials derived based on local landforms and bathymetry. The peninsula itself is, of course, too broad and too forested to allow for wreckage to derive from within Thunder Bay. Also, it is doubtful that there is enough open water between Thunder Bay and Sugar Islands and North Point to produce enough fetch to create large waves. Recall that the passage between the island and the peninsula was considered a lee passage for vessels in storms. It is therefore improbable that the wreckage ashore derives from wreckage trapped in the shoals immediately to the east of the beach. There remains, therefore, the potential for wave activity, produced from northerly and southeasterly winds, from which the wreckage may have derived.

Though there is enough open water for northerly and southeasterly winds to produce enough fetch to create powerful waves with the ability to force wreckage 
ashore, the bathymetry severely restricts the ability of waves to sustain cohesion and resist breaking before reaching the beach. As waves travel inshore and the bathymetry shoals, wavelength decreases while wave height increases in order to conserve energy. When wave height exceeds 0.8 times the depth of the water, the wave breaks. The bathymetry to the north-northeast of North Point significantly shoals at a distance of approximately two miles from the shore. It would be expected that there would be a significant concentration of wreckage that derived from shipwrecks to the northnortheast trapped within the pockets at the edge of the shoals; however, to complicate the system, seiches created by persistent wind can "pile up" water along the coast changing the relative water depth. In the presence of a seiche, the spatial location at which wave height exceeds 0.8 times the depth of the water can be variable. It is likely that wave-deposited wreckage would be found throughout these shoals, the concentration however decreasing shoreward. Because of the width of the extremely shallow shoals to the north-northeast, it is unlikely that much of the beached wreckage arrived from this direction.

On the other hand, the bathymetry to the southeast of the beach gently slopes toward the shore and does not shoal until within half of a mile of the beach. Waves break at the shore with the ability to deposit entrained wreckage. This bathymetry is consistent along the length of the beach. It is therefore most probable that the wreckage ashore derives from the southeast. The efficacy of the comparison between the ability of wave action to deposit wreckage ashore from the southeast versus the northeast would be improved through a survey of the beach along the north shore of North Point, an area that can only be affected by northeasterly waves. It is expected 
that there would be much less wreckage along the northern shore than along the eastern shore.

\section{Historic Maritime Activity}

A variety of maritime activities affect the distribution of mobilized wreckage. The purposeful clearing of shipwreck debris from active fishing grounds has already been discussed. While the clearing of debris from these areas affects already mobilized wreckage, two other common activities in the immediate vicinity of North Point work to produce mobilized wreckage from shipwreck sites: salvage of shipwrecks and the clearing of navigation hazards. A third possibility, the deposition of dredge spoil also distributes wreckage material; however, there is no evidence of dredge spoil in this area.

Pecoraro (2007) discusses at length the regularity of salvage activities at North Point Peninsula. Her research indicates that specific components of shipwrecks are typically targeted for salvage, including machinery, rigging, and cargo. In many cases, the hull or decking of the vessels had to be penetrated to reach the desired materials. For example, to secure the machinery of the $B . W$. Blanchard, the hull of the vessel had to be blown up (Alpena Evening News 1905: 5, col. 3). There is no doubt that fragments of the hull of the Blanchard constitute a portion of the mobilized wreckage located within the bathymetric traps of the North Point shoals.

Shipwrecks were not only blown up to access salvageable components and materials. In shallow water, shipwrecks often posed a hazard to navigation; vessels 
underway could rip open their hulls on shipwrecks resting just below the surface. For example, the steam barge O. E. Parks foundered off of North Point in 1929 (Figure 8.6). Sitting upright on the lake floor, the foremast protruded above the water surface. A lantern was hung from the spar to warn vessels to give the site a wide berth. The disposition of the shipwreck on the lake floor indicates that, on an unknown date, the vessel was blown up to mitigate the navigation hazard. Though the keel and both sides of the hull remain for the most part articulated, much of the hull and decking are no longer located in the immediate vicinity of the shipwreck and have become mobilized.

This cursory analysis of potential explanations for the deposition of mobilized wreckage in the vicinity of North Point peninsula and Thunder Bay and Sugar islands has elicited many hypotheses worthy of further testing. It also proves the efficacy of the use of the new archaeological maritime landscape formation model to include all archaeological materials, especially mobilized shipwreck components in the analysis of not just the archaeological record, but associated maritime behaviors in both space and time. Periodic surveys of these areas will provide the ability to compare the variable spatial component of the mobilized archaeological record providing qualitative data with which it will be possible to determine which human and environmental forces variably act upon it. 
Figures

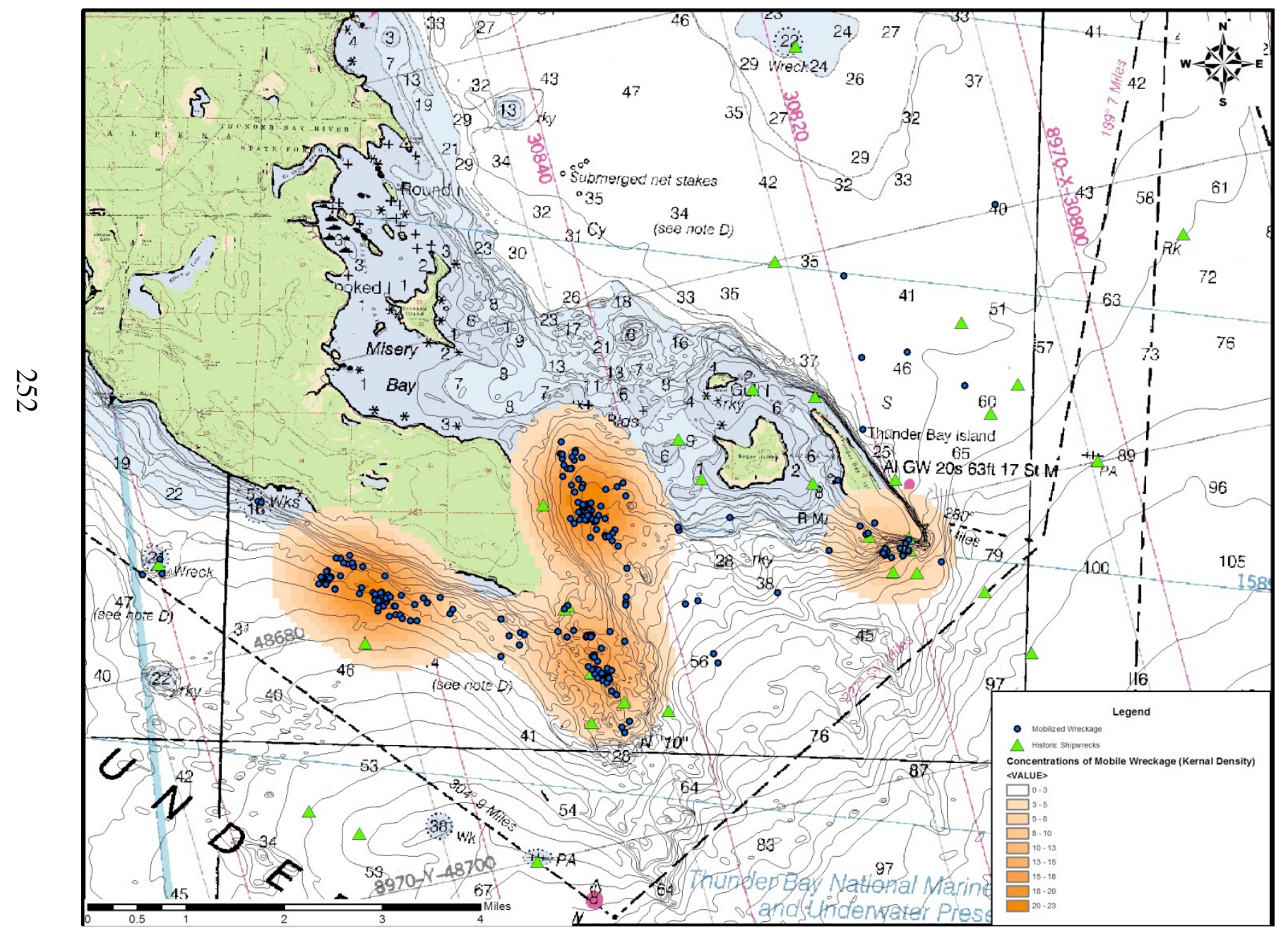

8.1 Concentrations of Mobilized Wreckage in the Vicinity of North Point Peninsula 


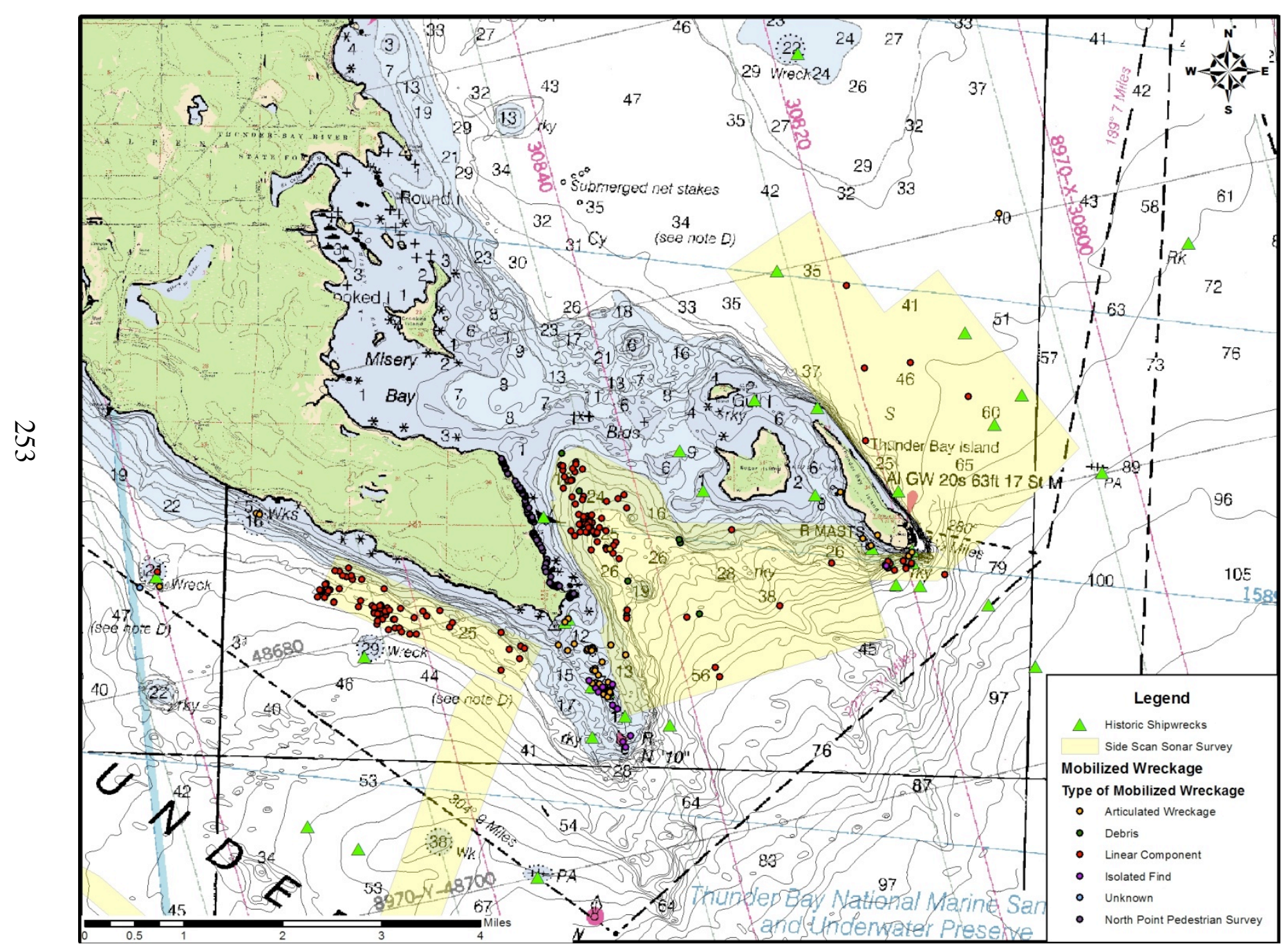

8.2 Distribution of Mobilized Wreckage by Type 


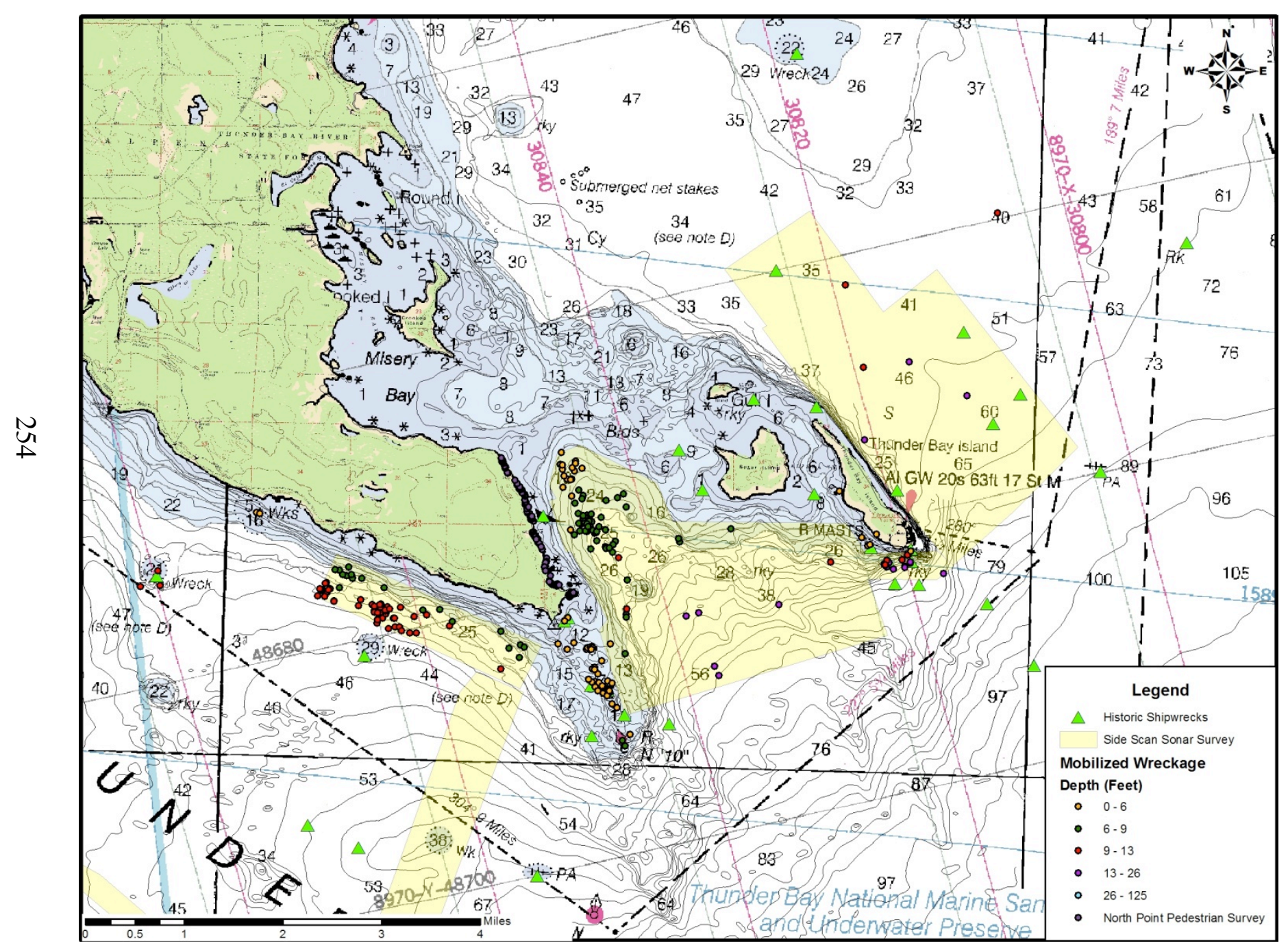

8.3 Distribution of Mobilized Wreckage by Depth 


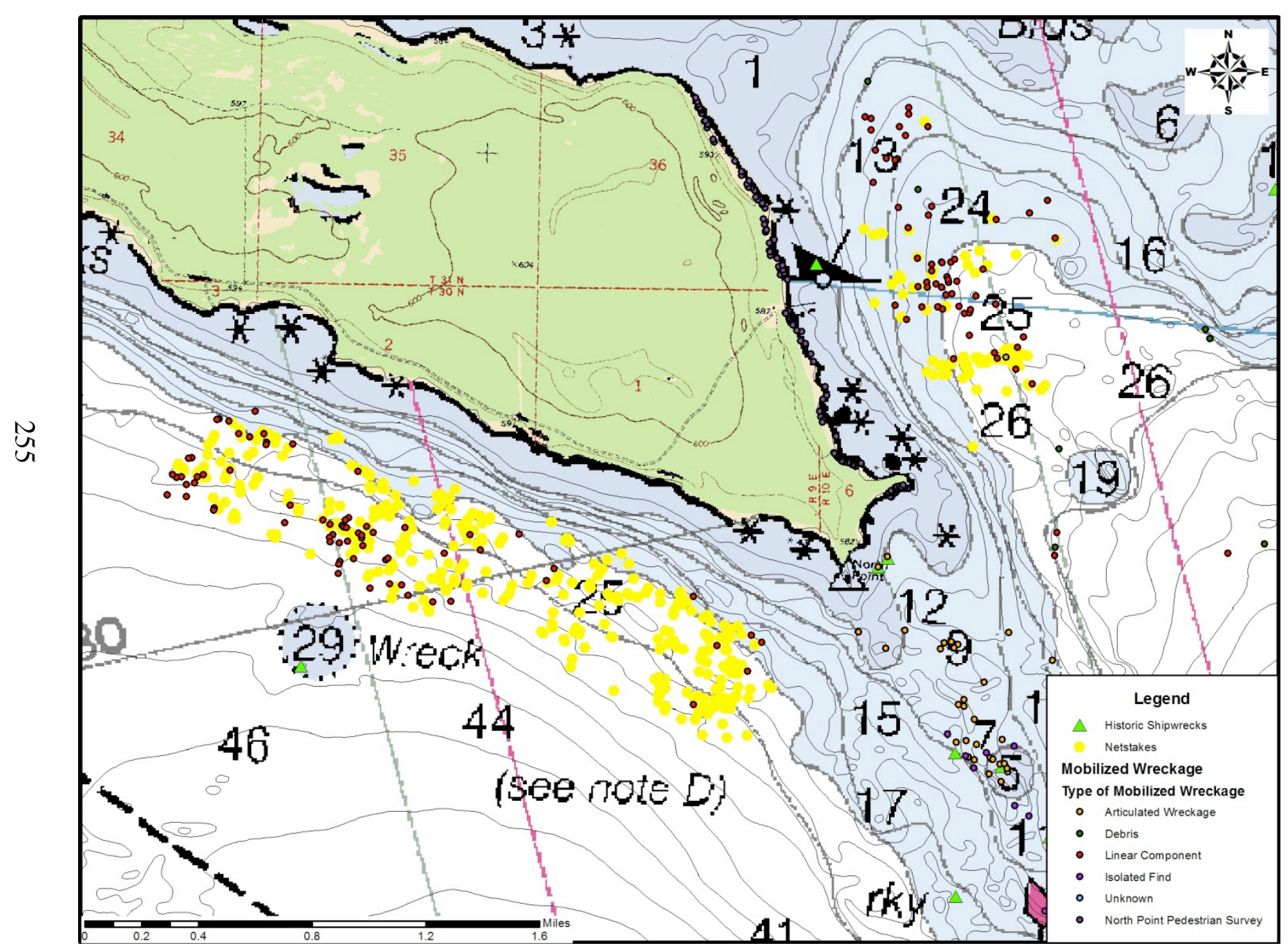

8.4a The Association of Mobilized Wreckage with Netstakes 


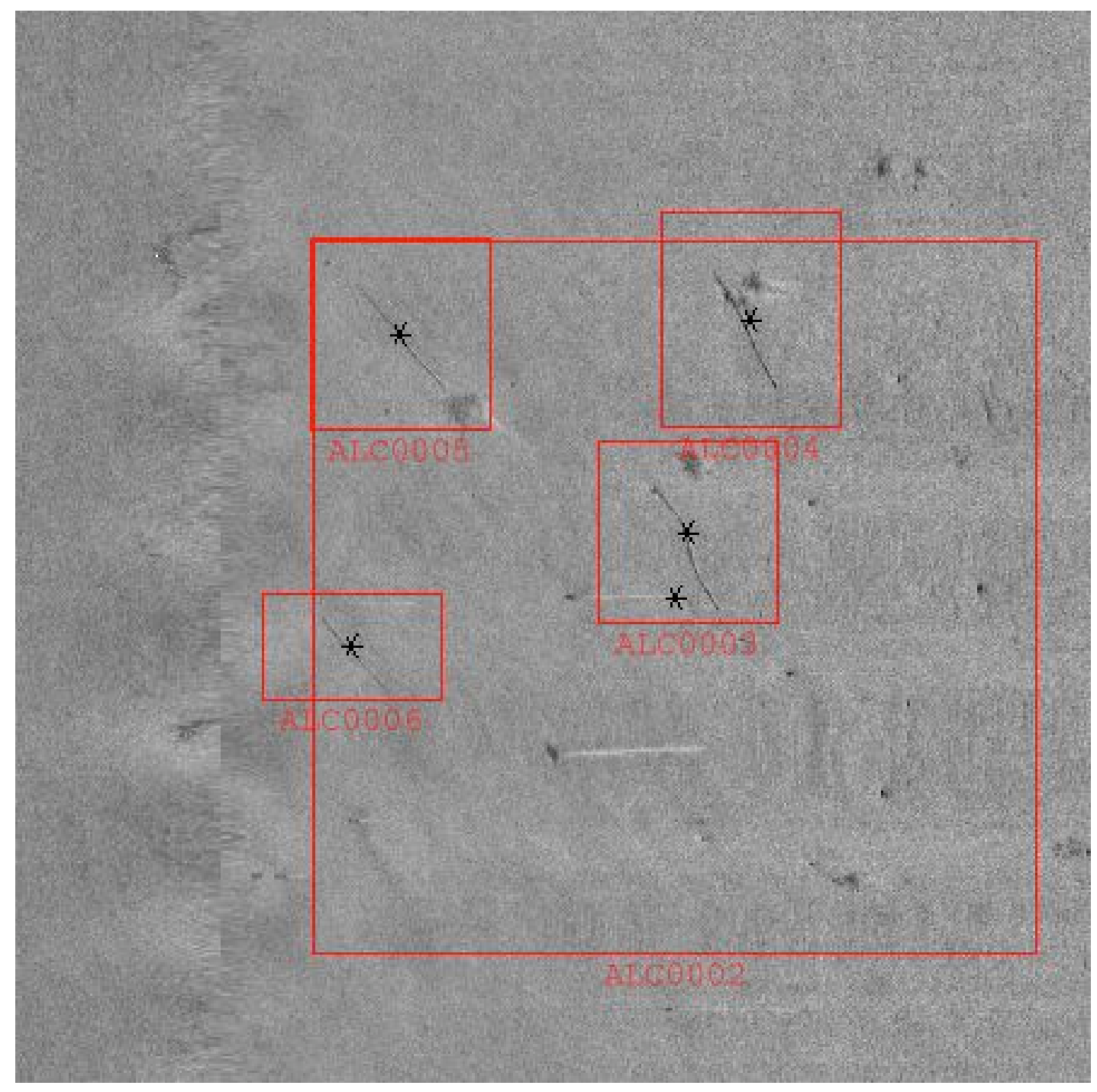

8.4b Side-scan Sonar Image of Mobilized Wreckage with Netstakes 

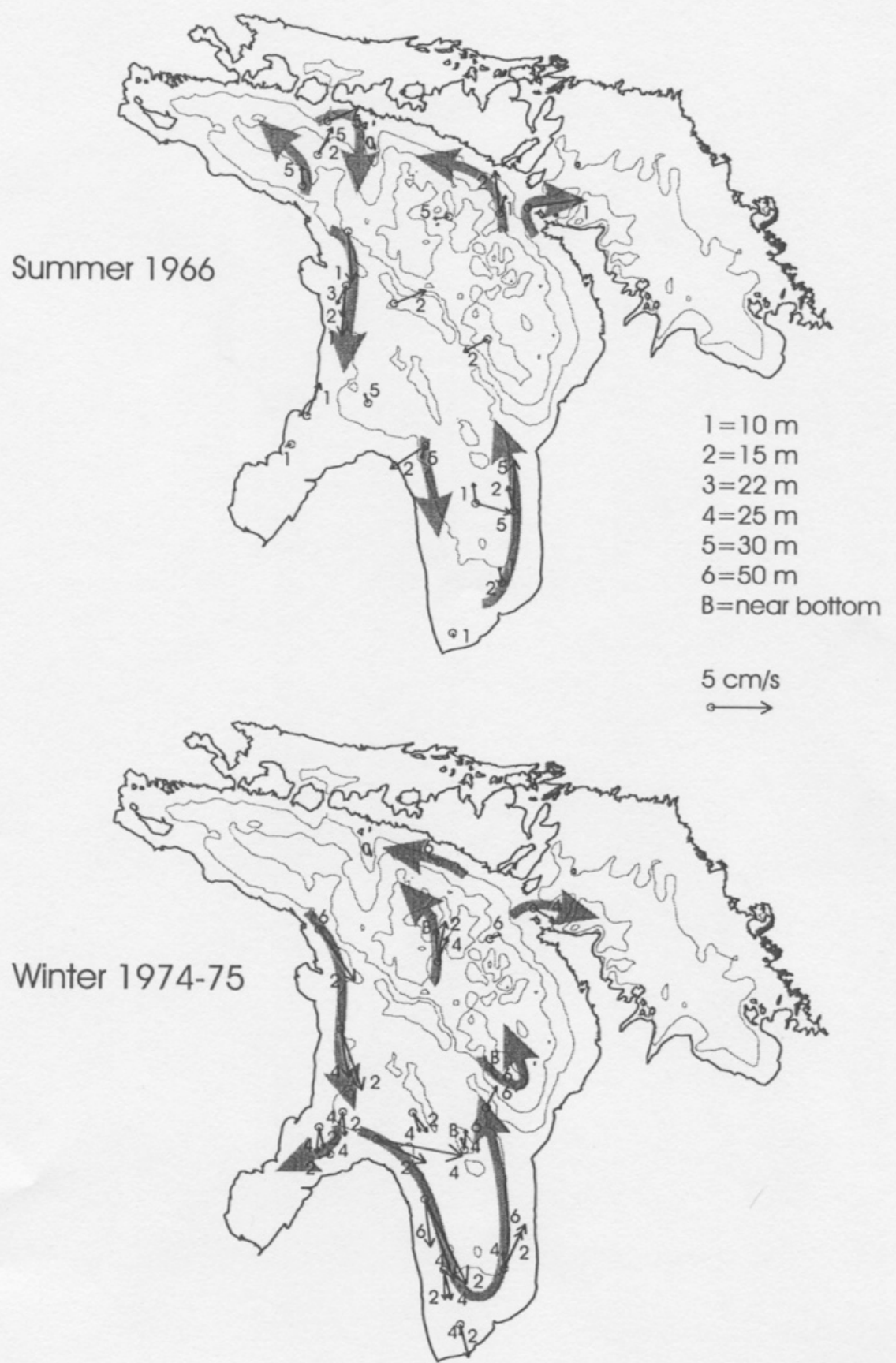

8.5 Average Current Flow within Lake Huron (Beletsky et al. 1999) 


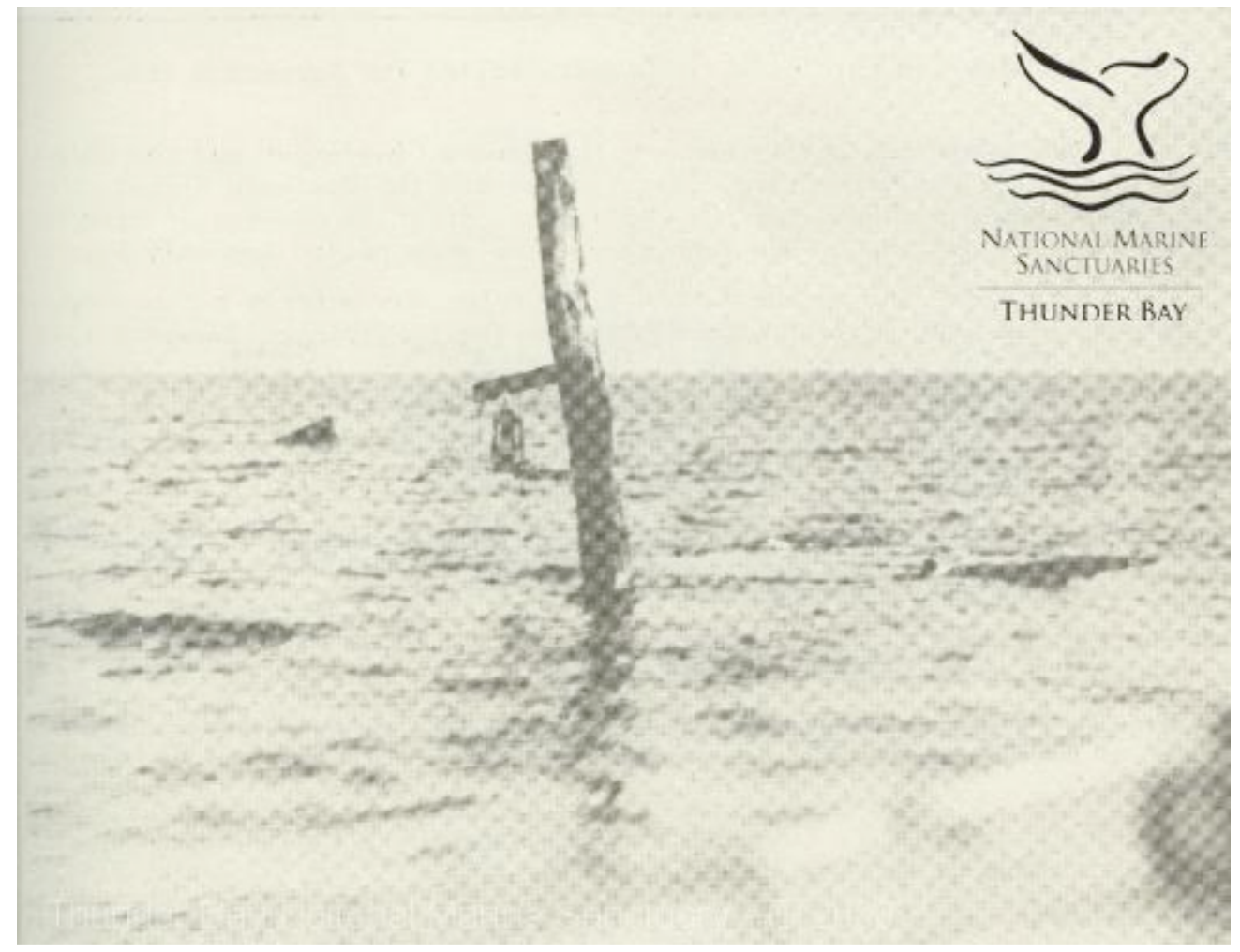

8.6 The wreck of the O.E. Parks (Courtesy Thunder Bay National Marine Sanctuary) 


\section{CHAPTER 9}

\section{CONCLUSION}

The goal of this dissertation is to illustrate the efficacy of combining archaeological and oceanographic techniques into a single analytical discourse in order to elicit new hypotheses in which to pose to the maritime archaeological record that would not be possible through either academic discipline alone. The combination of oceanography, ocean engineering, maritime history, anthropology, and archaeology into a single multi-disciplinary methodology for the study of maritime landscapes essentially defines the new field of archaeological oceanography. It provides the means to incorporate different categories of data and information, at various spatial and temporal scales, that ordinarily would be incompatible in traditional singlediscipline analyses. Additionally, archaeological oceanography assumes the multidisciplinary training of the practitioner. This does not infer expertise in all relevant fields, but, at minimum, an understanding of what is relevant to a particular research question, as well as from whom and from where this data and information can be obtained and how it can be used.

Archaeological oceanography allows for scientific inquiry of the systemic processes inherent in the socio-physical landscape: social, natural, and affective feedback, the result of which produces and constantly reforms the archaeological record by perpetually encorporating the effects of natural and cultural transforms. It permits the study of space in addition to place and precludes the recognition of empty space or spatial archaeological voids within the maritime landscape, as maritime 
activity as a whole occurs landscape-wide. In other words, not only are the locations in which archaeological remains are extant important, but the entire area of study, especially as archaeological survey has shown that much of the archaeological record can become periodically mobilized yet remain within the landscape. At Thunder Bay National Marine Sanctuary, this mobilized wreckage includes: articulated wreckage, isolated finds, indivdual components of historic structures such as hull timbers, and scattered archaeological debris.

While methodological approaches to the study of the physical landscape are generally quantitative, it is impossible to combine attributes of the social cognitive landscape with it that can fit into these analytical paradigms. Human behavior that works to produce the archaeological record in any given instance is not fully predictable; however, the result of these actions is measurable in both the historical and archaeological record. The lack of predictability explains why existing models that provide a systemic framework for the analysis of archaeological formation processes begin with the identified results of behavior, the creation of a shipwreck or other submerged archaeological site. The most robust of these models, Ward et al. (1999), is excellent for the analysis of dynamic formation processes on unique archaeological sites that are inherently linked with specific locations on the landscape. This is adequate for the analysis of intrasite archaeological formation processes and their associated physical expression.

These, models, however discount socially constrained human behavior that works to create the opportunity for the archaeological sites to form. They also decouple the result of the action/accident from affecting both future maritime activity and the 
evolving understanding of the past. Additionally, these models are fundamentally tied to place. When mobilized wreckage is entrained within the physical system and moved elsewhere or is salvaged from the archaeological site, it is eliminated from consideration in the models.

The maritime archaeological landscape retains all archaeological materials within and associated with it as well as the human behavior and, perhaps more importantly, the contemporary and historical understanding of its results and the associated social responses to it. These are, of course, variable, as they are dependent on interest, environmental and technical knowledge, and economic and social power. They also evolve variably over time. Tangible evidence for it may be found in the archaeological record or derived from the historical record; however, this information must be interpreted leading to essentially qualitative analyses of the maritime landscape.

The new maritime archaeological landscape formation model allows for the incorporation of both quantitative and qualitative analyses, conducted at variable temporal and spatial scales, into a single cogent interpretive framework. The model functions as a dialogic resource or arena in which subsections of the framework can be accessed in order to address specific scientific questions or to formulate hypotheses that can be addressed through nested modes of inquiry. For example, the use of a Stommel Diagram (Stommel 1963) to characterize and link the interaction and effects of physical and ecological processes in an incremental spatial and temporal logarithmic scale. The model allows for an infinite number of nested models of any type within all of the enclosed realms of activity present in the maritime landscape 
(maritime behavior, Stages 1-3, and post-wreck activity). The power of this model to produce new hypotheses in which to pose to the archaeological record is well illustrated in this study.

Thunder Bay National Marine Sanctuary is a significant locality of a well-defined maritime landscape (the Great Lakes) in which to test the efficacy of the model in the production of new hypotheses that address the formation of the archaeological record and maritime landscape. This has been successfully accomplished in two ways: through the analysis of individual shipwrecking events and the shipwrecked landscape in the vicinity of Thunder Bay relative to the history of commercial shipping on the Great Lakes and anthropological analysis of historic maritime behavior between 1830 and 1940, and through the spatial analysis of mobilized wreckage within the areas surveyed through the use of side-scan sonar at North Point Peninsula. The former allows for the processual and feedback processes of the whole model to be accessed with regards to primary shipwreck sites and the latter, in the context of the entire model, to access the Stage2/Stage 3 cyclical loop in particular.

Several hypotheses that could be tested in the context of the new maritime archaeological landscape formation model are proposed throughout this dissertation. One proposed hypothesis is that participants in the maritime landscape recognized patterns in accidents related to commercial shipping on a decadal scale. Feedback packaged at a decadal periodicity was powerful enough to affect maritime behavior. By looking at the patterns of commercial shipwrecking activity within the maritime landscape by decade, it has been possible to reveal the evolving patterns of maritime behavior over time. It is clear that individual accidents that could potentially result in 
shipwrecks were expected, and maritime behavior changed little specifically in response to them. What was required to fundamentally change maritime behavior was extra-normative discoveries, inventions, internal and external pressures, events, and accidents, the latter often involving shipwrecking. This is evident through analysis of the historical record, individual archaeological sites, and spatial analysis of the maritime landscape as a whole, all of which provide different data and information. For example, there is a significant concentration of vessels that wrecked by means of collision in the 1850s in the area in which vessels turn northward to sail towards the St. Mary's River and Lake Superior. Iron ore had recently been disovered around Lake Superior, and vessels newly shipped the cargo to eastern markets. As more sailors learned sailing conditions in this area with knowledge of the accidents that previously occurred, shipwrecks by means of collision in this area virtually cease by the 1870 s.

The study of mobilized wreckage within the context of the maritime archaeological landscape formation model is quite different from that of the shipwrecked landscape; as much of it cannot be attributed to a specific accident or shipwreck, in essence it is decoupled from the historical record with regard to its origin. This study has shown, however, that its presence can and does influence maritime behavior and its analysis can lead to a greater understanding of both social and oceanographic processes. For example, bathymetric traps preclude the movement of articulated wreckage; however, individual wreckage components appear to be able to break away from the wreckage, become entrained within the water column, and move elsewhere. Pecoraro (2007) has shown that these "ship traps" are recognized by 
the maritime community as places to effectively salvage wreckage including machinery, rigging, and cargo.

For example, the appearance of and contact with remobilized wreckage months after the initial shipwreck accident, which produced it has the ability to affect maritime behavior. This can be analyzed through the historical record. However, incorporating natural and cultural transforms that affect the landscape as a whole could allow for the analyses of where remobilized wreckage is likely to appear based on the overall distribution of shipwrecks and an understanding of the physical limnological processes that affect the landscape. The location on the landscape where remobilized wreckage is, or even is not, located informs the potential feeback that can in turn affect maritime behavior. In other words, there are places where it is "normal" to encounter remobilized wreckage, and places where it is not. These locations would produce different comparable affective feedback. This example hypothesis accesses the perpetual cycle of Stages 2 and 3 with affective feedback to Maritime Behavior in the model.

In the classical anthropological sense, Muckelroy is correct in his overarching statement:

"The study of the wrecking process itself is of limited intrinsic significance, its importance lying rather in the link it provides between the remains investigated and the original vessel. Furthermore, the potential and limitations of our understanding of the latter by archaeological means ultimately defines the scope of the whole sub-discipline of maritime archaeology (1978: 215)".

This is not a comprehensive view for why we need to study archaeological site formation processes. With the recognized importance of being stewards managing the archaeological landscape, understanding the nature of the archaeological landscape 
and its associated maritime behavior is as important as determining the anthropological and historical information that can be derived from it. 


\title{
APPENDICES
}

\author{
APPENDIX 1
}

\section{THE ARCHAEOLOGICAL RECORD AT THUNDER BAY NATIONAL MARINE SANCTUARY AND UNDERWATER PRESERVE}

Previously identified and recorded archaeological materials

The known archaeological record at Thunder Bay National Marine Sanctuary and surrounding waters was identified through historical knowledge of shipwrecking events, modern sport diving, and the archaeological survey and analyses discussed in Chapter Four. All known archaeological material has been entered into a spreadsheet database (Appendix 2). The sites $(n=282)$ are described here under the site type headings of shipwrecks, articulated associated (with shipwreck) wreckage, articulated unassociated wreckage, unassociated isolated finds, historic landscape features, and other. Nested headings for shipwrecks include decade of loss, vessel type, cargo at loss, and wrecking type. This classificatory system was chosen as it best mirrors the organization of the description of the maritime history of Thunder Bay and the Great Lakes presented in Chapter Three and best informs in the interpretation of the archaeological record discussed in Chapter Seven.

Identified Shipwrecks $(\mathrm{n}=198)$

$1830-1839(n=2)$

Passenger Paddlewheel (Wood); Package Freight, Stranded 
Don Quixote (Record ID 72) b. 1836 sank January 14, 1837, reportedly near Thunder Bay Island. No locational data exists. This may represent the first known historic shipwreck in the region.

Schooner; Package Freight; Stranded

Utica (Record ID 265) b. 1834 sank October 25, 1837, off of Presque Isle in a heavy snowstorm. The vessel's location is projected based on the historical record.

$1840-1849(\mathrm{n}=4)$

Passenger Paddlewheel (Wood); Package Freight; Stranded

New Orleans (Record ID 173) b. 1838, sank June 11, 1849, off of Sugar Island. The cargo was subsequently salvaged. This is the oldest verified shipwreck in Thunder Bay National Marine Sanctuary.

Schooner; Food Products; Unknown

Arnoline (Record ID 25) b. unknown sank in 1842, reportedly in Thunder Bay. Little is known about this shipwreck and its existence is considered questionable.

Schooner; Salt; Stranded

Havre (Record ID 114) b. 1836 sank October 30, 1845, after it stranded between Thunder Bay and Middle Islands in a storm.

Schooner; Unknown; Foundered

Hubbard, Henry (Record ID 117) b. 1842 sank June 8, 1845, in a storm off of Thunder Bay Island. The remains have not been located.

$1850-1859(\mathrm{n}=8)$

Brig; Rail Iron; Collision

Audubon, John J. (Record ID 25) b. 1854 sank October 20, 1854, between Presque Isle and Thunder Bay Island in a collision with the Schooner Defiance in dense fog. The amount of rail iron scattered around the wreck site is likely from a deck load.

\section{Passenger Paddlewheel (Wood); Package Freight; Stranded}

Franklin, Benjamin (Record ID 92-94) b. 1842 sank October 8, 1850, off of Thunder Bay Island. Five hundred barrels of cargo were salvaged. 
Albany (Record ID 17) b. 1846 sank November 26, 1853, while attempting to reach Presque Isle harbor in a storm and was destroyed by a subsequent storm. The vessel's machinery was salvaged in 1854. It is interesting to note that the vessel's insurance policy had expired a few days before it wrecked (Buffalo Daily Courier, December 3, 1853).

Schooner; Grain; Collision

Defiance (Record ID 67) b. 1848 sank October 20, 1854, five miles off of Presque Isle in a collision with the Brig John J. Audubon in dense fog.

Schooner; Lumber/Logs/Forest Products; Foundered

Harwich (Record ID 112) b. 1846 sank October 18, 1858, just north of False Presque Isle in a storm. The vessel's location is projected based on the historical record.

Schooner; Rail Iron and Food Products; Stranded

Northampton (Record ID 180) b. 1847 sank February 11, 1854, near the southeast point of Thunder Bay Island in a storm. Government lifeboats carried on the vessel were used to rescue the crew. The vessel's location is projected based on the historical record.

Schooner, Salt; Collision

Northwestern (Record ID 182) b. 1847 sank August 30, 1850, 14 miles north of Presque Isle in a collision with the Passenger Paddlewheel Monticello. The Monticello was considered to be at fault.

Sloop; Grain; Stranded

Agate (Record ID 15) b. 1850 sank November 27, 1857, near Presque Isle Point in a storm. The vessel's location is projected based on the historical record.

$1860-1860(n=26)$

Barkentine; Grain; Collision

Adriatic (Record ID 14) b. 1856 sank November 19, 1863, off of Presque Isle in a collision with the Bark Two Fannies. The vessel's location is projected based on the historical record.

H. P. (Record ID 46) b. 1864 sank November 5, 1869, 40 miles southeast of Thunder Bay Island in a collision with the Steamboat Colorado in fog. In addition to oats, the cargo included 65,000 bricks. 


\section{Barkentine; Grain; Stranded}

Invincible (Record ID 127) b. 1857 sank November 11, 1869, three miles south of Presque Isle in a storm. Originally a schooner, the vessel was rerigged as a barkentine in 1858. During its 12-year life, the Invincible stranded twice and collided with vessels while underway five times, the last approximately one month before it wrecked. In May 1870, the vessel was salvaged. The vessel's location is projected based on the historical record.

\section{Brig; Grain; Collision}

Spangler, Kyle (Record ID 254) b. 1856 sank November 7, 1860, off of Presque Isle in a collision with the Schooner Racine. The vessels purportedly could not see each other in the dark. It appears that the Spangler was built specifically for the grain trade.

\section{Brig; Grain; Stranded}

Stevens, William H. (Record ID 256) b. 1855 sank November 15, 1863, off of Scarecrow Island. Originally a Schooner, the Stevens was converted to a Brig in 1862. The vessel was subsequently salvaged.

\section{Passenger Propeller (Wood); Copper, Passengers; Collision}

Pewabic (Record ID 223) b. 1863 sank August 9, 1865, seven miles east of Thunder Bay in a collision with the Passenger Propeller Meteor on a calm, clear day. The cause of the collision was pilot error. It is considered to be one of the worst disasters on the Great Lakes. The Pewabic was salvaged several times in the 1880 s.

Passenger Propeller (Wood); Copper, Passengers; Foundered

Waterwitch (Record ID 272) b. 1862 sank November 11, 1863, off of Au Sable.

Passenger Propeller (Wood); Grain; Stranded

Avon (Record ID 27) b. 1857 sank October 14, 1869, near Presque Isle while being towed from near Forty-Mile point where it had sprung a leak, stranded, sank, and was subsequently raised. Attempts were made to raise Avon once again, but it wrecked during a (concurrent?) storm. The vessel's location is projected based on the historical record.

\section{Passenger Propeller (Wood); Iron; Stranded}

Portsmouth (Record ID 228) b. 1852 sank November 15, 1868, off of the northeast end of Middle Island in a storm. Originally built for passenger service, the Portsmouth was converted to a bulk freighter specifically for the iron ore trade in 1866. 
Passenger Propeller (Wood); Salt, Rail Iron, Food Products; Stranded, Fire

Congress (Record ID 60, 61) b. 1861 sank October 22, 1868, off Thunder Bay Island after it caught fire and was (purposefully?) stranded. The vessel spent part of its commercial career in 1866 as a Fenian privateer. In 1868, the owners of the Congress began experimenting with petroleum for fuel. Note that the Congress has secondary site locations.

Schooner; Coal; Collision

Barney, F.T. (Record ID 34) b. 1856 sank October 23, 1868, approximately 25 miles northwest of Presque Isle in a collision with the Schooner Tracy J. Bronson.

Schooner; Coal; Foundered

Syracuse (Record ID 257) b. 1853 sank November 10, 1863, off of Forty-Mile Point after springing a leak. The vessel's location is projected based on the historical record.

Schooner; Coal; Stranded

Raynor, Anna C. (Record ID 235) b. 1858 sank November 19, 1863, off of Middle Island in a storm. The sails and rigging were later salvaged. The vessel's location is projected based on the historical record.

Schooner; Grain; Collision

Caledonia (Record ID 49) b. 1855 sank September 21, 1860, off of Black River in a collision with the Propeller Wabash Valley. The vessel's location is projected based on the historical record.

Commodore Foot (Record ID 59) b. 1862 sank November 21, 1867, off of Forty-Mile Point in a collision with the Schooner John Kelderhouse. The vessel's location is unclear.

Persian (Record ID 222) b. 1855 sank September 16, 1868, off Forty-Mile Point in a collision with Schooner E. B. Allen.

Schooner; Grain; Foundering

Martin, J. B. (Record ID 151) b. 1858 sank November 5, 1869, northeast of Presque Isle in a storm. Salvage of the wreck was attempted in 1871. The vessel's location is projected based on the historical record.

Schooner; Grain; Stranded 
Mason, L. M. (Record ID 152) b. 1853 sank October 22, 1861, near Presque Isle in a storm. The vessel was immediately salvaged. The vessel's location is projected based on the historical record.

Nelson, W. S. (Record ID 169) b. 1855 sank October 22, 1861, off of Presque Isle in a storm. The vessel's location is projected based on the historical record.

Raab, Lucy (Record ID 230) b. 1858 sank November 2, 1862, off of Middle Island in a storm. The following week the sails and rigging were salvaged. The vessel's location is projected based on the historical record.

Schooner; Lumber/Logs/Forest Products; Foundered

Roanoke (Record ID 238) b. 1848 sank October 27, 1866, in the vicinity of Thunder Bay. Location of vessel is unclear.

Schooner; Lumber/Logs/Forest Products; Stranded

Hagar, Henry (Record ID 107) b. 1848 sank October 19, 1868, near Harrisville in a storm. The vessel's location is projected based on the historical record.

Schooner; Iron Ore; Stranded

Nonpareil (Record ID 176) b. 1856 sank in July of 1866, one mile southwest of Middle Island. The vessel was subsequently salvaged. The vessel's location is projected based on the historical record.

Racer (Record ID 231) b. 1856 sank November 17, 1869, in Hammond Bay in a storm. The vessel may have been rerigged as a Brig. The vessel's location is projected based on the historical record.

Wavertree (Record ID 273) b. 1855 sank in June of 1868, at Black River. The vessel may have been abandoned and was subsequently salvaged. The vessel's location is projected based on the historical record.

Schooner; Unknown, Collision

Perseverance (Record ID 221) b. 1855 sank November 24, 1864, near Cheboygan. $1870-1879(n=24)$

Barge (Propeller; Wood); Lumber/Logs/Forest Products; Foundered

Galena (Record ID 96) b. 1857 sank September 25, 1872, south of North Point. Barkentine; Grain; Foundered 
Excelsior (Record ID 84) b. 1865 sank October 15, 1871, north of Thunder Bay Island in a storm. The vessel may have been rigged as a Bark. The vessel's location is projected based on the historical record.

Barge (Sidewheel, Wood); Lumber/Logs/Forest Products; Stranded

Detroit (Record ID 69) b. 1859 sank August 29, 1872, between Greenbush and Harrisville, potentially in a storm. The Detroit was towing the Barge Hunter. The vessel also carried coal when it wrecked. The machinery was salvaged in 1875 .

Passenger Propeller (Wood); Grain; Foundered

Coburn, R. G. (Record ID 58) b. 1870 sank October 15, 1871, approximately 20 miles north of Point aux Barques in a storm. The vessel's location is projected based on the historical record.

Schooner; Coal; Collision

Egan, Marion (Record ID 77) b. 1861 sank September 22, 1875, 17 miles southeast of Thunder Bay Island in a collision with the Schooner E. R. Williams. The location of the vessel is unclear.

Schooner; Grain; Collision

Allen, E. B. (Record ID 18) b. 1864 sank September 18, 1871, off of Thunder Bay Island in a collision with the Bark Newsboy.

Berriman, Francis (Record ID 39) b. 1872 sank May 7, 1877, ten miles off of Sturgeon Point in a collision with the Wooden Bulk Freighter David Rust. The vessel's location is projected based on the historical record.

Schooner; Grain; Foundered

Bentley, James R. (Record ID 38) b. 1867 sank November 12, 1878, off of Forty-Mile Point. The figurehead was salvaged in 1984.

Windiate, Cornelia B. (Record ID 280) b. 1873 sank December 10, 1875, off of Middle Island towards Rogers City. The vessels may have become stuck in ice.

\section{Schooner; Lumber/Logs/Forest Products; Stranded}

Dixon, C. K. (Record ID 71) b. 1869 sank October 1, 1877, near Middle Island in a storm. The storm had begun the previous day. The outfit was subsequently salvaged. The vessel's location is projected based on the historical record. 
Maid of the Mist (Record ID 146-149) b. 1863 sank August 25, 1878, off of Nine Mile Point in a storm.

Schooner; Iron Ore; Foundered

Corsair (Record ID 62) b. 1866 sank September 29, 1972, off of Sturgeon Point in a storm. The location of this vessel is unclear.

Schooner; Iron Ore; Stranded

Buckingham, Alvin (Record ID 48) b. 1853 sank October 15, 1870, one mile below Black River Island after springing a leak and attempting to beach in a storm.

Czar (Record ID 64) b. 1862 sank September 16, 1875, near Presque Isle in a storm. After the vessel's crew was rescued, it washed off of the reef into deeper water.

Darien (Record ID 65) b. 1855 sank October 31, 1870, off of Presque Isle. The vessel may have broken into two sections. The vessel's location is projected based on the historical record.

Empire State (Record ID 80, 81) b. 1853 sank November 8, 1877, on North Point Reef in a storm. The vessel was originally a Bark. The vessel's location is projected based on the historical record.

Neshota (Record ID 170) b. 1864 sank September 28, 1872, off of Sturgeon Point in a storm. The vessel's location is projected based on the historical record.

Schooner; Salt; Stranded

Portland (Record ID 227) b. 1863 sank October 13, 1877, in Bell Bay in a storm. The Portland was converted to a Barge in 1871. The vessel's location is projected based on the historical record.

Schooner; Unknown; Foundered

Nina (Record ID 175) b. 1866 sank May 24, 1875, off of Harrisville after springing a leak. The vessel's location is projected based on the historical record.

Schooner (Consort); Grain; Foundered

Bruce, Kate L. (Record ID 47) b. 1872 sank November 8, 1877, near Thunder Bay in a storm. A consort, the Bruce had broken from its tow off Forty-Mile Point. The lifeboat and mainmast broke free and washed ashore. The vessel's location is projected based on the historical record.

Schooner (Consort); Iron Ore; Stranded 
Gold Hunter (Record ID 100) b. 1856 sank November 6, 1879, ten miles north of Sturgeon Point in a storm. A consort, the Gold Hunter had been released from its tow. There were several unsuccessful salvage attempts in 1880 . The vessel's location is projected based on the historical record.

Scow; Unknown; Foundered

Braman, D. R. (Record ID 44) b. 1868 sank October 29, 1870, off Black River. The vessel's location is projected based on the historical record.

Tug; Package Freight; Fire

Bemis, Philo S. (Record ID 37) b. 1859 sank September 14, 1872, in Thunder Bay after catching fire and burning to the water line. Salvage was unsuccessful. The vessel's location is projected based on the historical record.

Yacht (Propeller, Wood); None; Stranded

Brampton, Nellie (Record ID 45) b. unknown sank October 27, 1875, off of North Point. The location of the vessel is unclear.

$1880-1889(\mathrm{n}=20)$

Barge (Propeller, Wood); Coal; Foundered

Wilson, Belle (Record ID 278) b. 1881 sank August 8, 1888, seven miles off of Harrisville after springing a leak, losing its boiler fires, and clogging its pumps with coal in a storm. The location of the vessel is unclear.

Barge (Unpowered, Wood); Unknown; Stranded

Northern Light (Record ID 181) b. 1858 sank in October of 1881, off of Harrisville. The machinery was removed and the vessel rebuilt as a Barge in 1873. The vessel's location is projected based on the historical record.

Barkentine; Unknown; Stranded

Fame (Record ID 86) b. 1853 sank October 30, 1887, near the Presque Isle harbor entrance. A June 27, 1926 photograph indicates that a portion of this wreck was at one time on land (photo archived at the Jesse Besser Museum). The vessel was rerigged as a Lumber Barge in 1871 and as a Sloop in 1879. The vessel's location is projected based on the historical record.

Bulk Freighter; Coal; Stranded 
Davidson, James (Record ID 66) b. 1874 sank October 4, 1883, off of Thunder Bay Island in a storm. At the time, the Davidson was towing the consort Middlesex.

Smith, Anna (Record ID 252) b. 1873 sank November 27, 1889, approximately 5 miles southeast of the Cheboygan lighthouse in a storm. Three days later the wreckage burned. The vessel was salvaged of all buts its boiler and engine. The vessel's location is projected based on the historical record.

Passenger Paddlewheel (Wood); Food Products; Fire

Marine City (Record ID 150) b. 1866 sank August 29, 1880, two miles southwest of Alcona.

Schooner; Coal; Collision

Van Valkenburg, Lucinda (Record ID 266) b. 1862 sank June 1, 1887, three miles from Thunder Bay Island in a collision with the Iron Propeller Lehigh in a storm with fog.

Schooner; Lumber/Logs/Forest Products; Foundered

New Hampshire (Record ID 171) b. 1846 sank October 21, 1885, at the Alcona pier after its seams were pounded open in a storm. The vessel was towed out of the harbor and sank at a nearby reef. The "outfit" was salvaged. The vessel's location is projected based on the historical record. Note vessel location is not at accident location.

Schooner; Lumber/Logs/Forest Products; Stranded

Acontias (Record ID 13) b. 1856 sank October 29, 1887, off Presque Isle. The vessel's location is projected based on the historical record.

Hathaway, Colonel (Record ID 113) b. 1870 sank September 16, 1881, off of Harrisville. The vessel's location is projected based on the historical record.

Schooner; Grain; Stranded

Garner, Nellie (Record ID 97) b. 1873 sank October 14, 1883, southeast of South Point. The vessel's location is projected based on the historical record.

Schooner; Iron Ore; Foundered

Harvest Queen (Record ID 111) b. 1863 sank September 14, 1880, 25 miles southeast of Presque Isle. The insurance company questioned the cause of the accident. The location of the vessel is unclear. 
Merrick, M.F. (Record ID 156) b. 1863 sank May 17, 1889, off of Presque Isle in a collision with the Wooden Propeller Rufus P. Ranney in heavy fog. The vessel had a cargo of furnace sand. The vessel's location is projected based on the historical record.

Schooner; Unknown; Collision

Equator (Record ID 82) b. unknown sank June 29, 1880, off of Nine Mile Point in a collision. The vessel's location is projected based on the historical record.

Schooner; Unknown; Unknown

Guillotine (Record ID 106) b. unknown sank April 1, 1881, off of Middle Island. The location of the vessel is unclear.

Schooner Barge; Stone; Foundered

Venus (Record ID 267) b. 1872 sank October 3, 1887, near the mouth of the Black River in a storm.

Tug; Package Freight; Fire

City of Alpena (Record ID 55) b. 1874 sank August 9, 1880, two miles north of Alcona, one half mile from shore after catching fire and burning to the waterline.

Moffatt, Kate (Record ID 161) b. 1864 sank May 31, 1885, off of Blue Point after running aground and catching fire in fog. At the time of wrecking the vessel was towing the Schooners Metropolis and Havana. The machinery was subsequently salvaged. The Moffatt posed a navigation hazard and may have been removed in the late 1880s. The vessel's location is projected based on the historical record.

\section{Tug; Package Freight; Stranded}

Carkin, W. S. (Record ID 51) b. 1874 sank November 23, 1887, near Presque Isle in a storm. The vessel's location is projected based on the historical record

\section{Yacht; Food Products; Stranded}

Aimee (Record ID 16) b. 1879 sank November 20, 1880, north of Presque Isle. The vessel was destroyed by waves and ice, broke moorings, and foundered. It is unclear where the stranding event occurred. The vessel's location is projected based on the historical record.

$1890-1899(n=25)$ 
Barge (Propeller, Wood); Coal; Fire

Mackinac (Record ID 144) b. 1866 sank October 28, 1890, off of Black River after catching fire at the dock.

Barge (Propeller, Wood); Lumber/Logs/Forest Products; Fire

Messenger (Record ID 157) b. 1866 sank November 11, 1890, off of Rogers City after catching fire and burning to the waterline. The vessel caught fire in the harbor and was allowed to drift out onto the lake.

Barge (Propeller, Wood); Lumber/Logs/Forest Products; Foundered

Liken, John C. (Record ID 141) b. 1873 sank May 6, 1890, in Hammond Bay after springing a leak. The vessel's location is projected based on the historical record.

Oswegatchie (Record ID 214) b. 1867 sank November 26, 1891, off of Sturgeon Point in a storm. The vessel was towing the Schooner Consorts A. J. McBrier, N.P. Goodell, and H.C. Potter. The Goodell and the Potter also sank in the accident, but were recovered. The vessel's location is projected based on the historical record, however it may have been identified in 1971.

Barge (Propeller, Wood); Other; Foundered

Ryan, Charles C. (Record ID 242) b. 1872 sank July 6, 1890, ten miles north of Port Austin after springing a leak. The Ryan was carrying a cargo of ice. The vessel was towing the Schooner Consort Journeyman and the Brigantine Consort Cohen. The location of the vessel is unclear.

Barge (Unpowered, Wood); Unknown; Fire

Loretta (Record ID 142) b. 1892 sank October 7, 1896, at the Black River dock after catching fire. The vessel may have had a cargo of lumber and shingles. The vessel's location is projected based on the historical record.

Bark; Unknown; Stranded

American Union (Record ID 20, 21) b. 1862 sank May 6, 1894, off of Thompson's Harbor in a storm. Salvage attempts were unsuccessful. This vessel may have been rerigged as a Schooner.

Bulk Freighter (Wood); Coal; Fire

Egyptian (Record ID 78) b. 1873 sank January 12, 1897, off of Sturgeon Point after catching fire. The vessel's location is projected based on the historical record. 
Bulk Freighter (Wood); Coal; Foundered

Wilson, D. M. (Record ID 279) b. 1873 sank October 27, 1894, two and one half miles northeast of Thunder Bay Island after springing a leak. The vessel was towing the Barge Manitowoc.

\section{Bulk Freighter (Wood); Grain; Collision}

Ohio (Record ID 213) b. 1875 sank September 26, 1894, approximately eight miles northeast of Presque Isle after colliding wit the Schooner Ironton. The vessel's location is projected based on the historical record.

Bulk Freighter (Steel); Package Freight; Collision

Norman (Record ID 178) b. 1890 sank May 30, 1895, four miles northeast of Middle Island after colliding with the Wooden Propeller Barge Jack in heavy fog. Salvage efforts were unsuccessful.

Package Freighter (Wood); Package Freight; Collision

Florida (Record ID 91) b. 1889 sank May 21, 1897, in Thunder Bay after colliding with the Wooden Bulk Freighter George W. Roby in heavy fog.

Schooner; Coal; Collision

Corsican (Record ID 63) b. 1862 sank June 2, 1893, off of Thunder Bay Island in a collision with the Steel Bulk Freighter Corsica.

Tyрo (Record ID 264) b. 1873 sank October 14, 1899, six miles northeast of Presque Isle in a collision with the W.P. Ketchum.

Schooner; Lumber/Logs/Forest Products; Stranded

Reindeer (Record ID 236) b. 1847 sank October 8, 1895, off of Rogers City in a storm. The vessel carried a cargo of cordwood. The vessel's location is projected based on the historical record.

Schooner; Iron; Foundered

Fillmore, Millard (Record ID 89) b. 1856 sank August 27, 1891, approximately four miles north of Rogers City. The Cargo was subsequently salvaged. The location of the vessel is unclear.

Schooner; Iron Ore; Collision 
Morse, Fred A. (Record ID 167) b. 1871 sank June 27, 1892, 12 miles southeast of Thunder Bay Island in a collision with the Wooden Propeller Barge John C. Pringle.

Schooner; Stone; Stranded

Palmer, E. B. (Record ID 215-218) b. 1856 sank November 1, 1892, on North Point Reef.

Schooner; Unknown; Stranded

Lady Franklin (Record ID 135) b. 1861 sank September 30, 1895, off of Rogers City. This vessel was originally a Wooden Propeller and was remodeled and rerigged several times. The vessel's location is projected based on the historical record.

Glad Tidings (Record ID 99) b. 1866 sank April 19, 1898, below Nine Mile Point in a storm. The vessel was subsequently salvaged. The vessel's location is projected based on the historical record.

Schooner (Consort); Grain; Foundered

Eddy; Newell A. (Record ID 76) b. 1890 sank April 22, 1893, between Bois Blanc Island and Spectacle Reef in a storm. A Consort, the Eddy was in the tow of the Wooden Bulk Freighter Charles A. Eddy.

Schooner (Consort); Lumber/Logs/Forest Products; Abandoned/Derelict

Warner, John F. (Record ID 271) b. 1855 sank October 13, 1890, near the mouth of the Thunder Bay River after parting its chain while seeking shelter in Thunder Bay and drifting to shore.

Schooner Barge (Consort); Package Freight; Collision

Ironton (Record ID 128) b. 1873 sank September 26, 1894, ten miles north of Presque Isle in a collision with the Wooden Bulk Freighter Ohio while in tow of the Bulk Freighter C.J. Kershaw. The vessel's location is projected based on the historical record.

Scow Schooner; Lumber/Logs/Forest Products; Foundered

Magruder, J.H. (Record ID 145) b. 1869 sank September 17, 1895, off of the Harrisville dock after springing a leak in a storm. The vessel's location is projected based on the historical record.

Tug; Log Raft; Foundered 
Acme (Record ID 12) b. 1874 sank October 14, 1893, 25 miles from Black River while towing a log raft. The vessel was attempting to seek shelter in Thunder Bay. The vessel's location is projected based on the historical record.

1900-1909 (n=32)

Barge (Propeller, Wood); Coal; Fire

Birckhead, P. H. (Record ID 41) b. 1870 sank September 30, 1905, off of Alpena after catching fire. The wreckage was sold in 1907 and therefore may not be extant. The vessel's location is projected based on the historical record.

Barge (Propeller, Wood); Lumber/Logs/Forest Products; Abandoned/Derelict

Shamrock (Record ID 248, 249) b. 1875 sank June 26, 1905, south of the mouth of the Thunder Bay River. The vessel was abandoned after foundering wile being towed after springing a leak of off Presque Isle. The Shamrock was originally built as a Schooner. An August 1905 storm carried the cabin and stacks to the south of the shipwreck.

Barge (Propeller, Wood); Lumber/Logs/Forest Products; Stranded

Blanchard, B.W. (Record ID 43) b. 1870 sank November 28, 1904, on North Point Reef in a storm. The Blanchard was towing the Schooner Barge John T. Johnson and the Schooner John Kelderhouse. The boiler and some of the cargo were salvaged.

Barge (Unpowered, Wood); None; Abandoned/Derelict

Murray Company Dredge (Record ID 168) b. unknown sank August 29, 1906, in Isaacson Bay. The vessel was humorously referred to in local papers as the Faintheart and Heart Failure as it often sank in the vicinity of Alpena.

Rumbell, J.E. (Record ID 241) b. 1883 sank October 15, 1907, off of Alpena. The vessel may have been dismantled. The vessel's location is projected based on the historical record.

Barge (Propeller, Wood); None; Collision

Thew, William Peter (Record ID 258) b. 1884 sank June 22, 1909, three and one half miles east of Thunder Bay Island in a collision with the Steel Bulk Freighter William Livingston in fog.

Barge (Propeller, Wood); Stone; Fire 
Flint, Oscar T. (Record ID 90) b. 1889 sank November 25, 1909, nine miles southeast of Alpena after catching fire and burning to the waterline. In July 1910, the machinery was dynamited.

\section{Barkentine; Coal; Fire}

Ogarita (Record ID 212) b. 1864 sank October 29, 1905, after catching fire.

\section{Bulk Freighter (Steel); Coal; Collision}

Etruria (Record ID 83) b. 1902 sank June 18, 1905, approximately 10 miles off of Presque Isle in a collision with the Steel Bulk Freighter Stone Amasa in fog. The vessel's location is projected based on the historical record.

\section{Bulk Freighter (Wood); Coal; Collision}

New Orleans (Record ID 172) b. 1885 sank June 30, 1906, ten miles from the Thunder Bay Island lighthouse in a collision with the Steel Bulk Freighter William R. Linn in fog.

\section{Bulk Freighter (Wood); Coal; Fire}

Monohansett (Record ID 162-164) b. 1872 sank November 23, 1907, off of the south end of Thunder Bay Island after catching fire.

\section{Bulk Freighter (Wood); Coal; Foundered}

Baltimore (Record ID 28) b. 1881 sank May 24, 1901, approximately three miles south of the Au Sable pier head. The vessel broke into two after striking a reef. The machinery and gear was subsequently salvaged.

\section{Bulk Freighter (Wood); Iron Ore; Foundered}

Kaliyuga (Record ID 133) b. 1887 sank October 19, 1905, off of Presque Isle in the "Great Gale of 1905". The vessel's location is projected based on the historical record.

Bulk Freighter (Wood); Iron Ore; Stranded

Fay, Joseph S. (Record ID 87, 88) b. 1871 sank October 19, 1905, off of Forty-Mile Point. Part of the wreckage is on land.

Bulk Freighter (Wood); Package Freight; Abandoned/Derelict

Emerald (Record ID 78) b. 1863 sank November 13, 1909, off of Thunder Bay Island. The vessel's location is projected based on the historical record. 
Bulk Freighter (Steel) (Consort); Package Freight; Foundered

Grecian (Record ID 105) b. 1891 sank June 15, 1906, north of Thunder Bay Island. The vessel was in the tow of the Steel Bulk Freighter Sir Henry Bessemer. Salvage attempts were unsuccessful.

Schooner; Coal; Stranded

Ishpeming (Record ID 129) b. 1872 sank November 29, 1903, on Black River Reef. The vessel was salvaged. The vessel's location is projected based on the historical record.

Rounds, W. H. (Record ID 239) b. 1875 sank May 2, 1905, on Black River Reef in a storm. The vessel's location is projected based on the historical record.

Schooner; Lumber/Logs/Forest Products; Foundered

Jupiter (Record ID 132) b. 1857 sank September 15, 1901, off of Alpena. The vessel was rebuilt as a one-masted Barge in 1875. The vessel's location is projected based on the historical record.

West Side (Record ID 276) b. 1870 sank October 28, 1906, 25 miles off of Thunder Bay Island after struggling in a storm for two days. The vessel's location is projected based on the historical record.

Schooner; None; Abandoned/Derelict

Lathrop, S. H. (Record ID 138) b. 1856 sank May 14, 1902, at Alpena after being stripped and beached. The vessel's location is projected based on the historical record.

Light Guard (Record ID 140) b. 1866 sank July 22, 1903, in Whitefish Bay.

Schooner; Package Freight; Abandoned/Derelict

Knight Templar (Record ID 134) b. 1865 sank July 25, 1903, in Whitefish Bay. The vessel may have been severely damaged in a storm prior to abandonment.

Schooner; Package Freight; Foundered

Vienna (Record ID 269) b. 1871 sank October 27, 1906, four miles northeast of Thunder Bay Island in a storm.

Schooner; Package Freight; Unknown

Cascade (Record ID 52) b. 1853 sank in 1900, off of Harrisville. The vessel's location is projected based on the historical record. 
Schooner (Consort); Lumber/Logs/Forest Products; Collision

Sheldon, Thomas P. (Record ID 250) b. 1871 sank August 10, 1901, off of Au Sable Point in a collision with its tow the Waverly in a storm.

Schooner Barge; Lumber/Logs/Forest Products; Abandoned/Derelict

Bissell, Harvey (Record ID 42) b. 1866 sank November 28, 1905, at Alpena harbor. The wreck was towed to Alpena and salvaged after wrecking between Thunder Bay Island and Presque Isle. The Bissell was originally rigged as a Barkentine.

Schooner Barge; Lumber/Logs/Forest Products; Stranded

Wesley, G. W. (Record ID 275) b. 1867 sank September 19, 1902, off of Presque Isle after springing a leak and likely purposefully run ashore. The vessel appears to originally have been a Scow Schooner that was cut down to serve as a Schooner Barge Consort. The vessel's location is projected based on the historical record.

Schooner Barge; None; Collision

Bay City (Record ID 35) b. 1857 sank November 29, 1902, at Alpena after dragging anchors and being driven against the pier at the harbor entrance. The vessel originally appears to have been a Brig that was cut down to serve as a Schooner Barge Consort. The vessel's location is projected based on the historical record.

Schooner Barge (Consort); Lumber/Logs/Forest Products; Stranded

Johnson, John T. (Record ID 131) b. 1873 sank November 28, 1904, on North Point Reef in a storm. A consort, the Johnson was in tow of the Wooden Propeller $B$. $W$. Blanchard.

Tug; Food Products; Stranded

Maxwell, William (Record ID 154, 155) b. 1883 sank September 19, 1908, on the southeast shore of Thunder Bay Island in a storm. A fish tug, the vessel had a cargo of fish and fishing equipment.

Tug; Package Freight; Foundered

Ochs, Jay (Record ID 211) b. 1888 sank October 20, 1905, three and one half miles southwest of Middle Island. The final cargo is unclear. The vessel's location is projected based on the historical record.

$1910-1919(n=15)$ 
Barge (Propeller, Wood); Lumber/Logs/Forest Products; Foundered

Barge No. 1 (Record ID 30) b. unknown sank November 18, 1918, off of North Point. In addition to lumber, the vessel contained several hundred chickens.

Barge (Propeller, Wood); Package Freight; Fire

Montana (Record ID 166) b. 1872 sank September 6, 1914, in Thunder Bay after its firebox caught fire and the vessel burned to the waterline.

Barge (Propeller, Wood); Stone; Stranded

Rend, William P. (Record ID 237) b. 1888 sank September 22, 1917, off of North

Point in a storm. Originally a bulk freighter, the Rend was rebuilt a barge in 1915 .

Barge (Wood); Unknown; Foundered

Sampson (Record ID 243) b. unknown sank October 21, 1916, in Thunder Bay. It is unknown whether or not the vessel was powered. The location of the vessel is unclear.

\section{Bulk Freighter (Wood); Coal; Foundered}

New York (Record ID 174) b. 1879 sank October 1, 1910, between 15 and 30 miles off of Thunder Bay Island in a storm. Originally a Package Freighter, the New York was rebuilt a Bulk Freighter in 1908.

Bulk Freighter (Steel); Coal; Foundered

Scott, Isaac M. (Record ID 247) b. 1909 sank November 10, 1913, off of Thunder Bay Island in the 'White Hurricane' of 1913. The vessel is upside down on the lake floor.

Bulk Freighter (Wood); Grain; Collision

Hanna, D. R. (Record ID 109) b. 1906 sank May 16, 1919, approximately six miles off of Thunder Bay Island in a collision with the Quincy A. Shaw in heavy fog.

Bulk Freighter (Steel); Unknown; Collision

Gilbert, W. H. (Record ID 98) b. 1892 sank May 22, 1914, 15 miles south of Thunder Bay Island in a collision with the Steel Bulk Freighter Caldera.

Choctaw (Record ID 54) b. 1892 sank July 12, 1915, off of Presque Isle in a collision in heavy fog. The vessel's location is projected based on the historical record.

Schooner; Lumber/Logs/Forest Products; Fire 
Hall, James H. (Record ID 108) b. 1885 sank November 7, 1916, at Alpena after catching fire. The vessel may have struck the pier prior to burning. The vessel's location is projected based on the historical record.

Schooner; Lumber/Logs/Forest Products; Stranded

Larson, Julia (Record ID 137) b. 1874 sank August 26, 1912, off of the southeast corner of Thunder Bay Island in a storm. The vessel may have been salvaged. The vessel's location is projected based on the historical record.

Schooner (Consort); Coal; Foundered

Young, William A. (Record ID 282) b. 1883 sank November 17, 1911, six miles south of Middle Island in a storm. The vessel was in the tow of the Wooden Propeller Isabella J. Boyce.

Schooner (Consort); Lumber/Logs/Forest Products; Stranded

Exile (Record ID 85) b. 1867 sank November 25, 1916, seven miles south of Sturgeon Point after parting its towline in a storm. There is some historical evidence that the wreck actually took place in Lake Michigan. The location of the vessel is unclear.

Yacht; None; Fire

Tu Jax I (Record ID 262) b. 1913 sank September 5, 1913, off of Squaw Bay after being intentionally burned. The vessel's location is projected based on the historical record.

Tu Jax II (Record ID 263) b. 1914 sank September 29, 1915, off of Sulphur Island after being intentionally burned. The vessel's location is projected based on the historical record.

$1920-1929(n=13)$

Barge (Propeller, Wood); Lumber/Logs/Forest Products; Foundered

Parks, O. E. (Record ID 220) b. 1891 sank May 3, 1929, off of Thunder Bay Island. The disposition of the wreckage indicates that it was purposefully dynamited as navigation hazard mitigation.

Barge (Propeller, Wood); Unknown; Fire

Miami (Record ID 158) b. 1888 sank August 6, 1924, 48 miles off of Thunder Bay Island on a line from Thunder Bay and Burnt Island, Ontario after catching fire. The vessel's location is projected based on the historical record. 
Bulk Freighter (Steel); Coal; Collision

Demmer, Edward U. (Record ID 68) b. 1899 sank May 20, 1923, 40 miles southeast of Thunder Bay Island in a collision with the Steel Bulk Freighter Saturn in heavy fog.

Bulk Freighter (Steel Whaleback); Stone; Foundered

Clifton (Record ID 57) b. 1892 sank September 21, 1924, off of Forty-Mile Point after the cargo shifted and the vessel flipped. The vessel's location is projected based on the historical record.

Passenger Craft (Steel, Consort); None; Foundered

Thousand Islander (Record ID 259) b. 1912 sank November 21, 1928, midlake off of Thunder Bay after parting the towline in a storm. The vessel was being towed to a repair port. The vessel's location is projected based on the historical record.

Schooner (Consort); Salt; Foundered

Woolson, Mary (Record ID 281) b. 1888 sank July 18, 1920, eight miles north of Sturgeon Point after colliding with its tow, the Wooden Propeller Charles H. Bradley. The vessel's location is projected based on the historical record.

Sloop; Lumber/Logs/Forest Products; Fire

Stevens, J.H. (Record ID 255) b. 1859 sank June 10, 1927, off of Presque Isle after catching fire. The vessel had a gas engine installed in 1908. The vessel's location is projected based on the historical record.

Tug; None; Abandoned/Derelict

Duncan City (Record ID 75) b. 1883 sank in 1920, at Rogers City.

Mason, W. G. (Record ID 153) b. 1898 sank in 1926, at Rogers City. The vessel was likely salvaged. The vessel's location is projected based on the historical record.

Ralph (Record ID 232) b. 1874 sank November 24, 1920, at Alpena. The vessel may have been burned, salvaged, and abandoned as early as 1917. The vessel's location is projected based on the historical record.

Tug; None; Fire

Dewey, J.N. (Record ID 70) b. 1911 sank November 24, 1920, off of Sugar Island after catching fire. The location of the vessel is unclear. 
Tug; None; Stranded

Dottie (Record ID 73) b. 1919 sank January 29, 1921, off of Presque Isle. The location of the vessel is unclear.

Yacht; None; Stranded

Wanderer (Record ID 270) b. 1878 sank October 2, 1924, off of Middle Island. The vessel's location is projected based on the historical record.

$1930-1939(n=12)$

Barge (Propeller, Wood); Other; Fire

Simons, William H. (Record ID 251) b. 1919 sank September 16, 1933, in Thunder Bay after catching fire. The vessel was carrying a cargo of carbide. The location of the vessel is unclear.

Barge (Propeller, Wood); Unknown; Fire

Langell Boys (Record ID 136) b. 1890 sank June 13, 1931, off of Au Sable after catching fire. The vessel was likely carrying lumber.

Barge (Propeller, Wood); Unknown; Foundered

Barge No. 105 (Record ID 31) b. unknown sank August 3, 1934, off of Middle Island. The location of this vessel is unclear.

Barge (Propeller, Wood); Unknown; Unknown

Barge (Record ID 29) b. unknown sank in 1937, on North Point. This vessel is subaerial.

Dump Scow (Record ID 74) b. unknown sank in 1930, off of Middle Island.

Bulk Freighter (Steel); Oil; Foundered

Becker, B. H. (Record ID 36) b. 1932 sank August 10, 1937, off of Greenbush in a storm. The vessel's location is projected based on the historical record.

Bulk Freighter (Steel); Package Freight; Collision

Franz, W. C. (Record ID 95) b. 1901 sank November 21, 1934, 30 miles southeast of Thunder Bay Island in a collision with the Steel Package Freighter Edward E. Loomis in heavy fog. 
Ocean Vessel; Food Products; Collision

Viator (Record ID 268) b. 1904 sank October 31, 1935, off of Thunder Bay Island in a collision with the Propeller Ormidale. The vessel was carrying pickled herring and other fish products.

Schooner; Lumber/Logs/Forest Products; Foundered

Bertha May (Record ID 40) b. 1901 sank July 28, 1930, off of Sugar Island. The vessel's location is projected based on the historical record.

Tug; None; Fire

Claire, Rosalie (Record ID 56) b. unknown sank August 10, 1934, after catching fire and exploding. The accident was investigated as arson (The Alpena News, Saturday 8/11/1934: 1, col. 5). The vessel's location is projected based on the historical record.

Tug; Unknown; Fire

Jeka (Record ID 130) b. 1914 sank April 22, 1930, off of Rock Port after catching fire. The vessel's location is projected based on the historical record.

Tug; Unknown; Foundered

Chase; Stephen (Record ID 53) b. 1902 sank April 18, 1933, off of Presque Isle. The Chase was likely a fishing vessel. The location of the vessel is unclear.

$1940-1949(n=2)$

Barge (Propeller; Wood); Heavy Freight; Foundered

Barge No. 83 (Record ID 33) b. 1920 sank October 26, 1941, off of Thunder Bay Island.

Yacht; None; Fire

Topaz VII (Record ID 261) b. 1917 sank August 15, 1941, off of Rogers City after catching fire. The vessel's location is projected based on the historical record.

$1950-1959(n=1)$

Ocean Vessel; Steel; Collision

Monrovia (Record ID 165) b. 1943 sank June 25, 1959, off of Thunder Bay Island in a collision with the Steel Bulk Freighter Royalton in heavy fog. Apparently the Monrovia was on the incorrect shipping lane. 
1960-1969 (n=1)

Ocean Vessel; Steel; Stranded

Nordmeer (Record ID 177) b. 1954 sank November 19, 1966, off of Thunder Bay Island due to a piloting error. Part of the vessel is subaerial.

$1970-1979(n=3)$

Barge (Steel); None; Abandoned/Derelict

Alpena Marine Barge (Record ID 19) b. unknown sank September 17, 1970, at Alpena. The location of the vessel is unclear.

Barge (Steel); None; Foundered

Barge No. 12 (Record ID 32) b. unknown sank in 1974, adjacent to the Nordmeer.

Barge (Propeller, Steel); Petroleum Products; Foundered

Great Lakes Barge Unlimited (Record ID 104) b. unknown sank August 1, 1976, off of Middle Island. The location of the vessel is unclear.

$1980-1989(\mathrm{n}=1)$

Sailboat (Fiberglass); None; Unknown

Panacea (Record ID 219) b. unknown wrecked in the late 1980s. The vessel is subaerial and located on Thunder Bay Island.

Unknown Wrecking Dates $(\mathrm{n}=4)$

Barge (Steel); Unknown; Foundered

Carbide Barge (Record ID 50) b. unknown located in Thunder Bay.

Barge (Wood); Unknown; Foundered

Scanlon's Barge (Record ID 244-246) b. unknown located off of North Point.

Chriscraft; None; Unknown

Golden Voyage (Record ID 101-103) b. unknown.

Lifeboat; None; Unknown 
Unnamed Lifeboat (Record ID 140) b. unknown.

$\underline{\text { Unidentified Shipwrecks }}$

Unknown; Unknown; Unknown

Harrisville Wreck (Record ID 110) b. unknown.

Ludington State Park Wreck (Record ID 143) b. unknown.

North Bay Wreck (Record ID 179) b. unknown.

Port Huron Black River Wreck (Record ID 226) b. unknown.

Articulated Associated Wreckage $(\mathrm{n}=12)$

Boom $(\mathrm{n}=1)$

One boom (Record ID 244), associated with the Scanlon's Barge, is located on North Point Reef. It is a part of the vessel's dredging equipment.

Bow Winch $(\mathrm{n}=1)$

One bow winch (Record ID 162), associated with the Monohansett, is located off of Thunder Bay Island.

$\operatorname{Cargo}(\mathrm{n}=3)$

Three cargo piles have been identified including: a 40 by 20 foot pile of iron ore (Record ID 80) associated with the Empire State is located on North Point Reef; a pile of cedar logs (Record ID 146) associated with the Maid of the Mist is located on Huron Beach; and a pile of stone (Record ID 217) associated with the E. B. Palmer is located on North Point Reef.

Engine $(\mathrm{n}=1)$

The engine if the Scanlon's Barge (Record ID 245) is located on North Point Reef.

Paddle Shaft $(\mathrm{n}=2)$

Two paddle shafts (Record ID 92; Record ID 93), both associated with the Benjamin Franklin, are located off of Thunder Bay Island.

Rudder $(\mathrm{n}=1)$ 
The rudder of the William Maxwell (Record ID 154) is located off of Thunder Bay Island.

Stem $(\mathrm{n}=1)$

The stem of the Monohansett (Record ID 163) is located off of Thunder Bay Island.

Unknown $(\mathrm{n}=2)$

Two collections of uncharacterized wreckage (Record ID 215; Record ID 216), associated with the E. B. Palmer, are located on North Point Reef.

\section{Articulated Unassociated Wreckage $\mathrm{n}=31$ )}

Anchor $(\mathrm{n}=2)$

Two articulated anchors (Record ID 22; Record ID 23) are located within Thunder Bay.

Boiler $(\mathrm{n}=1)$

213/NP0010b A possible donkey boiler, (Record ID 11) is located within the North Point reef.

Eye $(\mathrm{n}=1)$

211 (Record ID 9) is located within the North Point reef.

Hull Wreckage (Schooner); Wood $(\mathrm{n}=13)$

NP0001 (Record ID 183), a centerboard trunk, is located within the North Point reef.

NP0002 (Record ID 184), a side section, is located within the North Point reef.

NP0004 (Record ID 186), a keelson with six articulated double frames, is located within the North Point reef.

NP0006 (Record ID 188), a section of six single frames and one double frame set, is located within the North Point reef.

NP0007 (Record ID 189), a centerboard trunk and keelson, is located within the North Point reef.

NP0008 (Record ID 190), a keelson, three triple frames, and one double frame, is located within the North Point reef. 
NP0009 (Record ID 191), a keelson with eight notches, is located within the North Point reef.

NP0010 (Record ID 192), a gripe, stempost, and keel, is located within the North Point reef.

NP0011 (Record ID 193), a bilge, is located within the North Point reef.

NP0012 (Record ID 194), an overturned hull section with 13 frame sets, and attached deadeyes and chain plates, is located within the North Point reef.

NP0013 (Record ID 195), an overturned hull section with nine single frames, one double frame, and five hull strakes, is located within the North Point reef.

NP0014 (Record ID 196), six double frames and one single frame, is located within the North Point reef.

NP0024 (Record ID 204), 28 double frame sets, 17 hull strakes, and copper scupper liner, is located within the North Point reef.

Hull Wreckage (Steam Vessel); Iron $(\mathrm{n}=1)$

NP0017 (Record ID 198), one beam, one channel beam, and iron plating, is located within the North Point Reef.

Hull Wreckage (Unknown); Wood $(\mathrm{n}=5)$

NP0003 (Record ID 185), a side section with metal banding, is located within the North Point reef.

NP0020 (Record ID 200), a keel and seven sets of close double frames with iron plating, is located within the North Point reef.

NP0022 (Record ID 202), 14 double frame sets and 17 hull strakes with iron plating, is located within the North Point reef.

NP0026 (Record ID 206), identified as "wreckage", is located within the North Point reef.

NP0027 (Record ID 208), two deadwood with three notches for cant frames, is located within the North Point reef.

Hull Wreckage (Unknown); Iron $(\mathrm{n}=2)$

NP0018 (Record ID 199), four pieces of iron plate; is located within the North Point reef. 
NP0021 (Record ID 201), iron cross bracing on a side section and a possible transom, is located within the North Point reef.

Rudder $(\mathrm{n}=1)$

Rudder (Record ID 240) is located within the North Point reef. This rudder may be associated with $N P 0016 b$, a sternpost.

Superstructure (Unknown); Wood $(\mathrm{n}=3)$

Arch (Record ID 24), an arch is located within Thunder Bay.

$N P 0016 b$ (Record ID 24), a sternpost, is located within the North Point reef. This sternpost may be associated with $N P 0016$, a rudder.

NP0029 (Record ID 208), a hogging truss fragment, is located within the North Point reef.

Superstructure (Unknown); Iron $(\mathrm{n}=2)$

NP0005 (Record ID 187), an iron davit with a welded hook, is located within the North Point reef.

NP0023 (Record ID 203), a circular iron bar with knuckle and iron strap, is located within the North Point reef.

$\underline{\text { Unassociated Isolated Find }(\mathrm{n}=11)}$

Bar (Origin Vessel) $(\mathrm{n}=1)$

NP0025 (Record ID 205), a 16-foot iron bar with bent end, is located within the North Point reef.

Cone (Origin Vessel) $(\mathrm{n}=1)$

202 (Record ID 1), an iron cone, is located within the North Point reef.

Strap (Origin Unknown) $(\mathrm{n}=1)$

204 (Record ID 3), a strap, material unidentified, is located within the North Point reef.

Timber (Origin Vessel) $(\mathrm{n}=3)$

210 (Record ID 8), a 16-foot timber, is located within the North Point reef. 
212 (Record ID 10), a ship timber, is located within the North Point reef.

An unnamed group of timbers (Record ID 260) is located within the North Point reef.

Unidentified (Origin Unknown) $(\mathrm{n}=5)$

An iron object (205; Record ID 4); a stone object (203; Record ID 2) and three unidentified objects (206, Record ID 5; 207, Record ID 6; 208, Record ID 7) are located within the North Point reef.

Historical Archaeological Landscape Feature ( $\mathrm{n}=20)$

Cribbing $(\mathrm{n}=10)$

Nine crib structures (Record ID 118-126) are located within Issacson's Bay and one cribbing structure (Record ID 277) is located within White Fish Bay.

Dredge Spoil $(\mathrm{n}=2)$

Mischley Log Dredge Spoil (Record ID 159; 160) two piles of dredge spoil are located within Thunder Bay.

Graffiti $(\mathrm{n}=2)$

Two sites of historic graffiti are located on Thunder Bay Island.

Pole $(\mathrm{n}=1)$

A pole (Record ID 225) is located on Middle Island.

$\operatorname{Privy}(\mathrm{n}=1)$

A privy (Record ID 229) is located on Middle Island.

$\operatorname{Ramp}(\mathrm{n}=2)$

A ramp base (Record ID 233) and a ramp top (Record ID 234) are located on Middle Island.

Smokestack $(\mathrm{n}=1)$

A smokestack (Record ID 253) is located on Thunder Bay Island.

Well $(\mathrm{n}=1)$ 
A well (Record ID 274) is located on Middle Island.

Other $(\mathrm{n}=3)$

Aircraft

Piper PA-24 (Record ID 224) located approximately one mile northeast of North Point.

Historic Chart Obstruction $(\mathrm{n}=2)$

Two navigation obstructions (Record ID 209; Record ID 210) are noted on historic charts.

Newly identified and recorded archaeological materials

The following list of archaeological materials was identified through the use of side-scan sonar. A random selection of targets was ground-truthed to verify identity attribution. All recorded materials have been entered into a spreadsheet database (Appendix 3). The targets $(\mathrm{n}=919)$ are described here under the target type heading of debris, linear, netstakes, rock, shipwreck, wreckage, and unknown. All targets were valued as to the surety of their archaeological identification. For all targets not identified as netstakes, values are defined as: 1 (highly likely); 2 (possible); and 3 (highly unlikely) (figures A1.1a and A1.1b). Except for targets identified as shipwrecks or netstakes, all targets are considered to have the potential to be mobilized through environmental forces. Netstakes, as purposefully interred nonmobile features, have been assigned the value 4 . Each netstake target represents one or more features within the immediate vicinity of the target location. Refer to Appendix 3 for a detailed description of each individual target.

Debris $(\mathrm{n}=33)$ 
Debris represents a collection of closely spaced objects that appear to be archaeological in origin but cannot be defined specifically as wreckage. It may represent jettisoned materials, dredge spoil, or a collection of mobilized individual objects.

\section{Value $1(\mathrm{n}=1)$}

Value $2(\mathrm{n}=7)$

Value $3(\mathrm{n}=25)$

Linear $(\mathrm{n}=307)$

Linear represents at least one linear object. For example, it may represent ship timbers, iron bars, or a length of chain or cable. It may be straight or curved. The presence or absence and the size of an associated shadow were recorded.

Value $1(\mathrm{n}=119)$

Value $2(\mathrm{n}=84)$

Value $3(\mathrm{n}=104)$

Netstakes $(\mathrm{n}=544)$

By far the most common archaeological feature located within Thunder Bay, each netstake target represents one or more netstake, which together functioned as a poundnet fishing system. In total there are thousands of netstakes in Thunder Bay and hundreds of thousands of netstakes extant in the Great Lakes (figure A1.2).

Value $4(\mathrm{n}=544)$

\section{$\underline{\operatorname{Rock}(\mathrm{n}=1)}$}

The significant size of this rock was considered worthy of being recorded as a target by the archaeologist processing the sonar data.

Value $3(\mathrm{n}=1)$

\section{$\underline{\text { Shipwreck }(\mathrm{n}=15)}$}

Fifteen shipwrecks were identified during the side-scan sonar survey. Most have been identified specifically as one of the vessels listed in the Thunder Bay Archaeological Database (Appendix 1). These include the Audubon, Flint, Messenger, Monohansett, 
Montana, Parks, Wilson, Van Valkenburg, and Windiate. The shipwreck targets not assigned to a specific vessel likely are also represented in the Database.

Value $1(\mathrm{n}=15)$

$\underline{\text { Wreckage }(\mathrm{n}=6)}$

Wreckage represents articulated ship-related wreckage. In most cases it can be attributed to a specific nearby shipwreck.

Value $1(\mathrm{n}=4)$

Value $2(\mathrm{n}=2)$

$\underline{\text { Unknown }(\mathrm{n}=13)}$

Unknown represents side-scan sonar targets that stand out from the surrounding environment of the lake floor yet cannot be attributed to a specific target type. All unknown targets have the value 3 .

Value $3(\mathrm{n}=13)$ 
Figures

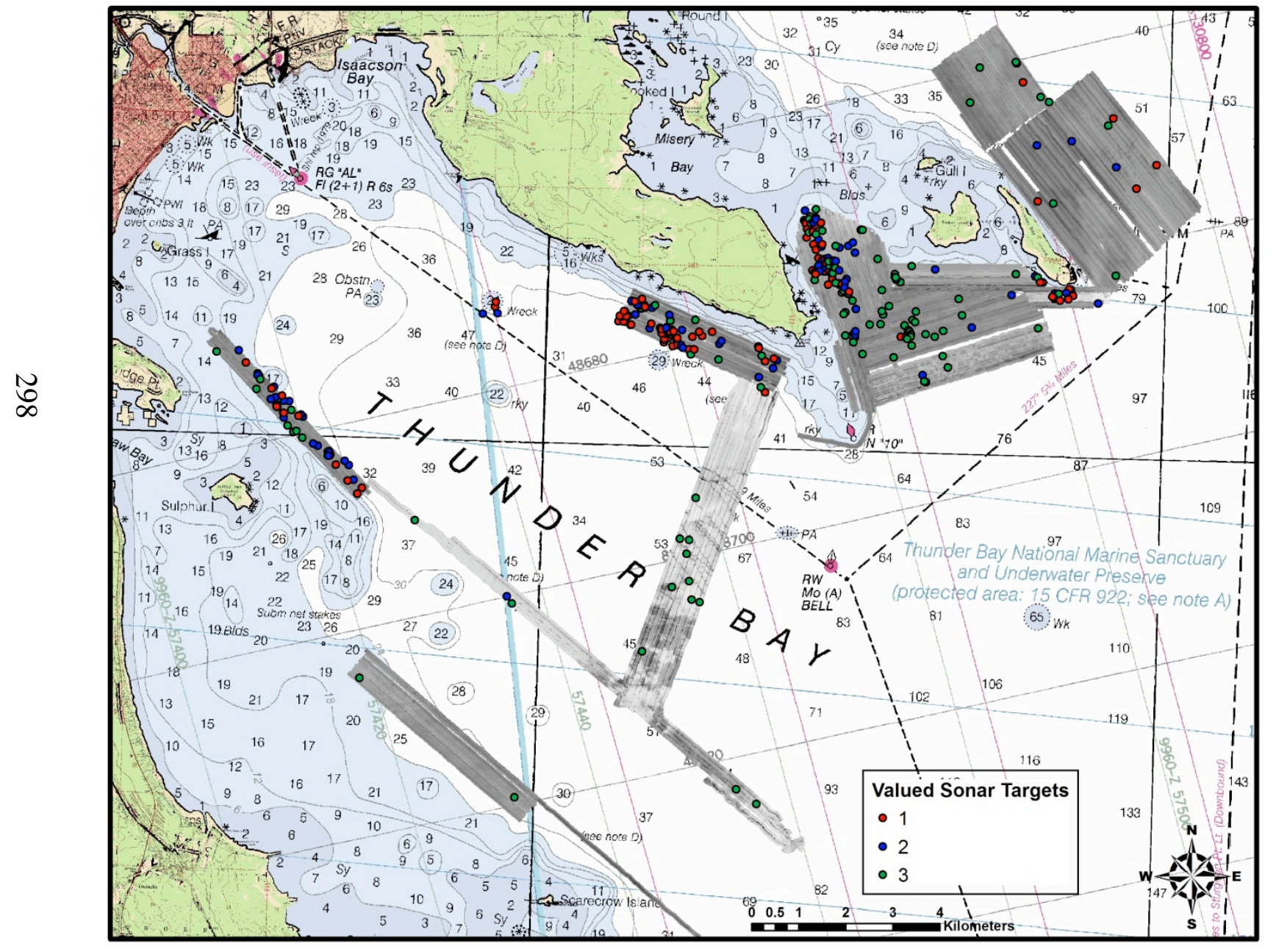

A1.1a 2005-2007 Valued Side-scan Sonar Targets: Mobilized Wreckage 


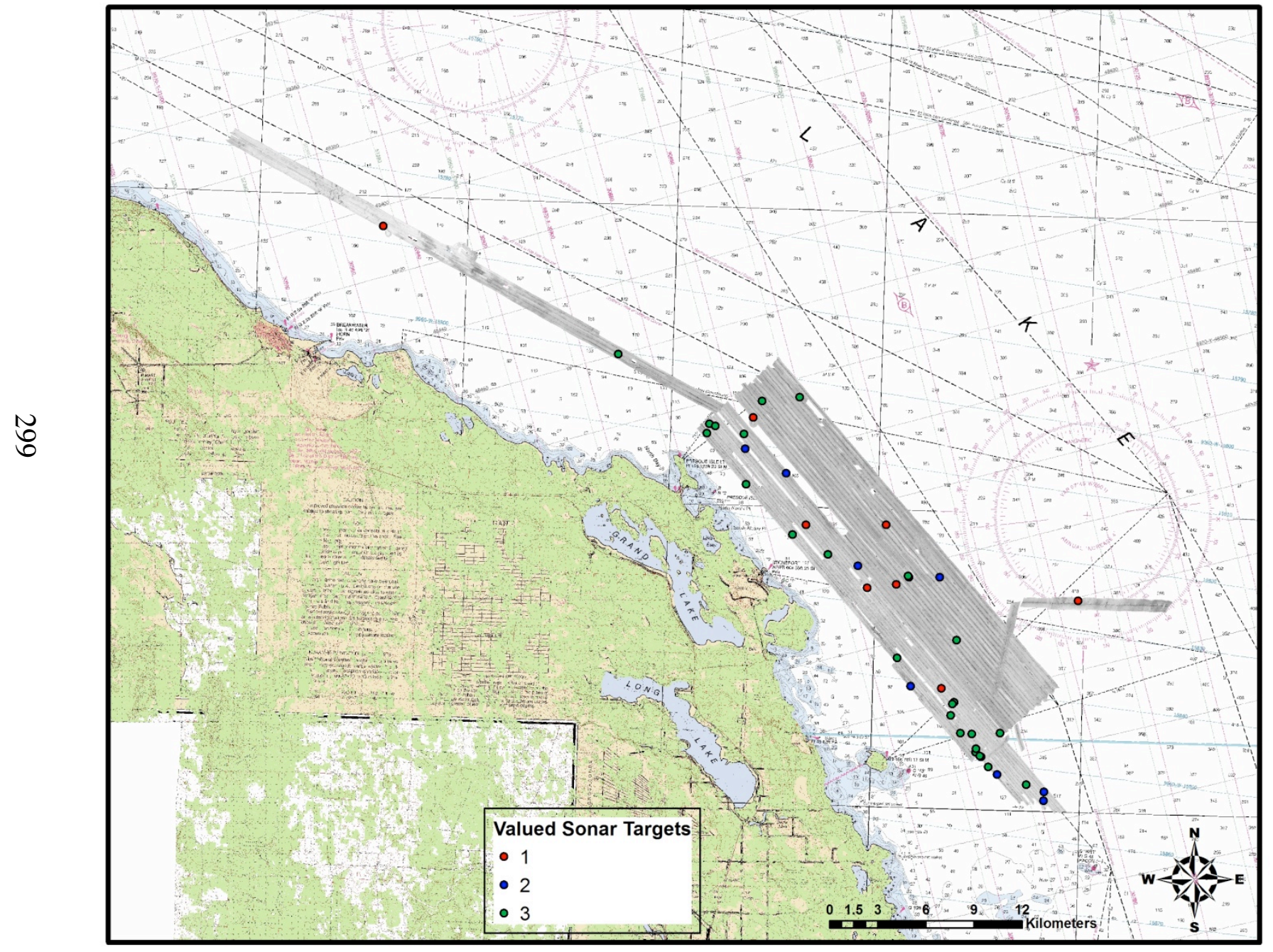

A1.1b 2008 Valued Side-scan Sonar Targets: Mobilized Wreckage 


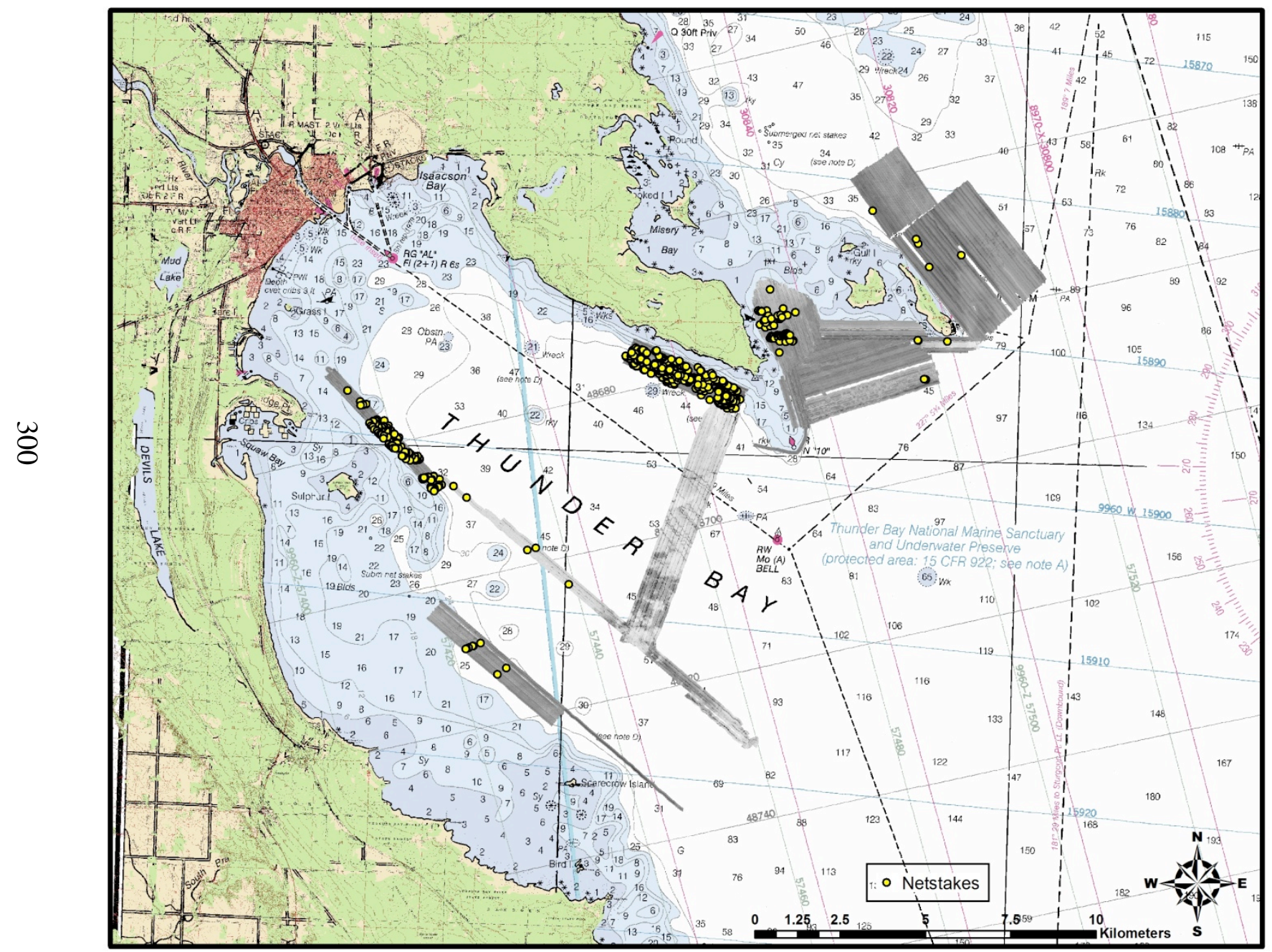

A1.2 Netstakes (Each point represents one or more Netstakes). 


\section{APPENDIX 2}

THUNDER BAY NATIONAL MARINE SANCTUARY SHIPWRECK DATABASE

\begin{tabular}{|c|c|c|c|c|c|}
\hline \begin{tabular}{|c|} 
Record \\
ID
\end{tabular} & Common Name & Code & Latitude & Longitude & Confidence \\
\hline 1 & 202 & Unassociated Isolated Find & 45.003883 & -83.25005 & Verified \\
\hline 2 & 203 & Unassociated Isolated Find & 45.00315 & -83.2495 & Verified \\
\hline 3 & 204 & Unassociated Isolated Find & 45.009217 & -83.2524166 & Verified \\
\hline 4 & 205 & Unassociated Isolated Find & 45.0087 & -83.2513833 & Verified \\
\hline 5 & 206 & Unassociated Isolated Find & 45.00485 & -83.2485166 & Verified \\
\hline 6 & 207 & Unassociated Isolated Find & 45.011867 & -83.25455 & Verified \\
\hline 7 & 208 & Unassociated Isolated Find & 45.011667 & -83.2560666 & Verified \\
\hline 8 & 210 & Unassociated Isolated Find & 45.011083 & -83.25545 & Verified \\
\hline 9 & 211 & Articulated Unassociated Wreckage & 45.011483 & -83.2554 & Verified \\
\hline 10 & 212 & Unassociated Isolated Find & 45.012767 & -83.2574 & Verified \\
\hline 11 & 213 & Articulated Unassociated Wreckage & 45.012467 & -83.25605 & Verified \\
\hline 12 & Acme & Primary Wreck Concentration & 44.820817 & -83.2313 & Projected \\
\hline 13 & Acontias & Primary Wreck Concentration & 45.357917 & -83.4847667 & Projected \\
\hline 14 & Adriatic & Primary Wreck Concentration & 45.504867 & -83.8923833 & Projected \\
\hline 15 & Agate & Primary Wreck Concentration & 45.362383 & -83.4952167 & Projected \\
\hline 16 & Aimee & Primary Wreck Concentration & 45.040883 & -83.2118 & Projected \\
\hline 17 & Albany & Primary Wreck Concentration & 45.323271 & -83.458466 & Verified \\
\hline 18 & Allen, E. B. & Primary Wreck Concentration & 45.016575 & -83.165375 & Verified \\
\hline 19 & Alpena Marine Barge & Primary Wreck Concentration & 44.970598 & -83.315915 & Projected \\
\hline 20 & American Union & Primary Wreck Concentration & 45.354795 & -83.58986 & Verified \\
\hline 21 & American Union & Secondary Wreck Concentration & 45.35695 & -83.58945 & Verified \\
\hline 22 & Anchor & Articulated Unassociated Wreckage & 45.017167 & -83.2571833 & Verified \\
\hline
\end{tabular}




\begin{tabular}{|c|c|c|c|c|c|}
\hline 23 & Anchor & Articulated Unassociated Wreckage & 45.082811 & -83.175397 & Verified \\
\hline 24 & Arch & Articulated Unassociated Wreckage & 45.251518 & -83.41628 & Verified \\
\hline 25 & Arnoline & Primary Wreck Concentration & 44.987153 & -83.304042 & Projected \\
\hline 26 & Audubon, John J. & Primary Wreck Concentration & 45.289341 & -83.339749 & Verified \\
\hline 27 & Avon & Primary Wreck Concentration & 45.416517 & -83.7349667 & Projected \\
\hline 28 & Baltimore & Primary Wreck Concentration & 44.361733 & -83.302067 & Reported \\
\hline 29 & Barge & Primary Wreck Concentration & 45.036567 & -83.2677833 & Verified \\
\hline 30 & Barge No. 1 & Primary Wreck Concentration & 45.015312 & -83.303963 & Verified \\
\hline 31 & Barge No. 105 & Primary Wreck Concentration & 45.199842 & -83.311041 & Projected \\
\hline 32 & Barge No. 12 & Primary Wreck Concentration & 45.136017 & -83.159762 & Observed \\
\hline 33 & Barge No. 83 & Primary Wreck Concentration & 45.079167 & -83.091667 & Verified \\
\hline 34 & Barney, F. T. & Primary Wreck Concentration & 45.487667 & -83.841667 & Verified \\
\hline 35 & Bay City & Primary Wreck Concentration & 45.061033 & -83.4256167 & Projected \\
\hline 36 & Becker, B. H. & Primary Wreck Concentration & 44.590389 & -83.304389 & Projected \\
\hline 37 & Bemis, Philo S. & Primary Wreck Concentration & 45.059067 & -83.4270333 & Projected \\
\hline 38 & Bentley, James R. & Primary Wreck Concentration & 45.690667 & -84.151833 & Verified \\
\hline 39 & Berriman, Francis & Primary Wreck Concentration & 44.731267 & -83.0759167 & Projected \\
\hline 40 & Bertha May & Primary Wreck Concentration & 45.041017 & -83.2349333 & Projected \\
\hline 41 & Birckhead, P. H. & Primary Wreck Concentration & 45.051017 & -83.4343667 & Projected \\
\hline 42 & Bissell, Harvey & Primary Wreck Concentration & 45.054783 & -83.4267166 & Verified \\
\hline 43 & Blanchard, B. W. & Primary Wreck Concentration & 45.021181 & -83.26272 & Verified \\
\hline 44 & Braman, D. R. & Primary Wreck Concentration & 44.807733 & -83.2537 & Projected \\
\hline 45 & Brampton, Nellie & Primary Wreck Concentration & 45.006586 & -83.240532 & Projected \\
\hline 46 & Bridge, H. P. & Primary Wreck Concentration & 44.359604 & -83.010876 & Projected \\
\hline 47 & Bruce, Kate L. & Primary Wreck Concentration & 45.073467 & -83.2209833 & Projected \\
\hline 48 & Buckingham, Alvin & Primary Wreck Concentration & 44.840983 & -83.2853833 & Verified \\
\hline 49 & Caledonia & Primary Wreck Concentration & 44.769667 & -83.1550333 & Projected \\
\hline 50 & Carbide Barge & Primary Wreck Concentration & 44.976233 & -83.221333 & Verified \\
\hline 51 & Carkin, W. S. & Primary Wreck Concentration & 45.340583 & -83.4758667 & Projected \\
\hline 52 & Cascade & Primary Wreck Concentration & 44.663283 & -83.2818167 & Projected \\
\hline 53 & Chase, Stephen & Primary Wreck Concentration & 45.348857 & -83.465429 & Projected \\
\hline 54 & Choctaw & Primary Wreck Concentration & 45.250883 & -83.27795 & Projected \\
\hline 55 & City of Alpena & Primary Wreck Concentration & 44.7878 & -83.2944 & Verified \\
\hline 56 & Claire, Rosalie & Primary Wreck Concentration & 45.427564 & -83.807438 & Projected \\
\hline 57 & Clifton & Primary Wreck Concentration & 44.697083 & -82.8180667 & Projected \\
\hline
\end{tabular}




\begin{tabular}{|c|c|c|c|c|c|}
\hline 58 & Coburn, R. G. & Primary Wreck Concentration & 44.59285 & -82.9350167 & Projected \\
\hline 59 & Commodore Foote & Primary Wreck Concentration & 45.503864 & -83.9081 & Projected \\
\hline 60 & Congress & Secondary Wreck Concentration & 45.011717 & -83.2565166 & Verified \\
\hline 61 & Congress & Primary Wreck Concentration & 45.011833 & -83.2568166 & Verified \\
\hline 62 & Corsair & Primary Wreck Concentration & 44.715945 & -83.247303 & Projected \\
\hline 63 & Corsican & Primary Wreck Concentration & 44.912667 & -83.055 & Verified \\
\hline 64 & Czar & Primary Wreck Concentration & 45.248817 & -83.4075 & Verified \\
\hline 65 & Darien & Primary Wreck Concentration & 45.353033 & -83.47915 & Projected \\
\hline 66 & Davidson, James & Primary Wreck Concentration & 45.031286 & -83.196063 & Verified \\
\hline 67 & Defiance & Primary Wreck Concentration & 45.2343 & -83.27845 & Verified \\
\hline 68 & Demmer, Edward. U. & Primary Wreck Concentration & 44.559783 & -82.9829667 & Projected \\
\hline 69 & Detroit & Primary Wreck Concentration & 44.585517 & -83.30705 & Verified \\
\hline 70 & Dewey, J. N. & Primary Wreck Concentration & 45.054563 & -83.224836 & Projected \\
\hline 71 & Dixon, C. K. & Primary Wreck Concentration & 45.182483 & -83.3165333 & Projected \\
\hline 72 & Don Quixote & Primary Wreck Concentration & 45.053673 & -83.211811 & Projected \\
\hline 73 & Dottie & Primary Wreck Concentration & 45.360397 & -83.488391 & Projected \\
\hline 74 & Dump Scow & Primary Wreck Concentration & 45.212667 & -83.299567 & Verified \\
\hline 75 & Duncan City & Primary Wreck Concentration & 45.41625 & -83.7608333 & Verified \\
\hline 76 & Eddy, Newell A. & Primary Wreck Concentration & 45.781333 & -84.229167 & Reported \\
\hline 77 & Egan, Marion & Primary Wreck Concentration & 44.717091 & -83.982403 & Projected \\
\hline 78 & Egyptian & Primary Wreck Concentration & 44.8378 & -83.11845 & Projected \\
\hline 79 & Emerald & Primary Wreck Concentration & 45.0417 & -83.1947 & Projected \\
\hline 80 & Empire State & Articulated Associated Wreckage & 45.014217 & -83.2562833 & Verified \\
\hline 81 & Empire State & Primary Wreck Concentration & 45.004499 & -83.256485 & Projected \\
\hline 82 & Equator & Primary Wreck Concentration & 45.149948 & -83.196221 & Projected \\
\hline 83 & Etruria & Primary Wreck Concentration & 45.3961 & -83.2135667 & Projected \\
\hline 84 & Excelsior & Primary Wreck Concentration & 45.1591 & -83.17465 & Projected \\
\hline 85 & Exile & Primary Wreck Concentration & 44.614599 & -83.312409 & Projected \\
\hline 86 & Fame & Primary Wreck Concentration & 45.348667 & -83.4755333 & Projected \\
\hline 87 & Fay, Joseph S. & Primary Wreck Concentration & 45.486905 & -83.914823 & Verified \\
\hline 88 & Fay, Joseph S. & Secondary Wreck Concentration & 45.490644 & -83.911956 & Verified \\
\hline 89 & Fillmore, Millard & Primary Wreck Concentration & 45.480566 & -83.802932 & Projected \\
\hline 90 & Flint, Oscar T. & Primary Wreck Concentration & 45.026139 & -83.347378 & Verified \\
\hline 91 & Florida & Primary Wreck Concentration & 45.29635 & -83.283517 & Verified \\
\hline 92 & Franklin, Benjamin & Articulated Associated Wreckage & 45.032235 & -83.192149 & Verified \\
\hline
\end{tabular}




\begin{tabular}{|c|c|c|c|c|c|}
\hline 93 & Franklin, Benjamin & Articulated Associated Wreckage & 45.032798 & -83.191472 & Verified \\
\hline 94 & Franklin, Benjamin & Primary Wreck Concentration & 45.0313 & -83.191367 & Verified \\
\hline 95 & Franz, W. C. & Primary Wreck Concentration & 44.647917 & -82.906533 & Observed \\
\hline 96 & Galena & Primary Wreck Concentration & 45.007667 & -83.249833 & Verified \\
\hline 97 & Garner, Nellie & Primary Wreck Concentration & 44.898617 & -83.33055 & Projected \\
\hline 98 & Gilbert, W. H. & Primary Wreck Concentration & 44.836583 & -82.9787 & Verified \\
\hline 99 & Glad Tidings & Primary Wreck Concentration & 45.518833 & -84.0682333 & Projected \\
\hline 100 & Gold Hunter & Primary Wreck Concentration & 44.8265 & -83.2858333 & Projected \\
\hline 101 & Golden Voyage & Primary Wreck Concentration & 45.034549 & -83.195872 & Verified \\
\hline 102 & Golden Voyage & Secondary Wreck Concentration & 45.037932 & -83.201507 & Verified \\
\hline 103 & Golden Voyage & Secondary Wreck Concentration & 45.039382 & -83.203866 & Verified \\
\hline 104 & Great Lakes Barge Unlimited & Primary Wreck Concentration & 45.194441 & -83.306816 & Projected \\
\hline 105 & Grecian & Primary Wreck Concentration & 44.968491 & -83.200959 & Verified \\
\hline 106 & Guillotine & Primary Wreck Concentration & 45.201932 & -83.324974 & Projected \\
\hline 107 & Hagar, Henry & Primary Wreck Concentration & 44.655338 & -83.288333 & Projected \\
\hline 108 & Hall, James H. & Primary Wreck Concentration & 45.060667 & -83.42555 & Projected \\
\hline 109 & Hanna, D. R. & Primary Wreck Concentration & 45.084167 & -83.08655 & Verified \\
\hline 110 & Harrisville Wreck & Primary Wreck Concentration & 44.782033 & -83.123767 & Reported \\
\hline 111 & Harvest Queen & Primary Wreck Concentration & 45.194245 & -83.017756 & Projected \\
\hline 112 & Harwich & Primary Wreck Concentration & 45.2862 & -83.4006833 & Projected \\
\hline 113 & Hathaway, Colonel & Primary Wreck Concentration & 44.654267 & -83.28255 & Projected \\
\hline 114 & Havre & Primary Wreck Concentration & 45.134583 & -83.3152667 & Projected \\
\hline 115 & Historic Graffiti & Historic Archaeological Landscape Feature & 45.042755 & -83.199686 & Verified \\
\hline 116 & Historic Graffiti & Historic Archaeological Landscape Feature & 45.039222 & -83.195966 & Verified \\
\hline 117 & Hubbard, Henry & Primary Wreck Concentration & 45.025481 & -83.175439 & Projected \\
\hline 118 & IB CRIB 5 & Historic Archaeological Landscape Feature & 45.06497 & -83.369241 & Verified \\
\hline 119 & IB CRIB 6 & Historic Archaeological Landscape Feature & 45.065891 & -83.37155 & Verified \\
\hline 120 & IB CRIB 7 & Historic Archaeological Landscape Feature & 45.066099 & -83.37167 & Verified \\
\hline 121 & IB CRIB 8 & Historic Archaeological Landscape Feature & 45.068865 & -83.381279 & Verified \\
\hline 122 & IB CRIB 9 & Historic Archaeological Landscape Feature & 45.069097 & -83.382034 & Verified \\
\hline 123 & IB CRIB1 & Historic Archaeological Landscape Feature & 45.062121 & -83.372055 & Verified \\
\hline 124 & IB CRIB2 & Historic Archaeological Landscape Feature & 45.063079 & -83.373144 & Verified \\
\hline 125 & IB CRIB3 & Historic Archaeological Landscape Feature & 45.063893 & -83.373595 & Verified \\
\hline 126 & IB CRIB4 & Historic Archaeological Landscape Feature & 45.064505 & -83.377421 & Verified \\
\hline 127 & Invincible & Primary Wreck Concentration & 45.3073 & -83.43445 & Projected \\
\hline
\end{tabular}




\begin{tabular}{|c|c|c|c|c|c|}
\hline 128 & Ironton & Primary Wreck Concentration & 45.517333 & -83.5669167 & Projected \\
\hline 129 & Ishpeming & Primary Wreck Concentration & 44.799417 & -83.2587 & Projected \\
\hline 130 & Jeka & Primary Wreck Concentration & 45.20375 & -83.3816833 & Projected \\
\hline 131 & Johnson, John T. & Primary Wreck Concentration & 45.021658 & -83.262012 & Verified \\
\hline 132 & Jupiter & Primary Wreck Concentration & 45.181283 & -83.0132333 & Projected \\
\hline 133 & Kaliyuga & Primary Wreck Concentration & 45.247767 & -82.9122167 & Projected \\
\hline 134 & Knight Templar & Primary Wreck Concentration & 45.06175 & -83.3683166 & Verified \\
\hline 135 & Lady Franklin & Primary Wreck Concentration & 45.501933 & -84.0443833 & Projected \\
\hline 136 & Langell Boys & Primary Wreck Concentration & 44.367733 & -83.300467 & Reported \\
\hline 137 & Larson, Julia & Primary Wreck Concentration & 45.028034 & -83.194602 & Projected \\
\hline 138 & Lathrop, S. H. & Primary Wreck Concentration & 45.066117 & -83.36945 & Projected \\
\hline 139 & Lifeboat & Primary Wreck Concentration & 45.045046 & -83.205451 & Verified \\
\hline 140 & Light Guard & Primary Wreck Concentration & 45.061167 & -83.36825 & Verified \\
\hline 141 & Liken, John C. & Primary Wreck Concentration & 45.565833 & -84.022 & Projected \\
\hline 142 & Loretta & Primary Wreck Concentration & 44.81735 & -83.2495833 & Projected \\
\hline 143 & Ludington State Park Wreck & Primary Wreck Concentration & 44.043321 & -86.513456 & Verified \\
\hline 144 & Mackinac & Primary Wreck Concentration & 44.81505 & -83.282583 & Verified \\
\hline 145 & Magruder, J. H. & Primary Wreck Concentration & 44.638067 & -83.2801167 & Projected \\
\hline 146 & Maid of the Mist & Articulated Associated Wreckage & 45.113904 & -83.315807 & Verified \\
\hline 147 & Maid of the Mist & Primary Wreck Concentration & 45.116179 & -83.317396 & Verified \\
\hline 148 & Maid of the Mist & Secondary Wreck Concentration & 45.116148 & -83.317789 & Verified \\
\hline 149 & Maid of the Mist & Secondary Wreck Concentration & 45.115964 & -83.317155 & Verified \\
\hline 150 & Marine City & Primary Wreck Concentration & 44.770617 & -83.2894333 & Verified \\
\hline 151 & Martin, J. B. & Primary Wreck Concentration & 45.519317 & -83.9073333 & Projected \\
\hline 152 & Mason, L. M. & Primary Wreck Concentration & 45.361933 & -83.5009667 & Projected \\
\hline 153 & Mason, W. G. & Primary Wreck Concentration & 45.420567 & -83.7800167 & Projected \\
\hline 154 & Maxwell, William & Articulated Associated Wreckage & 45.035167 & -83.19875 & Verified \\
\hline 155 & Maxwell, William & Primary Wreck Concentration & 45.033168 & -83.191545 & Verified \\
\hline 156 & Merrick, M. F. & Primary Wreck Concentration & 45.397917 & -83.3669 & Projected \\
\hline 157 & Messenger & Primary Wreck Concentration & 45.483475 & -83.733995 & Verified \\
\hline 158 & Miami & Primary Wreck Concentration & 45.684133 & -83.253 & Projected \\
\hline 159 & Mischley logs dredge spoil & Historic Archaeological Landscape Feature & 45.009513 & -83.349025 & Verified \\
\hline 160 & Mischley logs dredge spoil & Historic Archaeological Landscape Feature & 45.00985 & -83.349729 & Verified \\
\hline 161 & Moffatt, Kate & Primary Wreck Concentration & 45.360833 & -83.542 & Projected \\
\hline 162 & Monohansett & Articulated Associated Wreckage & 45.033608 & -83.200002 & Verified \\
\hline
\end{tabular}




\begin{tabular}{|c|c|c|c|c|c|}
\hline 163 & Monohansett & Articulated Associated Wreckage & 45.041364 & -83.206588 & Verified \\
\hline 164 & Monohansett & Primary Wreck Concentration & 45.033259 & -83.199801 & Verified \\
\hline 165 & Monrovia & Primary Wreck Concentration & 44.983667 & -82.923 & Verified \\
\hline 166 & Montana & Primary Wreck Concentration & 44.983744 & -83.266891 & Verified \\
\hline 167 & Morse, Fred A. & Primary Wreck Concentration & 44.97155 & -82.9745833 & Projected \\
\hline 168 & Murray Company Dredge & Primary Wreck Concentration & 45.0689 & -83.3739667 & Verified \\
\hline 169 & Nelson, W. S. & Primary Wreck Concentration & 45.368167 & -83.4977833 & Projected \\
\hline 170 & Neshota & Primary Wreck Concentration & 44.713967 & -83.2573667 & Projected \\
\hline 171 & New Hampshire & Primary Wreck Concentration & 44.762917 & -83.2758167 & Projected \\
\hline 172 & New Orleans & Primary Wreck Concentration & 45.16755 & -83.217383 & Verified \\
\hline 173 & New Orleans & Primary Wreck Concentration & 45.046762 & -83.240028 & Verified \\
\hline 174 & New York & Primary Wreck Concentration & 44.603833 & -82.470667 & Reported \\
\hline 175 & Nina & Primary Wreck Concentration & 44.721217 & -82.4276667 & Projected \\
\hline 176 & Nonpariel & Primary Wreck Concentration & 45.181617 & -83.3453833 & Projected \\
\hline 177 & Nordmeer & Primary Wreck Concentration & 45.136017 & -83.159762 & Verified \\
\hline 178 & Norman & Primary Wreck Concentration & 45.311567 & -83.27895 & Verified \\
\hline 179 & North Bay Wreck & Primary Wreck Concentration & 45.346283 & -83.4934333 & Verified \\
\hline 180 & Northampton & Primary Wreck Concentration & 45.028015 & -83.1896055 & Projected \\
\hline 181 & Northern Light & Primary Wreck Concentration & 44.647667 & -83.2875167 & Projected \\
\hline 182 & Northwestern & Primary Wreck Concentration & 45.452017 & -83.7010667 & Verified \\
\hline 183 & NP0001 & Articulated Unassociated Wreckage & 45.021717 & -83.26205 & Verified \\
\hline 184 & NP0002 & Articulated Unassociated Wreckage & 45.021183 & -83.2627166 & Verified \\
\hline 185 & NP0003 & Articulated Unassociated Wreckage & 45.016667 & -83.25 & Verified \\
\hline 186 & NP0004 & Articulated Unassociated Wreckage & 45.017833 & -83.264 & Verified \\
\hline 187 & NP0005 & Articulated Unassociated Wreckage & 45.017033 & -83.2619833 & Verified \\
\hline 188 & NP0006 & Articulated Unassociated Wreckage & 45.018 & -83.2606666 & Verified \\
\hline 189 & NP0007 & Articulated Unassociated Wreckage & 45.0171 & -83.2580666 & Verified \\
\hline 190 & NP0008 & Articulated Unassociated Wreckage & 45.0174 & -83.2578166 & Verified \\
\hline 191 & NP0009 & Articulated Unassociated Wreckage & 45.017483 & -83.2573 & Verified \\
\hline 192 & NP0010 & Articulated Unassociated Wreckage & 45.01735 & -83.2568166 & Verified \\
\hline 193 & NP0011 & Articulated Unassociated Wreckage & 45.017167 & -83.2570833 & Verified \\
\hline 194 & NP0012 & Articulated Unassociated Wreckage & 45.015467 & -83.2548833 & Verified \\
\hline 195 & NP0013 & Articulated Unassociated Wreckage & 45.01455 & -83.2563 & Verified \\
\hline 196 & NP0014 & Articulated Unassociated Wreckage & 45.014283 & -83.2566833 & Verified \\
\hline 197 & NP0016b & Articulated Unassociated Wreckage & 45.01155 & -83.25415 & Verified \\
\hline
\end{tabular}




\begin{tabular}{|c|c|c|c|c|c|}
\hline 198 & NP0017 & Articulated Unassociated Wreckage & 45.011617 & -83.2542833 & Verified \\
\hline 199 & NP0018 & Articulated Unassociated Wreckage & 45.010783 & -83.2543333 & Verified \\
\hline 200 & NP0020 & Articulated Unassociated Wreckage & 45.010933 & -83.2530166 & Verified \\
\hline 201 & NP0021 & Articulated Unassociated Wreckage & 45.018017 & -83.2531833 & Verified \\
\hline 202 & NP0022 & Articulated Unassociated Wreckage & 45.010417 & -83.2534666 & Verified \\
\hline 203 & NP0023 & Articulated Unassociated Wreckage & 45.01355 & -83.2555166 & Verified \\
\hline 204 & NP0024 & Articulated Unassociated Wreckage & 45.012567 & -83.2534666 & Verified \\
\hline 205 & NP0025 & Unassociated Isolated Find & 45.01225 & -83.2525666 & Verified \\
\hline 206 & NP0026 & Articulated Unassociated Wreckage & 45.011633 & -83.2558666 & Verified \\
\hline 207 & NP0027 & Articulated Unassociated Wreckage & 45.012283 & -83.2553 & Verified \\
\hline 208 & NP0029 & Articulated Unassociated Wreckage & 45.012367 & -83.25675 & Verified \\
\hline 209 & Obstruction from Historic Chart & Unknown & 45.25055 & -83.317217 & Reported \\
\hline 210 & Obstruction from Historic Chart & Unknown & 45.235583 & -83.33 & Reported \\
\hline 211 & Ochs, Jay & Primary Wreck Concentration & 45.1587 & -83.3408833 & Projected \\
\hline 212 & Ogarita & Primary Wreck Concentration & 45.105433 & -83.217957 & Verified \\
\hline 213 & Ohio & Primary Wreck Concentration & 45.5175 & -83.5669167 & Projected \\
\hline 214 & Oswegatchie & Primary Wreck Concentration & 44.726217 & -83.2112833 & Projected \\
\hline 215 & Palmer, E. B. & Articulated Associated Wreckage & 45.0113 & -83.2535666 & Verified \\
\hline 216 & Palmer, E. B. & Articulated Associated Wreckage & 45.01135 & -83.2532333 & Verified \\
\hline 217 & Palmer, E. B. & Articulated Associated Wreckage & 45.0111 & -83.25305 & Verified \\
\hline 218 & Palmer, E. B. & Primary Wreck Concentration & 45.011183 & -83.2534333 & Verified \\
\hline 219 & Panacea & Primary Wreck Concentration & 45.03455 & -83.1958333 & Verified \\
\hline 220 & Parks, O. E. & Primary Wreck Concentration & 45.05189 & -83.175183 & Verified \\
\hline 221 & Perseverance & Primary Wreck Concentration & 45.701333 & -84.439167 & Reported \\
\hline 222 & Persian & Primary Wreck Concentration & 45.7 & -84.433333 & Reported \\
\hline 223 & Pewabic & Primary Wreck Concentration & 44.965133 & -83.102133 & Verified \\
\hline 224 & Piper PA-24 & Primary Wreck Concentration & 45.060271 & -83.261208 & Projected \\
\hline 225 & Pole & Historic Archaeological Landscape Feature & 45.197154 & -83.334484 & Verified \\
\hline 226 & Port Huron Black River Wreck & Primary Wreck Concentration & 42.972109 & -82.419254 & Verified \\
\hline 227 & Portland & Primary Wreck Concentration & 45.30415 & -83.41585 & Projected \\
\hline 228 & Portsmouth & Primary Wreck Concentration & 45.197833 & -83.333833 & Verified \\
\hline 229 & Privy & Historic Archaeological Landscape Feature & 45.197125 & -83.334088 & Verified \\
\hline 230 & Raab, Lucy & Primary Wreck Concentration & 45.182567 & -83.3315833 & Projected \\
\hline 231 & Racer & Primary Wreck Concentration & 45.51345 & -84.0487833 & Projected \\
\hline 232 & Ralph & Primary Wreck Concentration & 45.057517 & -83.4280167 & Projected \\
\hline
\end{tabular}




\begin{tabular}{|c|c|c|c|c|c|}
\hline 233 & Ramp Base & Historic Archaeological Landscape Feature & 45.19645 & -83.333652 & Verified \\
\hline 234 & Ramp Top & Historic Archaeological Landscape Feature & 45.196506 & -83.333859 & Verified \\
\hline 235 & Raynor, Anna C. & Primary Wreck Concentration & 45.18585 & -83.3085667 & Projected \\
\hline 236 & Reindeer & Primary Wreck Concentration & 45.427584 & -83.812947 & Projected \\
\hline 237 & Rend, William P. & Primary Wreck Concentration & 45.062367 & -83.3925833 & Verified \\
\hline 238 & Roanoke & Primary Wreck Concentration & 44.877667 & -83.22545 & Projected \\
\hline 239 & Rounds, W.H. & Primary Wreck Concentration & 44.84035 & -83.2859833 & Projected \\
\hline 240 & Rudder & Articulated Unassociated Wreckage & 45.011533 & -83.2540666 & Verified \\
\hline 241 & Rumbell, J.E. & Primary Wreck Concentration & 45.068483 & -83.3739667 & Projected \\
\hline 242 & Ryan, Charles C. & Primary Wreck Concentration & 44.226513 & -82.941963 & Projected \\
\hline 243 & Sampson & Primary Wreck Concentration & 44.990179 & -83.314672 & Projected \\
\hline 244 & Scanlon's Barge & Articulated Associated Wreckage & 45.035823 & -83.327109 & Verified \\
\hline 245 & Scanlon's Barge & Articulated Associated Wreckage & 45.035671 & -83.326483 & Verified \\
\hline 246 & Scanlon's Barge & Primary Wreck Concentration & 45.034842 & -83.326585 & Verified \\
\hline 247 & Scott, Isaac M. & Primary Wreck Concentration & 45.051533 & -83.039217 & Verified \\
\hline 248 & Shamrock & Primary Wreck Concentration & 45.051131 & -83.433712 & Verified \\
\hline 249 & Shamrock & Secondary Wreck Location & 45.051007 & -83.433795 & Verified \\
\hline 250 & Sheldon, Thomas P. & Primary Wreck Concentration & 44.368483 & -83.306883 & Reported \\
\hline 251 & Simons, William H. & Primary Wreck Concentration & 44.972214 & -83.325435 & Projected \\
\hline 252 & Smith, Anna & Primary Wreck Concentration & 45.54305 & -84.0739 & Projecteo \\
\hline 253 & Smokestack & Historic Archaeological Landscape Feature & 45.040125 & -83.204819 & Verified \\
\hline 254 & Spangler, Kyle & Primary Wreck Concentration & 45.38352 & -83.43525 & Verified \\
\hline 255 & Stevens, J. H. & Primary Wreck Concentration & 45.525383 & -83.3908167 & Projected \\
\hline 256 & Stevens, William H. & Primary Wreck Concentration & 45.896217 & -83.32755 & Verified \\
\hline 257 & Syracuse & Primary Wreck Concentration & 45.524383 & -83.94445 & Projected \\
\hline 258 & Thew, William Peter & Primary Wreck Concentration & 45.045267 & -83.1527333 & Verified \\
\hline 259 & Thousand Islander & Primary Wreck Concentration & 44.6255 & -81.7767667 & Projected \\
\hline 260 & Timbers & Unassociated Isolated Find & 45.030765 & -83.196758 & Verified \\
\hline 261 & Topaz VII & Primary Wreck Concentration & 45.423233 & -83.7611167 & Projected \\
\hline 262 & Tu Jax I & Primary Wreck Concentration & 44.99835 & -83.4440333 & Projected \\
\hline 263 & Tu Jax II & Primary Wreck Concentration & 44.990733 & -83.4250333 & Projected \\
\hline 264 & Typo & Primary Wreck Concentration & 45.29125 & -83.31585 & Verified \\
\hline 265 & Utica & Primary Wreck Concentration & 45.387 & -83.66195 & Projected \\
\hline 266 & Van Valkenburg, Lucinda & Primary Wreck Concentration & 45.056333 & -83.169667 & Verified \\
\hline 267 & Venus & Primary Wreck Concentration & 44.809817 & -83.2775 & Verified \\
\hline
\end{tabular}




\begin{tabular}{|l|c|c|c|c|c|}
\hline 268 & Viator & Primary Wreck Concentration & 44.9916 & -83.03795 & Verified \\
\hline 269 & Vienna & Primary Wreck Concentration & 45.079167 & -83.136117 & Reported \\
\hline 270 & Wanderer & Primary Wreck Concentration & 45.180883 & -83.323747 & Projected \\
\hline 271 & Warner, John F. & Primary Wreck Concentration & 45.050829 & -83.435461 & Verified \\
\hline 272 & Waterwitch & Primary Wreck Concentration & 44.4167 & -83.3165 & Verified \\
\hline 273 & Wavertree & Primary Wreck Concentration & 44.807817 & -83.2725833 & Projected \\
\hline 274 & Well & Historic Archaeological Landscape Feature & 45.196709 & -83.334336 & Verified \\
\hline 275 & Wesley, G. W. & Primary Wreck Concentration & 45.068483 & -83.3728167 & Projected \\
\hline 276 & West Side & Primary Wreck Concentration & 45.021617 & -82.74075 & Projected \\
\hline 277 & WF CRIB & Historic Archaeological Landscape Feature & 45.058489 & -83.368933 & Verified \\
\hline 278 & Wilson, Belle & Primary Wreck Concentration & 44.600633 & -83.172256 & Projected \\
\hline 279 & Wilson, D. M. & Primary Wreck Concentration & 45.065209 & -83.181838 & Verified \\
\hline 280 & Windiate, Cornelia B. & Primary Wreck Concentration & 45.32538 & -83.32693 & Verified \\
\hline 281 & Woolson, Mary & Primary Wreck Concentration & 44.747267 & -83.1469 & Projected \\
\hline 282 & Young, William A. & Primary Wreck Concentration & 45.147217 & -83.24445 & Reported \\
\hline
\end{tabular}




\section{APPENDIX 3}

\section{VALUED SIDE-SCAN SONAR TARGETS}

\begin{tabular}{|c|c|c|c|c|c|c|}
\hline Target Name & Date & Latitude & Longitude & Type & Value & Description \\
\hline LHNPA31_1_01 & 2005_160 & 45.0151778 & -83.2314693 & Linear & 2 & $\begin{array}{l}\text { Linear with long vertical } \\
\text { shadow }\end{array}$ \\
\hline LHNPA33_1_01 & $2005 \_160$ & 45.0214699 & -83.2013913 & Netstake & 4 & Netstake \\
\hline LHNPA33_1_02 & 2005_160 & 45.0214871 & -83.201957 & Netstake & 4 & Netstake \\
\hline LHNPA33_1_03 & 2005_160 & 45.0138412 & -83.2305643 & Linear & 2 & Linear shadow \\
\hline LHNPC13_1_01 & 2005_161 & 45.0349186 & -83.2070415 & Unknown & 3 & Unknown partially in nadir \\
\hline LHNPC13_1_02 & 2005_161 & 45.0343321 & -83.2397582 & Linear & 3 & Long linear shadow \\
\hline LHNPC17_1_01 & 2005_161 & 45.035409 & -83.2288911 & Linear & 2 & Linear shadow \\
\hline LHNPC20_1_01 & 2005_161 & 45.0359235 & -83.2352256 & Rock & 3 & Large rock \\
\hline LHNPD01_1_01 & 2005_161 & 45.0346573 & -83.2634977 & Netstake & 4 & Netstake \\
\hline LHNPD05_1_01 & 2005_161 & 45.0339792 & -83.2615218 & Netstake & 4 & Netstake \\
\hline LHNPD05_1_02 & 2005_161 & 45.0345578 & -83.2620194 & Linear & 1 & $\begin{array}{c}\text { Long straight linear with narrow } \\
\text { shadow }\end{array}$ \\
\hline LHNPD05_1_04 & 2005_161 & 45.0383903 & -83.2643753 & Netstake & 4 & Netstake \\
\hline LHNPD05_1_05 & 2005_161 & 45.0381097 & -83.2636486 & Netstake & 4 & Netstake \\
\hline LHNPD05_1_06 & 2005_161 & 45.0327666 & -83.2613708 & Linear & 3 & Shadow only \\
\hline LHNPD07_1_01 & 2005_161 & 45.0382432 & -83.2631315 & Netstake & 4 & Netstake \\
\hline LHNPD07_1_02 & 2005_161 & 45.0360765 & -83.26176 & Netstake & 4 & Netstake \\
\hline LHNPD07_1_03 & 2005_161 & 45.0356398 & -83.2622615 & Netstake & 4 & Netstake \\
\hline LHNPD07_1_04 & 2005_161 & 45.0341808 & -83.2613683 & Linear & 3 & Linear with no shadow \\
\hline LHNPD07_1_05 & 2005_161 & 45.031795 & -83.2591462 & Netstake & 4 & Netstake \\
\hline LHNPD07_1_06 & 2005_161 & 45.0312153 & -83.2595841 & Netstake & 4 & Netstake \\
\hline LHNPD07_1_07 & 2005_161 & 45.0310658 & -83.2590977 & Netstake & 4 & Netstake \\
\hline LHNPD09_1_01 & 2005_161 & 45.0315651 & -83.2586993 & Netstake & 4 & Netstake \\
\hline LHNPD09_1_02 & 2005_161 & 45.0310874 & -83.2583518 & Netstake & 4 & Netstake \\
\hline LHNPD09_1_05 & 2005_161 & 45.03439 & -83.2602095 & Linear & 3 & Faint linear near nadir \\
\hline LHNPD09_1_06 & 2005_161 & 45.0355079 & -83.2607067 & Netstake & 4 & Netstake \\
\hline LHNPD09_1_07 & 2005_161 & 45.0359108 & -83.2616129 & Netstake & 4 & Netstake \\
\hline LHNPD09_1_08 & 2005_161 & 45.0407895 & -83.2638502 & Linear & 1 & $\begin{array}{l}\text { Long straight linear with narrow } \\
\text { shadow }\end{array}$ \\
\hline LHNPD11_1_01 & 2005_161 & 45.0441191 & -83.2645638 & Linear & 1 & $\begin{array}{c}\text { Long slightly curved linear with } \\
\text { narrow shadow }\end{array}$ \\
\hline LHNPD11_1_02 & 2005_161 & 45.0395496 & -83.2619872 & Linear & 1 & \begin{tabular}{|c|}
$\begin{array}{c}\text { Two timbers in contact with one } \\
\text { another }\end{array}$ \\
\end{tabular} \\
\hline LHNPD11_1_03 & 2005_161 & 45.0357497 & -83.2598092 & Linear & 1 & $\begin{array}{l}\text { Short linear with narrow } \\
\text { shadow }\end{array}$ \\
\hline LHNPD11_1_04 & 2005_161 & 45.0345203 & -83.2589307 & Linear & 1 & Long linear with narrow shadow \\
\hline LHNPD11_1_05 & 2005_161 & 45.0223302 & -83.252684 & Debris & 3 & Potential rock \\
\hline LHNPD11_1_06 & 2005_161 & 45.0440366 & -83.2641105 & Linear & 2 & $\begin{array}{c}\text { Short linear with irregular } \\
\text { shadow }\end{array}$ \\
\hline
\end{tabular}




\begin{tabular}{|c|c|c|c|c|c|c|}
\hline LHNPD11_1_07 & 2005_161 & 45.0385311 & -83.2612505 & Linear & 1 & $\begin{array}{c}\text { Short linear with narrow } \\
\text { shadow }\end{array}$ \\
\hline LHNPD11_1_08 & 2005_161 & 45.0384171 & -83.2611664 & Netstake & 4 & Netstake \\
\hline LHNPD11_1_09 & 2005_161 & 45.0369755 & -83.2604928 & Linear & 1 & $\begin{array}{l}\text { Short linear with narrow } \\
\text { shadow }\end{array}$ \\
\hline LHNPD11_1_10 & 2005_161 & 45.0355145 & -83.2597608 & Linear & 1 & $\begin{array}{c}\text { Short linear with narrow } \\
\text { shadow }\end{array}$ \\
\hline LHNPD11_1_12 & 2005_161 & 45.0343713 & -83.2597538 & Netstake & 4 & Netstake \\
\hline LHNPD11_1_13 & 2005_161 & 45.0319015 & -83.2577106 & Linear & 1 & $\begin{array}{c}\text { Short linear with narrow } \\
\text { shadow }\end{array}$ \\
\hline LHNPD13_1_01 & 2005_161 & 45.0345267 & -83.2584292 & Netstake & 4 & Netstake \\
\hline LHNPD13_1_02 & 2005_161 & 45.0355438 & -83.2587054 & Linear & 2 & $\begin{array}{l}\text { One or two linears with no } \\
\text { shadow }\end{array}$ \\
\hline LHNPD13_1_03 & 2005_161 & 45.0357004 & -83.2591308 & Linear & 1 & $\begin{array}{l}\text { Two linears with narrow } \\
\text { shadow }\end{array}$ \\
\hline LHNPD13_1_04 & 2005_161 & 45.0361862 & -83.259399 & Netstake & 4 & Netstake \\
\hline LHNPD13_1_06 & 2005_161 & 45.0420381 & -83.2629659 & Linear & 1 & $\begin{array}{c}\text { One to three timbers with } \\
\text { shadow }\end{array}$ \\
\hline LHNPD13_1_07 & 2005_161 & 45.0459288 & -83.2644302 & Debris & 2 & $\begin{array}{l}\text { Three parallel lines with no } \\
\text { shadow }\end{array}$ \\
\hline LHNPD13_1_08 & 2005_161 & 45.0311522 & -83.2566077 & Netstake & 4 & Netstake \\
\hline LHNPD13_1_09 & 2005_161 & 45.0309349 & -83.2569576 & Netstake & 4 & Netstake \\
\hline LHNPD13_1_10 & 2005_161 & 45.0315597 & -83.2568313 & Netstake & 4 & Netstake \\
\hline LHNPD13_1_11 & 2005_161 & 45.0319247 & -83.2570941 & Netstake & 4 & Netstake \\
\hline LHNPD13_1_13 & 2005_161 & 45.0344123 & -83.2586145 & Linear & 1 & Linear with narrow shadow \\
\hline LHNPD13_1_14 & 2005_161 & 45.0345179 & -83.2589444 & Linear & 1 & Linear with narrow shadow \\
\hline LHNPD13_1_15 & 2005_161 & 45.0363569 & -83.259475 & Linear & 1 & $\begin{array}{c}\text { Short linear with narrow } \\
\text { shadow }\end{array}$ \\
\hline LHNPD13_1_16 & 2005_161 & 45.0419519 & -83.2623182 & Linear & 2 & $\begin{array}{l}\text { Two parallel lines with no } \\
\text { shadow }\end{array}$ \\
\hline LHNPD13_1_17 & 2005_161 & 45.0370679 & -83.2604651 & Netstake & 4 & Netstake \\
\hline LHNPD27_1_01 & 2005_161 & 45.0391266 & -83.2551639 & Netstake & 4 & Netstake \\
\hline LHNPD27_1_03 & 2005_161 & 45.0331136 & -83.2527121 & Linear & 2 & Linear with faint shadow \\
\hline LHNPD27_1_04 & 2005_161 & 45.0306966 & -83.251054 & Netstake & 4 & Netstake \\
\hline LHNPD29_1_03 & 2005_161 & 45.0373066 & -83.2534195 & Netstake & 4 & Netstake \\
\hline LHNPD29_1_04 & 2005_161 & 45.0390751 & -83.2549125 & Linear & 2 & $\begin{array}{l}\text { Faint linear with irregular } \\
\text { shadow }\end{array}$ \\
\hline LHNPD35_1_01 & 2005_161 & 45.0394558 & -83.2525483 & Linear & 2 & Long linear with narrow shadow \\
\hline LHNPD37_1_01 & 2005_161 & 45.0381944 & -83.2506689 & Linear & 2 & Faint linear with narrow shadow \\
\hline LHNPD37_1_02 & 2005_161 & 45.0381433 & -83.2505268 & Netstake & 4 & Netstake \\
\hline LHNPD39_1_01 & 2005_161 & 45.040108 & -83.2512672 & Linear & 2 & $\begin{array}{c}\text { Short faint linear with narrow } \\
\text { shadow }\end{array}$ \\
\hline LHNPD47_1_01 & 2005_161 & 45.0311717 & -83.2431187 & Unknown & 3 & Oval discoloration \\
\hline LHNPD47_1_02 & 2005_161 & 45.0425467 & -83.2492067 & Linear & 3 & Faint linear with faint shadow \\
\hline LHNPD47_1_03 & 2005_161 & 45.0425839 & -83.2488248 & Linear & 3 & $\begin{array}{l}\text { Irregular linear with very } \\
\text { narrow shadow }\end{array}$ \\
\hline LHNPD51_1_01 & 2005_161 & 45.0371356 & -83.2445336 & Linear & 3 & Faint linear with shadow \\
\hline Monhan_001_01 & 2005_161 & 45.0334432 & -83.1997643 & Shipwreck & 1 & Monohansett \\
\hline Monhan_001_03 & 2005_161 & 45.0346406 & -83.2017898 & Wreckage & 2 & Monohansett \\
\hline Monhan_001_04 & 2005_161 & 45.0344506 & -83.2011161 & Linear & 3 & Unclear linear and shadow \\
\hline
\end{tabular}




\begin{tabular}{|c|c|c|c|c|c|c|}
\hline Monhan_001_06 & 2005_161 & 45.0334307 & -83.2004048 & Wreckage & 1 & Monohansett \\
\hline LHNPA2_12_1_01 & 2005_162 & 45.0183845 & -83.2393905 & Linear & 3 & Curved object and shadow \\
\hline LHNPA2_12_1_02 & 2005_162 & 45.026536 & -83.2425323 & Debris & 3 & Debris or rocks \\
\hline LHNPA2_13_1_01 & 2005_162 & 45.0271731 & -83.2429151 & Debris & 3 & Debris or rocks \\
\hline LHNPC07_1_01 & 2005_162 & 45.0328272 & -83.2381689 & Debris & 3 & Debris \\
\hline LHNPC09_1_01 & 2005_162 & 45.0332902 & -83.2393516 & Debris & 2 & $\begin{array}{l}\text { Mix of faint linears with } \\
\text { shadows }\end{array}$ \\
\hline LHNPC11_1_01 & 2005_162 & 45.0337625 & -83.2396611 & Debris & 2 & $\begin{array}{l}\text { Mix of faint linears with } \\
\text { shadows }\end{array}$ \\
\hline LHNPC11_2_01 & 2005_162 & 45.0336872 & -83.2394155 & Debris & 3 & $\begin{array}{l}\text { Mix of faint linears with } \\
\text { shadows }\end{array}$ \\
\hline LHNPD011_2_02 & 2005_162 & 45.0434624 & -83.2640868 & Linear & 1 & $\begin{array}{l}\text { Short linear with narrow } \\
\text { shadow }\end{array}$ \\
\hline LHNPD011_2_03 & $2005 \_162$ & 45.0424403 & -83.2637316 & Linear & 1 & Linear with narrow shadow \\
\hline LHNPD011_2_07 & 2005_162 & 45.0355899 & -83.2597846 & Netstake & 4 & Netstake \\
\hline LHNPD011_2_08 & 2005_162 & 45.0418356 & -83.2632787 & Linear & 3 & Faint linear with shadow \\
\hline LHNPD011_2_09 & 2005_162 & 45.0355368 & -83.2603957 & Linear & 2 & Curved linear \\
\hline LHNPD011_2_10 & 2005_162 & 45.0344937 & -83.2600886 & Linear & 2 & $\begin{array}{l}\text { Very long linear with faint } \\
\text { shadow }\end{array}$ \\
\hline LHNPD011_2_12 & 2005_162 & 45.0343779 & -83.2597538 & Netstake & 4 & Netstake \\
\hline LHNPD011_2_13 & 2005_162 & 45.0316374 & -83.2578195 & Netstake & 4 & Netstake \\
\hline LHNPD011_2_14 & 2005_162 & 45.0315761 & -83.2583977 & Netstake & 4 & Netstake \\
\hline LHNPD011_2_15 & 2005_162 & 45.0311326 & -83.2581579 & Netstake & 4 & Netstake \\
\hline LHNPD011_2_16 & 2005_162 & 45.027474 & -83.2561258 & Netstake & 4 & Netstake \\
\hline LHNPD07_2_01 & 2005_162 & 45.0338518 & -83.2611668 & Linear & 1 & $\begin{array}{c}\text { Short linear with narrow } \\
\text { shadow }\end{array}$ \\
\hline LHNPD07_2_02 & 2005_162 & 45.0351486 & -83.2614469 & Netstake & 4 & Netstake \\
\hline LHNPD07_2_03 & 2005_162 & 45.0359256 & -83.2617317 & Netstake & 4 & Netstake \\
\hline LHNPD07_2_04 & 2005_162 & 45.038217 & -83.2630686 & Netstake & 4 & Netstake \\
\hline LHNPD15_2_01 & 2005_162 & 45.0420098 & -83.2621482 & Linear & 1 & $\begin{array}{c}\text { Curved linear with very narrow } \\
\text { shadow }\end{array}$ \\
\hline LHNPD15_2_02 & 2005_162 & 45.0404907 & -83.2606181 & Debris & 2 & $\begin{array}{l}\text { Group of short linears with } \\
\text { narrow shadows }\end{array}$ \\
\hline LHNPD15_2_03 & 2005_162 & 45.0391777 & -83.2598107 & Linear & 2 & $\begin{array}{l}\text { Short linear with narrow } \\
\text { shadow }\end{array}$ \\
\hline LHNPD15_2_04 & 2005_162 & 45.0366822 & -83.2594794 & Linear & 2 & Linear with faint shadow \\
\hline LHNPD15_2_05 & 2005_162 & 45.0368202 & -83.2587629 & Linear & 1 & $\begin{array}{l}\text { Two linears with narrow } \\
\text { shadow }\end{array}$ \\
\hline LHNPD15_2_06 & 2005_162 & 45.0363783 & -83.259343 & Netstake & 4 & Netstake \\
\hline LHNPD15_2_08 & 2005_162 & 45.0358047 & -83.258207 & Linear & 1 & $\begin{array}{c}\text { Short linear with narrow } \\
\text { shadow }\end{array}$ \\
\hline LHNPD15_2_09 & 2005_162 & 45.0360659 & -83.2583368 & Linear & 1 & Linear with narrow shadow \\
\hline LHNPD15_2_10 & 2005_162 & 45.0352241 & -83.2579762 & Linear & 1 & $\begin{array}{l}\text { Two linears with narrow } \\
\text { shadow }\end{array}$ \\
\hline LHNPD15_2_11 & 2005_162 & 45.0345961 & -83.2583398 & Netstake & 4 & Netstake \\
\hline LHNPD15_2_14 & 2005_162 & 45.0448698 & -83.2630992 & Linear & 3 & Very wide linear shadow \\
\hline LHNPD15_2_15 & 2005_162 & 45.0444081 & -83.2632546 & Linear & 3 & Irregular linear with no shadow \\
\hline LHNPD15_2_16 & 2005_162 & 45.043491 & -83.2627917 & Linear & 3 & Short linear with faint shadow \\
\hline LHNPD15_2_17 & 2005_162 & 45.0414956 & -83.2613426 & Linear & 3 & Triangular linear shadow \\
\hline LHNPD15_2_19 & 2005_162 & 45.0351438 & -83.2584013 & Linear & 2 & $\begin{array}{l}\text { Curved linear with narrow } \\
\text { shadow }\end{array}$ \\
\hline
\end{tabular}




\begin{tabular}{|c|c|c|c|c|c|c|}
\hline LHNPD15_2_22 & 2005_162 & 45.0320351 & -83.2569572 & Netstake & 4 & Netstake \\
\hline LHNPD15_2_23 & 2005_162 & 45.0320086 & -83.256094 & Netstake & 4 & Netstake \\
\hline LHNPD15_2_24 & 2005_162 & 45.0316705 & -83.2567576 & Netstake & 4 & Netstake \\
\hline LHNPD15_2_25 & $2005 \_162$ & 45.0312897 & -83.2565656 & Netstake & 4 & Netstake \\
\hline LHNPD15_2_26 & 2005_162 & 45.0303663 & -83.2559601 & Netstake & 4 & Netstake \\
\hline LHNPD17_2_01 & 2005_162 & 45.0267106 & -83.2527507 & Linear & 3 & Linear debris or rock \\
\hline LHNPD17_2_02 & 2005_162 & 45.0263669 & -83.2532336 & Debris & 3 & Debris with no shadow \\
\hline LHNPD17_2_03 & 2005_162 & 45.0331256 & -83.2566102 & Linear & 1 & $\begin{array}{c}\text { One or two short linears with } \\
\text { narrow shadow }\end{array}$ \\
\hline LHNPD17_2_04 & 2005_162 & 45.0342237 & -83.2570333 & Linear & 1 & $\begin{array}{l}\text { Short linear with narrow } \\
\text { shadow }\end{array}$ \\
\hline LHNPD17_2_05 & 2005_162 & 45.034583 & -83.2574316 & Linear & 1 & $\begin{array}{c}\text { Short linear with narrow } \\
\text { shadow }\end{array}$ \\
\hline LHNPD17_2_06 & 2005_162 & 45.0342778 & -83.2566834 & Linear & 1 & Faint linear with narrow shadow \\
\hline LHNPD17_2_07 & 2005_162 & 45.0358665 & -83.2576529 & Linear & 1 & $\begin{array}{l}\text { Short linear with irregular } \\
\text { shadow }\end{array}$ \\
\hline LHNPD17_2_08 & 2005_162 & 45.0367896 & -83.2587127 & Linear & 1 & $\begin{array}{l}\text { Three or more linears with } \\
\text { narrow shadows }\end{array}$ \\
\hline LHNPD17_2_09 & 2005_162 & 45.0368362 & -83.2581097 & Linear & 1 & Linear with narrow shadow \\
\hline LHNPD17_2_10 & 2005_162 & 45.0369759 & -83.2578191 & Linear & 2 & $\begin{array}{c}\text { One or two linears with no } \\
\text { shadow }\end{array}$ \\
\hline LHNPD17_2_11 & $2005 \_162$ & 45.0396357 & -83.2595982 & Linear & 1 & $\begin{array}{c}\text { Irregular linear with very faint } \\
\text { shadow }\end{array}$ \\
\hline LHNPD17_2_12 & 2005_162 & 45.0432137 & -83.2616074 & Linear & 1 & Long linear with narrow shadow \\
\hline LHNPD17_2_13 & 2005_162 & 45.0317393 & -83.2557498 & Netstake & 4 & Netstake \\
\hline LHNPD17_2_14 & 2005_162 & 45.032009 & -83.2559016 & Netstake & 4 & Netstake \\
\hline LHNPD17_2_15 & 2005_162 & 45.0359453 & -83.258261 & Linear & 1 & $\begin{array}{c}\text { Very long irregular linear with } \\
\text { narrow shadow }\end{array}$ \\
\hline LHNPD17_2_17 & 2005_162 & 45.0436708 & -83.2620591 & Linear & 2 & Linear with faint shadow \\
\hline LHNPD17_2_18 & 2005_162 & 45.0323952 & -83.2557819 & Linear & 3 & Faint linear with faint shadow \\
\hline LHNPD17_2_19 & 2005_162 & 45.0317798 & -83.2552794 & Netstake & 4 & Netstake \\
\hline LHNPD19_2_04 & $2005 \_162$ & 45.0355743 & -83.2574537 & Linear & 3 & Short linear with no shadow \\
\hline LHNPD19_2_05 & 2005_162 & 45.0344213 & -83.2566109 & Linear & 1 & Linear with narrow shadow \\
\hline LHNPD19_2_06 & 2005_162 & 45.0322694 & -83.2547656 & Linear & 1 & Linear with shadow \\
\hline LHNPD19_2_07 & 2005_162 & 45.0319863 & -83.2545728 & Linear & 1 & Linear with shadow \\
\hline LHNPD19_2_08 & 2005_162 & 45.0446427 & -83.2614433 & Linear & 2 & Distinct linear shadow \\
\hline LHNPD19_2_09 & 2005_162 & 45.0444451 & -83.2618167 & Linear & 3 & Short linear with no shadow \\
\hline LHNPD19_2_10 & 2005_162 & 45.0443268 & -83.2614106 & Linear & 2 & $\begin{array}{c}\text { Faint linear with narrow shadow } \\
\text { into nadir }\end{array}$ \\
\hline LHNPD19_2_12 & 2005_162 & 45.0363862 & -83.2577599 & Linear & 3 & Short linear with no shadow \\
\hline LHNPD19_2_13 & 2005_162 & 45.0351454 & -83.256234 & Linear & 1 & $\begin{array}{c}\text { Short linear with narrow } \\
\text { shadow }\end{array}$ \\
\hline LHNPD19_2_14 & 2005_162 & 45.034097 & -83.2565001 & Debris & 3 & Short linear with no shadow \\
\hline LHNPD19_2_15 & 2005_162 & 45.0322647 & -83.2556108 & Linear & 3 & $\begin{array}{c}\text { Short linear with narrow } \\
\text { shadow }\end{array}$ \\
\hline LHNPD19_2_16 & 2005_162 & 45.0318846 & -83.2554007 & Netstake & 4 & Netstake \\
\hline LHNPD19_2_17 & $2005 \_162$ & 45.0321093 & -83.2548756 & Netstake & 4 & Netstake \\
\hline LHNPD19_2_18 & 2005_162 & 45.0304736 & -83.2538642 & Linear & 3 & Faint linear with faint shadow \\
\hline LHNPD21_2_01 & 2005_162 & 45.0303492 & -83.2538095 & Netstake & 4 & Netstake \\
\hline
\end{tabular}




\begin{tabular}{|c|c|c|c|c|c|c|}
\hline LHNPD21_2_02 & 2005_162 & 45.0320696 & -83.2539484 & Wreckage & 1 & $\begin{array}{l}\text { Groundtruthed unassociated } \\
\text { articulated wreckage }\end{array}$ \\
\hline LHNPD21_2_03 & 2005_162 & 45.0319355 & -83.2545873 & Netstake & 4 & Netstake \\
\hline LHNPD21_2_05 & 2005_162 & 45.0436892 & -83.260025 & Linear & 1 & Linear with wide shadow \\
\hline LHNPD21_2_06 & 2005_162 & 45.0462883 & -83.2615544 & Linear & 3 & Short linear with wide shadow \\
\hline LHNPD21_2_07 & 2005_162 & 45.0313504 & -83.2533727 & Linear & 3 & $\begin{array}{c}\text { Short linear with narrow } \\
\text { shadow }\end{array}$ \\
\hline LHNPD21_2_08 & 2005_162 & 45.0308377 & -83.2533963 & Linear & 3 & Faint linear with faint shadow \\
\hline LHNPD21_2_09 & 2005_162 & 45.03175 & -83.2534468 & Netstake & 4 & Netstake \\
\hline LHNPD21_2_10 & 2005_162 & 45.0319551 & -83.2541035 & Netstake & 4 & Netstake \\
\hline LHNPD21_2_11 & 2005_162 & 45.0324057 & -83.254028 & Netstake & 4 & Netstake \\
\hline LHNPD21_2_13 & 2005_162 & 45.0322391 & -83.2538562 & Netstake & 4 & Netstake \\
\hline LHNPD21_2_14 & 2005_162 & 45.0352079 & -83.2558602 & Linear & 3 & $\begin{array}{l}\text { Short faint linear with faint } \\
\text { narrow shadow }\end{array}$ \\
\hline LHNPD21_2_15 & $2005 \_162$ & 45.0363446 & -83.2563091 & Netstake & 4 & Netstake \\
\hline LHNPD21_2_17 & 2005_162 & 45.0365622 & -83.2563547 & Linear & 3 & $\begin{array}{l}\text { Short faint linear with faint } \\
\text { narrow shadow }\end{array}$ \\
\hline LHNPD21_2_18 & 2005_162 & 45.036726 & -83.2568421 & Netstake & 4 & Netstake \\
\hline LHNPD21_2_19 & 2005_162 & 45.0371865 & -83.2570622 & Netstake & 4 & Netstake \\
\hline LHNPD21_2_20 & 2005_162 & 45.0421813 & -83.2596951 & Linear & 3 & $\begin{array}{l}\text { Short faint linear with faint } \\
\text { narrow shadow }\end{array}$ \\
\hline LHNPD21_2_21 & $2005 \_162$ & 45.0439812 & -83.2602246 & Netstake & 4 & Netstake \\
\hline LHNPD23_2_02 & 2005_162 & 45.0365211 & -83.2557694 & Linear & 2 & Bright linear shadow \\
\hline LHNPD23_2_03 & 2005_162 & 45.0347379 & -83.2547936 & Linear & 2 & $\begin{array}{l}\text { Short linear with narrow } \\
\text { shadow }\end{array}$ \\
\hline LHNPD23_2_05 & 2005_162 & 45.0325779 & -83.2531591 & Linear & 2 & Indistinct linear with shadow \\
\hline LHNPD23_2_06 & 2005_162 & 45.0374564 & -83.2560309 & Netstake & 4 & Netstake \\
\hline LHNPD23_2_07 & 2005_162 & 45.0367381 & -83.2554654 & Netstake & 4 & Netstake \\
\hline LHNPD23_2_08 & 2005_162 & 45.0324824 & -83.2539345 & Netstake & 4 & Netstake \\
\hline LHNPD23_2_09 & 2005_162 & 45.0325103 & -83.2536275 & Netstake & 4 & Netstake \\
\hline LHNPD23_2_10 & 2005_162 & 45.0325234 & -83.2534232 & Netstake & 4 & Netstake \\
\hline LHNPD23_2_11 & 2005_162 & 45.0322934 & -83.2537392 & Netstake & 4 & Netstake \\
\hline LHNPD23_2_12 & 2005_162 & 45.0324326 & -83.25319 & Netstake & 4 & Netstake \\
\hline LHNPD23_2_13 & 2005_162 & 45.0321648 & -83.2529852 & Netstake & 4 & Netstake \\
\hline LHNPD23_2_14 & 2005_162 & 45.0318116 & -83.2533312 & Netstake & 4 & Netstake \\
\hline LHNPD23_2_15 & 2005_162 & 45.0316268 & -83.2529536 & Netstake & 4 & Netstake \\
\hline LHNPD23_2_16 & $2005 \_162$ & 45.0314672 & -83.2532315 & Linear & 2 & $\begin{array}{l}\text { Short linear with narrow } \\
\text { shadow }\end{array}$ \\
\hline LHNPD23_2_17 & 2005_162 & 45.0307407 & -83.252283 & Netstake & 4 & Netstake \\
\hline LHNPD23_2_18 & 2005_162 & 45.0302871 & -83.2521688 & Linear & 3 & $\begin{array}{l}\text { Short faint linear with narrow } \\
\text { shadow }\end{array}$ \\
\hline LHNPD25_2_03 & 2005_162 & 45.0393461 & -83.2559562 & Debris & 3 & $\begin{array}{l}\text { Field of dark spots with no } \\
\text { shadow }\end{array}$ \\
\hline LHNPD25_2_04 & 2005_162 & 45.0274641 & -83.249971 & Debris & 2 & Debris depressed into lake floor \\
\hline LHNPD25_2_05 & 2005_162 & 45.0307226 & -83.2519899 & Netstake & 4 & Netstake \\
\hline LHNPD25_2_06 & 2005_162 & 45.0304551 & -83.2513184 & Netstake & 4 & Netstake \\
\hline LHNPD25_2_07 & 2005_162 & 45.0306667 & -83.2522063 & Linear & 1 & $\begin{array}{l}\text { Short linear with narrow } \\
\text { shadow }\end{array}$ \\
\hline LHNPD25_2_08 & 2005_162 & 45.0322807 & -83.2528712 & Netstake & 4 & Netstake \\
\hline LHNPD25_2_09 & 2005_162 & 45.0321694 & -83.252362 & Netstake & 4 & Netstake \\
\hline
\end{tabular}




\begin{tabular}{|c|c|c|c|c|c|c|}
\hline LHNPD25_2_10 & 2005_162 & 45.0290276 & -83.2509661 & Linear & 3 & Faint linear shadow \\
\hline LHNPA12_1_01 & 2005_164 & 45.0256687 & -83.2346159 & Linear & 3 & Indistinct linear with shadow \\
\hline LHNPA13_1_01 & 2005_164 & 45.0252301 & -83.233883 & Linear & 3 & Indistinct linear with shadow \\
\hline LHNPA13_1_02 & 2005_164 & 45.0245688 & -83.2367595 & Linear & 3 & Indistinct linear with shadow \\
\hline LHNPA14_1_01 & 2005_164 & 45.0309234 & -83.2080799 & Linear & 2 & $\begin{array}{l}\text { Long undulating linear with } \\
\text { narrow shadow }\end{array}$ \\
\hline LHNPA14_1_02 & 2005_164 & 45.0237007 & -83.2356759 & Linear & 3 & $\begin{array}{c}\text { Short faint linear with narrow } \\
\text { shadow }\end{array}$ \\
\hline Flint_02 & 2005_166 & 45.0244815 & -83.3506687 & Unknown & 2 & Donut-shaped wreckage \\
\hline Flint_04 & 2005_166 & 45.0259304 & -83.3473697 & Shipwreck & 1 & Flint \\
\hline Flint_05 & 2005_166 & 45.0246652 & -83.3466833 & Wreckage & 2 & Small field of wreckage \\
\hline Flint_06 & 2005_166 & 45.026851 & -83.3472381 & Linear & 1 & $\begin{array}{l}\text { Short linear with narrow } \\
\text { shadow }\end{array}$ \\
\hline LHNPA05_1_01 & 2005_166 & 45.0281499 & -83.241021 & Debris & 3 & Potential rocks \\
\hline LHNPA09_1_01 & 2005_166 & 45.0299184 & -83.2223314 & Linear & 3 & Narrow shadow \\
\hline LHNPA09_2_01 & 2005_166 & 45.0245201 & -83.2461777 & Debris & 3 & Potential rocks or debris \\
\hline LHNPA10_2_01 & 2005_166 & 45.0246909 & -83.2432182 & Linear & 3 & Short linear shadow \\
\hline LHNPA10_2_02 & 2005_166 & 45.0272272 & -83.2337931 & Linear & 3 & Potential linear \\
\hline LHNPA11_1_01 & 2005_166 & 45.0220157 & -83.250068 & Linear & 2 & $\begin{array}{c}\text { Short linear with narrow } \\
\text { shadow }\end{array}$ \\
\hline LHNPA15_1_01 & 2005_166 & 45.0232303 & -83.2357441 & Debris & 3 & Small field of debris \\
\hline LHNPA15_1_02 & 2005_166 & 45.0233655 & -83.235305 & Debris & 3 & Small field of debris \\
\hline LHNPA15_1_03 & 2005_166 & 45.0267535 & -83.221223 & Debris & 3 & Irregular shadow \\
\hline LHNPA16_1_01 & 2005_166 & 45.0223879 & -83.2376271 & Linear & 1 & $\begin{array}{c}\text { Short linear with narrow } \\
\text { shadow }\end{array}$ \\
\hline LHNPA16_1_02 & 2005_166 & 45.0223142 & -83.2363126 & Linear & 3 & Obscured linear with shadow \\
\hline LHNPA16_1_03 & 2005_166 & 45.0226506 & -83.2352336 & Debris & 3 & Small field of debris \\
\hline LHNPA16_1_04 & $2005 \_166$ & 45.0227114 & -83.2353159 & Debris & 3 & Small field of debris \\
\hline LHNPA16_1_05 & 2005_166 & 45.0229085 & -83.2349954 & Debris & 2 & $\begin{array}{c}\text { Debris and faint linears with } \\
\text { narrow shadows }\end{array}$ \\
\hline LHNPA17_1_01 & 2005_166 & 45.0229044 & -83.2349607 & Debris & 3 & Short linear with shadow \\
\hline LHNPA17_1_02 & 2005_166 & 45.0228256 & -83.2349286 & Debris & 3 & Linear with shadow \\
\hline LHNPA17_1_03 & 2005_166 & 45.0223794 & -83.2350278 & Debris & 3 & Large field of debris \\
\hline LHNPA18_1_01 & 2005_166 & 45.0237432 & -83.2262723 & Linear & 3 & Long linear with narrow shadow \\
\hline LHNPA18_1_02 & 2005_166 & 45.0229788 & -83.2309697 & Debris & 3 & $\begin{array}{l}\text { Unclear object with large } \\
\text { shadow }\end{array}$ \\
\hline LHNPA18_1_03 & 2005_166 & 45.0188873 & -83.2478479 & Linear & 3 & Short linear with shadow \\
\hline LHNPA18_1_05 & 2005_166 & 45.0219798 & -83.2359896 & Linear & 3 & $\begin{array}{c}\text { Short faint linear with narrow } \\
\text { shadow }\end{array}$ \\
\hline LHNPF02_1_01 & 2006_216 & 45.0269291 & -83.3106683 & Netstake & 4 & Netstake \\
\hline LHNPF02_1_02 & 2006_216 & 45.025962 & -83.3081644 & Netstake & 4 & Netstake \\
\hline LHNPF02_1_03 & 2006_216 & 45.0261769 & -83.3078181 & Netstake & 4 & Netstake \\
\hline LHNPF02_1_04 & 2006_216 & 45.0234818 & -83.2984605 & Netstake & 4 & Netstake \\
\hline LHNPF02_1_05 & 2006_216 & 45.0233983 & -83.2989991 & Netstake & 4 & Netstake \\
\hline LHNPF02_1_06 & 2006_216 & 45.0235156 & -83.2982548 & Netstake & 4 & Netstake \\
\hline LHNPF02_1_07 & 2006_216 & 45.0231678 & -83.2986502 & Netstake & 4 & Netstake \\
\hline LHNPF02_1_08 & 2006_216 & 45.0230613 & -83.2979065 & Netstake & 4 & Netstake \\
\hline LHNPF02_1_09 & 2006_216 & 45.0225029 & -83.2967899 & Linear & 2 & Long linear with narrow shadow \\
\hline LHNPF02_1_10 & 2006_216 & 45.0228723 & -83.2964649 & Netstake & 4 & Netstake \\
\hline LHNPF02_1_11 & 2006_216 & 45.02247 & -83.2962782 & Netstake & 4 & Netstake \\
\hline
\end{tabular}




\begin{tabular}{|c|c|c|c|c|c|c|}
\hline LHNPF02_1_12 & 2006_216 & 45.0216505 & -83.2932458 & Netstake & 4 & Netstake \\
\hline LHNPF02_1_13 & 2006_216 & 45.0202803 & -83.2875812 & Netstake & 4 & Netstake \\
\hline LHNPF02_1_14 & 2006_216 & 45.019878 & -83.2877962 & Netstake & 4 & Netstake \\
\hline LHNPF02_1_15 & 2006_216 & 45.0199232 & -83.2864597 & Netstake & 4 & Netstake \\
\hline LHNPF02_1_16 & 2006_216 & 45.0200241 & -83.2865256 & Linear & 2 & $\begin{array}{c}\text { Short linear with narrow } \\
\text { shadow }\end{array}$ \\
\hline LHNPF02_1_17 & 2006_216 & 45.0193414 & -83.2852548 & Netstake & 4 & Netstake \\
\hline LHNPF02_1_18 & 2006_216 & 45.0188481 & -83.2826776 & Netstake & 4 & Netstake \\
\hline LHNPF02_1_19 & 2006_216 & 45.0169774 & -83.2775936 & Netstake & 4 & Netstake \\
\hline LHNPF02_1_20 & 2006_216 & 45.0171409 & -83.277197 & Netstake & 4 & Netstake \\
\hline LHNPF02_1_21 & 2006_216 & 45.0168218 & -83.2770029 & Netstake & 4 & Netstake \\
\hline LHNPF02_1_22 & 2006_216 & 45.0167245 & -83.2765286 & Netstake & 4 & Netstake \\
\hline LHNPF02_1_23 & 2006_216 & 45.0163818 & -83.2752061 & Netstake & 4 & Netstake \\
\hline LHNPF02_1_24 & 2006_216 & 45.0166415 & -83.2751219 & Netstake & 4 & Netstake \\
\hline LHNPF02_1_25 & 2006_216 & 45.0161037 & -83.2748252 & Netstake & 4 & Netstake \\
\hline LHNPF02_1_26 & 2006_216 & 45.016226 & -83.2752454 & Netstake & 4 & Netstake \\
\hline LHNPF02_1_27 & 2006_216 & 45.0159194 & -83.2735792 & Netstake & 4 & Netstake \\
\hline LHNPF02_1_28 & 2006_216 & 45.0157847 & -83.2733621 & Netstake & 4 & Netstake \\
\hline LHNPF02_1_29 & 2006_216 & 45.0161273 & -83.2731372 & Netstake & 4 & Netstake \\
\hline LHNPF02_1_30 & 2006_216 & 45.0155832 & -83.2730348 & Netstake & 4 & Netstake \\
\hline LHNPF02_1_31 & 2006_216 & 45.0159947 & -83.2727788 & Netstake & 4 & Netstake \\
\hline LHNPF02_1_32 & 2006_216 & 45.0155654 & -83.2725442 & Netstake & 4 & Netstake \\
\hline LHNPF02_1_33 & 2006_216 & 45.015667 & -83.2718889 & Linear & 2 & Linear with shadow \\
\hline LHNPF02_1_34 & 2006_216 & 45.0150186 & -83.2703172 & Netstake & 4 & Netstake \\
\hline LHNPF02_1_35 & 2006_216 & 45.0148753 & -83.2701381 & Netstake & 4 & Netstake \\
\hline LHNPF02_1_36 & 2006_216 & 45.0266458 & -83.3108247 & Netstake & 4 & Netstake \\
\hline LHNPF02_1_37 & 2006_216 & 45.017219 & -83.2783507 & Netstake & 4 & Netstake \\
\hline LHNPF04_1_02 & 2006_216 & 45.0160057 & -83.2722854 & Netstake & 4 & Netstake \\
\hline LHNPF04_1_03 & 2006_216 & 45.0160439 & -83.2727015 & Netstake & 4 & Netstake \\
\hline LHNPF04_1_04 & 2006_216 & 45.0159775 & -83.2727608 & Netstake & 4 & Netstake \\
\hline LHNPF04_1_05 & 2006_216 & 45.0162164 & -83.2730258 & Netstake & 4 & Netstake \\
\hline LHNPF04_1_06 & 2006_216 & 45.0167343 & -83.2733744 & Netstake & 4 & Netstake \\
\hline LHNPF04_1_07 & 2006_216 & 45.0172598 & -83.2747119 & Netstake & 4 & Netstake \\
\hline LHNPF04_1_08 & 2006_216 & 45.0167098 & -83.2746621 & Netstake & 4 & Netstake \\
\hline LHNPF04_1_09 & 2006_216 & 45.0175817 & -83.2775567 & Netstake & 4 & Netstake \\
\hline LHNPF04_1_10 & 2006_216 & 45.0176557 & -83.2778808 & Netstake & 4 & Netstake \\
\hline LHNPF04_1_11 & 2006_216 & 45.019119 & -83.2813019 & Netstake & 4 & Netstake \\
\hline LHNPF04_1_12 & 2006_216 & 45.0193035 & -83.2814405 & Netstake & 4 & Netstake \\
\hline LHNPF04_1_13 & 2006_216 & 45.0192656 & -83.281842 & Netstake & 4 & Netstake \\
\hline LHNPF04_1_14 & 2006_216 & 45.0197285 & -83.2833199 & Netstake & 4 & Netstake \\
\hline LHNPF04_1_15 & 2006_216 & 45.0199606 & -83.2846223 & Netstake & 4 & Netstake \\
\hline LHNPF04_1_16 & 2006_216 & 45.0203001 & -83.2856837 & Netstake & 4 & Netstake \\
\hline LHNPF04_1_17 & 2006_216 & 45.0200585 & -83.2857663 & Netstake & 4 & Netstake \\
\hline LHNPF04_1_18 & 2006_216 & 45.0206276 & -83.2860147 & Linear & 2 & Linear with very narrow shadow \\
\hline LHNPF04_1_20 & 2006_216 & 45.0214907 & -83.2913323 & Linear & 1 & Linear with narrow shadow \\
\hline LHNPF04_1_21 & 2006_216 & 45.0219536 & -83.2911873 & Netstake & 4 & Netstake \\
\hline LHNPF04_1_22 & 2006_216 & 45.0217484 & -83.2915006 & Netstake & 4 & Netstake \\
\hline LHNPF04_1_23 & 2006_216 & 45.0220284 & -83.2922085 & Netstake & 4 & Netstake \\
\hline LHNPF04_1_24 & 2006_216 & 45.0223907 & -83.2924582 & Netstake & 4 & Netstake \\
\hline LHNPF04_1_25 & 2006_216 & 45.0227435 & -83.2939375 & Netstake & 4 & Netstake \\
\hline LHNPF04_1_26 & 2006_216 & 45.0236684 & -83.2972897 & Netstake & 4 & Netstake \\
\hline
\end{tabular}




\begin{tabular}{|c|c|c|c|c|c|c|}
\hline LHNPF04_1_27 & 2006_216 & 45.0234926 & -83.2975761 & Netstake & 4 & Netstake \\
\hline LHNPF04_1_28 & 2006_216 & 45.0236616 & -83.2981407 & Netstake & 4 & Netstake \\
\hline LHNPF04_1_29 & 2006_216 & 45.0244267 & -83.299291 & Netstake & 4 & Netstake \\
\hline LHNPF04_1_30 & 2006_216 & 45.0241688 & -83.2999362 & Linear & 3 & $\begin{array}{l}\text { Short faint linear with faint } \\
\text { shadow }\end{array}$ \\
\hline LHNPF04_1_31 & 2006_216 & 45.0241997 & -83.3000517 & Linear & 3 & $\begin{array}{l}\text { Short faint linear with faint } \\
\text { shadow }\end{array}$ \\
\hline LHNPF04_1_32 & 2006_216 & 45.0259983 & -83.3057205 & Netstake & 4 & Netstake \\
\hline LHNPF04_1_33 & 2006_216 & 45.0265394 & -83.3069253 & Linear & 2 & $\begin{array}{l}\text { Short faint linear with narrow } \\
\text { shadow }\end{array}$ \\
\hline LHNPF04_1_34 & 2006_216 & 45.0263511 & -83.3079712 & Linear & 3 & $\begin{array}{c}\text { Short faint linear with faint } \\
\text { shadow }\end{array}$ \\
\hline LHNPF04_1_35 & 2006_216 & 45.0264277 & -83.3080189 & Linear & 3 & Faint linear with narrow shadow \\
\hline LHNPF04_1_36 & $2006 \_216$ & 45.0267732 & -83.3076275 & Netstake & 4 & Netstake \\
\hline LHNPF04_1_37 & 2006_216 & 45.026901 & -83.3081227 & Linear & 2 & Linear with very narrow shadow \\
\hline LHNPF04_1_38 & 2006_216 & 45.0268842 & -83.3087048 & Netstake & 4 & Netstake \\
\hline LHNPF04_1_39 & 2006_216 & 45.0271849 & -83.3088482 & Netstake & 4 & Netstake \\
\hline LHNPF04_1_40 & 2006_216 & 45.0270618 & -83.3089327 & Linear & 2 & Linear with no shadow \\
\hline LHNPF04_1_42 & 2006_216 & 45.0277713 & -83.3103725 & Linear & 1 & $\begin{array}{l}\text { Two linears in contact and } \\
\text { possibly articulated }\end{array}$ \\
\hline LHNPF06_2_02 & 2006_216 & 45.0277423 & -83.3105377 & Linear & 2 & Faint linear with narrow shadow \\
\hline LHNPF06_2_03 & 2006_216 & 45.0276744 & -83.3096599 & Linear & 1 & Long linear with narrow shadow \\
\hline LHNPF06_2_04 & 2006_216 & 45.0276268 & -83.309426 & Netstake & 4 & Netstake \\
\hline LHNPF06_2_06 & 2006_216 & 45.0273096 & -83.3088533 & Netstake & 4 & Netstake \\
\hline LHNPF06_2_07 & 2006_216 & 45.0269418 & -83.3075147 & Netstake & 4 & Netstake \\
\hline LHNPF06_2_08 & 2006_216 & 45.0272298 & -83.3072057 & Netstake & 4 & Netstake \\
\hline LHNPF06_2_09 & 2006_216 & 45.0271062 & -83.307112 & Linear & 2 & Linear with narrow shadow \\
\hline LHNPF06_2_10 & $2006 \_216$ & 45.0266586 & -83.3069283 & Linear & 1 & $\begin{array}{c}\text { Short linear with narrow } \\
\text { shadow }\end{array}$ \\
\hline LHNPF06_2_11 & 2006_216 & 45.0266573 & -83.3062891 & Netstake & 4 & Netstake \\
\hline LHNPF06_2_12 & 2006_216 & 45.0269319 & -83.306213 & Netstake & 4 & Netstake \\
\hline LHNPF06_2_13 & 2006_216 & 45.0271081 & -83.3067347 & Netstake & 4 & Netstake \\
\hline LHNPF06_2_14 & 2006_216 & 45.0264402 & -83.3053095 & Netstake & 4 & Netstake \\
\hline LHNPF06_2_15 & 2006_216 & 45.0266091 & -83.3050103 & Linear & 2 & Linear with narrow shadow \\
\hline LHNPF06_2_16 & 2006_216 & 45.0253073 & -83.3002908 & Linear & 2 & $\begin{array}{l}\text { Group of short linears with } \\
\text { narrow shadows }\end{array}$ \\
\hline LHNPF06_2_17 & 2006_216 & 45.0245728 & -83.2993844 & Netstake & 4 & Netstake \\
\hline LHNPF06_2_18 & 2006_216 & 45.0247506 & -83.2984152 & Netstake & 4 & Netstake \\
\hline LHNPF06_2_19 & 2006_216 & 45.02452 & -83.2984878 & Netstake & 4 & Netstake \\
\hline LHNPF06_2_20 & 2006_216 & 45.0244524 & -83.2983023 & Netstake & 4 & Netstake \\
\hline LHNPF06_2_21 & 2006_216 & 45.0241744 & -83.2975543 & Netstake & 4 & Netstake \\
\hline LHNPF06_2_22 & 2006_216 & 45.0235333 & -83.2944276 & Netstake & 4 & Netstake \\
\hline LHNPF06_2_23 & 2006_216 & 45.0229285 & -83.2938311 & Netstake & 4 & Netstake \\
\hline LHNPF06_2_24 & 2006_216 & 45.0229622 & -83.2923293 & Netstake & 4 & Netstake \\
\hline LHNPF06_2_25 & $2006 \_216$ & 45.0222459 & -83.2921302 & Linear & 1 & Linear with narrow shadow \\
\hline LHNPF06_2_26 & 2006_216 & 45.0224971 & -83.2918404 & Netstake & 4 & Netstake \\
\hline LHNPF06_2_27 & 2006_216 & 45.0220929 & -83.2912545 & Netstake & 4 & Netstake \\
\hline LHNPF06_2_29 & 2006_216 & 45.01997 & -83.2833402 & Netstake & 4 & Netstake \\
\hline
\end{tabular}




\begin{tabular}{|c|c|c|c|c|c|c|}
\hline LHNPF06_2_30 & 2006_216 & 45.0198639 & -83.2834093 & Netstake & 4 & Netstake \\
\hline LHNPF06_2_31 & 2006_216 & 45.019227 & -83.2813689 & Netstake & 4 & Netstake \\
\hline LHNPF06_2_32 & 2006_216 & 45.0194776 & -83.2806423 & Netstake & 4 & Netstake \\
\hline LHNPF06_2_33 & 2006_216 & 45.0193873 & -83.2804858 & Netstake & 4 & Netstake \\
\hline LHNPF06_2_34 & 2006_216 & 45.0193112 & -83.2799134 & Netstake & 4 & Netstake \\
\hline LHNPF06_2_35 & 2006_216 & 45.018476 & -83.2773224 & Netstake & 4 & Netstake \\
\hline LHNPF06_2_36 & 2006_216 & 45.0175438 & -83.27497 & Netstake & 4 & Netstake \\
\hline LHNPF06_2_37 & 2006_216 & 45.0174256 & -83.2747153 & Netstake & 4 & Netstake \\
\hline LHNPF06_2_38 & 2006_216 & 45.0169468 & -83.2741421 & Linear & 1 & $\begin{array}{c}\text { Short linear with narrow } \\
\text { shadow }\end{array}$ \\
\hline LHNPF06_2_39 & 2006_216 & 45.0173622 & -83.2738901 & Netstake & 4 & Netstake \\
\hline LHNPF06_2_40 & 2006_216 & 45.0172088 & -83.2734979 & Netstake & 4 & Netstake \\
\hline LHNPF06_2_41 & 2006_216 & 45.0167749 & -83.2734968 & Netstake & 4 & Netstake \\
\hline LHNPF06_2_42 & 2006_216 & 45.02273 & -83.2926852 & Netstake & 4 & Netstake \\
\hline LHNPF06_2_43 & 2006_216 & 45.0226745 & -83.2925096 & Netstake & 4 & Netstake \\
\hline LHNPF06_2_44 & 2006_216 & 45.0224419 & -83.2922122 & Netstake & 4 & Netstake \\
\hline LHNPF06_2_45 & 2006_216 & 45.0225447 & -83.2924911 & Netstake & 4 & Netstake \\
\hline LHNPF06_2_46 & 2006_216 & 45.0218621 & -83.2899383 & Netstake & 4 & Netstake \\
\hline LHNPF06_2_47 & 2006_216 & 45.0221603 & -83.2897238 & Netstake & 4 & Netstake \\
\hline LHNPF06_2_48 & 2006_216 & 45.0194345 & -83.2820701 & Netstake & 4 & Netstake \\
\hline LHNPF08_1_02 & 2006_216 & 45.0170464 & -83.271401 & Netstake & 4 & Netstake \\
\hline LHNPF08_1_04 & 2006_216 & 45.0175718 & -83.2723623 & Netstake & 4 & Netstake \\
\hline LHNPF08_1_05 & 2006_216 & 45.0178373 & -83.2731348 & Netstake & 4 & Netstake \\
\hline LHNPF08_1_06 & 2006_216 & 45.0180241 & -83.2736384 & Netstake & 4 & Netstake \\
\hline LHNPF08_1_07 & 2006_216 & 45.0174959 & -83.2735033 & Netstake & 4 & Netstake \\
\hline LHNPF08_1_08 & 2006_216 & 45.0174343 & -83.2731804 & Netstake & 4 & Netstake \\
\hline LHNPF08_1_09 & 2006_216 & 45.0181702 & -83.2746045 & Netstake & 4 & Netstake \\
\hline LHNPF08_1_10 & 2006_216 & 45.0183879 & -83.2751432 & Netstake & 4 & Netstake \\
\hline LHNPF08_1_11 & 2006_216 & 45.0187001 & -83.2760315 & Netstake & 4 & Netstake \\
\hline LHNPF08_1_12 & 2006_216 & 45.0190801 & -83.2769739 & Netstake & 4 & Netstake \\
\hline LHNPF08_1_13 & \begin{tabular}{|l|}
$2006 \_216$ \\
\end{tabular} & 45.0187182 & -83.2772544 & Netstake & 4 & Netstake \\
\hline LHNPF08_1_14 & 2006_216 & 45.0190835 & -83.2782589 & Netstake & 4 & Netstake \\
\hline LHNPF08_1_15 & 2006_216 & 45.0195389 & -83.2783097 & Netstake & 4 & Netstake \\
\hline LHNPF08_1_16 & 2006_216 & 45.0195368 & -83.2793238 & Netstake & 4 & Netstake \\
\hline LHNPF08_1_17 & 2006_216 & 45.0196773 & -83.2792426 & Netstake & 4 & Netstake \\
\hline LHNPF08_1_18 & 2006_216 & 45.0206744 & -83.2825017 & Netstake & 4 & Netstake \\
\hline LHNPF08_1_19 & 2006_216 & 45.0203614 & -83.2827931 & Netstake & 4 & Netstake \\
\hline LHNPF08_1_20 & 2006_216 & 45.0223424 & -83.288591 & Linear & 1 & Long linear with narrow shadow \\
\hline LHNPF08_1_21 & 2006_216 & 45.0230543 & -83.2907601 & Netstake & 4 & Netstake \\
\hline LHNPF08_1_22 & 2006_216 & 45.022868 & -83.2912535 & Netstake & 4 & Netstake \\
\hline LHNPF08_1_23 & 2006_216 & 45.0233618 & -83.2919412 & Netstake & 4 & Netstake \\
\hline LHNPF08_1_24 & 2006_216 & 45.023075 & -83.2921929 & Netstake & 4 & Netstake \\
\hline LHNPF08_1_25 & 2006_216 & 45.0235375 & -83.2934907 & Netstake & 4 & Netstake \\
\hline LHNPF08_1_26 & 2006_216 & 45.0240604 & -83.2937142 & Netstake & 4 & Netstake \\
\hline LHNPF08_1_27 & 2006_216 & 45.0238081 & -83.294187 & Netstake & 4 & Netstake \\
\hline LHNPF08_1_28 & 2006_216 & 45.0242097 & -83.2945608 & Netstake & 4 & Netstake \\
\hline LHNPF08_1_29 & 2006_216 & 45.0247526 & -83.2984647 & Netstake & 4 & Netstake \\
\hline LHNPF08_1_30 & 2006_216 & 45.0251477 & -83.2993742 & Netstake & 4 & Netstake \\
\hline LHNPF08_1_31 & 2006_216 & 45.0252461 & -83.2995652 & Netstake & 4 & Netstake \\
\hline LHNPF08_1_32 & 2006_216 & 45.0253402 & -83.2997973 & Netstake & 4 & Netstake \\
\hline LHNPF08_1_33 & 2006_216 & 45.0255341 & -83.3004541 & Netstake & 4 & Netstake \\
\hline
\end{tabular}




\begin{tabular}{|c|c|c|c|c|c|c|}
\hline LHNPF08_1_34 & 2006_216 & 45.0270547 & -83.3042335 & Linear & 3 & Faint linear with narrow shadow \\
\hline LHNPF08_1_36 & 2006_216 & 45.0180108 & -83.2750856 & Linear & 3 & $\begin{array}{l}\text { Short faint linear with narrow } \\
\text { shadow }\end{array}$ \\
\hline LHNPF08_1_37 & 2006_216 & 45.0232581 & -83.2913914 & Netstake & 4 & Netstake \\
\hline LHNPF08_1_38 & $2006 \_216$ & 45.0256394 & -83.300736 & Netstake & 4 & Netstake \\
\hline LHNPF10_1_01 & 2006_216 & 45.0171736 & -83.2709245 & Linear & 2 & Linear with wide shadow \\
\hline LHNPF10_1_02 & 2006_216 & 45.0175134 & -83.2717026 & Linear & 1 & Linear with wide shadow \\
\hline LHNPF10_1_03 & 2006_216 & 45.0179652 & -83.2726587 & Netstake & 4 & Netstake \\
\hline LHNPF10_1_04 & 2006_216 & 45.018484 & -83.2748112 & Netstake & 4 & Netstake \\
\hline LHNPF10_1_06 & 2006_216 & 45.0192234 & -83.2763555 & Netstake & 4 & Netstake \\
\hline LHNPF10_1_07 & 2006_216 & 45.0190244 & -83.2766605 & Netstake & 4 & Netstake \\
\hline LHNPF10_1_08 & 2006_216 & 45.0195229 & -83.2768891 & Netstake & 4 & Netstake \\
\hline LHNPF10_1_09 & 2006_216 & 45.0198053 & -83.27918 & Netstake & 4 & Netstake \\
\hline LHNPF10_1_10 & 2006_216 & 45.0202411 & -83.28025 & Netstake & 4 & Netstake \\
\hline LHNPF10_1_11 & 2006_216 & 45.0211849 & -83.2821499 & Netstake & 4 & Netstake \\
\hline LHNPF10_1_12 & 2006_216 & 45.0209542 & -83.2831073 & Netstake & 4 & Netstake \\
\hline LHNPF10_1_14 & 2006_216 & 45.02317 & -83.2906449 & Netstake & 4 & Netstake \\
\hline LHNPF10_1_15 & 2006_216 & 45.0244604 & -83.2932207 & Linear & 3 & Faint linear with no shadow \\
\hline LHNPF10_1_16 & 2006_216 & 45.0240997 & -83.2936328 & Netstake & 4 & Netstake \\
\hline LHNPF10_1_17 & 2006_216 & 45.0242882 & -83.2942655 & Netstake & 4 & Netstake \\
\hline LHNPF10_1_18 & 2006_216 & 45.0269491 & -83.3017119 & Netstake & 4 & Netstake \\
\hline LHNPF10_1_19 & 2006_216 & 45.0269255 & -83.3021828 & Netstake & 4 & Netstake \\
\hline LHNPF10_1_21 & 2006_216 & 45.0282397 & -83.307781 & Linear & 1 & Linear with narrow shadow \\
\hline LHNPF10_1_22 & 2006_216 & 45.0249128 & -83.2962349 & Netstake & 4 & Netstake \\
\hline LHNPF12_1_01 & 2006_216 & 45.0270998 & -83.3018196 & Netstake & 4 & Netstake \\
\hline LHNPF12_1_02 & 2006_216 & 45.0245515 & -83.2932081 & Netstake & 4 & Netstake \\
\hline LHNPF12_1_03 & 2006_216 & 45.0230181 & -83.2862601 & Netstake & 4 & Netstake \\
\hline LHNPF12_1_04 & 2006_216 & 45.0222178 & -83.2851229 & Netstake & 4 & Netstake \\
\hline LHNPF12_1_05 & 2006_216 & 45.0220523 & -83.284896 & Netstake & 4 & Netstake \\
\hline LHNPF12_1_06 & 2006_216 & 45.0220947 & -83.2852278 & Netstake & 4 & Netstake \\
\hline LHNPF12_1_07 & 2006_216 & 45.0215151 & -83.2811653 & Netstake & 4 & Netstake \\
\hline LHNPF12_1_08 & 2006_216 & 45.020994 & -83.2805847 & Netstake & 4 & Netstake \\
\hline LHNPF12_1_09 & 2006_216 & 45.0196429 & -83.2768584 & Netstake & 4 & Netstake \\
\hline LHNPF12_1_10 & 2006_216 & 45.0197111 & -83.2760114 & Linear & 3 & Faint linear with narrow shadow \\
\hline LHNPF12_1_11 & 2006_216 & 45.0194291 & -83.2759311 & Linear & 1 & Linear with narrow shadow \\
\hline LHNPA20_1_01 & 2006_217 & 45.0207212 & -83.2346869 & Linear & 3 & Short linear shadow \\
\hline LHNPA20_1_02 & 2006_217 & 45.0225645 & -83.2284883 & Linear & 3 & Short linear shadow \\
\hline LHNPA20_1_03 & 2006_217 & 45.0244775 & -83.2185333 & Linear & 2 & Faint linear with wide shadow \\
\hline LHNPE14_2_01 & 2006_217 & 45.0210975 & -83.2504546 & Linear & 3 & Linear shadow \\
\hline LHNPE14_2_02 & 2006_217 & 45.0223759 & -83.25082 & Debris & 3 & Small group of debris \\
\hline LHNPE16_2_01 & 2006_217 & 45.0226834 & -83.2503988 & Linear & 3 & Short linear shadow \\
\hline LHNPE16_2_02 & 2006_217 & 45.0224389 & -83.2500249 & Debris & 2 & Small group of debris \\
\hline LHNPE18_2_01 & 2006_217 & 45.0231952 & -83.2499412 & Linear & 2 & $\begin{array}{c}\text { Linear with shadow partially in } \\
\text { nadir }\end{array}$ \\
\hline LHNPA27_1_01 & 2006_219 & 45.0188664 & -83.226149 & Linear & 3 & $\begin{array}{l}\text { Short linear with narrow } \\
\text { shadow }\end{array}$ \\
\hline LHNPA27_1_02 & 2006_219 & 45.0246559 & -83.200666 & Linear & 3 & $\begin{array}{c}\text { Short linear with narrow } \\
\text { shadow }\end{array}$ \\
\hline
\end{tabular}




\begin{tabular}{|c|c|c|c|c|c|c|}
\hline LHNPA31_1_01 & 2006_219 & 45.0166974 & -83.2247865 & Unknown & 3 & Short potentially linear shadow \\
\hline LHNPA33_1_01 & 2006_219 & 45.0139877 & -83.2309962 & Linear & 3 & $\begin{array}{l}\text { Two potential linears likely } \\
\text { thermocline artifact }\end{array}$ \\
\hline LHNPB11_1_02 & 2006_219 & 45.0297067 & -83.1846456 & Linear & 2 & Short linear \\
\hline LHNPF1_01_01 & 2006_219 & 45.0122936 & -83.2731913 & Netstake & 4 & Netstake \\
\hline LHNPF1_01_02 & 2006_219 & 45.012373 & -83.2749667 & Netstake & 4 & Netstake \\
\hline LHNPF1_01_03 & 2006_219 & 45.0131566 & -83.2764896 & Netstake & 4 & Netstake \\
\hline LHNPF1_01_04 & 2006_219 & 45.013584 & -83.2777337 & Netstake & 4 & Netstake \\
\hline LHNPF1_01_05 & 2006_219 & 45.0136934 & -83.2777169 & Netstake & 4 & Netstake \\
\hline LHNPF1_01_06 & 2006_219 & 45.0182921 & -83.2948667 & Netstake & 4 & Netstake \\
\hline LHNPF1_01_07 & 2006_219 & 45.0184471 & -83.2949654 & Netstake & 4 & Netstake \\
\hline LHNPF1_01_08 & 2006_219 & 45.0187744 & -83.2946588 & Linear & 1 & $\begin{array}{l}\text { Short linear with narrow } \\
\text { shadow }\end{array}$ \\
\hline LHNPF1_01_09 & 2006_219 & 45.0178842 & -83.2941522 & Linear & 3 & Short faint linear with shadow \\
\hline LHNPF1_01_10 & 2006_219 & 45.0184831 & -83.2959958 & Netstake & 4 & Netstake \\
\hline LHNPF1_01_11 & 2006_219 & 45.0189054 & -83.2975802 & Netstake & 4 & Netstake \\
\hline LHNPF1_01_13 & 2006_219 & 45.0193417 & -83.2974708 & Netstake & 4 & Netstake \\
\hline LHNPF1_01_14 & 2006_219 & 45.0193664 & -83.2991755 & Linear & 1 & Linear with shadow \\
\hline LHNPF1_01_15 & 2006_219 & 45.020073 & -83.3014978 & Linear & 1 & Linear with narrow shadow \\
\hline LHNPF1_01_16 & 2006_219 & 45.0205456 & -83.301461 & Linear & 2 & Faint linear with narrow shadow \\
\hline LHNPF1_01_17 & 2006_219 & 45.0210343 & -83.3035153 & Netstake & 4 & Netstake \\
\hline LHNPF1_01_18 & 2006_219 & 45.0218323 & -83.3061038 & Netstake & 4 & Netstake \\
\hline LHNPF1_01_19 & 2006_219 & 45.0219941 & -83.3063463 & Netstake & 4 & Netstake \\
\hline LHNPF1_01_20 & 2006_219 & 45.0227413 & -83.3089497 & Netstake & 4 & Netstake \\
\hline LHNPF1_01_21 & 2006_219 & 45.0227409 & -83.3091377 & Netstake & 4 & Netstake \\
\hline LHNPF1_01_22 & 2006_219 & 45.0228275 & -83.3090679 & Netstake & 4 & Netstake \\
\hline LHNPF1_01_23 & 2006_219 & 45.0229789 & -83.3090451 & Netstake & 4 & Netstake \\
\hline LHNPF1_01_24 & 2006_219 & 45.0231879 & -83.3102392 & Netstake & 4 & Netstake \\
\hline LHNPF1_01_25 & 2006_219 & 45.0231285 & -83.3105921 & Linear & 2 & $\begin{array}{c}\text { Linear with no shadow partially } \\
\text { in nadir }\end{array}$ \\
\hline LHNPF1_01_26 & 2006_219 & 45.0238256 & -83.3139514 & Linear & 1 & Linear with narrow shadow \\
\hline LHNPF1_01_27 & 2006_219 & 45.0145075 & -83.2814263 & Netstake & 4 & Netstake \\
\hline LHNPB01_1_02 & 2006_220 & 45.0322817 & -83.1920755 & Wreckage & 1 & Wreckage \\
\hline LHNPB02_1_01 & 2006_220 & 45.0322871 & -83.1925958 & Shipwreck & 1 & Shipwreck \\
\hline LHNPB02_1_02 & 2006_220 & 45.0316465 & -83.2045976 & Netstake & 4 & Netstake \\
\hline LHNPB03_1_01 & 2006_220 & 45.0316978 & -83.2046428 & Netstake & 4 & Netstake \\
\hline LHNPB03_1_02 & 2006_220 & 45.0315925 & -83.19373 & Netstake & 4 & Netstake \\
\hline LHNPB04_1_01 & 2006_220 & 45.0312488 & -83.1915832 & Linear & 2 & Linear with wide shadow \\
\hline LHNPB05_1_01 & 2006_220 & 45.0311584 & -83.196163 & Shipwreck & 1 & Shipwreck \\
\hline LHNPB05_1_02 & 2006_220 & 45.0314108 & -83.1964153 & Linear & 2 & Long narrow shadow \\
\hline LHNPB05_1_03 & 2006_220 & 45.0310418 & -83.1959253 & Linear & 1 & Faint linear with shadow \\
\hline LHNPB05_1_04 & 2006_220 & 45.0313552 & -83.1953851 & Linear & 3 & Short linear shadow \\
\hline LHNPB05_1_05 & 2006_220 & 45.031557 & -83.1932775 & Linear & 2 & $\begin{array}{l}\text { Short faint linear with narrow } \\
\text { shadow }\end{array}$ \\
\hline LHNPB07_1_01 & 2006_220 & 45.0310634 & -83.1915055 & Debris & 1 & Small group of debris \\
\hline LHNPB07_1_02 & 2006_220 & 45.030579 & -83.1927034 & Linear & 1 & $\begin{array}{l}\text { One or two short linears with } \\
\text { narrow shadow }\end{array}$ \\
\hline LHNPB07_1_03 & 2006_220 & 45.030418 & -83.1926986 & Linear & 1 & Faint linear with narrow shadow \\
\hline
\end{tabular}




\begin{tabular}{|c|c|c|c|c|c|c|}
\hline LHNPB07_1_05 & 2006_220 & 45.0304295 & -83.1964203 & Linear & 1 & Faint linear with narrow shadow \\
\hline LHNPB07_1_06 & 2006_220 & 45.0306178 & -83.1967416 & Linear & 1 & Faint linear with narrow shadow \\
\hline LHNPB07_1_07 & 2006_220 & 45.0308 & -83.1970052 & Wreckage & 1 & Group of linear wreckage \\
\hline LHNPB09_1_02 & 2006_220 & 45.0301044 & -83.1949776 & Linear & 1 & Linear with narrow shadow \\
\hline LHNPF103_1_01 & 2006_220 & 45.024407 & -83.3126059 & Linear & 1 & Linear with narrow shadow \\
\hline LHNPF103_1_02 & 2006_220 & 45.0244885 & -83.3120055 & Linear & 1 & Linear with narrow shadow \\
\hline LHNPF103_1_03 & 2006_220 & 45.0237867 & -83.3125688 & Linear & 1 & Linear with narrow shadow \\
\hline LHNPF103_1_04 & 2006_220 & 45.0232289 & -83.3105597 & Linear & 1 & Linear with narrow shadow \\
\hline LHNPF103_1_05 & 2006_220 & 45.0237541 & -83.3105943 & Netstake & 4 & Netstake \\
\hline LHNPF103_1_06 & 2006_220 & 45.0233596 & -83.3101594 & Netstake & 4 & Netstake \\
\hline LHNPF103_1_07 & 2006_220 & 45.0229174 & -83.3090273 & Netstake & 4 & Netstake \\
\hline LHNPF103_1_08 & 2006_220 & 45.0225808 & -83.3054592 & Linear & 2 & Short linear with faint shadow \\
\hline LHNPF103_1_09 & 2006_220 & 45.0219879 & -83.3060051 & Netstake & 4 & Netstake \\
\hline LHNPF103_1_10 & 2006_220 & 45.0211041 & -83.300576 & Netstake & 4 & Netstake \\
\hline LHNPF103_1_11 & 2006_220 & 45.0208581 & -83.3004313 & Linear & 1 & Linear with narrow shadow \\
\hline LHNPF103_1_12 & 2006_220 & 45.0206866 & -83.3014083 & Linear & 1 & Linear with narrow shadow \\
\hline LHNPF103_1_13 & 2006_220 & 45.0199398 & -83.2993239 & Netstake & 4 & Netstake \\
\hline LHNPF103_1_14 & 2006_220 & 45.0202406 & -83.2986075 & Netstake & 4 & Netstake \\
\hline LHNPF103_1_15 & 2006_220 & 45.020086 & -83.2992286 & Netstake & 4 & Netstake \\
\hline LHNPF103_1_16 & 2006_220 & 45.0196224 & -83.2977876 & Linear & 1 & $\begin{array}{c}\text { Two linears oriented parallel to } \\
\text { each other }\end{array}$ \\
\hline LHNPF103_1_17 & 2006_220 & 45.0194964 & -83.297305 & Netstake & 4 & Netstake \\
\hline LHNPF103_1_18 & 2006_220 & 45.0195946 & -83.296914 & Linear & 2 & $\begin{array}{l}\text { Short linear with narrow } \\
\text { shadow partially in nadir }\end{array}$ \\
\hline LHNPF103_1_19 & 2006_220 & 45.0190603 & -83.2964259 & Linear & 2 & Linear with very narrow shadow \\
\hline LHNPF103_1_20 & 2006_220 & 45.019547 & -83.2955249 & Netstake & 4 & Netstake \\
\hline LHNPF103_1_21 & 2006_220 & 45.0188726 & -83.2952627 & Netstake & 4 & Netstake \\
\hline LHNPF103_1_23 & 2006_220 & 45.0186373 & -83.2948448 & Netstake & 4 & Netstake \\
\hline LHNPF103_1_25 & 2006_220 & 45.014375 & -83.2782402 & Netstake & 4 & Netstake \\
\hline LHNPF103_1_26 & 2006_220 & 45.0140147 & -83.2782215 & Netstake & 4 & Netstake \\
\hline LHNPF103_1_27 & 2006_220 & 45.0138105 & -83.2776795 & Netstake & 4 & Netstake \\
\hline LHNPF103_1_28 & 2006_220 & 45.0131774 & -83.2755218 & Netstake & 4 & Netstake \\
\hline LHNPF103_1_29 & 2006_220 & 45.0131519 & -83.2755344 & Netstake & 4 & Netstake \\
\hline LHNPF103_1_30 & 2006_220 & 45.0136146 & -83.2752531 & Netstake & 4 & Netstake \\
\hline LHNPF103_1_31 & 2006_220 & 45.0135605 & -83.2752693 & Netstake & 4 & Netstake \\
\hline LHNPF103_1_32 & 2006_220 & 45.0160692 & -83.2844732 & Netstake & 4 & Netstake \\
\hline LHNPF103_1_33 & 2006_220 & 45.0156507 & -83.2845794 & Netstake & 4 & Netstake \\
\hline LHNPF105_1_01 & 2006_220 & 45.0124309 & -83.2717592 & Netstake & 4 & Netstake \\
\hline LHNPF105_1_02 & 2006_220 & 45.0129759 & -83.2735558 & Netstake & 4 & Netstake \\
\hline LHNPF105_1_03 & 2006_220 & 45.0137938 & -83.2742476 & Netstake & 4 & Netstake \\
\hline LHNPF105_1_04 & 2006_220 & 45.01346 & -83.2746166 & Netstake & 4 & Netstake \\
\hline LHNPF105_1_05 & 2006_220 & 45.0138915 & -83.2749689 & Netstake & 4 & Netstake \\
\hline LHNPF105_1_06 & 2006_220 & 45.0136662 & -83.2749979 & Netstake & 4 & Netstake \\
\hline LHNPF105_1_07 & 2006_220 & 45.0139128 & -83.2757043 & Linear & 2 & $\begin{array}{c}\text { One or two faint linears with } \\
\text { narrow shadows }\end{array}$ \\
\hline LHNPF105_1_08 & 2006_220 & 45.0142512 & -83.2756323 & Netstake & 4 & Netstake \\
\hline LHNPF105_1_09 & 2006_220 & 45.0147132 & -83.2777569 & Netstake & 4 & Netstake \\
\hline LHNPF105_1_10 & 2006_220 & 45.0144055 & -83.2781021 & Netstake & 4 & Netstake \\
\hline
\end{tabular}




\begin{tabular}{|c|c|c|c|c|c|c|}
\hline LHNPF105_1_11 & 2006_220 & 45.0149087 & -83.2781947 & Netstake & 4 & Netstake \\
\hline LHNPF105_1_12 & 2006_220 & 45.0166628 & -83.2835869 & Netstake & 4 & Netstake \\
\hline LHNPF105_1_13 & 2006_220 & 45.0173418 & -83.2865937 & Netstake & 4 & Netstake \\
\hline LHNPF105_1_14 & 2006_220 & 45.0170206 & -83.2867212 & Linear & 3 & Short linear shadow \\
\hline LHNPF105_1_15 & 2006_220 & 45.018828 & -83.2933506 & Linear & 1 & Linear with narrow shadow \\
\hline LHNPF105_1_16 & 2006_220 & 45.019371 & -83.2936699 & Netstake & 4 & Netstake \\
\hline LHNPF105_1_17 & 2006_220 & 45.0198274 & -83.2941088 & Netstake & 4 & Netstake \\
\hline LHNPF105_1_18 & 2006_220 & 45.019958 & -83.2947157 & Netstake & 4 & Netstake \\
\hline LHNPF105_1_19 & 2006_220 & 45.0205487 & -83.2975619 & Netstake & 4 & Netstake \\
\hline LHNPF105_1_20 & 2006_220 & 45.0203223 & -83.2978186 & Netstake & 4 & Netstake \\
\hline LHNPF105_1_21 & 2006_220 & 45.0208537 & -83.2981249 & Linear & 1 & Two linears with faint shadows \\
\hline LHNPF105_1_22 & $2006 \_220$ & 45.021533 & -83.2998057 & Linear & 1 & Linear with faint shadow \\
\hline LHNPF105_1_23 & 2006_220 & 45.0214279 & -83.300187 & Netstake & 4 & Netstake \\
\hline LHNPF105_1_25 & 2006_220 & 45.0210732 & -83.3005462 & Netstake & 4 & Netstake \\
\hline LHNPF105_1_26 & 2006_220 & 45.0217317 & -83.3009108 & Linear & 1 & Linear with faint shadow \\
\hline LHNPF105_1_27 & 2006_220 & 45.0216284 & -83.3014923 & Linear & 2 & $\begin{array}{l}\text { Short linear with narrow } \\
\text { shadow partially in nadir }\end{array}$ \\
\hline LHNPF105_1_28 & 2006_220 & 45.0220321 & -83.3019513 & Linear & 1 & Linear with narrow shadow \\
\hline LHNPF105_1_29 & 2006_220 & 45.0219123 & -83.3021834 & Linear & 1 & Linear with narrow shadow \\
\hline LHNPF105_1_30 & 2006_220 & 45.0216846 & -83.3021587 & Linear & 1 & Linear with narrow shadow \\
\hline LHNPF105_1_31 & $2006 \_220$ & 45.0240951 & -83.3086632 & Netstake & 4 & Netstake \\
\hline LHNPF105_1_32 & 2006_220 & 45.0235535 & -83.3097268 & Netstake & 4 & Netstake \\
\hline LHNPF105_1_33 & 2006_220 & 45.0247977 & -83.3111489 & Netstake & 4 & Netstake \\
\hline LHNPF105_1_34 & 2006_220 & 45.0249201 & -83.311402 & Linear & 1 & Linear with narrow shadow \\
\hline LHNPF105_1_35 & 2006_220 & 45.0247193 & -83.3117651 & Netstake & 4 & Netstake \\
\hline LHNPF105_1_37 & 2006_220 & 45.0250454 & -83.3117541 & Netstake & 4 & Netstake \\
\hline LHNPF105_1_39 & 2006_220 & 45.0247691 & -83.3129755 & Linear & 1 & Linear with narrow shadow \\
\hline LHNPF105_1_40 & 2006_220 & 45.0250908 & -83.3127777 & Netstake & 4 & Netstake \\
\hline LHNPF105_1_41 & 2006_220 & 45.0253285 & -83.3131968 & Netstake & 4 & Netstake \\
\hline LHNPF105_1_42 & 2006_220 & 45.0247444 & -83.3133272 & Linear & 1 & Linear with narrow shadow \\
\hline LHNPF105_1_43 & 2006_220 & 45.0248613 & -83.3136104 & Linear & 1 & Linear with narrow shadow \\
\hline LHNPF105_1_44 & 2006_220 & 45.0169518 & -83.2850064 & Netstake & 4 & Netstake \\
\hline LHNPF105_1_45 & 2006_220 & 45.0195642 & -83.2955677 & Netstake & 4 & Netstake \\
\hline LHNPF107_1_01 & 2006_220 & 45.0137692 & -83.2730339 & Netstake & 4 & Netstake \\
\hline LHNPF107_1_02 & 2006_220 & 45.0141478 & -83.272917 & Netstake & 4 & Netstake \\
\hline LHNPF107_1_03 & 2006_220 & 45.0137718 & -83.2734498 & Netstake & 4 & Netstake \\
\hline LHNPF107_1_04 & 2006_220 & 45.0142916 & -83.273398 & Netstake & 4 & Netstake \\
\hline LHNPF107_1_05 & 2006_220 & 45.013938 & -83.2738234 & Netstake & 4 & Netstake \\
\hline LHNPF107_1_06 & 2006_220 & 45.0141963 & -83.274187 & Netstake & 4 & Netstake \\
\hline LHNPF107_1_07 & 2006_220 & 45.0139444 & -83.2741856 & Netstake & 4 & Netstake \\
\hline LHNPF107_1_08 & 2006_220 & 45.0142587 & -83.2749321 & Netstake & 4 & Netstake \\
\hline LHNPF107_1_09 & 2006_220 & 45.014368 & -83.2753848 & Netstake & 4 & Netstake \\
\hline LHNPF107_1_10 & 2006_220 & 45.0145441 & -83.2761679 & Netstake & 4 & Netstake \\
\hline LHNPF107_1_11 & 2006_220 & 45.0151778 & -83.2777482 & Netstake & 4 & Netstake \\
\hline LHNPF107_1_12 & 2006_220 & 45.0147925 & -83.2777786 & Netstake & 4 & Netstake \\
\hline LHNPF107_1_13 & 2006_220 & 45.0149928 & -83.2780785 & Netstake & 4 & Netstake \\
\hline LHNPF107_1_14 & 2006_220 & 45.0152719 & -83.2782017 & Netstake & 4 & Netstake \\
\hline LHNPF107_1_15 & 2006_220 & 45.0151481 & -83.2785076 & Netstake & 4 & Netstake \\
\hline LHNPF107_1_16 & 2006_220 & 45.0173253 & -83.2840678 & Netstake & 4 & Netstake \\
\hline LHNPF107_1_17 & 2006_220 & 45.0174339 & -83.2844138 & Netstake & 4 & Netstake \\
\hline LHNPF107_1_18 & 2006_220 & 45.0170722 & -83.2851096 & Netstake & 4 & Netstake \\
\hline
\end{tabular}




\begin{tabular}{|c|c|c|c|c|c|c|}
\hline LHNPF107_1_19 & 2006_220 & 45.0176582 & -83.2859695 & Netstake & 4 & Netstake \\
\hline LHNPF107_1_20 & 2006_220 & 45.0174281 & -83.2867478 & Netstake & 4 & Netstake \\
\hline LHNPF107_1_21 & 2006_220 & 45.0189482 & -83.289565 & Netstake & 4 & Netstake \\
\hline LHNPF107_1_22 & 2006_220 & 45.0196032 & -83.2922033 & Netstake & 4 & Netstake \\
\hline LHNPF107_1_23 & 2006_220 & 45.0198046 & -83.2931166 & Netstake & 4 & Netstake \\
\hline LHNPF107_1_24 & 2006_220 & 45.0194429 & -83.2936587 & Netstake & 4 & Netstake \\
\hline LHNPF107_1_25 & 2006_220 & 45.0202269 & -83.2940694 & Netstake & 4 & Netstake \\
\hline LHNPF107_1_26 & 2006_220 & 45.0208275 & -83.2962402 & Netstake & 4 & Netstake \\
\hline LHNPF107_1_27 & 2006_220 & 45.0207356 & -83.2977049 & Netstake & 4 & Netstake \\
\hline LHNPF107_1_28 & 2006_220 & 45.02092 & -83.2979419 & Linear & 1 & Faint linear with narrow shadow \\
\hline LHNPF107_1_29 & 2006_220 & 45.0219155 & -83.2996146 & Netstake & 4 & Netstake \\
\hline LHNPF107_1_30 & 2006_220 & 45.0219219 & -83.2998637 & Linear & 1 & $\begin{array}{c}\text { Short linear with narrow } \\
\text { shadow }\end{array}$ \\
\hline LHNPF107_1_31 & 2006_220 & 45.0221792 & -83.3001233 & Linear & 1 & Linear with narrow shadow \\
\hline LHNPF107_1_33 & 2006_220 & 45.0215538 & -83.300251 & Netstake & 4 & Netstake \\
\hline LHNPF107_1_34 & 2006_220 & 45.0214295 & -83.2993514 & Netstake & 4 & Netstake \\
\hline LHNPF107_1_38 & 2006_220 & 45.0221131 & -83.3004944 & Netstake & 4 & Netstake \\
\hline LHNPF107_1_39 & 2006_220 & 45.0223427 & -83.3013095 & Netstake & 4 & Netstake \\
\hline LHNPF107_1_40 & 2006_220 & 45.022523 & -83.3013137 & Linear & 1 & Linear with narrow shadow \\
\hline LHNPF107_1_41 & 2006_220 & 45.0224508 & -83.3011938 & Linear & 1 & Linear with narrow shadow \\
\hline LHNPF107_1_42 & 2006_220 & 45.0224282 & -83.3009993 & Linear & 1 & Linear with narrow shadow \\
\hline LHNPF107_1_43 & 2006_220 & 45.0224689 & -83.3021724 & Netstake & 4 & Netstake \\
\hline LHNPF107_1_44 & 2006_220 & 45.0227772 & -83.3027097 & Linear & 1 & Linear with narrow shadow \\
\hline LHNPF107_1_45 & 2006_220 & 45.0231992 & -83.3044335 & Netstake & 4 & Netstake \\
\hline LHNPF107_1_46 & 2006_220 & 45.0234995 & -83.3050993 & Linear & 1 & $\begin{array}{l}\text { Short linear with narrow } \\
\text { shadow }\end{array}$ \\
\hline LHNPF107_1_47 & 2006_220 & 45.0237209 & -83.3052449 & Netstake & 4 & Netstake \\
\hline LHNPF107_1_48 & 2006_220 & 45.0241834 & -83.3087011 & Netstake & 4 & Netstake \\
\hline LHNPF107_1_49 & 2006_220 & 45.02475 & -83.3097832 & Netstake & 4 & Netstake \\
\hline LHNPF107_1_50 & 2006_220 & 45.0251893 & -83.3114153 & Netstake & 4 & Netstake \\
\hline LHNPF107_1_51 & 2006_220 & 45.0248545 & -83.3117857 & Netstake & 4 & Netstake \\
\hline LHNPF107_1_52 & 2006_220 & 45.0247866 & -83.3118206 & Linear & 1 & Faint linear with narrow shadow \\
\hline LHNPF107_1_53 & 2006_220 & 45.0257714 & -83.3122718 & Linear & 1 & Linear with narrow shadow \\
\hline LHNPF107_1_54 & 2006_220 & 45.0257377 & -83.3124989 & Linear & 1 & Linear with narrow shadow \\
\hline LHNPF107_1_55 & 2006_220 & 45.0252303 & -83.312826 & Netstake & 4 & Netstake \\
\hline LHNPF107_1_56 & 2006_220 & 45.0254407 & -83.3131828 & Netstake & 4 & Netstake \\
\hline LHNPF109_1_01 & 2006_220 & 45.0253449 & -83.3113215 & Netstake & 4 & Netstake \\
\hline LHNPF109_1_02 & 2006_220 & 45.0259267 & -83.3110984 & Netstake & 4 & Netstake \\
\hline LHNPF109_1_03 & 2006_220 & 45.0251696 & -83.3094821 & Linear & 2 & $\begin{array}{l}\text { Short linear with narrow } \\
\text { shadow partially in nadir }\end{array}$ \\
\hline LHNPF109_1_04 & 2006_220 & 45.0252854 & -83.3094398 & Netstake & 4 & Netstake \\
\hline LHNPF109_1_05 & 2006_220 & 45.0250933 & -83.3096426 & Netstake & 4 & Netstake \\
\hline LHNPF109_1_06 & 2006_220 & 45.0248469 & -83.3097361 & Netstake & 4 & Netstake \\
\hline LHNPF109_1_07 & 2006_220 & 45.0244584 & -83.3087521 & Netstake & 4 & Netstake \\
\hline LHNPF109_1_08 & 2006_220 & 45.0248599 & -83.3075171 & Netstake & 4 & Netstake \\
\hline LHNPF109_1_09 & 2006_220 & 45.0244903 & -83.3077456 & Netstake & 4 & Netstake \\
\hline LHNPF109_1_11 & 2006_220 & 45.0233337 & -83.3044529 & Netstake & 4 & Netstake \\
\hline LHNPF109_1_12 & 2006_220 & 45.0228483 & -83.3027163 & Netstake & 4 & Netstake \\
\hline LHNPF109_1_13 & 2006_220 & 45.022563 & -83.3021839 & Linear & 1 & $\begin{array}{c}\text { Three linears oriented parallel to } \\
\text { each other }\end{array}$ \\
\hline
\end{tabular}




\begin{tabular}{|c|c|c|c|c|c|c|}
\hline LHNPF109_1_14 & 2006_220 & 45.0226609 & -83.3017057 & Netstake & 4 & Netstake \\
\hline LHNPF109_1_16 & 2006_220 & 45.0222643 & -83.3011324 & Netstake & 4 & Netstake \\
\hline LHNPF109_1_17 & 2006_220 & 45.0221798 & -83.3006949 & Netstake & 4 & Netstake \\
\hline LHNPF109_1_18 & 2006_220 & 45.0227437 & -83.2999912 & Netstake & 4 & Netstake \\
\hline LHNPF109_1_19 & 2006_220 & 45.0225252 & -83.2995397 & Linear & 1 & Linear with faint shadow \\
\hline LHNPF109_1_20 & 2006_220 & 45.0220613 & -83.2998783 & Linear & 1 & Linear with narrow shadow \\
\hline LHNPF109_1_21 & 2006_220 & 45.0218693 & -83.3000195 & Netstake & 4 & Netstake \\
\hline LHNPF109_1_22 & 2006_220 & 45.0222874 & -83.2992778 & Netstake & 4 & Netstake \\
\hline LHNPF109_1_24 & 2006_220 & 45.0221248 & -83.2995606 & Netstake & 4 & Netstake \\
\hline LHNPF109_1_25 & 2006_220 & 45.0217562 & -83.2992816 & Netstake & 4 & Netstake \\
\hline LHNPF109_1_26 & 2006_220 & 45.0216591 & -83.2971316 & Netstake & 4 & Netstake \\
\hline LHNPF109_1_27 & 2006_220 & 45.0212813 & -83.2970396 & Netstake & 4 & Netstake \\
\hline LHNPF109_1_28 & 2006_220 & 45.0217813 & -83.2968328 & Netstake & 4 & Netstake \\
\hline LHNPF109_1_29 & 2006_220 & 45.0208929 & -83.2961916 & Netstake & 4 & Netstake \\
\hline LHNPF109_1_30 & 2006_220 & 45.0211738 & -83.2950307 & Netstake & 4 & Netstake \\
\hline LHNPF109_1_31 & 2006_220 & 45.0203079 & -83.2940768 & Netstake & 4 & Netstake \\
\hline LHNPF109_1_32 & 2006_220 & 45.0205337 & -83.2927628 & Netstake & 4 & Netstake \\
\hline LHNPF109_1_33 & 2006_220 & 45.0199689 & -83.293124 & Netstake & 4 & Netstake \\
\hline LHNPF109_1_34 & 2006_220 & 45.0197506 & -83.2921945 & Netstake & 4 & Netstake \\
\hline LHNPF109_1_35 & 2006_220 & 45.0193073 & -83.2910443 & Netstake & 4 & Netstake \\
\hline LHNPF109_1_36 & 2006_220 & 45.0192645 & -83.2892075 & Netstake & 4 & Netstake \\
\hline LHNPF109_1_37 & 2006_220 & 45.0178465 & -83.2860077 & Netstake & 4 & Netstake \\
\hline LHNPF109_1_38 & 2006_220 & 45.0176714 & -83.2842634 & Netstake & 4 & Netstake \\
\hline LHNPF109_1_39 & 2006_220 & 45.0175344 & -83.2839703 & Netstake & 4 & Netstake \\
\hline LHNPF109_1_40 & 2006_220 & 45.0172623 & -83.2817232 & Netstake & 4 & Netstake \\
\hline LHNPF109_1_41 & 2006_220 & 45.0142856 & -83.273888 & Netstake & 4 & Netstake \\
\hline LHNPF109_1_42 & 2006_220 & 45.0144227 & -83.272724 & Netstake & 4 & Netstake \\
\hline LHNPF109_1_43 & 2006_220 & 45.014132 & -83.2729238 & Netstake & 4 & Netstake \\
\hline LHNPF111_1_01 & 2006_220 & 45.0148047 & -83.2716368 & Netstake & 4 & Netstake \\
\hline LHNPF111_1_02 & 2006_220 & 45.0143065 & -83.2717416 & Netstake & 4 & Netstake \\
\hline LHNPF111_1_03 & 2006_220 & 45.0148814 & -83.2725119 & Netstake & 4 & Netstake \\
\hline LHNPF111_1_04 & 2006_220 & 45.014374 & -83.2726175 & Netstake & 4 & Netstake \\
\hline LHNPF111_1_05 & 2006_220 & 45.0148292 & -83.2737632 & Netstake & 4 & Netstake \\
\hline LHNPF111_1_06 & 2006_220 & 45.0147317 & -83.2740902 & Netstake & 4 & Netstake \\
\hline LHNPF111_1_07 & 2006_220 & 45.0152261 & -83.2737546 & Netstake & 4 & Netstake \\
\hline LHNPF111_1_08 & 2006_220 & 45.0154735 & -83.2747305 & Netstake & 4 & Netstake \\
\hline LHNPF111_1_09 & 2006_220 & 45.0156147 & -83.275352 & Netstake & 4 & Netstake \\
\hline LHNPF111_1_10 & 2006_220 & 45.0167012 & -83.2782366 & Netstake & 4 & Netstake \\
\hline LHNPF111_1_11 & 2006_220 & 45.0172434 & -83.2816006 & Netstake & 4 & Netstake \\
\hline LHNPF111_1_12 & 2006_220 & 45.0178969 & -83.2822524 & Netstake & 4 & Netstake \\
\hline LHNPF111_1_13 & 2006_220 & 45.0184499 & -83.2840548 & Netstake & 4 & Netstake \\
\hline LHNPF111_1_14 & 2006_220 & 45.0184186 & -83.2859644 & Netstake & 4 & Netstake \\
\hline LHNPF111_1_15 & 2006_220 & 45.0193389 & -83.2891222 & Netstake & 4 & Netstake \\
\hline LHNPF111_1_16 & 2006_220 & 45.0197406 & -83.2889431 & Netstake & 4 & Netstake \\
\hline LHNPF111_1_17 & 2006_220 & 45.0203901 & -83.2908696 & Netstake & 4 & Netstake \\
\hline LHNPF111_1_18 & 2006_220 & 45.0205129 & -83.2928008 & Netstake & 4 & Netstake \\
\hline LHNPF111_1_19 & 2006_220 & 45.0207597 & -83.292486 & Netstake & 4 & Netstake \\
\hline LHNPF111_1_20 & 2006_220 & 45.020754 & -83.293535 & Netstake & 4 & Netstake \\
\hline LHNPF111_1_21 & 2006_220 & 45.0212499 & -83.2939241 & Linear & 1 & $\begin{array}{l}\text { Short linear with narrow } \\
\text { shadow }\end{array}$ \\
\hline LHNPF111_1_22 & 2006_220 & 45.0216496 & -83.2966066 & Netstake & 4 & Netstake \\
\hline
\end{tabular}




\begin{tabular}{|c|c|c|c|c|c|c|}
\hline LHNPF111_1_23 & 2006_220 & 45.0220699 & -83.2967415 & Netstake & 4 & Netstake \\
\hline LHNPF111_1_24 & 2006_220 & 45.0222171 & -83.2990642 & Linear & 1 & Linear with narrow shadow \\
\hline LHNPF111_1_25 & 2006_220 & 45.0229855 & -83.2990397 & Netstake & 4 & Netstake \\
\hline LHNPF111_1_26 & 2006_220 & 45.0225213 & -83.2994525 & Netstake & 4 & Netstake \\
\hline LHNPF111_1_27 & 2006_220 & 45.0229413 & -83.3008788 & Linear & 1 & $\begin{array}{c}\text { Two linears oriented parallel to } \\
\text { each other }\end{array}$ \\
\hline LHNPF111_1_28 & 2006_220 & 45.0228155 & -83.3010816 & Linear & 2 & Short linear with faint shadow \\
\hline LHNPF111_1_29 & 2006_220 & 45.0235313 & -83.3014595 & Netstake & 4 & Netstake \\
\hline LHNPF111_1_30 & 2006_220 & 45.0237146 & -83.3022309 & Netstake & 4 & Netstake \\
\hline LHNPF111_1_31 & 2006_220 & 45.0232974 & -83.3022408 & Netstake & 4 & Netstake \\
\hline LHNPF111_1_32 & 2006_220 & 45.0248526 & -83.3074141 & Netstake & 4 & Netstake \\
\hline LHNPF111_1_33 & 2006_220 & 45.0260691 & -83.3095764 & Netstake & 4 & Netstake \\
\hline LHNPF111_1_34 & 2006_220 & 45.0256204 & -83.3101359 & Netstake & 4 & Netstake \\
\hline LHNPF111_1_35 & 2006_220 & 45.0264501 & -83.3110593 & Netstake & 4 & Netstake \\
\hline LHNPF111_1_36 & 2006_220 & 45.0240633 & -83.3051943 & Netstake & 4 & Netstake \\
\hline LHNPG45_1_01 & 2006_221 & 45.0571674 & -83.2054986 & Netstake & 4 & Netstake \\
\hline LHNPG45_1_02 & 2006_221 & 45.0583729 & -83.2062929 & Netstake & 4 & Netstake \\
\hline LHNPG47_1_01 & 2006_221 & 45.0486124 & -83.1975088 & Unknown & 3 & Short linear shadow \\
\hline LHNPG47_1_02 & 2006_221 & 45.0351747 & -83.1800234 & Linear & 3 & Linear with no shadow \\
\hline LHNPG49_1_01 & 2006_221 & 45.0510594 & -83.2012662 & Netstake & 4 & Netstake \\
\hline LHNPG51_1_01 & 2006_221 & 45.0490018 & -83.2017014 & Linear & 1 & Faint linear with narrow shadow \\
\hline LHNPH06_1_01 & 2006_221 & 45.0675189 & -83.220677 & Linear & 3 & Linear shadow partially in nadir \\
\hline LHNPG11_1_02 & 2006_224 & 45.0564663 & -83.1698941 & Shipwreck & 1 & Shipwreck \\
\hline LHNPG13_1_01 & 2006_224 & 45.0652091 & -83.1818378 & Shipwreck & 1 & D. M. Wilson \\
\hline LHNPG15_1_01 & 2006_224 & 45.0638285 & -83.1832418 & Linear & 3 & $\begin{array}{l}\text { Short linear potentially a } \\
\text { partially buried rock }\end{array}$ \\
\hline LHNPG21_1_01 & 2006_224 & 45.051877 & -83.1751771 & Shipwreck & 1 & Shipwreck \\
\hline LHNPG23_1_01 & 2006_224 & 45.0558834 & -83.1807791 & Linear & 2 & Linear with faint shadow \\
\hline LHNPG29_1_01 & 2006_224 & 45.0606086 & -83.1929524 & Linear & 2 & Faint linear with narrow shadow \\
\hline LHNPG33_1_01 & 2006_224 & 45.0543671 & -83.1892995 & Netstake & 4 & Netstake \\
\hline LHNPG39_2_01 & 2006_224 & 45.0596187 & -83.2023291 & Linear & 2 & $\begin{array}{c}\text { Short linear with shadow } \\
\text { potentially a rock }\end{array}$ \\
\hline LHHBA11_1_01 & 2006_226 & 44.9923943 & -83.3832288 & Netstake & 4 & Netstake \\
\hline LHHBA11_1_02 & 2006_226 & 44.9915938 & -83.3810694 & Netstake & 4 & Netstake \\
\hline LHHBA11_1_03 & 2006_226 & 44.9948185 & -83.3855408 & Linear & 2 & Short linear with no shadow \\
\hline LHHBA11_1_04 & 2006_226 & 44.9955699 & -83.3867436 & Linear & 2 & Linear with narrow shadow \\
\hline LHHBA11_1_05 & 2006_226 & 44.9967328 & -83.3885894 & Netstake & 4 & Netstake \\
\hline LHHBA11_1_06 & 2006_226 & 44.9965124 & -83.3890172 & Netstake & 4 & Netstake \\
\hline LHHBA11_1_07 & 2006_226 & 44.9969974 & -83.3887118 & Netstake & 4 & Netstake \\
\hline LHHBA11_1_08 & 2006_226 & 44.9968338 & -83.3896 & Netstake & 4 & Netstake \\
\hline LHHBA11_1_09 & 2006_226 & 44.9975414 & -83.3894191 & Netstake & 4 & Netstake \\
\hline LHHBA11_1_10 & 2006_226 & 45.0022476 & -83.3965267 & Netstake & 4 & Netstake \\
\hline LHHBA11_1_11 & 2006_226 & 45.0020457 & -83.3970916 & Netstake & 4 & Netstake \\
\hline LHHBA11_1_12 & 2006_226 & 45.0032601 & -83.3985429 & Netstake & 4 & Netstake \\
\hline LHHBA11_1_13 & 2006_226 & 45.0038166 & -83.3982797 & Linear & 2 & Linear with no shadow \\
\hline LHHBA11_1_14 & 2006_226 & 45.0039349 & -83.3995308 & Netstake & 4 & Netstake \\
\hline LHHBA11_1_15 & 2006_226 & 45.0042269 & -83.3988713 & Linear & 2 & Short linear with no shadow \\
\hline LHHBA11_1_16 & 2006_226 & 45.0047939 & -83.4007709 & Netstake & 4 & Netstake \\
\hline
\end{tabular}




\begin{tabular}{|c|c|c|c|c|c|c|}
\hline LHHBA11_1_17 & 2006_226 & 45.0053316 & -83.4005235 & Netstake & 4 & Netstake \\
\hline LHHBA11_1_18 & 2006_226 & 45.0050402 & -83.4015014 & Linear & 3 & Short linear with no shadow \\
\hline LHHBA11_1_19 & 2006_226 & 45.006562 & -83.4022558 & Netstake & 4 & Netstake \\
\hline LHHBA11_1_20 & $2006 \_226$ & 45.006691 & -83.4021876 & Linear & 2 & Linear with no shadow \\
\hline LHHBA11_1_21 & 2006_226 & 45.0067253 & -83.4036364 & Linear & 2 & $\begin{array}{c}\text { Short linear with narrow } \\
\text { shadow }\end{array}$ \\
\hline LHHBA11_1_22 & $2006 \_226$ & 45.0077139 & -83.4040965 & Linear & 1 & Linear with no shadow \\
\hline LHHBA11_1_23 & 2006_226 & 45.0113441 & -83.4103928 & Linear & 1 & Linear with narrow shadow \\
\hline LHHBA11_1_24 & 2006_226 & 45.0138896 & -83.4141329 & Linear & 1 & $\begin{array}{c}\text { Two linears with narrow } \\
\text { shadow }\end{array}$ \\
\hline LHHBA11_1_25 & 2006_226 & 45.016108 & -83.4161653 & Linear & 2 & Linear with narrow shadow \\
\hline LHHBA11_1_26 & 2006_226 & 45.0093379 & -83.4063207 & Linear & 2 & Linear with narrow shadow \\
\hline LHHBA13_1_01 & 2006_226 & 45.0118287 & -83.410874 & Linear & 2 & Short linear with no shadow \\
\hline LHHBA13_1_02 & 2006_226 & 45.0115277 & -83.4108898 & Linear & 2 & Short linear with no shadow \\
\hline LHHBA13_1_03 & 2006_226 & 45.011425 & -83.4112988 & Netstake & 4 & Netstake \\
\hline LHHBA13_1_04 & 2006_226 & 45.0106094 & -83.4100768 & Netstake & 4 & Netstake \\
\hline LHHBA13_1_05 & 2006_226 & 45.0106873 & -83.4101797 & Linear & 3 & Linear with no shadow \\
\hline LHHBA13_1_06 & 2006_226 & 45.0107793 & -83.4092096 & Netstake & 4 & Netstake \\
\hline LHHBA13_1_07 & 2006_226 & 45.0090039 & -83.4070141 & Linear & 1 & $\begin{array}{l}\text { Short linear with narrow } \\
\text { shadow }\end{array}$ \\
\hline LHHBA13_1_08 & 2006_226 & 45.0067029 & -83.4048656 & Netstake & 4 & Netstake \\
\hline LHHBA13_1_09 & 2006_226 & 45.0050804 & -83.4023671 & Netstake & 4 & Netstake \\
\hline LHHBA13_1_10 & 2006_226 & 45.0049381 & -83.4021133 & Netstake & 4 & Netstake \\
\hline LHHBA13_1_11 & 2006_226 & 45.0047304 & -83.4009609 & Netstake & 4 & Netstake \\
\hline LHHBA13_1_12 & 2006_226 & 45.0040491 & -83.4010692 & Netstake & 4 & Netstake \\
\hline LHHBA13_1_13 & 2006_226 & 45.0039067 & -83.3996077 & Linear & 1 & Linear with narrow shadow \\
\hline LHHBA13_1_14 & 2006_226 & 45.0032151 & -83.3987542 & Netstake & 4 & Netstake \\
\hline LHHBA13_1_15 & 2006_226 & 45.0031312 & -83.3983192 & Netstake & 4 & Netstake \\
\hline LHHBA13_1_16 & 2006_226 & 44.9979357 & -83.3919307 & Netstake & 4 & Netstake \\
\hline LHHBA13_1_17 & 2006_226 & 44.9973274 & -83.391005 & Linear & 1 & Linear with narrow shadow \\
\hline LHHBA13_1_18 & 2006_226 & 44.9972552 & -83.3908558 & Linear & 1 & Linear with narrow shadow \\
\hline LHHBA13_1_19 & 2006_226 & 44.9967197 & -83.3905995 & Linear & 1 & Linear with narrow shadow \\
\hline LHHBA13_1_20 & 2006_226 & 44.9967694 & -83.3901598 & Netstake & 4 & Netstake \\
\hline LHHBA13_1_21 & 2006_226 & 44.996389 & -83.3901481 & Netstake & 4 & Netstake \\
\hline LHHBA13_1_22 & 2006_226 & 44.9905477 & -83.3818279 & Linear & 1 & Linear with narrow shadow \\
\hline LHHBA13_1_23 & 2006_226 & 44.9900755 & -83.3811603 & Netstake & 4 & Netstake \\
\hline LHHBA13_1_24 & 2006_226 & 44.9898493 & -83.3807881 & Netstake & 4 & Netstake \\
\hline LHHBA13_1_25 & 2006_226 & 44.9900842 & -83.3801983 & Netstake & 4 & Netstake \\
\hline LHHBA13_1_26 & 2006_226 & 44.9973238 & -83.3903723 & Netstake & 4 & Netstake \\
\hline LHHBA13_1_27 & 2006_226 & 44.9923121 & -83.3832975 & Netstake & 4 & Netstake \\
\hline LHHBA15_1_01 & 2006_226 & 44.9899831 & -83.3811014 & Netstake & 4 & Netstake \\
\hline LHHBA15_1_03 & 2006_226 & 44.9914345 & -83.3838963 & Netstake & 4 & Netstake \\
\hline LHHBA15_1_04 & 2006_226 & 44.9920571 & -83.3841967 & Linear & 2 & $\begin{array}{l}\text { Short linear with narrow } \\
\text { shadow }\end{array}$ \\
\hline LHHBA15_1_06 & 2006_226 & 44.9965892 & -83.3906997 & Linear & 1 & Linear with narrow shadow \\
\hline LHHBA15_1_08 & 2006_226 & 44.9966926 & -83.3903816 & Netstake & 4 & Netstake \\
\hline LHHBA15_1_09 & 2006_226 & 44.9972947 & -83.3913688 & Linear & 2 & Linear with narrow shadow \\
\hline LHHBA15_1_10 & 2006_226 & 44.9971825 & -83.39114 & Linear & 2 & Linear with narrow shadow \\
\hline LHHBA15_1_11 & 2006_226 & 44.9974605 & -83.3916344 & Netstake & 4 & Netstake \\
\hline LHHBA15_1_12 & 2006_226 & 44.9978587 & -83.3923436 & Netstake & 4 & Netstake \\
\hline LHHBA15_1_13 & 2006_226 & 44.9982885 & -83.3927666 & Netstake & 4 & Netstake \\
\hline LHHBA15_1_14 & 2006_226 & 44.9982851 & -83.3936297 & Netstake & 4 & Netstake \\
\hline
\end{tabular}




\begin{tabular}{|c|c|c|c|c|c|c|}
\hline LHHBA15_1_15 & 2006_226 & 44.999857 & -83.3956752 & Netstake & 4 & Netstake \\
\hline LHHBA15_1_16 & $2006 \_226$ & 45.0039909 & -83.4008913 & Netstake & 4 & Netstake \\
\hline LHHBA15_1_17 & 2006_226 & 45.0037749 & -83.4013303 & Netstake & 4 & Netstake \\
\hline LHHBA15_1_18 & 2006_226 & 45.0047379 & -83.4030479 & Netstake & 4 & Netstake \\
\hline LHHBA15_1_19 & 2006_226 & 45.0048839 & -83.4023049 & Netstake & 4 & Netstake \\
\hline LHHBA15_1_20 & 2006_226 & 45.0049883 & -83.4025205 & Netstake & 4 & Netstake \\
\hline LHHBA15_1_21 & 2006_226 & 45.0067098 & -83.4050618 & Netstake & 4 & Netstake \\
\hline LHHBA15_1_22 & 2006_226 & 45.0065539 & -83.4055729 & Netstake & 4 & Netstake \\
\hline LHHBA15_1_23 & 2006_226 & 45.0073526 & -83.4059803 & Linear & 2 & Faint linear with narrow shadow \\
\hline LHHBA15_1_24 & 2006_226 & 45.0105205 & -83.4101699 & Netstake & 4 & Netstake \\
\hline LHHBA15_1_25 & 2006_226 & 45.0103908 & -83.4110856 & Netstake & 4 & Netstake \\
\hline LHHBA15_1_26 & 2006_226 & 44.9983563 & -83.3940991 & Linear & 2 & Linear with no shadow \\
\hline LHHBA15_1_27 & 2006_226 & 45.000797 & -83.3971268 & Netstake & 4 & Netstake \\
\hline LHHBA15_1_28 & $2006 \_226$ & 45.0141496 & -83.4161455 & Netstake & 4 & Netstake \\
\hline LHHBA17_1_01 & 2006_226 & 45.0064032 & -83.4062076 & Netstake & 4 & Netstake \\
\hline LHHBA17_1_02 & 2006_226 & 45.0057202 & -83.4054236 & Netstake & 4 & Netstake \\
\hline LHHBA17_1_07 & 2006_226 & 45.0050371 & -83.4041925 & Netstake & 4 & Netstake \\
\hline LHHBA17_1_10 & 2006_226 & 45.0048008 & -83.4030196 & Netstake & 4 & Netstake \\
\hline LHHBA17_1_11 & 2006_226 & 45.0046545 & -83.403993 & Netstake & 4 & Netstake \\
\hline LHHBA17_1_12 & 2006_226 & 45.0037512 & -83.4029623 & Netstake & 4 & Netstake \\
\hline LHHBA17_1_13 & 2006_226 & 45.0010664 & -83.3981204 & Netstake & 4 & Netstake \\
\hline LHHBA17_1_14 & 2006_226 & 45.000667 & -83.3980652 & Netstake & 4 & Netstake \\
\hline LHHBA17_1_15 & 2006_226 & 45.0007191 & -83.3972362 & Netstake & 4 & Netstake \\
\hline LHHBA17_1_16 & 2006_226 & 44.9995082 & -83.3966511 & Netstake & 4 & Netstake \\
\hline LHHBA17_1_17 & 2006_226 & 44.9985431 & -83.3946767 & Netstake & 4 & Netstake \\
\hline LHHBA17_1_18 & 2006_226 & 44.998478 & -83.3941698 & Netstake & 4 & Netstake \\
\hline LHHBA17_1_19 & 2006_226 & 44.9965644 & -83.3913362 & Linear & 2 & $\begin{array}{c}\text { Short linear with narrow } \\
\text { shadow }\end{array}$ \\
\hline LHHBA17_1_20 & 2006_226 & 44.9965169 & -83.3911515 & Linear & 2 & $\begin{array}{c}\text { Short linear with narrow } \\
\text { shadow }\end{array}$ \\
\hline LHHBA17_1_21 & 2006_226 & 44.9948132 & -83.3890928 & Linear & 1 & Linear with narrow shadow \\
\hline LHHBA17_1_22 & 2006_226 & 44.9920913 & -83.3852856 & Netstake & 4 & Netstake \\
\hline LHHBA17_1_23 & 2006_226 & 44.9912837 & -83.3840678 & Netstake & 4 & Netstake \\
\hline LHHBA17_1_24 & 2006_226 & 44.9892848 & -83.3818701 & Netstake & 4 & Netstake \\
\hline LHHBA17_1_25 & 2006_226 & 44.9895228 & -83.3814205 & Netstake & 4 & Netstake \\
\hline LHHBA17_1_26 & 2006_226 & 45.0023184 & -83.40082 & Netstake & 4 & Netstake \\
\hline LHHBA19_1_01 & 2006_226 & 44.9891327 & -83.3828537 & Netstake & 4 & Netstake \\
\hline LHHBA19_1_02 & 2006_226 & 44.9894368 & -83.3831023 & Linear & 1 & Linear with narrow shadow \\
\hline LHHBA19_1_04 & 2006_226 & 44.9918291 & -83.3857733 & Linear & 1 & Linear with narrow shadow \\
\hline LHHBA19_1_05 & 2006_226 & 44.9918312 & -83.3863841 & Netstake & 4 & Netstake \\
\hline LHHBA19_1_06 & 2006_226 & 44.9916721 & -83.3865848 & Netstake & 4 & Netstake \\
\hline LHHBA19_1_07 & 2006_226 & 44.991789 & -83.3868573 & Netstake & 4 & Netstake \\
\hline LHHBA19_1_08 & 2006_226 & 44.996332 & -83.3922731 & Netstake & 4 & Netstake \\
\hline LHHBA19_1_09 & 2006_226 & 44.9966026 & -83.3937888 & Netstake & 4 & Netstake \\
\hline LHHBA19_1_10 & 2006_226 & 44.9973428 & -83.3947909 & Netstake & 4 & Netstake \\
\hline LHHBA19_1_11 & 2006_226 & 44.9987226 & -83.3953607 & Linear & 2 & Linear with no shadow \\
\hline LHHBA19_1_12 & 2006_226 & 44.9993468 & -83.3965608 & Netstake & 4 & Netstake \\
\hline LHHBA19_1_13 & 2006_226 & 44.9992799 & -83.3976621 & Netstake & 4 & Netstake \\
\hline LHHBA19_1_14 & 2006_226 & 44.9997762 & -83.3983405 & Linear & 3 & Short linear with no shadow \\
\hline LHHBA19_1_15 & $2006 \_226$ & 44.9997942 & -83.3983161 & Netstake & 4 & Netstake \\
\hline LHHBA19_1_16 & 2006_226 & 45.0013188 & -83.4000422 & Netstake & 4 & Netstake \\
\hline
\end{tabular}




\begin{tabular}{|c|c|c|c|c|c|c|}
\hline LHHBA19_1_17 & 2006_226 & 45.0022877 & -83.4007422 & Netstake & 4 & Netstake \\
\hline LHHBA19_1_18 & $2006 \_226$ & 45.0027359 & -83.4023123 & Netstake & 4 & Netstake \\
\hline LHHBA19_1_19 & $2006 \_226$ & 45.0036367 & -83.403048 & Netstake & 4 & Netstake \\
\hline LHHBA19_1_20 & 2006_226 & 45.0035691 & -83.4035105 & Linear & 2 & $\begin{array}{c}\text { Short linear with narrow } \\
\text { shadow }\end{array}$ \\
\hline LHHBA19_1_21 & 2006_226 & 45.0044262 & -83.4037156 & Linear & 1 & Linear with narrow shadow \\
\hline LHHBA19_1_22 & 2006_226 & 45.0044436 & -83.4035879 & Linear & 1 & Linear with narrow shadow \\
\hline LHHBA19_1_23 & 2006_226 & 45.0044862 & -83.4039874 & Netstake & 4 & Netstake \\
\hline LHHBA19_1_24 & 2006_226 & 45.0043371 & -83.4044354 & Netstake & 4 & Netstake \\
\hline LHHBA19_1_25 & 2006_226 & 45.0048714 & -83.4043493 & Netstake & 4 & Netstake \\
\hline LHHBA19_1_26 & 2006_226 & 45.0056088 & -83.4052495 & Linear & 1 & Linear with narrow shadow \\
\hline LHHBA19_1_27 & 2006_226 & 45.005872 & -83.4055043 & Linear & 1 & Linear with narrow shadow \\
\hline LHHBA19_1_28 & 2006_226 & 45.0057815 & -83.4054591 & Linear & 1 & Linear with narrow shadow \\
\hline LHHBA19_1_29 & 2006_226 & 45.0054922 & -83.4054287 & Linear & 1 & Linear with narrow shadow \\
\hline LHHBA19_1_30 & 2006_226 & 45.0056035 & -83.4055195 & Linear & 1 & Linear with narrow shadow \\
\hline LHHBA19_1_31 & 2006_226 & 45.0056495 & -83.4054591 & Netstake & 4 & Netstake \\
\hline LHHBA19_1_32 & 2006_226 & 45.006275 & -83.4062876 & Netstake & 4 & Netstake \\
\hline LHHBA19_1_33 & $2006 \_226$ & 45.0070185 & -83.407184 & Linear & 2 & Linear with no shadow \\
\hline LHHBA21_1_01 & 2006_226 & 45.0158024 & -83.4221677 & Linear & 3 & Linear with narrow shadow \\
\hline LHHBA21_1_02 & 2006_226 & 45.0088834 & -83.4110577 & Linear & 3 & Linear with narrow shadow \\
\hline LHHBA21_1_03 & 2006_226 & 45.0058118 & -83.4076782 & Netstake & 4 & Netstake \\
\hline LHHBA21_1_04 & 2006_226 & 45.0051909 & -83.4070312 & Netstake & 4 & Netstake \\
\hline LHHBA21_1_05 & 2006_226 & 45.004816 & -83.4063368 & Netstake & 4 & Netstake \\
\hline LHHBA21_1_06 & 2006_226 & 45.0042232 & -83.4058056 & Netstake & 4 & Netstake \\
\hline LHHBA21_1_07 & 2006_226 & 45.0038935 & -83.4048391 & Netstake & 4 & Netstake \\
\hline LHHBA21_1_08 & $2006 \_226$ & 45.0033576 & -83.4042279 & Netstake & 4 & Netstake \\
\hline LHHBA21_1_09 & 2006_226 & 45.0029204 & -83.4035729 & Netstake & 4 & Netstake \\
\hline LHHBA21_1_10 & 2006_226 & 45.0027771 & -83.4032729 & Netstake & 4 & Netstake \\
\hline LHHBA21_1_11 & 2006_226 & 45.0028555 & -83.4029999 & Netstake & 4 & Netstake \\
\hline LHHBA21_1_12 & 2006_226 & 45.0025767 & -83.4022097 & Netstake & 4 & Netstake \\
\hline LHHBA21_1_13 & 2006_226 & 45.0020075 & -83.4024339 & Linear & 3 & Faint linear with no shadow \\
\hline LHHBA21_1_14 & 2006_226 & 45.0018538 & -83.4023551 & Netstake & 4 & Netstake \\
\hline LHHBA21_1_15 & 2006_226 & 45.0008998 & -83.400837 & Linear & 3 & Short linear with no shadow \\
\hline LHHBA21_1_16 & $2006 \_226$ & 45.0010278 & -83.400046 & Linear & 3 & $\begin{array}{c}\text { Short linear with narrow } \\
\text { shadow }\end{array}$ \\
\hline LHHBA21_1_17 & 2006_226 & 45.0003809 & -83.4001939 & Netstake & 4 & Netstake \\
\hline LHHBA21_1_18 & 2006_226 & 45.0000026 & -83.3995335 & Netstake & 4 & Netstake \\
\hline LHHBA21_1_19 & 2006_226 & 45.0001337 & -83.3990241 & Netstake & 4 & Netstake \\
\hline LHHBA21_1_20 & 2006_226 & 44.9994525 & -83.3986312 & Netstake & 4 & Netstake \\
\hline LHHBA21_1_21 & 2006_226 & 44.9974182 & -83.3952071 & Netstake & 4 & Netstake \\
\hline LHHBA21_1_22 & 2006_226 & 44.9917692 & -83.3873929 & Netstake & 4 & Netstake \\
\hline LHHBA21_1_23 & 2006_226 & 44.9914031 & -83.3873522 & Netstake & 4 & Netstake \\
\hline LHHBA21_1_24 & 2006_226 & 44.9917593 & -83.3871544 & Netstake & 4 & Netstake \\
\hline LHHBA21_1_25 & 2006_226 & 44.991716 & -83.3866498 & Netstake & 4 & Netstake \\
\hline LHHBA21_1_26 & 2006_226 & 44.9918199 & -83.3869054 & Netstake & 4 & Netstake \\
\hline LHHBA21_1_27 & 2006_226 & 44.9895029 & -83.3842241 & Netstake & 4 & Netstake \\
\hline LHHBA21_1_28 & 2006_226 & 44.9890604 & -83.3840042 & Netstake & 4 & Netstake \\
\hline LHHBA21_1_30 & 2006_226 & 44.9887599 & -83.3826371 & Netstake & 4 & Netstake \\
\hline LHHBA21_1_31 & 2006_226 & 44.9883936 & -83.3828793 & Netstake & 4 & Netstake \\
\hline LHHBA21_1_32 & 2006_226 & 44.9993625 & -83.3978394 & Netstake & 4 & Netstake \\
\hline LHSPA105_1_01 & 2006_229 & 44.948771 & -83.3640356 & Netstake & 4 & Netstake \\
\hline LHSPA107_1_01 & 2006_229 & 44.9424335 & -83.3541519 & Netstake & 4 & Netstake \\
\hline
\end{tabular}




\begin{tabular}{|c|c|c|c|c|c|c|}
\hline LHSPA111_1_01 & 2006_229 & 44.9322074 & -83.3383365 & Linear & 3 & Linear with no shadow \\
\hline LHSPA111_1_02 & 2006_229 & 44.9479453 & -83.366678 & Netstake & 4 & Netstake \\
\hline LHSPA113_1_01 & 2006_229 & 44.9479638 & -83.3670254 & Netstake & 4 & Netstake \\
\hline LHSPA115_1_01 & 2006_229 & 44.9475064 & -83.3683403 & Netstake & 4 & Netstake \\
\hline LHSPA117_1_01 & 2006_229 & 44.9542184 & -83.3810326 & Linear & 3 & $\begin{array}{c}\text { Short linear with narrow } \\
\text { shadow }\end{array}$ \\
\hline LHSPA117_1_02 & 2006_229 & 44.9472799 & -83.3692055 & Netstake & 4 & Netstake \\
\hline LHSPA117_1_03 & 2006_229 & 44.9406559 & -83.3574862 & Netstake & 4 & Netstake \\
\hline LHSPA119_1_01 & 2006_229 & 44.9471207 & -83.3694169 & Netstake & 4 & Netstake \\
\hline LHNPH01_1_01 & 2006_230 & 45.0655083 & -83.2228526 & Netstake & 4 & Netstake \\
\hline LHNPH16_1_01 & 2006_230 & 45.0741939 & -83.2183109 & Linear & 3 & Short linear with shadow \\
\hline LHNPH25_1_01 & 2006_230 & 45.0716237 & -83.206514 & Linear & 1 & Linear with narrow shadow \\
\hline LHNPH27_1_01 & 2006_230 & 45.0689451 & -83.2016967 & Linear & 3 & Long linear with faint shadow \\
\hline LHNPH27_1_02 & 2006_230 & 45.0752072 & -83.2083727 & Linear & 3 & $\begin{array}{l}\text { Short linear with narrow } \\
\text { shadow partially in nadir }\end{array}$ \\
\hline LHNPH27_1_03 & 2006_230 & 45.075437 & -83.2086261 & Linear & 3 & $\begin{array}{l}\text { Short linear with narrow } \\
\text { shadow partially in nadir }\end{array}$ \\
\hline LHNPH28_1_01 & 2006_230 & 45.0679975 & -83.1994109 & Linear & 3 & $\begin{array}{l}\text { Potential linear with narrow } \\
\text { shadow }\end{array}$ \\
\hline SPB070829175200_01 & 2007_241 & 44.9742076 & -83.3444714 & Netstake & 4 & Netstake \\
\hline SPB070829191600_01 & 2007_241 & 44.9322575 & -83.2731576 & Debris & 3 & Potential debris \\
\hline SPB070829191600_02 & 2007_241 & 44.9349696 & -83.2786983 & Linear & 3 & Two sets of long parallel lines \\
\hline CA070830100400_01 & 2007_242 & 44.9705275 & -83.2899019 & Linear & 3 & $\begin{array}{l}\text { Short linear with narrow } \\
\text { shadow }\end{array}$ \\
\hline CA070830105400_01 & 2007_242 & 44.9709843 & -83.2921212 & Linear & 3 & $\begin{array}{l}\text { Short linear with narrow } \\
\text { doubled shadow }\end{array}$ \\
\hline CA070830121800_01 & 2007_242 & 45.0109921 & -83.2738987 & Shipwreck & 1 & $\begin{array}{l}\text { Wreckage or potential } \\
\text { shipwreck }\end{array}$ \\
\hline CA070830122700_01 & 2007_242 & 45.0119853 & -83.2750656 & Linear & 3 & Linear with no shadow \\
\hline CA070830122700_02 & 2007_242 & 44.9745096 & -83.2928797 & Linear & 3 & $\begin{array}{c}\text { Short linear but may be a sonar } \\
\text { artifact }\end{array}$ \\
\hline CA070830180200_01 & 2007_242 & 44.9823875 & -83.2932527 & Linear & 3 & $\begin{array}{l}\text { Short linear potentially a } \\
\text { partially buried rock }\end{array}$ \\
\hline CA070830180200_02 & 2007_242 & 44.97972 & -83.2938138 & Linear & 3 & $\begin{array}{l}\text { Short linear potentially a } \\
\text { partially buried rock }\end{array}$ \\
\hline CA070830180200_03 & 2007_242 & 44.9733238 & -83.2974676 & Linear & 3 & $\begin{array}{c}\text { Short linear with narrow } \\
\text { shadow }\end{array}$ \\
\hline CA070830184800_01 & 2007_242 & 44.9608284 & -83.3051016 & Linear & 3 & Faint linear with narrow shadow \\
\hline CA070830193500_01 & 2007_242 & 44.990455 & -83.2917016 & Linear & 3 & $\begin{array}{l}\text { Short linear potentially a } \\
\text { partially buried rock }\end{array}$ \\
\hline CA070830193500_02 & 2007_242 & 44.9825539 & -83.2957542 & Linear & 3 & $\begin{array}{l}\text { Short linear potentially a } \\
\text { partially buried rock }\end{array}$ \\
\hline SPB070830081100_01 & 2007_242 & 44.9649036 & -83.331907 & Netstake & 4 & Netstake \\
\hline SPB070830081100_02 & 2007_242 & 44.9693149 & -83.3405479 & Linear & 3 & $\begin{array}{c}\text { Short linear with narrow } \\
\text { shadow }\end{array}$ \\
\hline SPB070830081100_03 & 2007_242 & 44.9706171 & -83.3419447 & Linear & 2 & Faint linear with narrow shadow \\
\hline SPB070830081100_04 & 2007_242 & 44.973598 & -83.3476015 & Netstake & 4 & Netstake \\
\hline SPB070830081100_05 & 2007_242 & 44.9899144 & -83.3758125 & Netstake & 4 & Netstake \\
\hline SPB070830081100_06 & 2007_242 & 44.986978 & -83.3708381 & Netstake & 4 & Netstake \\
\hline
\end{tabular}




\begin{tabular}{|c|c|c|c|c|c|c|}
\hline SPB070830081100_07 & 2007_242 & 44.9847006 & -83.367408 & Linear & 3 & $\begin{array}{c}\text { Short linear with narrow } \\
\text { shadow }\end{array}$ \\
\hline P1080814191200_02 & 2008_227 & 45.1965695 & -83.2456706 & Debris & 3 & Small group of debris \\
\hline P1080814191200_03 & 2008_227 & 45.1992519 & -83.2497072 & Netstake & 4 & Netstake \\
\hline P1080814191200_04 & 2008_227 & 45.1990431 & -83.2500256 & Debris & 3 & Potential rock \\
\hline P1080814191200_05 & 2008_227 & 45.2094242 & -83.2623346 & Unknown & 3 & Unknown \\
\hline P1080814204000_01 & 2008_227 & 45.2506569 & -83.3145675 & Unknown & 3 & Potential rock \\
\hline P1080814220800_01 & 2008_227 & 45.3179525 & -83.400292 & Unknown & 3 & Potential rock \\
\hline P1080814223800_01 & 2008_227 & 45.323924 & -83.4089147 & Netstake & 4 & Netstake \\
\hline P1080815000400_01 & $2008 \_228$ & 45.3733186 & -83.4708858 & Unknown & 3 & Unknown \\
\hline P1080815042900_01 & 2008_228 & 45.2191533 & -83.2706623 & Linear & 3 & Short linear with no shadow \\
\hline P1080815045900_01 & 2008_228 & 45.2008801 & -83.2497342 & Linear & 3 & Short linear with no shadow \\
\hline P1080815100000_01 & 2008_228 & 45.378457 & -83.4690935 & Unknown & 3 & Potential rock \\
\hline P1080815140000_01 & 2008_228 & 45.2091833 & -83.253512 & Linear & 3 & $\begin{array}{l}\text { Short linear with narrow } \\
\text { shadow }\end{array}$ \\
\hline P1080815191900_01 & 2008_228 & 45.3775092 & -83.464322 & Linear & 3 & $\begin{array}{l}\text { Short linear with narrow } \\
\text { shadow }\end{array}$ \\
\hline P1080815210300_01 & 2008_228 & 45.3074714 & -83.3716481 & Unknown & 3 & Unknown \\
\hline P1080815230300_01 & 2008_228 & 45.2342669 & -83.2784755 & Shipwreck & 1 & Shipwreck \\
\hline P1080815233300_01 & 2008_228 & 45.2266129 & -83.2683166 & Linear & 3 & $\begin{array}{l}\text { Short linear with narrow } \\
\text { shadow }\end{array}$ \\
\hline P1080815233300_02 & 2008_228 & 45.2256306 & -83.2696302 & Linear & 3 & $\begin{array}{l}\text { Short linear with narrow } \\
\text { shadow }\end{array}$ \\
\hline P1080816033300_01 & 2008_229 & 45.3236466 & -83.3898968 & Linear & 1 & Linear with narrow shadow \\
\hline P1080816061900_01 & 2008_229 & 45.3651322 & -83.4398973 & Linear & 2 & Linear with narrow shadow \\
\hline P1080816160800_01 & 2008_229 & 45.3452732 & -83.4384364 & Linear & 3 & $\begin{array}{l}\text { Short faint linear with narrow } \\
\text { shadow }\end{array}$ \\
\hline P1080816204800_01 & 2008_229 & 45.2893402 & -83.3397319 & Shipwreck & 1 & Shipwreck in nadir \\
\hline P1080817051300_01 & 2008_230 & 45.3734084 & -83.441336 & Linear & 3 & Linear shadow \\
\hline P1080817111500_01 & 2008_230 & 45.177938 & -83.195056 & Linear & 2 & $\begin{array}{c}\text { Short linear with narrow } \\
\text { shadow }\end{array}$ \\
\hline P1080817170900_01 & 2008_230 & 45.172853 & -83.1950198 & Linear & 2 & Faint linear with narrow shadow \\
\hline P1080817174100_01 & 2008_230 & 45.1815225 & -83.2092356 & Unknown & 3 & Potential rock \\
\hline P1080818004000_01 & 2008_231 & 45.1868174 & -83.2325704 & Linear & 2 & Linear with narrow shadow \\
\hline P1080818011000_01 & 2008_231 & 45.1969007 & -83.2467335 & Debris & 3 & $\begin{array}{c}\text { Two linears oriented parallel to } \\
\text { each other }\end{array}$ \\
\hline P1080818011000_02 & 2008_231 & 45.190943 & -83.2397557 & Linear & 3 & Small group of potential debris \\
\hline P1080818020000_01 & 2008_231 & 45.2100411 & -83.2311051 & Linear & 3 & Linear with narrow shadow \\
\hline P1080818043000_01 & 2008_231 & 45.3015006 & -83.3475451 & Linear & 2 & Linear with narrow shadow \\
\hline P4080818143900_01 & 2008_231 & 45.2854726 & -83.1718964 & Shipwreck & 1 & Shipwreck \\
\hline P1080820011700_01 & 2008_233 & 45.2918565 & -83.3166136 & Shipwreck & 1 & Shipwreck \\
\hline P1080820105900_01 & 2008_233 & 45.2614751 & -83.2676577 & Linear & 3 & $\begin{array}{l}\text { Short linear with narrow } \\
\text { shadow }\end{array}$ \\
\hline P1080820152600_01 & $2008 \_233$ & 45.3829701 & -83.4345641 & Shipwreck & 1 & Shipwreck \\
\hline P1080820194500_01 & 2008_233 & 45.2960334 & -83.3068438 & Linear & 3 & $\begin{array}{l}\text { Short linear with narrow } \\
\text { shadow }\end{array}$ \\
\hline P1080820194500_02 & 2008_233 & 45.2966393 & -83.3074817 & Linear & 3 & $\begin{array}{l}\text { Short linear with narrow } \\
\text { shadow }\end{array}$ \\
\hline P1080821032900_01 & 2008_234 & 45.3922194 & -83.4278771 & Linear & 3 & $\begin{array}{c}\text { Short linear with narrow } \\
\text { shadow }\end{array}$ \\
\hline P1080821182100_01 & 2008_234 & 45.3250658 & -83.3263143 & Shipwreck & 1 & Shipwreck \\
\hline
\end{tabular}




\begin{tabular}{|c|c|c|c|c|c|c|}
\hline P1080822072900_01 & 2008_235 & 45.2964899 & -83.2824745 & Unknown & 2 & Large unknown mass \\
\hline P1080822170400_01 & 2008_235 & 45.3948978 & -83.3978291 & Debris & 3 & Potential group of rocks \\
\hline P1080825150900_01 & 2008_238 & 45.2349726 & -83.3031463 & Linear & 2 & Linear with narrow shadow \\
\hline P1080826074800_01 & 2008_239 & 45.3520654 & -83.4069749 & Linear & 2 & Linear with narrow shadow \\
\hline P1080827092000_01 & 2008_240 & 45.4159465 & -83.5435889 & Linear & 3 & $\begin{array}{c}\text { Short linear with narrow } \\
\text { shadow }\end{array}$ \\
\hline P1080827185100_01 & 2008_240 & 45.4834751 & -83.7339954 & Shipwreck & 1 & Messenger \\
\hline
\end{tabular}




\section{BIBLIOGRAPHY}

Applegate, Vernon C. and Harry D. Van Meter

1970 A Brief History of Commercial Fishing in Lake Erie. USDI, US Fish and Wildlife, Bureau of Commercial Fisheries, Fishery Leaflet 630.

Barnett, Le Roy

1992 Shipping Literature of the Great Lakes: A Catalog of Company Publications 1852-1990. Michigan State University Press, East Lansing, Michigan.

Barry, James P.

1973 Ships of the Great Lakes: 300 Years of Navigation. Howell-North Books, Berkeley, California.

Basalla, George

1988 The Evolution of Technology. Cambridge University Press, Cambridge, England.

Beattie Bogue, Margaret

2000 Fishing the Great Lakes: An Environmental History, 1783-1933. University of Wisconsin Press, Madison, Wisconsin.

Beck, Ulrich

1992 Risk Society: Towards a New Modernity. Sage Publications, London, England.

Beletsky, Dmitry, James H. Saylor, and David J. Schwab

1999 Mean Circulation in the Great Lakes. Journal of Great Lakes Research 25(1): 78-93.

Benn, Douglas I. and David J. A. Evans

1998 Glaciers and Glaciation. Arnold Publishers, London, England.

Binford, Lewis R.

1983 In Pursuit of the Past: Decoding the Archaeological Record. University of California Press, Berkley, California.

Black, Tyrone J.

1997 Evaporite Karst of Lower Michigan. Carbonates and Evaporites 12(1): 81-83.

Boulton, William

1876 Complete History: Alpena County, Michigan. Argus Book and Job Rooms, Alpena, Michigan. 
Branster, Mark C.

1999 Euro-American Archaeology in Michigan: The American Period. In Retrieving Michigan's Buried Past: The Archaeology of the Great Lakes State, John R. Halsey, editor. Cranbrook Institute of Science, Bloomfield Hills, Michigan.

Brehm, Victoria

1998 Introduction. In "A Fully Accredited Ocean": Essays on the Great Lakes, Victoria Brehm, editor. The University of Michigan Press, Ann Arbor, Michigan.

Brose, David S. and Michael J. Hambacher

1999 The Middle Woodland in Northern Michigan. In Retrieving Michigan's Buried Past: The Archaeology of the Great Lakes State, John R. Halsey, editor. Cranbrook Institute of Science, Bloomfield Hills, Michigan.

Brown, David G.

2004 White Hurricane: A Great Lakes November Gale and America's Deadliest Maritime Disaster. International Marine/Ragged Mountain Press, Thomaston, Maine.

Clark, Peter U.

1992 The Last Interglacial-glacial Transition in North America: Introduction. In The Last Interglacial-glacial Transition in North America, Peter U. Clark and Peter D. Lea, editors. Geological Society of America, Boulder, Colorado.

Cleland, Charles E.

1982 The Inland Shore Fishery of the Northern Great Lakes: Its Development and Importance in Prehistory. American Antiquity 47(4): 761-784.

1992 Rites of Conquest: The History and Culture of Michigan's Native Americans. The University of Michigan Press, Ann Arbor, Michigan.

1999 Cultural Transformation: The Archaeology of Historic Indian Sites in Michigan. In Retrieving Michigan's Buried Past: The Archaeology of the Great Lakes State, John R. Halsey, editor. Cranbrook Institute of Science, Bloomfield Hills, Michigan.

Coleman, Dwight

2002 Underwater Archaeology in Thunder Bay National Marine Sanctuary Lake Huron - Preliminary Results from a Shipwreck Mapping Survey. MTS Journal 36(3):33-44.

2003 Archaeological Oceanography of Inundated Coastal Prehistoric Sites. Dissertation on file: University of Rhode Island. 
Connell, Joseph H.

1978 Diversity in Tropical Rain Forests and Coral Reefs. Science 199(4335): 13021310 .

Curwood, James Oliver

1909 The Great Lakes: The Vessels that Plow Them: Their Owners, Their Sailors, and Their Cargoes; Together with A Brief History of our Inland Seas. G. P. Putnam's Sons, New York, New York.

Cvancara, Alan M. and James C. Melik

1961 Geology: Bedrock Geology of Lake Huron. Great Lakes Research Division, Institute of Science and Technology Publication No. 7.

Dappert, Claire P.

2006 Oaken Whale with a Cast Iron Tail: The Single-Decked Wooden Bulk Carrier Monohansett. East Carolina University Research Report 13.

Darvill, Timothy

1999 The Historic Environment, Historic Landscapes, and Space-Time-Action Models in Landscape Archaeology. In The Archaeology and Anthropology of Landscape: Shaping your Landscape, Peter J. Ucko and Robert Layton, editors. Routledge, London, England.

Devendorf, John F.

1995 Great Lakes Bulk Carriers: 1869-1985. Published in 1996 by the author.

Dorr, J. A. J. and D. F. Eschman

1970 Geology of Michigan. The University of Michigan Press, Ann Arbor, Michigan.

Douglas, Mary

1985 Risk Acceptability According to the Social Sciences. Russell Sage Foundation, New York, New York.

1992 Risk and Blame: Essays in Cultural Theory. Routledge, London, England.

Douglas, Mary and Aaron Wildavsky

1982 Risk and Culture: An Essay on the Selection of Technical and Environmental Dangers. University of California Press, Berkeley, California.

Duncan, Brad

2004 Risky Business, the Role of Risk in Shaping the Maritime Cultural Landscape and Shipwreck Patterning: A Case Study Application in the Gippsland Region, Victoria. Bulletin of the Australasian Institute for Maritime Archaeology 28: 11-24. 
Erickson, Jon

1990 Ice Ages: Past and Future. TAB Books, Blue Ridge Summit, Pennsylvania.

Eschman, Donald F. and Paul F. Karrow

1985 Huron Basin Glacial Lakes: A Review. In Quaternary Evolution of the Great Lakes, P. F. Karrow and P. E. Calkin, editors. Geological Association of Canada Special Paper 30, St. Johns, Newfoundland.

Estellie Smith, M.

1977 Don't Call my Boat a Ship! Anthropological Quarterly 50(1): 9-17.

Farrand, William R.

1988 The Glacial Lakes around Michigan. Geological Survey Division, Michigan Department of Environmental Quality, Bulletin 4.

Firth, Antony

1997 Three Facets of Maritime Archaeology: Society, Landscape, and Critique. http://avebury.arch.soton.ac.uk/Research/Firth. Accessed 5 March 2009.

Fisher, James H. Michael W. Barratt John B. Droste and Robert H. Shaver

1988 Michigan Basin. The Geology of North America, Vol. D-2. Geological Society of America, Boulder, Colorado.

Fitting, James E.

1970 The Archaeology of Michigan: A Guide to the Prehistory of the Great Lakes Region. The Natural History Press, Garden City, New York.

Fitting, James E. and Charles E. Cleland

1969 Late Prehistoric Settlement Patterns in the Upper Great Lakes. Ethnohistory 16(4): 289-302.

Flatman, Joe

2003 Cultural Biographies, Cognitive Landscapes, and Dirty Old Bits of Boat: 'Theory' in Maritime Archaeology. The International Journal of Nautical Archaeology 32(2): 143-157.

Fleming, Andrew

2006 Post-Processual Landscape Archaeology: A Critique. Cambridge Archaeological Journal 16(3): 267-280.

Forsythe, W., C. Breen, C. Callaghan and R. McConkey

2000 Historic Storms and Shipwrecks in Ireland: A Preliminary Survey of Severe Synoptic Conditions as a Causal Factor in Underwater Archaeology. International Journal of Nautical Archaeology 29(2): 247-259. 
Franzen, John G.

1999 The Archaeology of the Lumber Industry in Northern Michigan. In Retrieving Michigan's Buried Past: The Archaeology of the Great Lakes State, John R. Halsey, editor. Cranbrook Institute of Science, Bloomfield Hills, Michigan.

Garland, Elizabeth and Scott G. Beld

1999 The Early Woodland: Ceramics, Domesticated Plants, and Burial Mounds Fortell the Shape of the Future. In Retrieving Michigan's Buried Past: The Archaeology of the Great Lakes State, John R. Halsey, editor. Cranbrook Institute of Science, Bloomfield Hills, Michigan.

Gibbs, Martin

2006 Cultural Site Formation Processes in Maritime Archaeology: Disaster Response, Salvage and Muckelroy 30 Years on. International Journal of Nautical Archaeology 35(1): 4-19.

Gjerset, Knut.

1928 Norwegian Sailors on the Great Lakes: A Chapter in the History of American Inland Transportation. The Norwegian-American Historical Association, Northfield, Minnesota.

Gough, Barry

2002 Fighting Sail on Lake Huron and Georgian Bay: The War of 1812 and its Aftermath. Naval Institute Press, Annapolis, Maryland.

Gould, Richard A.

1983a Looking Below the Surface: Shipwreck Archaeology as Anthropology. In Shipwreck Anthropology, Richard A. Gould, editor. School of American Research Advanced Seminar Series 45, University of New Mexico Press, Albuquerque, New Mexico.

1983b The Archaeology of War: Wrecks of the Spanish Armada of 1588 and the Battle of Britain, 1940. In Shipwreck Anthropology, Richard Gould, editor. University of New Mexico Press, Albuquerque, New Mexico.

1990 Recovering the Past. University of New Mexico Press, Albuquerque, New Mexico.

Harris, Dianne

1999 The Postmodernization of Landscape: A Critical Historiography. The Journal of the Society of Architectural Historians 58(3): 434-443.

Harris, Edward

1989 Principles of Archaeological Stratigraphy. Academic Press, London, England. 
Havighurst, Walter

1975 The Long Ships Passing: The Story of the Great Lakes (Revised and Expanded Edition). Macmillan Publishing Co., Inc., New York, New York.

Heldman, Donald P.

1999 Euro-American Archaeology in Michigan: The French Period. In Retrieving Michigan's Buried Past: The Archaeology of the Great Lakes State, John R. Halsey, editor. Cranbrook Institute of Science, Bloomfield Hills, Michigan.

Hoagland, Henry Elmer

1917 Wage Bargaining on the Great Lakes. University of Illinois, Urbana, Illinois. Reprint published, Johnson Reprint Corp. 1970.

Holman, Margaret B. and Janet G. Brashler

1999 Economics, Material Culture, and Trade in the Late Woodland Lower Penninsula of Michigan. In Retrieving Michigan's Buried Past: The Archaeology of the Great Lakes State, John R. Halsey, editor. Cranbrook Institute of Science, Bloomfield Hills, Michigan.

Hovden, Jan and Tore J. Larsson

1987 Risk: Culture and Concepts. In Risk and Decisions, W. T. Singleton, editor. John Wiley and Sons, Chichester, England.

Howey, Meghan C. L.

2007 Using Multi-Criteria Cost Surface Analysis to Explore Past Regional Landscapes: A Case Study of Ritual Activity and Social Interaction in Michigan, AD 1200-1600. Journal of Archaeological Science 34: 1830-1846.

Jackson, Lawrence J. Christpher Ellis Alan V. Morgan and John H. McAndrews 2000 Glacial Lake Levels and Eastern Great Lakes Paleo-Indians. Geoarchaeology 15(5): 415-40.

Jordan, Brian A.

2003 Analysis of Environmental Conditions and Types of Biodeterioration Affecting the Preservation of Archaeological Wood at the Kolding Shipwreck Site. Dissertation on file: University of Minnesota, St. Paul, Minnesota.

Kelso, John R. M., R. J. Steedman, and S. Stoddart

1996 Historical Causes of Change in Great Lakes Fish Stocks and the Implications for Ecosystem Rehabilitation. Canadian Journal of Fisheries and Aquatic Sciences 53(Supplement 1): 10-19. 
Kingsley, Robert G.

1999 The Middle Woodland Period in Southern Michigan. In Retrieving Michigan's Buried Past: The Archaeology of the Great Lakes State, John R. Halsey, editor. Cranbrook Institute of Science, Bloomfield Hills, Michigan.

Krakker, James J.

1999 Late Woodland Settlement Patterns, Population, and Social Organization Viewed from Southeastern Michigan. In Retrieving Michigan's Buried Past: The Archaeology of the Great Lakes State, John R. Halsey, editor. Cranbrook Institute of Science, Bloomfield Hills, Michigan.

Lafferty, William

1998 Technological Innovation on Great Lakes Shipping: Leathem D. Smith and the Rise of the Self-Unloader. In "A Fully Accredited Ocean”: Essays on the Great Lakes, Victoria Brehm, editor. The University of Michigan Press, Ann Arbor, Michigan.

Landon, Fred

1944 Lake Huron. The Bobbs-Merrill Company, Indianapolis, Indiana.

Larson, Grahame, and Randall Schaetzl

2001 Origin and Evolution of the Great Lakes. Journal of Great Lakes Research 27(4): 518-546.

Layton, Robert and Peter J. Ucko

1999 Introduction: Gazing on the landscape and encountering the environment. In The Archaeology and Anthropology of Landscape: Shaping your Landscape, Peter J. Ucko and Robert Layton, editors. Routledge, London, England.

Lewis, C. F. Michael, John W. King, Stefan M. Blasco, Gregory R. Brooks, John P. Coakley, Thomas E. Croley II, David L. Dettman, Thomas W. D. Edwards, Clifford W. Heil, Jr., J. Bradford Hubeny, Kathleen R. Laird, John H. McAndrews, Francine M. G. McCarthy, Barbara E. Medioli, Theodore C. Moore, Jr., David K. Rea, and Alison J. Smith

2008 Dry Climate Disconnected the Laurentian Great Lakes. EOS 89(52): 541-552.

Lewis, Kenneth E.

2002 West to Far Michigan: Settling the Lower Peninsula, 1815-1860. Michigan State University Press, East Lansing, Michigan.

Lovis, William A.

1999 The Middle Archaic: Learning to Live in the Woodlands. In Retrieving Michigan's Buried Past: The Archaeology of the Great Lakes State, John R. Halsey, editor. Cranbrook Institute of Science, Bloomfield Hills, Michigan. 
Mason, Ronald J.

1981 Great Lakes Archaeology. Academic Press, New York, New York.

McGlade, James

1995 An Integrative Multiscalar Modelling Framework for Human Ecodynamic Research in the Vera Basin, South-East Spain. In L'Homme et la Degredation de l'environement, S. E, van der Leeuw, editor. Juan les Pins, APDCA.

1999 Archaeology and the Evolution of Cultural Landscapes: Towards an Interdisciplinary Research Agenda. In The Archaeology and Anthropology of Landscape: Shaping your Landscape, Peter J. Ucko and Robert Layton, editors. Routledge, London, England.

Mills, James C.

1910 Our Inland Seas: their Shipping and Commerce for Three Centuries. A. C. McClurg and Co., Chicago, Illinois.

Muckelroy, Keith

1978 Maritime Archaeology. Cambridge University Press, London, England.

Murphy, Larry.

1983 Shipwrecks and Database for Human Behavioral Studies. In Shipwreck Anthropology, Richard A. Gould, editor. University of New Mexico Press, Albuquerque, New Mexico.

Noble, Dennis L.

1994 That Others Might Live: The U.S. Life-Saving Service, 1783-1915. Naval Institute Press, Annapolis, Maryland.

O’Brien, T. Michael

1976 Guardians of the Eighth Sea: A History of the U.S. Coast Guard on the Great Lakes. Ninth Coast Guard District, Cleveland, Ohio.

O'Shea, John M.

2002 The Archaeology of Scattered Wreck Sites: Formation Processes and Shallow Water Archaeology in Western Lake Huron. International Journal of Nautical Archaeology 31(2): 211-227.

2004 The Identification of Shipwreck Sites: A Bayesian Approach. Journal of Archaeological Science 31: 1533-1552.

O'Shea, John M. and Guy A. Meadows

2009 Evidence for Early Hunters Beneath the Great Lakes. Proceedings of the National Academy of Sciences 106(25): 10120-10123. 
Odum, Howard T.

2007 Environment, Power, and Society for the Twenty-First Century: The Hierarchy of Energy. Columbia University Press, New York, New York.

Pecoraro, Tiffany A.

2007 Great Lakes Ship Traps and Salvage: A Regional Analysis of an Archaeological Phenomenon. Thesis on file: East Carolina University.

Peteet, D., D. Rind, and G. Kukla

1992 Wisconsinan Ice-Sheet Initiation: Milankovich Forcing, Paleoclimatic Data, and Global Climate Modeling. In The Last Interglacial-glacial Transition in North America, Peter U. Clark and Peter D. Lea, editors. Geological Society of America, Boulder, Colorado.

Petroski, Henry

1994 The Evolution of Useful Things. Vintage Books, New York, New York.

Quimby, George I.

1963 A New Look at Geochronology in the Upper Great Lakes Region. American Antiquity 28(4): 558-559.

Ramsey, Raymond

2006 For Whom the Bells Toll: The Unexplained Losses of S.S. Edmund Fitzgerald, M.V. Derbyshire, and Other Vessels of the Bulk-Cargo Silent Services.

Dorrance Publishing Co., Inc., Pittsburgh, Pennsylvania.

Rea, David K., Theodore C. Moore Jr., C. F. Michael Lewis, Larry A. Mayer, David L. Dettman, Alison J. Smith, and David M. Dobson

1994 Stratigraphy and Paleolimnologic Record of Lower Holocene Sediments in Northern Lake Huron and Georgian Bay. Canadian Journal of Earth Science 31: 1586-605.

Rea, David K., Theodore C. Moore Jr., Thane W. Anderson, C. F. Michael Lewis, David M. Dobson, David L. Dettman, Alison J. Smith, and Larry A. Mayer 1994 Great Lakes Paleohydrology: Complex Interplay of Glacial Meltwater, Lake Levels, and Sill Depths. Geology 22: 1059-62.

Rao, Yerubandi R. and David J. Schwab

2007 Transport and Mixing between the Coastal and Offshore Waters in the Great Lakes: A Review. Journal of Great Lakes Research 33: 202-218.

Robertson, James A., William A. Lovis, and John R. Halsey

1999 The Late Archaic: Hunter-Gatherers in an Uncertain Environment. In Retrieving Michigan's Buried Past: The Archaeology of the Great Lakes State, John R. Halsey, editor. Cranbrook Institute of Science, Bloomfield Hills, Michigan. 
Salmon, M. Stephen

1998 "A Prosperous Season": Investment in Canadian Great Lakes Shipping, 19001914. In “A Fully Accredited Ocean”: Essays on the Great Lakes, Victoria Brehm, editor. The University of Michigan Press, Ann Arbor, Michigan.

Schiffer, Michael B.

1987 Formation Processes of the Archaeological Record. University of New Mexico Press, Albuquerque, New Mexico.

Schott, Michael J.

1999 The Early Archaic: Life After the Glaciers. In Retrieving Michigan's Buried Past: The Archaeology of the Great Lakes State, John R. Halsey, editor. Cranbrook Institute of Science, Bloomfield Hills, Michigan.

Schott, Michael J. and Henry T. Wright

1999 The Paleo-Indians: Michigan's First People. In Retrieving Michigan's Buried Past: The Archaeology of the Great Lakes State, John R. Halsey, editor. Cranbrook Institute of Science, Bloomfield Hills, Michigan.

Sloss, Peter W. and James H. Saylor

1976 Large-Scale Current Measurements in Lake Huron. Journal of Geophysical Research 81(18): 3069-3078.

Souza, Donna J.

1998 The Persistence of Sail in the Age of Steam: Underwater Archaeological Evidence from the Dry Tortugas. Plenum Press, New York, New York.

Stein, Julie K. and William R. Farrand, eds.

2001 Sediments in Archaeological Context. University of Utah Press, Salt Lake City, Utah.

Stommel, Henry

1963 Varieties of Oceanographic Experience. Science 139(3555): 572-576.

Stonehouse, Frederick

1994 Wreck Ashore: The United States Life-Saving Service on the Great Lakes. Lake Superior Port Cities Inc., Duluth, Minnesota.

Thiesen, William $\mathrm{H}$.

2006 Industrializing American Shipbuilding: The Transformation of Ship Design and Construction, 1820-1920. University Press of Florida, Gainesville, Florida. 
Thomas, R. L. A. L. Kemp and C. F. M. Lewis

1973 The Surficial Sediments of Lake Huron. Canadian Journal of Earth Science 10: $226-70$.

Thompson, Mark L.

1991 Steamboats and Sailors of the Great Lakes. Wayne State University Press, Detroit, Michigan.

Thompson, Thomas S.

1878 Thompson's Coast Pilot and Sailing Directions for the Northwestern Lakes. Wm. A. Scripps, Detroit, Michigan.

Thunder Bay National Marine Sanctuary and Underwater Preserve (TBNMS/UP) 2006 http://thunderbay.noaa.gov, Accessed 1 December 2006.

True, Frederick W. and Ludwig Kumlein

1887 The Fishing Grounds of the Great Lakes. In The Fisheries and Fishery Industries of the United States, Section III, Richard Rathbun, editor. Government Printing Office, Washington, D.C.

Wallach, Michael A., Nathan Kogan, and Daryl J. Bem

1964 Diffusion of Responsibility and Level of Risk Taking in Groups. Journal of Abnormal and Social Psychology 68(3): 263-274.

Ward, I. A. K., P. Larcombe, and P. Veth.

1999 A New Process-based Model for Wreck Site Formation. Journal of Archaeological Science 26: 561-570.

Warner, Edward S.

1998 Towing with Steam Tugs: An Aspect of the Great Lakes Commercial Trade under Sail. In "A Fully Accredited Ocean”: Essays on the Great Lakes, Victoria Brehm, editor. The University of Michigan Press, Ann Arbor, Michigan.

Warner, Thomas D. and Donald F. Holocek

1975 Thunder Bay Shipwreck Survey Study Report: A Summary of Findings for an Underwater Inventory of Lake Huron Shipwrecks Located off Alpena County, Michigan. Michigan State University, East Lansing, Michigan.

Westerdahl, Christer

1998 The Maritime Cultural Landscape: On the Concept of the Traditional Zones of Transport Geography. Institute of Archaeology and Ethnology, University of Copenhagen, Copenhagen, Denmark. 
Wheeler, A. J.

2002 Environmental Controls on Shipwreck Preservation: The Irish Context. Journal of Archaeological Science 29: 1149-1159.

White, Richard

1991 The Middle Ground: Indians, Empires, and Republics in the Great Lakes Region, 1650-1815. Cambridge University Press, Cambridge, England.

Whitaker, Herschel

1892 Early History of the Fisheries on the Great Lakes. Transactions of the American Fisheries Society 21(1): 163-179.

Wright, Richard J.

1980 Michigan Department of Natural Resources Inventory of Shipwrecks within Michigan Coastal Waters. Report on file, Michigan Department of Natural Resources and Northwest Ohio-Great Lakes Research Center.

Woodford, Arthur M.

1991 Charting the Inland Seas: A History of the U.S. Lake Survey. U.S. Army Corps of Engineers, Detroit, Michigan.

Zurel, Richard L.

1999 Earthwork Enclosure Sites in Michigan. In Retrieving Michigan's Buried Past: The Archaeology of the Great Lakes State, John R. Halsey, editor. Cranbrook Institute of Science, Bloomfield Hills, Michigan. 